\title{
Exsolved nanoparticle decorated redox stable ceramic anode material with high performance for Solid Oxide Fuel Cells
}

He Qi

hiqi@mix.wvu.edu

Follow this and additional works at: https://researchrepository.wvu.edu/etd

Part of the Ceramic Materials Commons

\section{Recommended Citation}

Qi, He, "Exsolved nanoparticle decorated redox stable ceramic anode material with high performance for Solid Oxide Fuel Cells" (2019). Graduate Theses, Dissertations, and Problem Reports. 7444.

https://researchrepository.wvu.edu/etd/7444

This Dissertation is protected by copyright and/or related rights. It has been brought to you by the The Research Repository @ WVU with permission from the rights-holder(s). You are free to use this Dissertation in any way that is permitted by the copyright and related rights legislation that applies to your use. For other uses you must obtain permission from the rights-holder(s) directly, unless additional rights are indicated by a Creative Commons license in the record and/ or on the work itself. This Dissertation has been accepted for inclusion in WVU Graduate Theses, Dissertations, and Problem Reports collection by an authorized administrator of The Research Repository @ WVU.

For more information, please contact researchrepository@mail.wvu.edu. 


\title{
Exsolved Nanoparticle Decorated Redox Stable Ceramic Anode Material with High Performance for Solid Oxide Fuel Cells
}

\author{
He Qi \\ Dissertation submitted \\ to the Benjamin M. Statler College of Engineering and Mineral Resources \\ at West Virginia University
}

in partial fulfillment of the requirements for the degree of

Doctor of Philosophy in

Material Science and Engineering

Xingbo Liu, Ph.D., Chair

Edward M. Sabolsky, Ph.D.

Konstantinos A. Sierros, Ph.D.

David Mebane, Ph.D.

Harry Finklea, Ph.D.

Department of Mechanical and Aerospace Engineering

\author{
Morgantown, West Virginia
}

2019

Keywords: solid-oxide fuel cells, ceramic anode, redox stability, in-situ exsolution, hydrogen oxidation reaction, catalytic effect of $\mathrm{H}_{2} \mathrm{O}$

Copyright 2019 He Qi 


\title{
ABSTRACT
}

\section{Exsolved nanoparticle decorated redox stable ceramic anode material with high performance for Solid Oxide Fuel Cells}

\author{
He Qi
}

The solid oxide fuel cell (SOFC) is an efficient high-temperature device that can directly convert chemical energy to electrical energy. Because of its high efficiency and environmental friendliness, extensive investigations have been made worldwide in past decades. Though broadly used as the anode material for Solid-Oxide Fuel Cells, Ni-YSZ is limited in some practical applications by severe carbon deposition on $\mathrm{Ni}$ in hydrocarbon fuels and a significant volume change of $\mathrm{Ni}-\mathrm{NiO}$ among redox cycling. In order to overcome these problems and achieve excellent performance in the redox environment, a Ni-free ceramic material $\mathrm{La}_{0.5} \mathrm{Sr}_{1.5} \mathrm{Fe}_{1.5} \mathrm{Mo}_{0.5} \mathrm{O}_{6-\delta}(\mathrm{LSFM})$ is developed in this work.

LSFM possesses good phase stability in oxidizing and reducing atmospheres. Compared with $\mathrm{Sr}_{2} \mathrm{Fe}_{1.5} \mathrm{Mo}_{0.5} \mathrm{O}_{6-\delta}(\mathrm{SF} 1.5 \mathrm{M})$ and other related compositions, LSFM displays a closer CTE to electrolytes, better reversibility (i.e., expansion reversibility and electrical conductivity reversibility) in redox cycling and higher power density in hydrogen. First, the CTE is reduced from $17.12 \times 10^{-6} \mathrm{~K}^{-1}(\mathrm{SF} 1.5 \mathrm{M})$ to $15.01 \times 10^{-}$ ${ }^{6} \mathrm{~K}^{-1}$ (LSFM), and the thermal expansion can be further reduced with a higher lanthanum doping. Second, the excellent reversibility of the chemical expansion during redox cycling is confirmed, which is necessary to perfect electrical conductivity reversibility. In three redox cycles, no conductivity loss is observed. The smaller thermal expansion and better reversibility result from a stronger metal-oxygen (M-O) bond, specifically, La-O bond, in the LSFM. The strong M-O bond is helpful to stabilize the crystal structure, limit the crystal cell's expansion and sometimes maintain the phase stability. The small polarization resistance $\left(0.16 \Omega \cdot \mathrm{cm}^{2}\right)$ and the attractive maximum power density $\left(1156 \mathrm{~mW} \mathrm{~cm}{ }^{-2}\right.$ at $800{ }^{\circ} \mathrm{C}$ in the humidified $\mathrm{H}_{2}$ ) make the LSFM as a promising anode candidate for SOFCs.

Besides the good redox stability, La also helps to accelerate the in-situ exsolution of nanoparticles (NPs) onto LSFM surface in $\mathrm{H}_{2}$. The exsolved material was characterized as uniformly distributed Fe NPs with a particle size of about $100 \mathrm{~nm}$. Minor Fe exsolution occurs in a strong reducing atmosphere (wet or dry $\mathrm{H}_{2}$ ) at $800{ }^{\circ} \mathrm{C}$ in the first several hours. After that, the exsolution will stop automatically. Also, thorough and rapid dissolution of exsolved NPs is observed after re-oxidizing LSFM in the air at $800{ }^{\circ} \mathrm{C}$ for 1 hour. Most Fe NPs disappeared after the re-oxidizing and the phase evolution was recorded as the waved grain boundary and surface. Electrical conductivity relaxation (ECR) analysis demonstrated that the surface reaction kinetics on the LSFM anode is enhanced by in-situ exsolution. Based on electrochemical impedance spectroscopy (EIS) and distribution of relaxation time (DRT) analysis, the ionic conductivity was increased during exsolution. The higher surface catalytic activity and faster oxygen transportation lead to this enhanced electrochemical performance.

Based on SF1.5M and related perovskite materials, the positive effect of $\mathrm{H}_{2} \mathrm{O}$ on hydrogen oxidation reaction is proved and researched. Experimental results demonstrate that the electrochemical performance of perovskite material is significantly improved in humidified gas (low and high $\mathrm{P}_{\mathrm{H} 2}$ environment). This performance promotion mainly comes from the faster surface reaction process. In order to deeper understand this mechanism, the DFT calculation was performed. DFT modeling shows that the $\mathrm{H}_{2} \mathrm{O}$ plus surface oxygen vacancy formation step is the highest energy intermediate state on the surfaces and this state can be reduced with (1) a lower $\delta$ near the surfaces, (2) the formation of hydroxyl $\left(\mathrm{OH}_{O}^{*}\right)$ and hydride $\left(\mathrm{H}^{-}\right)$ relative to the surfaces containing $\mathrm{O}$ vacancies. The promotion effect of humidity is further explained by 
the lower surface electron chemical potential with increase of $\mathrm{O}$ chemical potential, as well as enhanced interaction between the surface-bound $\mathrm{H}^{+}$(surface hydroxyl) with the surface lattice oxygen in the $2 \mathrm{HatO}$ hydrated surfaces and interaction between surface adsorbed hydride $\mathrm{H}^{-}$with surface $\mathrm{O}$ vacancies in the HatM\&HatO hydrated surfaces. The similar phenomenon is also observed from other perovskite materials, indicating the humidity promotion effect and the identified enhancing factors can be general for HOR on perovskite ceramics used in the SOFC anodes. 


\section{ACKNOWLEDGEMENTS}

First, I would love to thank my advisor Dr. Liu, who gave me a great opportunity to research as a scientist and patient instructions in my whole Ph.D. study. I appreciate his guidance and support to help me go through all tough times.

Secondly, I want to thank for the help of Dr. Wenyuan Li and Dr. Wei Li. My experiment design and paper writing involved their professional guidance. They use their actions to show me how to be a good researcher. The crucial technical supports from Dr. Greg Collins and Dr. Liang Ma helped me to overcome obstacles in my experiments and makes my research possible.

Besides, I will also thank several people who give me significant help with my research. Dr. Yueh-Lin Li helped me with DFT calculation and HOR mechanism interpretation. Dr. Fang Xia helped me with synchrotron XRD operation and crystal structure analysis. Dr. Tao Yang helped with ECR grogram writing and ECR data analysis. For my project work, Dr. Richard Hart, Dr. John Zondlo Dr. Edward Sabolsky and Dr. Tony Thomas guided me from the start and provided many precious suggestions to improve my work. Next, I want to thank my committee members, Dr. Edward Sabolsky, Dr. Konstantinos A. Sierros, Dr. David Mebane and Dr. Harry Finklea, for their helpful suggestions on my work.

Further, thank my parents for their company, understanding and supporting. They gave my courage and confidence to start my Ph.D. life and purchase my Ph.D. degree.

At last, I will thank all my group members, Bo guan, Zhipeng Zeng, Shanshan Hu, Nan Zhang, et al. They make my Ph.D. life rich and colorful. 


\section{TABLE OF CONTENTS}

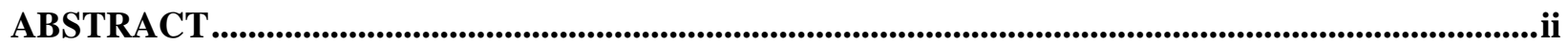

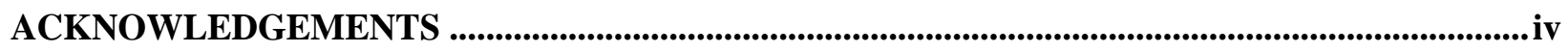

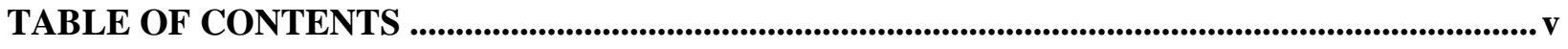

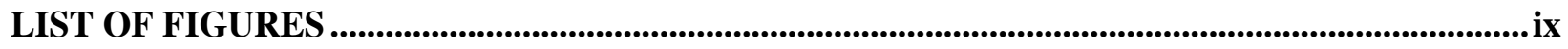

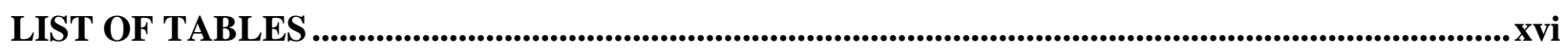

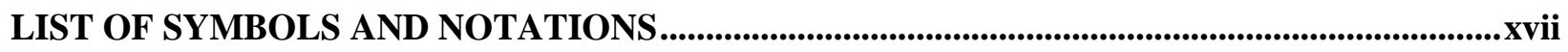

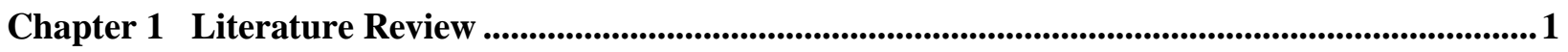

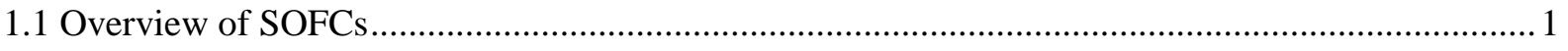

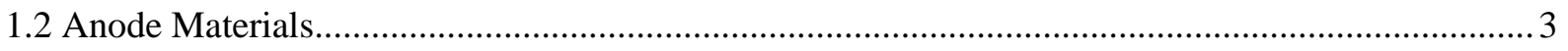

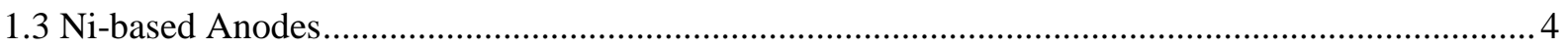

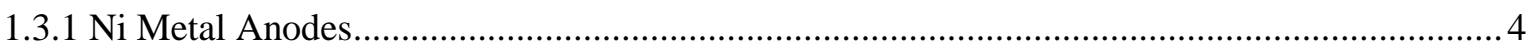

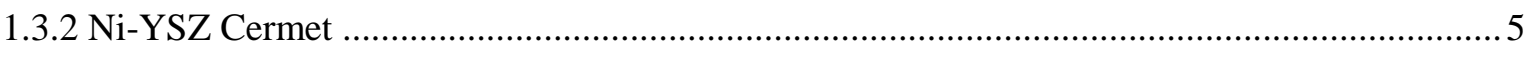

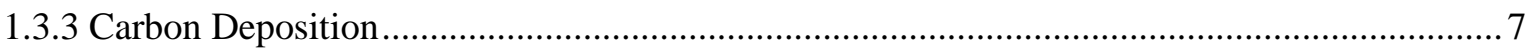

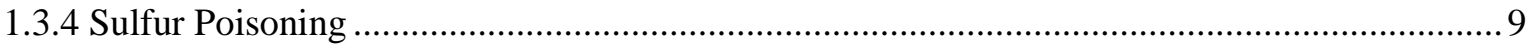

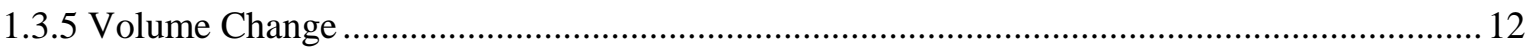

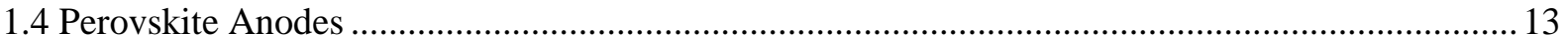

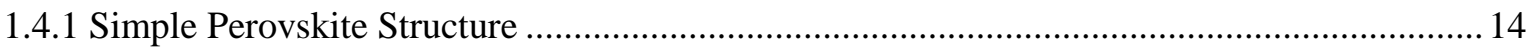

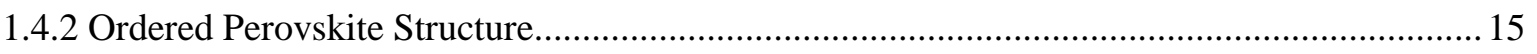

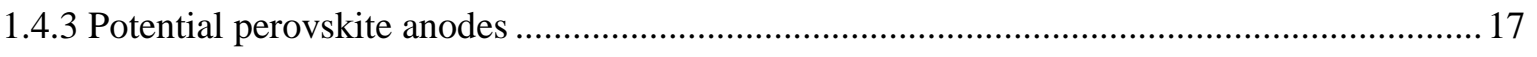

1.4.4 In-situ Exsolution of Perovskite materials........................................................................... 19

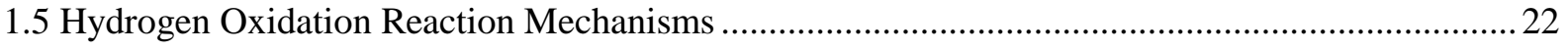

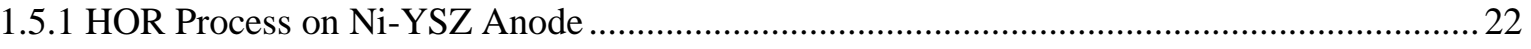

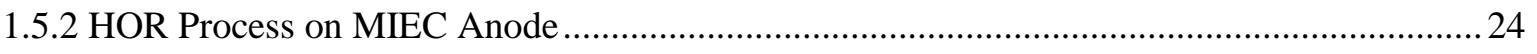

1.5.3 Catalytic Effect of $\mathrm{H}_{2} \mathrm{O}$ to HOR Process on Ni-YSZ Anode ….......................................25

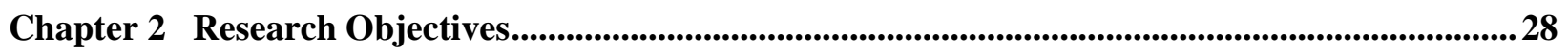




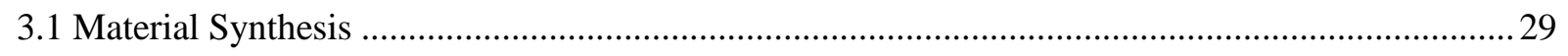

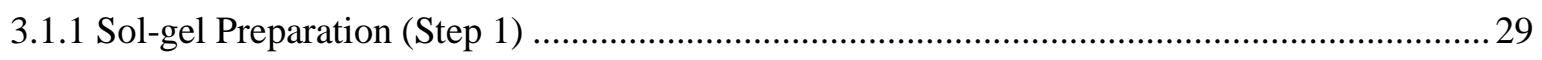

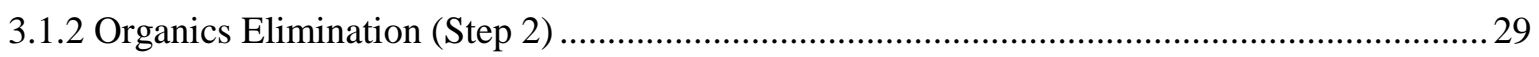

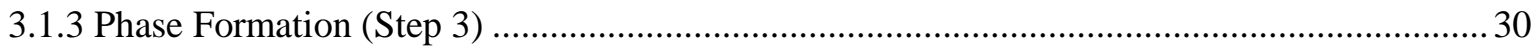

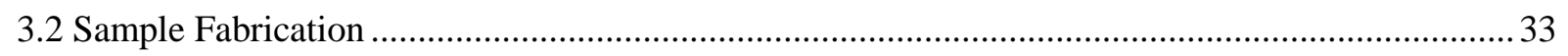

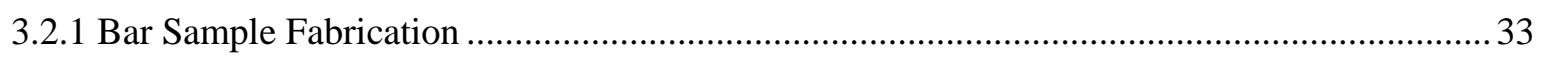

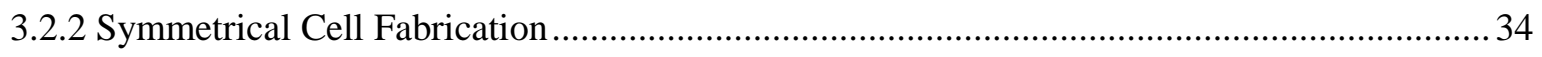

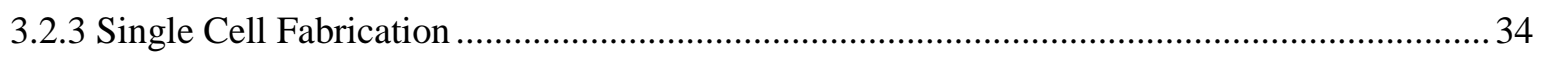

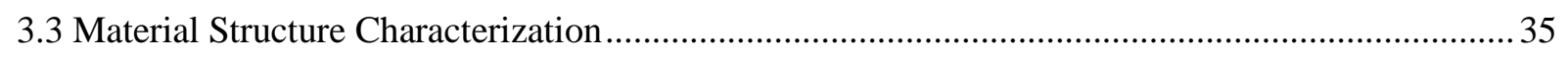

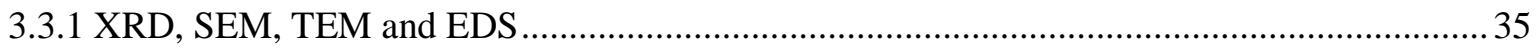

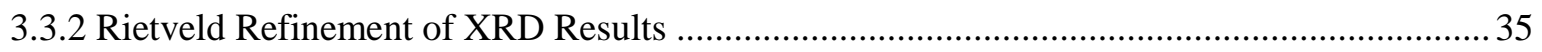

3.3.3 Synchrotron X-ray diffraction and Rietveld Refinement ................................................35

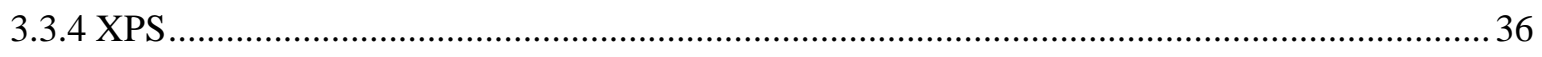

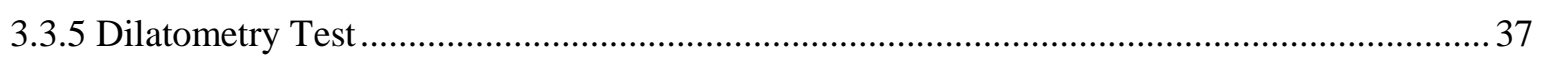

3.4 Electrical and Electrochemical Characterization .................................................................... 37

3.4.1 Four-point DC Method Conductivity Measurement........................................................... 37

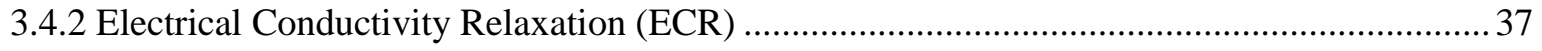

3.4.3 Electrochemical Impedance Spectroscopy (EIS) ......................................................... 40

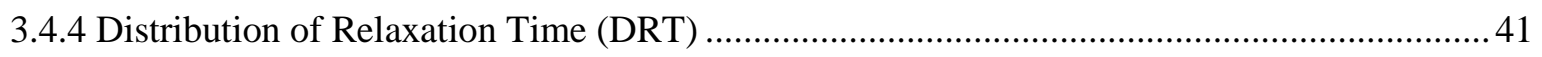

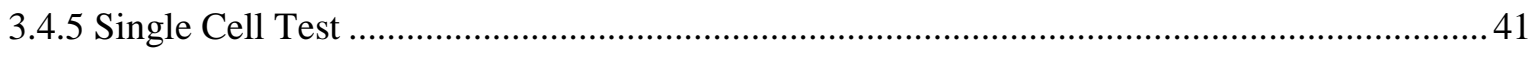

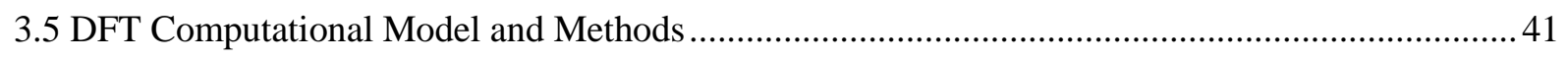

Chapter 4 Modification Strategy and Performance of SFM-Based Materials..................................43

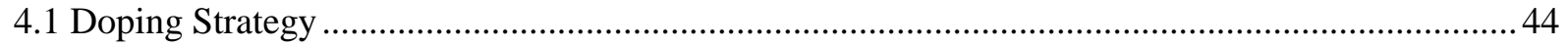

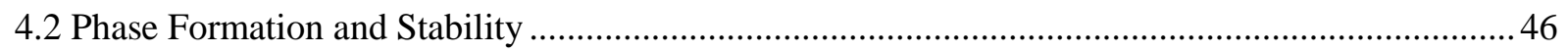

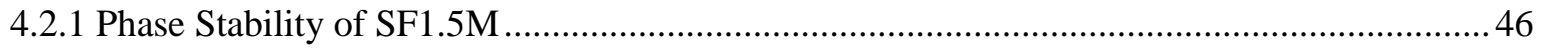

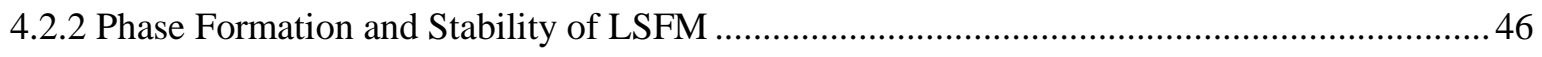




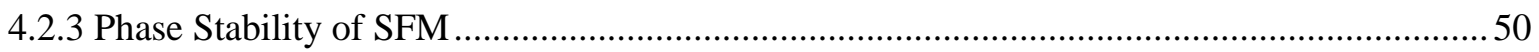

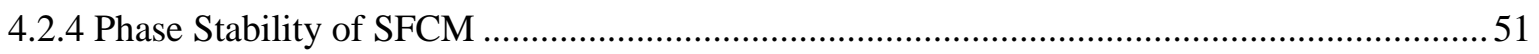

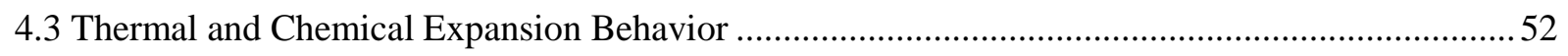

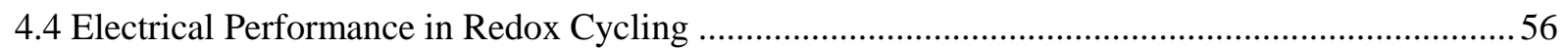

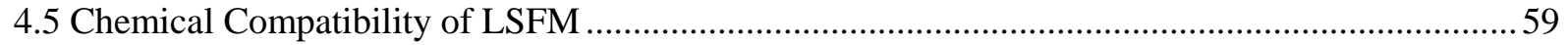

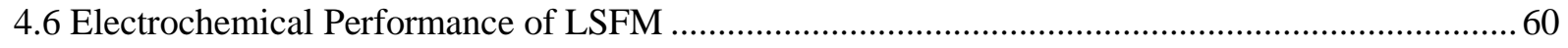

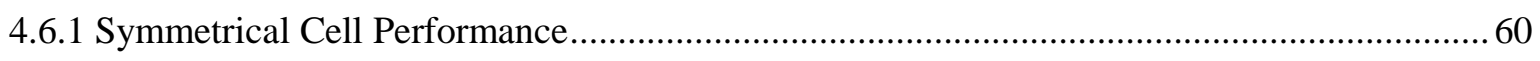

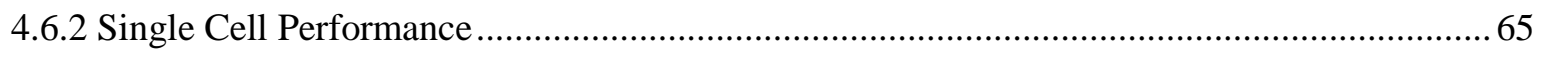

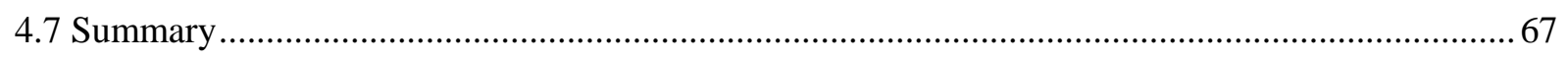

Chapter 5 In-situ Exsolution on LSFM and Promotion to the Electrochemical Performance ......... 70

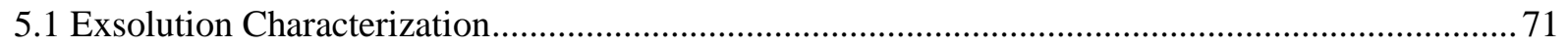

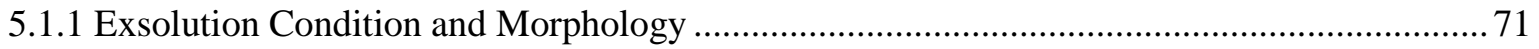

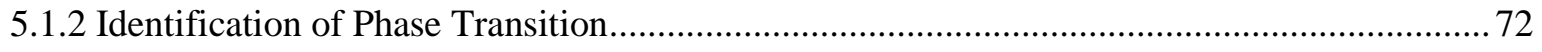

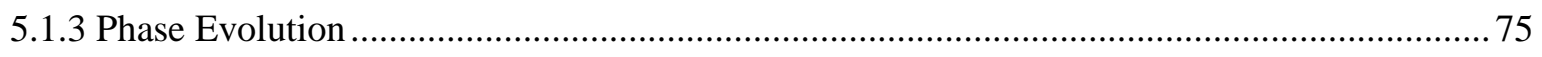

5.1.4 Exsolution Induced by "Valence Excess" and "Co-Fe Cooperation" ................................... 76

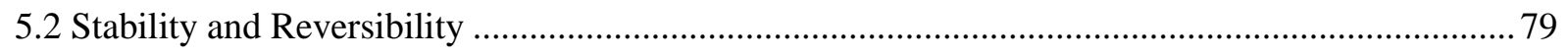

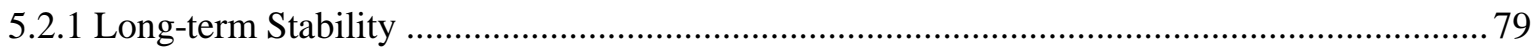

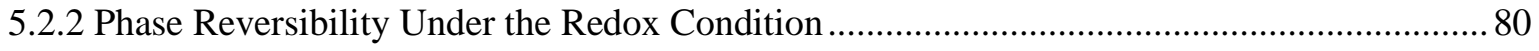

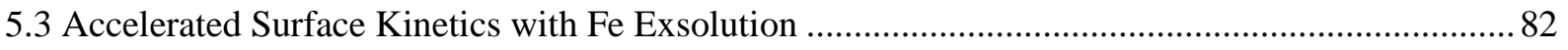

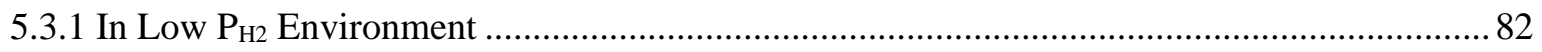

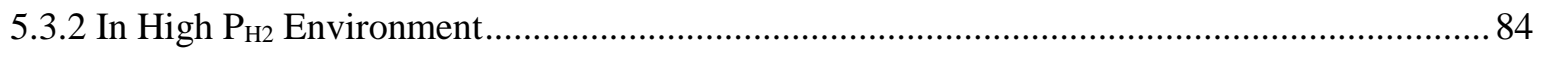

5.3.3 The Influence of Exsolution on Surface and Bulk Properties ............................................ 89

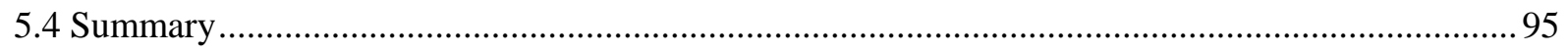

Chapter 6 The Role of Water in Hydrogen Oxidation Reaction ........................................................96

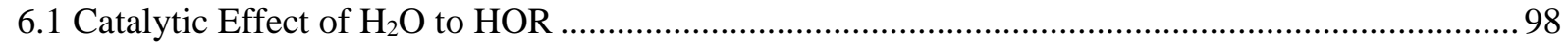

6.1.1 Accelerated surface process in humidified gas (ECR) ............................................. 98

6.1.2 Accelerated Surface Process in humidified gas (EIS) …............................................... 101 


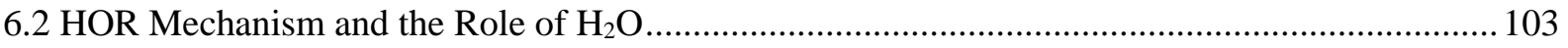

6.2.1 Rate-determining Steps on SF1.5M Surfaces ................................................................ 103

6.2.2 Effect of Slab Non-stoichiometry on HOR Reaction Energy ........................................... 104

6.2.3 The Effect of $\mathrm{H}_{2} \mathrm{O}(\mathrm{g})$ on the HOR with the same $\delta$ change

6.2.4 The Effect of $\mathrm{H}_{2} \mathrm{O}(\mathrm{g})$ on the Surface HOR Reaction....................................................... 108

6.2.5 Effect of Surface Hydroxyl Groups on HOR Reaction Energy .......................................... 112

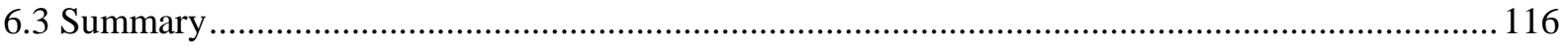

Chapter 7 Conclusion .............................................................................................................................................. 117

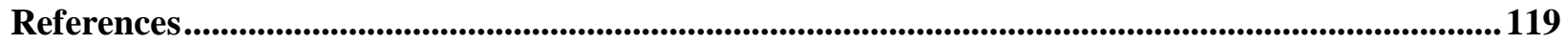




\section{LIST OF FIGURES}

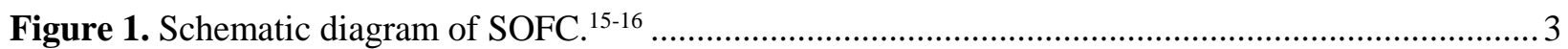

Figure 2. (a-b) SEM images of Ni patterned anode with $15 \mu \mathrm{m}$ stripe width and $800 \mathrm{~nm}$ layer thickness. (c) Scheme of sample holder for Ni pattern anode..$^{29}$................................................................... 5

Figure 3. Schematic diagram (left) and microscopy image (right) of carbon formation from unsupported $\mathrm{Ni}$ exposed to $20 \% \mathrm{C}_{2} \mathrm{H}_{4} / 7 \% \mathrm{H}_{2}$ at $823 \mathrm{~K} .{ }^{42-43}$ 7

Figure 4. (a) Schematic graph and (b) Cross-sectional TEM image of the Ni/carbon interface with the perpendicular alignment of basal planes of graphite to the $\mathrm{Ni}(110)$ surface after reaction at $650{ }^{\circ} \mathrm{C}$ for $1 \mathrm{~h}$ at $\mathrm{CO} / \mathrm{H}_{2}=25$. (c) Cross-sectional TEM image of the interface between carbon (graphite and amorphous carbon) and $\mathrm{Ni}$ grain after reaction at $550{ }^{\circ} \mathrm{C}$ for $7 \mathrm{~h}$ at $\mathrm{CO} / \mathrm{H}_{2}=25$. (d) Crosssectional TEM image of the interface between filamentous coke and carbon after reaction at 550 ${ }^{\circ} \mathrm{C}$ for $7 \mathrm{~h}$ at $\mathrm{CO} / \mathrm{H}_{2}=25 .{ }^{51}$

Figure 5. Impedance spectra under open-circuit conditions (a) for a full cell, (b) for anode/electrolyte interface..$^{33}$ 10

Figure 6. (a-b) Optical microscopy (a, b) and SEM (c, d, e) images of the Ni-YSZ composite after exposure to an $\mathrm{H}_{2} \mathrm{~S}$-containing fuel $\left(50 \mathrm{ppm} \mathrm{H}_{2} \mathrm{~S} / 1.5 \% \mathrm{H}_{2} \mathrm{O} / 48.5 \% \mathrm{~N}_{2} / 50 \% \mathrm{H}_{2}\right)$ at $800{ }^{\circ} \mathrm{C}$ for $48 \mathrm{~h}^{13} \ldots \ldots .11$

Figure 7. SEM image and EDX elemental maps of the Ni-YSZ composite after exposure to an $\mathrm{H}_{2} \mathrm{~S}$ containing fuel (50 $\mathrm{ppm}_{2} \mathrm{~S} / 1.5 \% \mathrm{H}_{2} \mathrm{O} / 48.5 \% \mathrm{~N}_{2} / 50 \% \mathrm{H}_{2}$ ) at $800{ }^{\circ} \mathrm{C}$ for $48 \mathrm{~h}^{13}$

Figure 8. Schematic diagram of the microstructure change in Ni/NiO-YSZ electrode upon successive redox cycling. ${ }^{11}$ 13

Figure 9. Crystal structure of the perovskite with $\mathrm{ABO}_{3}$ form. 14

Figure 10. A number of $\mathrm{ABO}_{3}$ compounds reported with different values of tolerance factor $t .^{77}$ 15

Figure 11. Cation ordering schemes of perovskites. From top to bottom are 0D (rock salt), 1D (columnar ordering) and 2D (layered ordering) for B-site ordering in $\mathrm{A}_{2} \mathrm{BB}^{\prime} \mathrm{X}_{6}$ perovskites (left) and A-site ordering in $\mathrm{AA}^{\prime} \mathrm{B}_{2} \mathrm{X}_{6}$ (right) perovskites. ${ }^{79}$ 16

Figure 12. (a) Electrical conductivity of $\mathrm{Sr}_{2} \mathrm{FeMoO}_{6-\delta}$ in $5 \% \mathrm{H}_{2}$, (2) Dilatometry data of $\mathrm{Sr}_{2} \mathrm{FeMoO}_{6-\delta}$ in air, inset is the bar sample after test, (c) Electrical resistance of $\mathrm{Sr}_{2} \mathrm{FeMoO}_{6-\delta}$ and related materials in $\mathrm{H}_{2},{ }^{103}$ (d) Electrical conductivity of $\mathrm{Sr}_{2} \mathrm{FeMoO}_{6-\delta}$ and associated materials in $5 \% \mathrm{H}_{2}{ }^{104}$ 18 
Figure 13. (a-d) Particle-substrate interface on perovskite surface with exsolved Ni particles. (e-h) Carbon deposition on perovskite surface with (e) deposited particles and (f-g) exsolved particles. (i-l) Thermal stability of (i-j) deposited particles and (k-l) exsolved particles. ${ }^{115}$

Figure 14. (a) Particles reduced in pure $\mathrm{H}_{2}$ (left) and $20 \% \mathrm{H}_{2}$ (right) for 5, 10, 15, 20, and $30 \mathrm{~h}$. Scale bar is $100 \mathrm{~nm}$. (b) The average particle size with reduction time and the fitting results with three models.

Figure 15. Charge transfer mechanisms at the Ni/YSZ three-phase boundary. The "wall" in panel (c) indicates potential segregated impurities. ${ }^{130}$

Figure 16. 2PB reaction regions for an MIEC anode (left) and 3PB reaction regions for an electronic-ionic composite anode (right). .25

Figure 17. Proposed mechanism for $\mathrm{H}_{2}$ oxidation on $\mathrm{Sr}_{2} \mathrm{Fe}_{1.5} \mathrm{Mo}_{0.5} \mathrm{O}_{6}$ surface. ${ }^{134}$ .25

Figure 18. Impedance spectra for $\mathrm{H}_{2}$ oxidation on (a) porous $\mathrm{Ni}$ electrode and (b) porous Pt electrode, at $1000{ }^{\circ} \mathrm{C}$ for different $\mathrm{H}_{2} \mathrm{O} \%$ in $\mathrm{H}_{2}$ gas. ${ }^{22}$ 26

Figure 19. Model for the catalytic effect of the addition of water in the fuel gas atmosphere on the performance of SOFC anodes. ${ }^{26}$ .27

Figure 20. XRD patterns of SF1.5M calcined in air at different temperatures: (a) precursor with organics residues, (b) precursor without organics residues. SF1.5M standard pattern (98-009-6233 from COD) are provided in figures.

Figure 21. SEM images of SF1.5M powders as synthesized and after reduction. (a-b) Without organics elimination and (c-d) with thorough organic elimination. (a) Synthesized in the air at $1200{ }^{\circ} \mathrm{C}$ for 5 h, (b) reduced in $\mathrm{H}_{2}$ at $800{ }^{\circ} \mathrm{C}$ for $1 \mathrm{~h}$, (c) synthesized in the air at $1050{ }^{\circ} \mathrm{C}$ for $4 \mathrm{~h}$, (d) reduced in $\mathrm{H}_{2}$ at $800{ }^{\circ} \mathrm{C}$ for $5 \mathrm{~h}$. 32

Figure 22. XRD patterns of SF1.5M reduced in $\mathrm{H}_{2}$ at $800{ }^{\circ} \mathrm{C}$ (a) without organics elimination, (b) with thorough organic elimination...... 32

Figure 23. (a) and (b) Cross-section SEM images of LSGM/LSFM interface after sintering at $1150{ }^{\circ} \mathrm{C}$ for $2 \mathrm{~h}$ in $\mathrm{N}_{2}$. .34

Figure 24. Cross section of LSCF/LSGM/LSFM single cell. 34

Figure 25. Schematic structure of home-made ECR chamber. .38 
Figure 26. Schematic structure of ECR holder with (a) $3 \mathrm{~cm}$ chamber, (b) $10 \mathrm{~cm}$ chamber. (c) Normalized ECR data of LSCF measured with different chamber lengths at different temperatures. $\mathrm{P}_{\mathrm{O} 2}$ was switched from 0.05 to 0.06 atm for all tests in (c).

Figure 27. (a) XRD patterns of LSFM calcined in $5 \% \mathrm{H}_{2}$, air, and $\mathrm{N}_{2}$, respectively. (b) XRD pattern with Rietveld refinement result of LSFM calcined in $\mathrm{N}_{2}$. Crystal structure of LSFM is shown in the inset.

Figure 28. (a) XRD pattern of LSFM synthesized in $\mathrm{N}_{2}$. (b) XRD main peak at $32^{\circ}$. (c) XRD main peak at $46^{\circ}$.

Figure 29. XRD patterns of LSFM pure phase following heat treatment at $850{ }^{\circ} \mathrm{C}$ for $20 \mathrm{~h}$ in air and $5 \% \mathrm{H}_{2}$.

Figure 30. (a) XRD patterns of SFM as synthesized in $5 \% \mathrm{H}_{2}$ and oxidized in air, (b) Dilatometry data of SFM heated up in the air, inset is the bar sample after dilatometry test. .50

Figure 31. (a) XRD patterns of $\mathrm{Sr}_{2} \mathrm{Fe}_{1.5} \mathrm{Co}_{0.1} \mathrm{Mo}_{0.4} \mathrm{O}_{6-\delta}$ (SFCM) as synthesized and reduced in $\mathrm{H}_{2}$, (b) SEM image of SFCM as synthesized, (c) SEM image of SFCM reduced in $\mathrm{H}_{2}$

Figure 32. Dilatometry results of (a) SF1.5M, (b) SFCM and (c) LSFM from RT to $800{ }^{\circ} \mathrm{C}$ in air and two redox cycles in air and $5 \% \mathrm{H}_{2}$

Figure 33. Effect of La on thermal expansion behavior. .54

Figure 34. Thermal expansion and chemical expansion behavior of LSFM (green line) and SF1.5M (purple line). Crystal structure of the two materials can be found from inset.

Figure 35. Dilatometry behavior of (a) LSFM and (b) SF1.5M from room temperature to $800{ }^{\circ} \mathrm{C}$ in the air followed by two redox cycles at $800{ }^{\circ} \mathrm{C}$. .55

Figure 36. Dilatometry behavior of (a) $\mathrm{LSFM}$ and (b) $\mathrm{LaSrFe}_{1.5} \mathrm{Mo}_{0.5} \mathrm{O}_{6-\delta}$ from room temperature to $800{ }^{\circ} \mathrm{C}$ in the air followed by two redox cycles at $800^{\circ} \mathrm{C}$. .56

Figure 37. The conductivity of compositions without (a-c) and with (d-f) Co doping in two redox cycles.

Figure 38. The conductivity of LSFM in three redox cycles. .59

Figure 39. XRD patterns of (a) LSFM + YSZ, (b) LSFM + GDC, (c) LSFM + LSGM mixtures sintered at $1150{ }^{\circ} \mathrm{C}$ in $\mathrm{N}_{2}$ for $2 \mathrm{~h}$ and (d) LSFM+GDC, (e) LSFM+LSGM mixtures sintered at $800{ }^{\circ} \mathrm{C}$ in $\mathrm{H}_{2}$ for $10 \mathrm{~h}$. 
Figure 40. SEM images of (a) the cross section of LSFM/LSGM/LSFM symmetrical cell, (b) the porous Ag current collector.

Figure 41. Symmetrical cell LSFM/LSGM/LSFM tested in wet $\mathrm{H}_{2}$ from 600 to $800{ }^{\circ} \mathrm{C}$ : (a) Nyquist plots of impedance from 700 to $800{ }^{\circ} \mathrm{C}$. the ohmic resistance $\mathrm{R}_{1}$ is subtracted from the impedance plot. (b) Arrhenius plot and activation energy. (c) Raw data and fitting line at $800{ }^{\circ} \mathrm{C}$. The equivalent circuit is shown in the inset. (d) $R_{\text {chem }}$ and $C_{\text {chem }}$ as a function of temperature.

Figure 42. Nyquist plot of LSFM symmetrical cell (black dots) and fitting lines obtained in humidified $\mathrm{H}_{2}$ at (a) $800{ }^{\circ} \mathrm{C}$, (b) $750{ }^{\circ} \mathrm{C}$, (c) $700{ }^{\circ} \mathrm{C}$ and (d) $650{ }^{\circ} \mathrm{C}$. 64

Figure 43. Voltage (open symbols) and power density (filled symbols) as a function of current density for an electrolyte-supported single cell LSCF/LSGM/LSFM under humidified $\mathrm{H}_{2}$ from $700{ }^{\circ} \mathrm{C}$ to 800 ${ }^{\circ} \mathrm{C}$. .66

Figure 44. XRD patterns of LSFM: (a) as synthesized, (b) reduced in $5 \% \mathrm{H}_{2}$ at $850{ }^{\circ} \mathrm{C}$ for $20 \mathrm{~h}$ and (c) reduced in $\mathrm{H}_{2}$ at $800{ }^{\circ} \mathrm{C}$ for $5 \mathrm{~h}$. 71

Figure 45. SEM of LSFM powders (a) as synthesized, (b) reduced in $\mathrm{H}_{2}$ at $800{ }^{\circ} \mathrm{C}$ for $5 \mathrm{~h}$. .72

Figure 46. (a-b) Fe2p and (c-d) Mo3d spectra of LSFM. Spectra in (a, c) are collected from as-synthesized powders, spectra in (b, d) are collected after reduction in $\mathrm{H}_{2}$ at $800{ }^{\circ} \mathrm{C}$ for $5 \mathrm{~h}$. .73

Figure 47. (a-b) TEM bright field images of LSFM with exsolved particles; (c) EDS plot and atomic concentration of the bulk; (d) EDS plot of the exsolved particle. .73

Figure 48. (a) XRD patterns of LSFM with partial $\left(\mathrm{H}_{2}, 800{ }^{\circ} \mathrm{C} 5 \mathrm{~h}\right)$ and total phase transition $\left(\mathrm{H}_{2}, 1200{ }^{\circ} \mathrm{C}\right.$ $2 \mathrm{~h}$ ), (b) Synchrotron XRD and Rietveld refinement of LSFM after total phase transition. 74

Figure 49. LSFM powder that reduced in $\mathrm{H}_{2}$ at $1200{ }^{\circ} \mathrm{C}$ for $2 \mathrm{~h}$, (a) EDS spectrum and the atomic ratio of elements in reduced LSFM, (b) Converted synchrotron pattern and $\mathrm{Cu} \mathrm{K} \alpha$ pattern of reduced LSFM.

Figure 50. XRD patterns of materials as synthesized and reduced in $\mathrm{H}_{2}$ at $800{ }^{\circ} \mathrm{C}$ for $5 \mathrm{~h}$. (a) SF1.5M, (b) $\mathrm{Sr}_{2} \mathrm{Fe}_{1.5} \square_{0.1} \mathrm{Mo}_{0.4} \mathrm{O}_{6-\delta}$, (c) $\mathrm{Sr}_{2} \mathrm{Fe}_{1.5} \mathrm{Co}_{0.1} \mathrm{Mo}_{0.4} \mathrm{O}_{6-\delta}$, and (d) $\mathrm{Sr}_{1.9} \mathrm{Fe}_{1.5} \mathrm{Co}_{0.1} \mathrm{Mo}_{0.4} \mathrm{O}_{6-\delta}$. .78

Figure 51. (a-c) Phase stability of LSFM in $\mathrm{H}_{2}$ at $800{ }^{\circ} \mathrm{C}$ for (a) $0 \mathrm{~h}$, (b) $5 \mathrm{~h}$ and (c) $105 \mathrm{~h}$. (d, e) SEM images of LSFM powders reduced for (d) $5 \mathrm{~h}$ and (e) $105 \mathrm{~h}$ 80

Figure 52. XRD patterns of LSFM powder (a) after reduction in $\mathrm{H}_{2}$ at $800{ }^{\circ} \mathrm{C}$ for $5 \mathrm{~h}$ and (b) after reoxidization in air at $800^{\circ} \mathrm{C}$ for $1 \mathrm{~h}$. (c-d) SEM images of LSFM after $1 \mathrm{~h}$ oxidation (c) without Fe 
residual, and (d) with Fe residual. (e) Surface and grain boundary morphology of synthesized LSFM. (f) Surface and grain boundary morphology of LSFM after one redox cycle.

Figure 53. ECR fitting results of LSFM bar sample at $800{ }^{\circ} \mathrm{C}$ in humidified $\mathrm{H}_{2}$. (a) Raw data (open circle) and the fitting result (solid line) from $5 \% \mathrm{H}_{2}$ to $8 \% \mathrm{H}_{2}$ after total reduction. 2D contour plot of error map and error map with $5 \%$ tolerance are shown in the inset. (b) $\mathrm{D}_{\text {chem }}$ and (c) $\mathrm{k}_{\mathrm{ex}}$ before and after total reduction as a function of equilibrium state oxygen partial pressure 83

Figure 54. 5\% tolerance error maps of all ECR fitting results. .83

Figure 55. LSFM/LSGM/LSFM symmetrical cell tested at $800{ }^{\circ} \mathrm{C}$ in humidified $\mathrm{H}_{2}$. (a) $\mathrm{R}_{\mathrm{p}}$ as a function of soaking time. (b) Nyquist plot (black) and the fitting result (red) at $5 \mathrm{~h}$. Inset is the corresponding equivalent circuit. (c) $R_{\text {chem }}$ and $C_{c h e m}$ as a function of soaking time. (d) $C_{c h e m} / R_{\text {chem }}$ (proportional to effective ionic conductivity $\sigma_{i, e f f}$ ) and $C_{\text {chem }} * R_{\text {chem }}$ (proportional to surface area-specific resistance $R_{\text {surf }}$ ) as a function of soaking time. .85

Figure 56. Polarization resistance of (a) LSFM, (b) SF1.5M symmetrical cells tested in humidified $\mathrm{H}_{2}$ at $800{ }^{\circ} \mathrm{C}$ as a function of soaking time. .86

Figure 57. Nyquist plots (black) and fitting results (red) of LSFM/LSGM/LSFM symmetrical cell tested at $800{ }^{\circ} \mathrm{C}$ in humidified $\mathrm{H}_{2}$ after (a-b) $0.5 \mathrm{~h}$ reduction and (c-d) $1 \mathrm{~h}$ reduction. .88

Figure 58. (a) Impedance simulation of the standard Lo element. (b) DRT result of the standard Lo element.

Figure 59. Simulated Lo element and corresponding DRT fitting spectra based on Table 10. (a-b) Increased $R_{\text {surf }}$ with fixed $\sigma_{i, e f f}$ and $f\left(\sigma_{i, e f f}=0.007, f=10\right)$. (c-d) Increased $\sigma_{i, e f f}$ with fixed $R_{\text {surf }}$ and $f\left(R_{\text {surf }}=\right.$ $0.0035, f=10)$. (e-f) increased $f$ with fixed $R_{\text {surf }}$ and $\sigma_{i, e f f}\left(R_{\text {surf }}=0.0035, \sigma_{i, e f f}=0.007\right)$. $(\mathrm{g}-\mathrm{h})$ Increased $\sigma_{i, e f f}$ and $f$ with fixed $R_{\text {surf }}\left(R_{\text {surf }}=0.0035\right)$.....

Figure 60. (a) Nyquist plots of LSFM/LSGM/LSFM symmetrical cell at $800{ }^{\circ} \mathrm{C}$ in humidified $\mathrm{H}_{2}$ for $1 \mathrm{~h}$, $2 \mathrm{~h}, 3 \mathrm{~h}$, and $5 \mathrm{~h}$. In this graph, inductance $(\mathrm{L})$ and ohmic resistance $\left(\mathrm{R}_{\mathrm{s}}\right)$ are subtracted from the plot. (b) The corresponding DRT spectra. .94

Figure 61. XRD patterns of PSFM synthesized in the $5 \% \mathrm{H}_{2}$ at $1000{ }^{\circ} \mathrm{C}$ for $4 \mathrm{~h}$ and reduced in dry $\mathrm{H}_{2}$ at $800{ }^{\circ} \mathrm{C}$ for $5 \mathrm{~h}$. .98

Figure 62. (a) ECR raw data and fitting results of SF1.5M bar sample at $800{ }^{\circ} \mathrm{C}$ in the dry (yellow) and wet (blue) gas mixture from $5 \% \mathrm{H}_{2}$ to $10 \% \mathrm{H}_{2}$. $2 \mathrm{D}$ error map in dry (b) and wet (d) gas, error map with $5 \%$ tolerance in dry (c) and wet (e) gas are also given. 
Figure 63. (a) ECR raw data and fitting results of the fresh LSFM bar sample (no exsolution) at $800{ }^{\circ} \mathrm{C}$ in the dry (yellow) and wet (blue) gas mixture from $2 \% \mathrm{H}_{2}$ to $4 \% \mathrm{H}_{2}$. $2 \mathrm{D}$ error map in dry (b) and wet (d) gas, error map with $5 \%$ tolerance in dry (c) and wet (e) gas are also given. 100

Figure 64. (a) ECR raw data and fitting results of fresh PSFM bar sample (no exsolution) at $800{ }^{\circ} \mathrm{C}$ in the dry (yellow) and wet (blue) gas mixture from $5 \% \mathrm{H}_{2}$ to $10 \% \mathrm{H}_{2}$. 2D error map in dry (b) and wet (d) gas, error map with $5 \%$ tolerance in dry (c) and wet (e) gas are also given. 101

Figure 65. Nyquist plots of the symmetrical cell SF1.5M/LSGM/SF1.5M obtained at $800{ }^{\circ} \mathrm{C}$ in dry and humidified (a) $\mathrm{H}_{2}$, (b) $5 \% \mathrm{H}_{2}$.

Figure 66. Nyquist plots of the symmetrical cell (a) LSFM/LSGM/LSFM, (b) PSFM/LSGM/PSFM obtained at $800{ }^{\circ} \mathrm{C}$ in dry and humidified $5 \% \mathrm{H}_{2}$

Figure 67. (a) Hydrogen dissociation reaction energy landscape calculated for the SF1.5M (001) $\mathrm{BO}_{2}$ surface for the dry condition (solid lines) of $\mathrm{T}=1000 \mathrm{~K}, \mathrm{P}_{\mathrm{H} 2}=0.05 \mathrm{bar}$, and $\mathrm{P}_{\mathrm{H} 2 \mathrm{O}}=0.0001$ bar and the wet condition (dashed lines) of $\mathrm{T}=1000 \mathrm{~K}, \mathrm{P}_{\mathrm{H} 2}=0.10 \mathrm{bar}$, and $\mathrm{P}_{\mathrm{H} 2 \mathrm{O}}=0.03$ bar. The color of the lines respresent different slab nonstoichiometry simulated in the slab models: $\delta=0$-blue, $\delta=0.25$ - green, $\delta=0.5$ - yellow, and $\delta=0.75$ - red. The dotted arrows are to highlight the competing steps of $\mathrm{I} 2$ and $\mathrm{I} 3$ for the $\mathrm{H}_{2}$ dissocative adsorption, in which $\mathrm{I} 2$ is higher in energy than $\mathrm{I} 3$ and can be by-passed to the I3 step. The top view of the surface states presented in Figure 67(a) are provided in (b) Surface, (c) I1 (HatM\&HatO), (d) I2 (HatM\&HatO), (e) I3 ( $\mathrm{H}_{2} \mathrm{OatM} \&$ Surf_Vo), (f) I4 (Surf_V $V_{O}$ ), and (g) I5 (Subsurf_V $V_{O}$ ), where the second surface layer is only included in the plot (g). The color of the spheres in Figure 67(b-g) are: brown - Fe, light purple - Mo, red - surface layer $\mathrm{O}$, dark purple- the second surface layer $\mathrm{O}$, green - Sr, dark pink - $\mathrm{O}$ of the adsorbed water, and light blue $-\mathrm{H}$. The shaded grey arrow indicates decrease of the I3 energy with decreasing $\delta \ldots . .106$

Figure 68. In ECR test, LSFM resistance change with $\mathrm{P}_{\mathrm{H} 2}$ in the humidified atmosphere $\left(3 \% \mathrm{H}_{2} \mathrm{O}\right)$ at 800 ${ }^{\circ} \mathrm{C}$. 107

Figure 69. ECR tests on the fresh LSFM bar sample at $800{ }^{\circ} \mathrm{C}$ with (a) the same resistance change, (b) the same theoretical $\mathrm{P}_{\mathrm{O} 2}$ change. 107

Figure 70. (a) The HOR energy landscapes of the Surface and I1-I3 states for the hydrated surface (blue color) and the dry surface (yellow color) under the condition of $\mathrm{T}=1000 \mathrm{~K}, \mathrm{P}_{\mathrm{H} 2}=0.97 \mathrm{bar}$, and $\mathrm{P}_{\mathrm{H} 2 \mathrm{O}}$ $=0.03$ bar. Three different slab $\delta(0.0,0.25$, and 0.5$)$ are included in plot. The top view of the configurations of the hydrated surface model and the dry surface model are presented in (b) and (c), respectively. The top view of the configurations of the plateau intermediate state - I3 (formation 
of $\mathrm{H}_{2} \mathrm{O}$ and surface $\mathrm{O}$ vacancy) on the hydrated and dry surfaces are presented in Figure 70 (d) and (e), respectively. The distance between the bound $\mathrm{H}^{+} \mathrm{s}$ of the surface hydroxyl groups and their second nearest neighbor surface $\mathrm{O}$ are labeled in Figure 70 (b) and (d). The color of the spheres for the elements is the same as in Figure 67. 114

Figure 71. Pathways of hydrogen oxidation reaction on dry surface (yellow line) and wet surface (blue line). The hydration process from dry to wet surface is provided as green line. 115 


\section{LIST OF TABLES}

Table 1. Vol\% of Ni-YSZ cermet with different compositions of NiO and YSZ. ${ }^{10}$.............................. 12

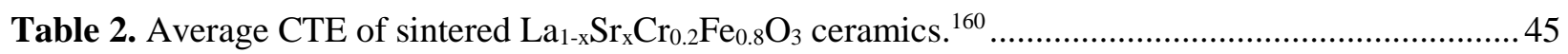

Table 3. Stability, reversibility, conductivity and CTE data of candidates............................................46

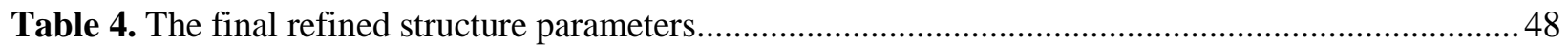

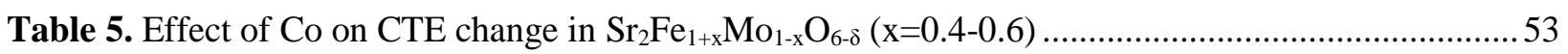

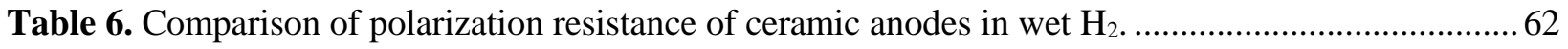

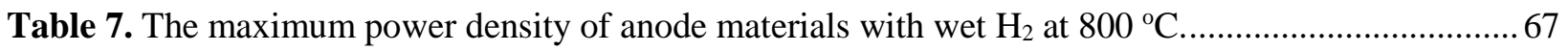

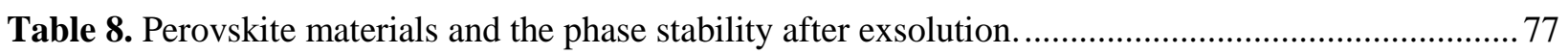

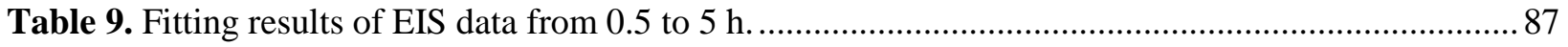

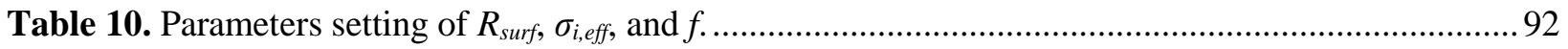




\section{LIST OF SYMBOLS AND NOTATIONS}

\begin{tabular}{|c|c|}
\hline SOFCs & Solid oxide fuel cells \\
\hline YSZ & Yttria-stabilized zirconia \\
\hline LSGM & Lanthanum strontium gallate magnesite \\
\hline LSM & Lanthanum strontium manganite \\
\hline LSCF & Lanthanum strontium cobalt ferrite \\
\hline ORR & Oxygen reduction reaction \\
\hline HOR & Hydrogen oxidation reaction \\
\hline CTE & Coefficient of thermal expansion \\
\hline TPB & Triple phase boundary \\
\hline NPs & Nanoparticles \\
\hline MIEC & Mixed ionic and electronic conductor \\
\hline ECR & Electrical conductivity relaxation \\
\hline EIS & Electrochemical impedance spectroscopy \\
\hline DRT & Distribution of relaxation time \\
\hline DFT & Density functional theory \\
\hline $\mathrm{P}_{\mathrm{O} 2}$ & Oxygen partial pressure \\
\hline $\mathrm{P}_{\mathrm{H} 2}$ & Hydrogen partial pressure \\
\hline $\mathrm{P}_{\mathrm{H} 2 \mathrm{O}}$ & Water partial pressure \\
\hline$\tau_{f}$ & Flush time \\
\hline $\mathrm{R}_{\mathrm{p}}$ & Polarization resistance \\
\hline$Z_{\text {chem }}$ & Chemical impedance \\
\hline$R_{\text {chem }}$ & Characteristic resistance \\
\hline$C_{\text {chem }}$ & Chemical capacitance \\
\hline$t_{\text {chem }}$ & Characteristic time \\
\hline$R_{\text {surf }}$ & Area-specific resistance \\
\hline$\sigma_{i, e f f}$ & Effective ionic conductivity \\
\hline
\end{tabular}




\begin{tabular}{ll}
$f$ & Thermodynamic factor \\
$l_{\delta}$ & Characteristic "utilization" length \\
$\varepsilon$ & Porosity \\
$\tau$ & Tortuosity \\
$a$ & Specific surface area \\
$V_{m}$ & Molar volume \\
$\mathrm{k}_{\mathrm{ex}}$ & Surface oxygen exchange \\
$\mathrm{D}_{\text {chem }}$ & Bulk chemical diffusion \\
$*$ & Active sites for chemisorption \\
$e^{-}$ & Electron \\
$V_{O}^{*}$ & Oxygen vacancy \\
$\mathrm{O}_{O}^{\times}$ & Lattice oxygen \\
$\mathrm{OH}_{O}^{*}$ & H attached on lattice oxygen \\
$\mathrm{H}_{O}^{*}$ & Hydride species filled in oxygen vacancy \\
$\mathrm{M}_{M}^{\times}$ & Lattice cation \\
$\mathrm{HM}_{M}^{\prime}$ & H attached on lattice cation \\
& \\
\hline &
\end{tabular}




\section{Chapter 1 Literature Review}

\subsection{Overview of SOFCs}

In recent decades, our planet is meeting the challenge of the rapidly growing population as well as the accelerated energy sources consumption. The investigation in the field of clean and renewable energy is one of the greatest research interests at present to dedicate to the worldwide energy problem. As a new power generation technique which possesses high conversion efficiency (about $50 \%$ to $75 \%$ ) from chemical energy to electrical energy without combustion, fuel cells ${ }^{2}$ have attracted considerable interests and became one of the most widely investigated new-energy devices in North American, Europe, and Asia. According to the properties of applied electrolytes, fuel cells are typically classified as ${ }^{3}$ :

(1) Proton Exchange Membrane Fuel Cells (PEMFCs);

(2) Direct-methanol Fuel Cells (DMFCs);

(3) Alkaline Fuel Cells (AFCs);

(4) Phosphoric Acid Fuel Cells (PAFCs);

(5) Molten Carbonate Fuel Cells (MCFCs);

(6) Solid Oxide Fuel Cells (SOFCs).

As an efficient and cost-effective fuel cell system, it is available for SOFCs to produce energy from hydrogen, natural gas or other renewable fuels at 500-1000 ${ }^{\circ} \mathrm{C}$. Although possesses huge advantages, the widespread application of SOFCs has not yet been realized. This is mainly because the unaffordable cost of fuel cell fabrication, materials and maintenance compared with current matured electric power generation technology. To accelerate the commercialization of SOFC technology, the system cost is suggested to no more than $\$ 800 / \mathrm{kW}$ and the fuel cell stack cost should be approximately between $\$ 80$ and $\$ 165$ per kilowatt 4. Meanwhile, the long-term stability of SOFCs should also be significantly increased. For a stationary power generation, the degradation rate of less than $1 \%$ per $1000 \mathrm{~h}$ is desired. In other words, the lifetime of 
a SOFC stack required to be at least $50,000 \mathrm{~h}^{5}$. To meet the above requirements, the materials, cell fabrication techniques, and stack designs should all be optimized ${ }^{6}$.

State-of-the-art SOFCs are composed of all-solid-state materials in many different configurations such as flat plate cell, tubular cell, and rolled tubes. The basic components of a flat plate button cell are electrolyte, anode, and cathode. The electrolyte is normally made of dense yttria-stabilized zirconia (YSZ) which is a pure oxygen-ion conductor. In laboratory-scale research, lanthanum strontium gallate magnesite (LSGM) is also employed as the electrolyte. On the air side, electronic conductor lanthanum strontium manganite (LSM) is commonly mixed with ionic conductor YSZ as composite cathode ${ }^{7-8}$. Mixed ionic and electronic conductors (MIECs) can be applied alone as the cathode, such as lanthanum strontium cobalt ferrite $(\mathrm{LSCF})^{9}$. On the fuel side, porous Ni/YSZ composite is a widely used commercialized anode ${ }^{10}$. To address the issues of significant volume change ${ }^{11}$, carbon deposition ${ }^{12}$ and sulfur positioning ${ }^{13}$ on $\mathrm{Ni}$, ceramic materials, especially MIEC materials ${ }^{14}$, are investigated as the potential substitute for Ni-YSZ.

The configuration and reaction principle of the SOFC system are summarized in Figure 1. Briefly, the reaction in SOFC is an oxidation reaction of fuels by oxygen. Take the hydrogen, for example, the corresponding overall reaction is:

$$
\mathrm{H}_{2}(g)+\frac{1}{2} \mathrm{O}_{2}(g) \rightarrow \mathrm{H}_{2} \mathrm{O}(g)
$$

On the cathode side, oxygen flows into the porous electrode, be reduced to $\mathrm{O}^{2-}$ and then incorporate into the electrolyte as the lattice oxygen $\mathrm{O}_{O}^{\times}$. This oxygen reduction reaction $(\mathrm{ORR})$ can be written as:

$$
\frac{1}{2} \mathrm{O}_{2}(g)+2 e^{-}+V_{o}^{*} \rightarrow \mathrm{O}_{O}^{\times}
$$

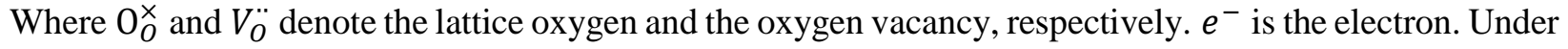
the influence of electric potential, $\mathrm{O}_{O}^{\times}$diffuse through the electrolyte and react with hydrogen on the anode side. The hydrogen oxidation reaction (HOR) can be written as: 


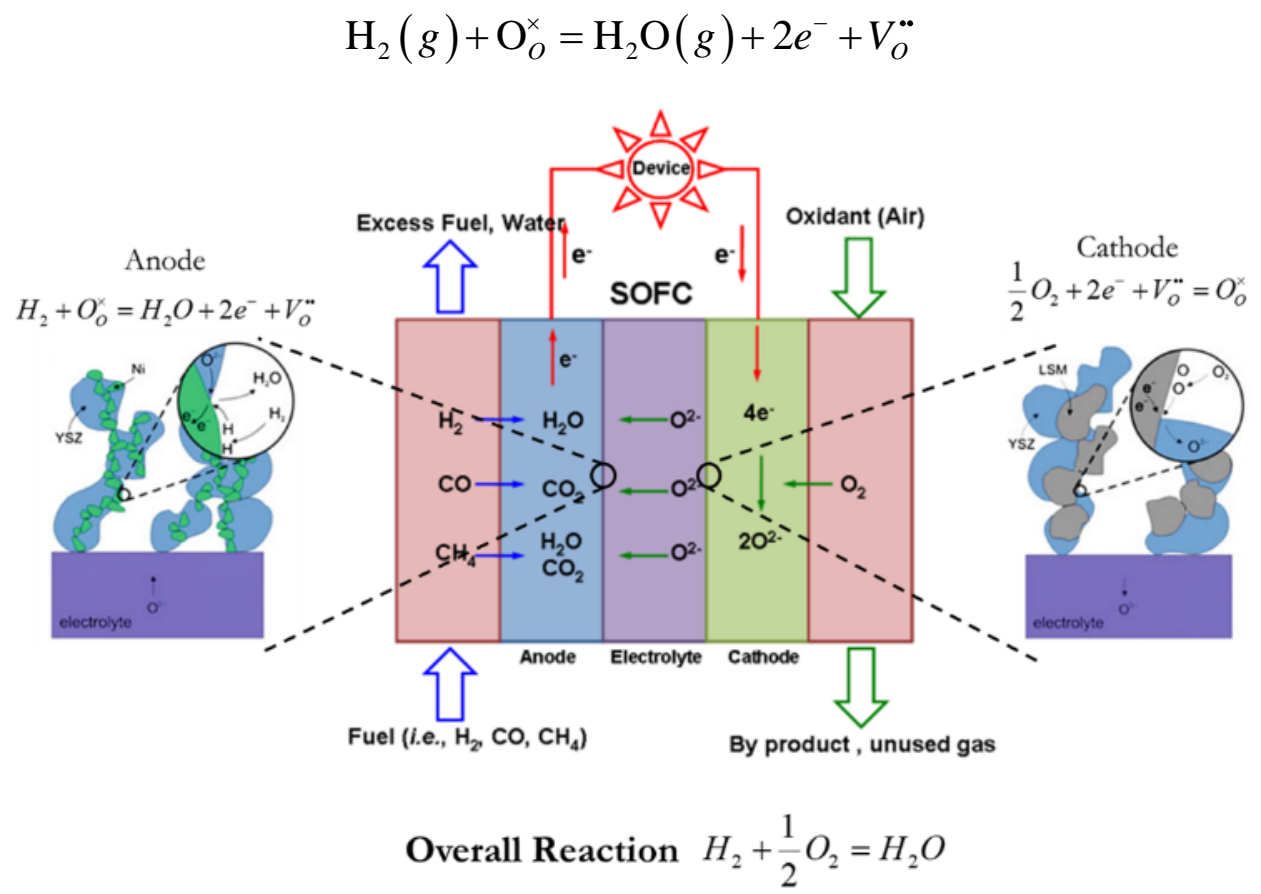

Figure 1. Schematic diagram of SOFC. ${ }^{15-16}$

The aim of this dissertation is to investigate the ceramic anode materials for SOFCs and to explore the HOR mechanisms based on perovskite anode materials. Thus, in the rest of this introduction, we will focus on the materials and mechanisms on the anode side.

\subsection{Anode Materials}

As one of the most important components in the SOFC, the anode must catalyze the reaction of the fuel with oxygen ions from the electrolyte and conduct the electrons produced in the electrochemical reaction to the external circuit according to the Eq. (3). The anode polarization resistance $\left(R_{p}\right)$ is strongly impacted by the catalytic activity towards the fuel oxidation and the microstructure of the electrode. Specifically, the microstructure involves anode morphology, size of the active area, porosity and the distribution of open pores for efficient gas transportation. Anode materials should possess a high electronic conductivity, a high ionic conductivity and sufficient catalytic activity to minimize energy loss during the fuel oxidation reaction. Besides these requirements, an ideal anode material must also possess the good chemical and thermal stability, the minimal CTE mismatch with other adjacent components and the sufficient mechanical strength 
to withstand the physical weight and mechanical stresses. Furthermore, the anode material must be stable in commonly used fuel gases, such as $\mathrm{H}_{2}, \mathrm{CO}$, and hydrocarbons while tolerating carbon deposition, sulfur poisoning and re-oxidation ${ }^{17-18}$. In consideration of the above conditions, an ideal SOFC anode needs to meet the following requirements ${ }^{19-20}$ :

(1) Great chemical compatibility with electrolyte to ensure clear interface.

(2) High ionic and electrical conductivity to support fast charge transfer.

(3) Satisfying catalytic activity towards fuel oxidation process.

(4) Excellent resistance to carbon coking and sulfur poisoning on hydrocarbon application.

(5) Similar coefficient of thermal expansion (CTE) with electrolyte to avoid cracking.

(6) Good phase stability in operating temperature and oxygen partial pressure $\left(\mathrm{P}_{\mathrm{O} 2}\right)$ to keep the cell's long-term performance.

(7) Simple fabrication routine and affordable price to lower the cost for large scale production.

\subsection{Ni-based Anodes}

\subsubsection{Ni Metal Anodes}

At the early stage of anode material exploration, metal materials in the transition group and platinum group are explored ${ }^{21}$. Among $\mathrm{Fe}, \mathrm{Co}, \mathrm{Ni},{ }^{22}, \mathrm{Mn}, \mathrm{Pt}^{23}$ and $\mathrm{Ru}^{24}$, $\mathrm{Ni}$ defeated other elements with the highest electrochemical activity for $\mathrm{HOR}^{25}$ and cost-effective price.

For an in-depth insight into the reaction mechanism at SOFC electrodes, it is essential to possess a controlled microstructure of the electrode (Figure 2). This will be beneficial to accurately determine the reaction sites and to clearly highlight the reaction rate of the unit area on the electrode ${ }^{26-30}$. Contrarily, it is not easy to determine the reaction area and the rate-determining step in a porous Ni-YSZ cermet with complicated and heterogeneous microstructure ${ }^{31-32}$. 
The anode reaction kinetics study was carried out by Yamamura et al. ${ }^{33}$ and Norby et al. ${ }^{34}$ on patterned $\mathrm{Ni}$ anode and $\mathrm{Ni}$ mesh, respectively. Mizusaki et al..$^{30,35}$ investigated the anode hydrogen oxidation reaction kinetics on patterned Ni anodes with YSZ as the electrolyte. Mizusaki ${ }^{30}$ prepared a total of 20 different nickel stripe patterns with the line widths of $5,10,25$, and $50 \mu \mathrm{m}$ on $8 \mathrm{YSZ}$ single crystal surface for anode impedance spectrum investigation. It was proved that the active region in a $\mathrm{Ni}$ pattern anode is limited to the triple phase boundary (TPB) and the $\mathrm{R}_{\mathrm{p}}$ is inversely proportional to the TPB length ${ }^{26-27}$.
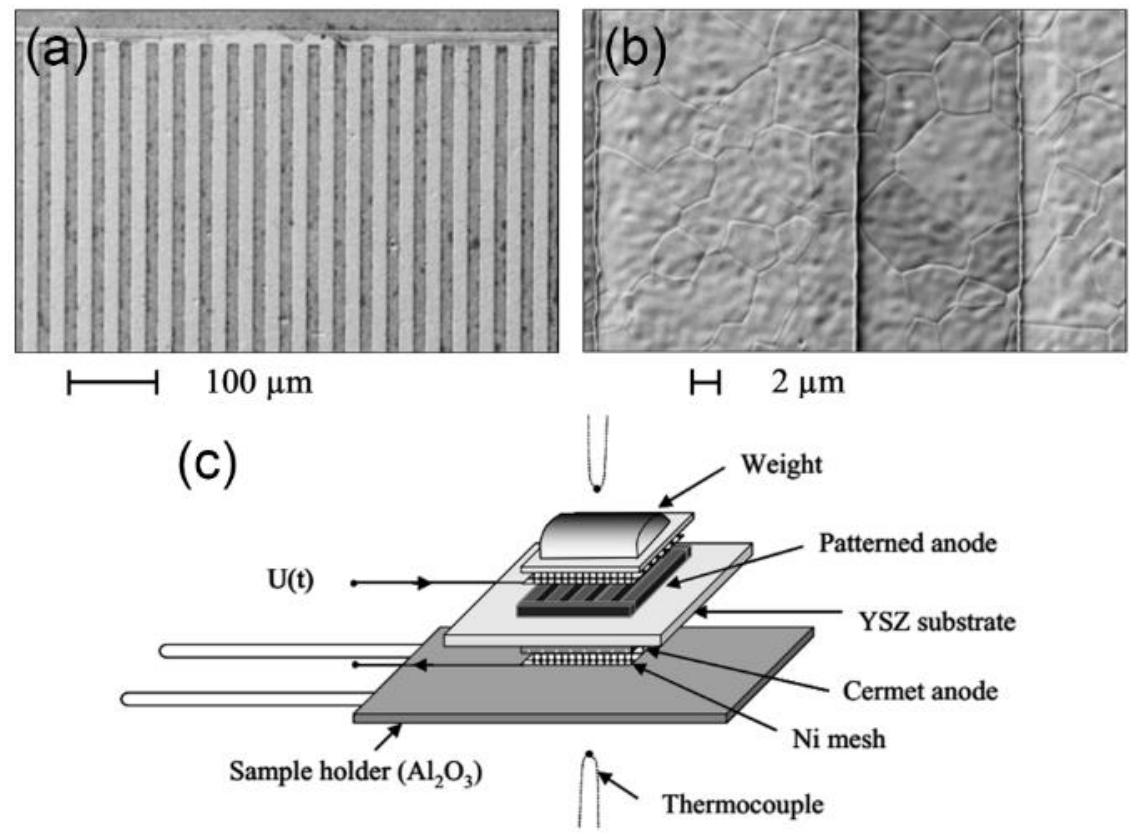

Figure 2. (a-b) SEM images of Ni patterned anode with $15 \mu \mathrm{m}$ stripe width and $800 \mathrm{~nm}$ layer thickness. (c) Scheme of sample holder for Ni pattern anode. ${ }^{29}$

\subsubsection{Ni-YSZ Cermet}

To overcome the drawbacks associated with pure Ni with regard to CTE and coarsening effects, Ni-YSZ cermet is introduced by Liu's group ${ }^{36}$ and receives considerable attention as a state-of-the-art anode for SOFCs. To be precise, the following favorable characteristics make the Ni-YSZ composite anode prominent:

(1) Catalytic activity: $\mathrm{Ni}$ is an excellent electrocatalyst for the electrochemical oxidation of $\mathrm{H}_{2}{ }^{10}$. This guarantees the high power density of the cell (about $2 \mathrm{~W} \mathrm{~cm}^{-2}$ in $\mathrm{H}_{2}$ at $\left.800{ }^{\circ} \mathrm{C}\right)^{37}$. 
(2) Electronic conductivity: Extremely high electronic conductivity $\left(\sim 2 \times 10^{4} \mathrm{~S} \mathrm{~cm}^{-1} \text { at } 1000{ }^{\circ} \mathrm{C}\right)^{10}$ of $\mathrm{Ni}$ provides a fast transmission channel for electrons. The electrical conductivity of Ni-YSZ cermet $\left(\sim 10^{2}-10^{3} \mathrm{~S} \mathrm{~cm}^{-1} \text { at } 600-1000{ }^{\circ} \mathrm{C} \text { in } \mathrm{H}_{2}\right)^{38-39}$ is still higher than most of the ceramic materials.

(3) TPB length: The abundant Ni/YSZ interface prolongs the TPB length and expands the active region from a limited two-dimensional electrolyte/electrode interface to the three-dimensional network.

(4) YSZ framework: The YSZ constitutes a framework for the dispersion of Ni and inhibits the coarsening of Ni during the operation to maintain the TPB length ${ }^{40}$. It also offers a significant part of ionic contribution to the overall conductivity, thus effectively broadening the TPB area.

(5) Chemical stability: Both YSZ and Ni are stable in a reducing atmosphere at high temperatures and the compatibility of Ni and YSZ is excellent over a very wide temperature range.

(6) CTE: The CTE of Ni-YSZ is close to the YSZ electrolyte and the CTE value can be matched with other cell components by adjusting the composition ${ }^{41}$.

(7) Charge transfer resistance: The intrinsic charge transfer resistance that is associated with the electrocatalytic activity at $\mathrm{Ni} / \mathrm{YSZ}$ boundary is $1 \mathrm{low}^{10}$.

As discussed with the Ni pattern electrode, the electrochemical reaction in Ni-YSZ occurs at the TPB where $\mathrm{Ni}$, YSZ, and pore (gas phase) coexist. Maximization of TPB length by fine-tuning the microstructure is crucial to improve the electrochemical performance of Ni-YSZ anode. Meanwhile, the connected electrical conductor network (Ni) and ionic conductor network (YSZ) is necessary to avoid the inert zone as well as to maximize the TPB density. Electrical and mechanical properties of anodes should also be considered upon the microstructure modification.

In view of the conventional ceramic powder mixing process, the general Ni/YSZ cermet anode preparation process involves the following steps ${ }^{10}$ :

(1) Homogeneously mix the appropriately sized NiO and YSZ in an appropriate composition.

(2) Fire the mixture at an appropriate high temperature for a certain time. 
(3) Reduce the NiO-YSZ into Ni-YSZ in the reducing atmosphere (pure $\mathrm{H}_{2}$ or $\mathrm{N}_{2}+\mathrm{H}_{2}$ mixture) at a fuel cell operating temperature $\left(600-1000{ }^{\circ} \mathrm{C}\right)$.

In the third step, the generation of pores into the anode is along with the reduction of $\mathrm{NiO}$ because of the huge volume reduction $(\sim 41 \%)$ during the conversion of $\mathrm{NiO}$ to $\mathrm{Ni}$. The volume of pores formed during the reduction depends on the composition of the cermet. The porosity of Ni-YSZ cermet increases with the amount of NiO. Volume percentage (Vol\%) of different components of the anode (NiO, Ni, YSZ and porosity), calculated from the molar volumes of YSZ, Ni and NiO.

\subsubsection{Carbon Deposition}
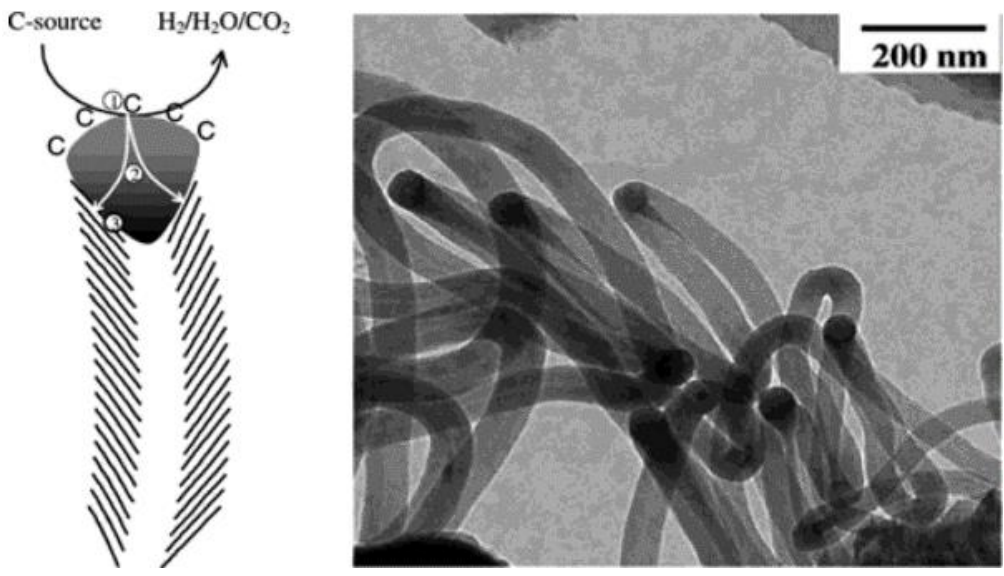

Figure 3. Schematic diagram (left) and microscopy image (right) of carbon formation from unsupported Ni exposed to $20 \%$ $\mathrm{C}_{2} \mathrm{H}_{4} / 7 \% \mathrm{H}_{2}$ at $823 \mathrm{~K}^{42-43}$

Carbon deposition is a critical problem to kill Ni-based anodes in a short time. As we know Ni is a great catalyst to promote the carbon nanofiber fabrication ${ }^{42}$, the formation of carbon with Ni-based system in a hydrocarbon environment is difficult to avoid. Carbon deposition takes place via the catalytic dissociative adsorption of hydrocarbons on the Ni surface ${ }^{10}$. When carbon source deposit onto Ni surface, carbon prefer to dissolve into the Ni bulk, after the carbon is saturated in Ni particle, it will precipitate out as fiber at some Ni surface. The schematic diagram and microscopy image of carbon fiber formation are described in Figure 3. Formed carbon covers the active sites of the anode and results in the loss of cell performance. Generally, the button cell would be killed by carbon coking in a few hours depending on temperature and environment. 
Carbon deposition on the Ni-YSZ anode materials takes place via the following chemical reactions ${ }^{44}$ : (1) $\mathrm{CH}_{4}$ cracking at a high temperature and under a low steam to carbon $(\mathrm{S} / \mathrm{C})$ ratio in thermodynamic equilibrium. (2) Reduction of $\mathrm{CO}$ to $\mathrm{C}$ at a low $\mathrm{CO}$ concentration. (3) disproportionation of $\mathrm{CO}$ (Boudouard reaction) at low temperatures at a high $\mathrm{CO}$ concentration.

$$
\begin{gathered}
\mathrm{CH}_{4} \rightarrow \mathrm{C}+2 \mathrm{H}_{2} \quad \Delta H_{298 \mathrm{~K}}=-172 \mathrm{~kJ} \mathrm{~mol}^{-1} \\
\mathrm{CO}+\mathrm{H}_{2} \rightarrow \mathrm{C}+\mathrm{H}_{2} \mathrm{O} \quad \Delta H_{298 \mathrm{~K}}=-131 \mathrm{~kJ} \mathrm{~mol}^{-1} \\
2 \mathrm{CO} \rightarrow \mathrm{C}+\mathrm{CO}_{2} \quad \Delta H_{298 \mathrm{~K}}=-172 \mathrm{~kJ} \mathrm{~mol}^{-1}
\end{gathered}
$$

The morphology of carbon is controlled by the temperature ${ }^{44-45}$, fuel composition and anode material ${ }^{46-47}$. At high S/C ratio ( 2), no degradation of the anode material is observed. Unfortunately, the Ni current collector is partly disintegrated at $\mathrm{S} / \mathrm{C}=0.5$ (despite stable operation) $)^{48}$. Meanwhile, the situation becomes more complicated with water because water is generally present in the reformate gas, syngas, biogas, etc., and trigger the water-gas shift reaction ${ }^{49}$ :

$$
\begin{gathered}
\mathrm{CO}+\mathrm{H}_{2} \mathrm{O} \rightarrow \mathrm{CO}_{2}+\mathrm{H}_{2} \\
\Delta H=-41.2 \mathrm{~kJ} \mathrm{~mol}^{-1} \quad \Delta G=-28.6 \mathrm{~kJ} \mathrm{~mol}^{-1}
\end{gathered}
$$

Besides wrapping Ni particles and inactivating the active sites of the anode, deposited carbon also induces corrosion of $\mathrm{Ni}$ particles ${ }^{50}$. Chun et al. ${ }^{51-52}$ state that at high temperatures $\left(<900{ }^{\circ} \mathrm{C}\right)$, carbon is transferred from the carbon supersaturated gaseous fuel environment and precipitate on the Ni surface via the catalytic graphitization mechanism. At certain regions of Ni surface, the basal planes of graphite are perpendicularly oriented to the metal surface, as shown in Figure 4a-b. The Ni metal cations will intercalate into these graphitic channels and subsequently coalesce at the outer surface of the graphite. Small Ni particles formed during this process and finally lead to the corrosion of Ni (Figure 4c-d). These small Ni particles at the outer surface catalyze the formation of carbon nanofibers. 

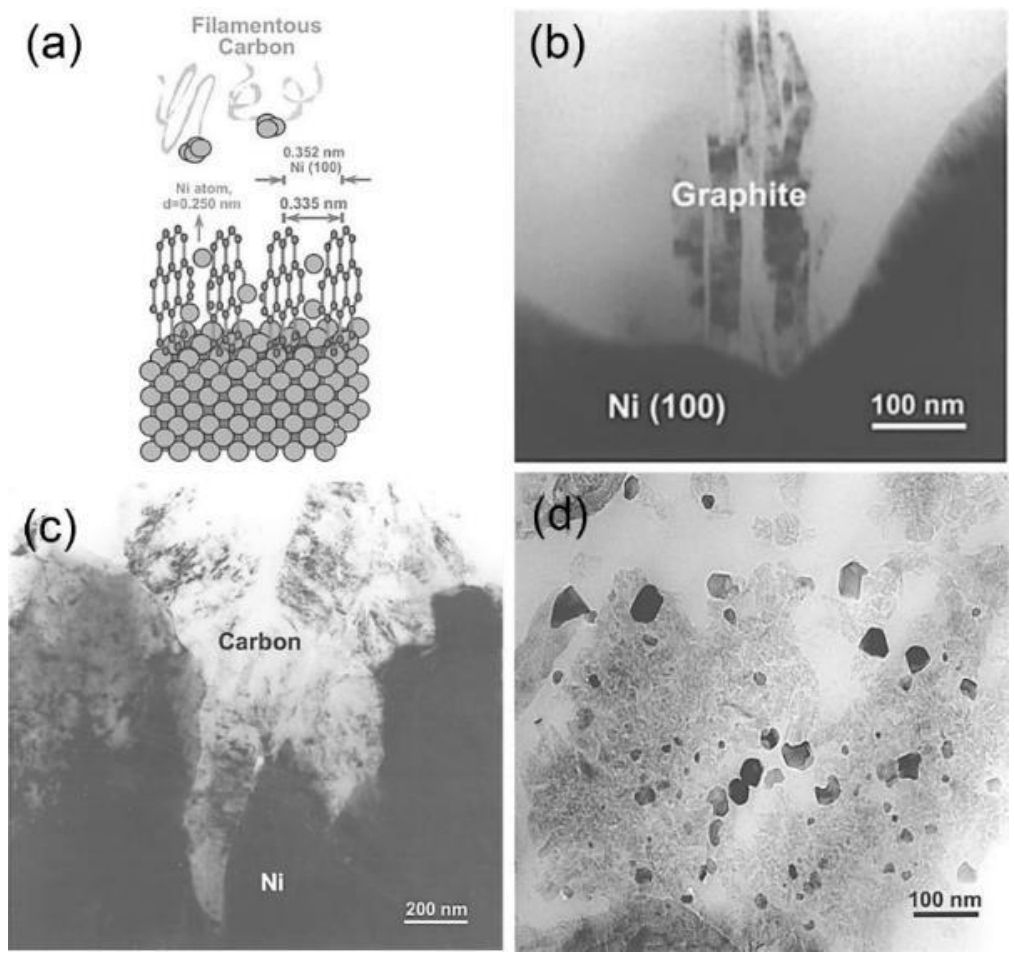

Figure 4. (a) Schematic graph and (b) Cross-sectional TEM image of the Ni/carbon interface with the perpendicular alignment of basal planes of graphite to the $\mathrm{Ni}(110)$ surface after reaction at $650{ }^{\circ} \mathrm{C}$ for $1 \mathrm{~h}$ at $\mathrm{CO} / \mathrm{H}_{2}=25$. (c) Cross-sectional TEM image of the interface between carbon (graphite and amorphous carbon) and $\mathrm{Ni}$ grain after reaction at $550{ }^{\circ} \mathrm{C}$ for $7 \mathrm{~h} \mathrm{at} \mathrm{CO} / \mathrm{H}_{2}=25$. $(\mathrm{d})$ Cross-sectional TEM image of the interface between filamentous coke and carbon after reaction at $550{ }^{\circ} \mathrm{C}$ for $7 \mathrm{~h}$ at $\mathrm{CO} / \mathrm{H}_{2}=25$. 51

\subsubsection{Sulfur Poisoning}

As another enemy to Ni-YSZ anode performance, sulfur poisoning usually has two sequential stages related to different surface processes ${ }^{53}$. The first stage dominated by a fast sulfur adsorption process on the $\mathrm{Ni}$ surface, which can be described as:

$$
\mathrm{H}_{2} \mathrm{~S}(\text { gas })+\mathrm{Ni}(\text { solid }) \rightarrow \mathrm{Ni}-\mathrm{S}(\text { surface })+\mathrm{H}_{2}
$$

As a strong absorption of sulfur on $\mathrm{Ni}$ surface, active sites for $\mathrm{H}_{2}$ adsorption are blocked and all the following processes such as dissociation, diffusion, and oxidation are prohibited along the poisoned surface. The degradation can be clearly observed in Figure 5 with a few ppm $\mathrm{H}_{2} \mathrm{~S}$ in $\mathrm{H}_{2}$. The degradation caused by 
the second stage is much slower. A reasonable explanation about the second stage is that, after surface poisoning at the first stage, continued sulfur exposure give rise to a surface reconstruction on $\mathrm{Ni}^{54}$. For the recovery process, Eq. (8) will be reversed as:

$$
\mathrm{Ni}-\mathrm{S}(\text { surface })+2 \mathrm{O}_{Y S Z}(\mathrm{TPB}) \rightarrow \mathrm{Ni}(\text { surface })+\mathrm{SO}_{2}(\text { gas })+2 V_{o}^{*}(\mathrm{TPB})+4 e^{-}(\mathrm{Ni})
$$

With the absent of $\mathrm{H}_{2} \mathrm{~S}$, surface adsorbed sulfur will be released first and followed by diffusion of sulfur from subsurface to outer surface and desorption. However, if the microstructure has to be altered to some extent, the recovery may not be complete ${ }^{53}$.
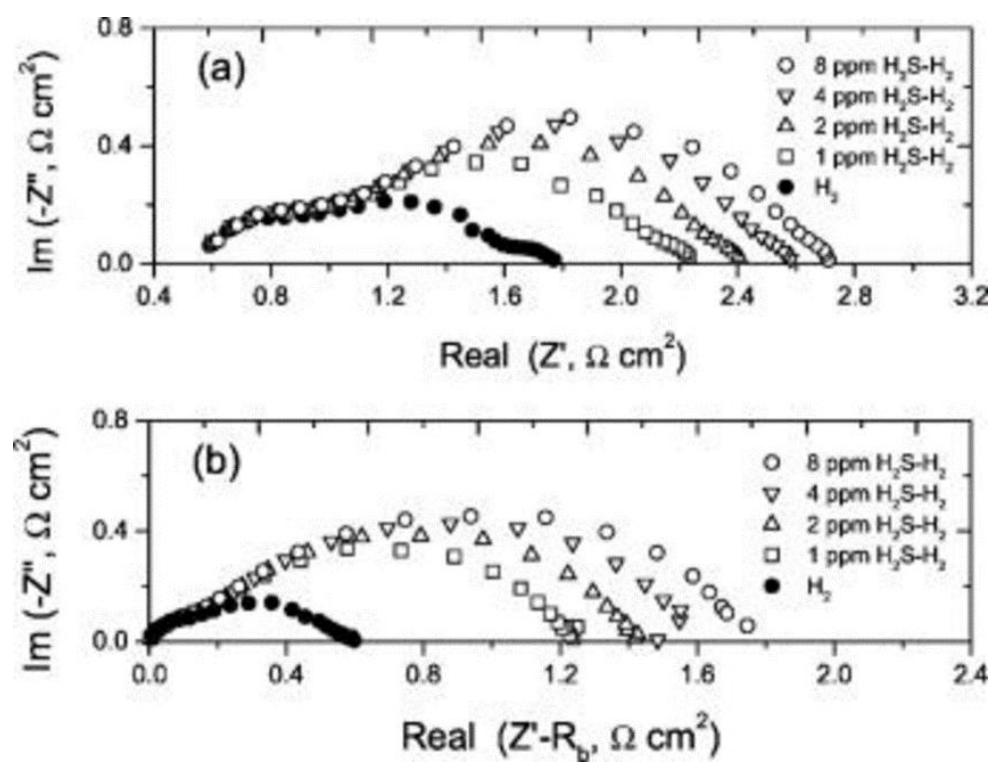

Figure 5. Impedance spectra under open-circuit conditions (a) for a full cell, (b) for anode/electrolyte interface..$^{53}$

Cheng et al. ${ }^{13}$ tested the Ni-YSZ composite in the fuel mixture with a nominal composition of $50 \mathrm{ppm}$ $\mathrm{H}_{2} \mathrm{~S} / 50 \% \mathrm{H}_{2} / 1.5 \% \mathrm{H}_{2} \mathrm{O} / 48.5 \% \mathrm{~N}_{2}$ for $48 \mathrm{~h}$ followed by a gradual cooling in the same fuel atmosphere. The ex situ optical and SEM images are given as Figure 6a-b and Figure 6c-e, respectively. With exposure to the sulfur-containing fuel, $\mathrm{Ni}$ is changed from metallic white to brown (Figure 6a) or yellow (Figure 6a). Besides, the morphology of $\mathrm{Ni}$ is various when exposure to the sulfur.

In some regions, Ni particles rise up along the particle edge to form a hump (Figure 6a and c). In other regions, the Ni surface is covered by micro-scale sphere-like structures (Figure 6b, $d$ and e). The surface of 
the spheres and the regions in between them seem to be composed of submicron-scale irregular shape particles.

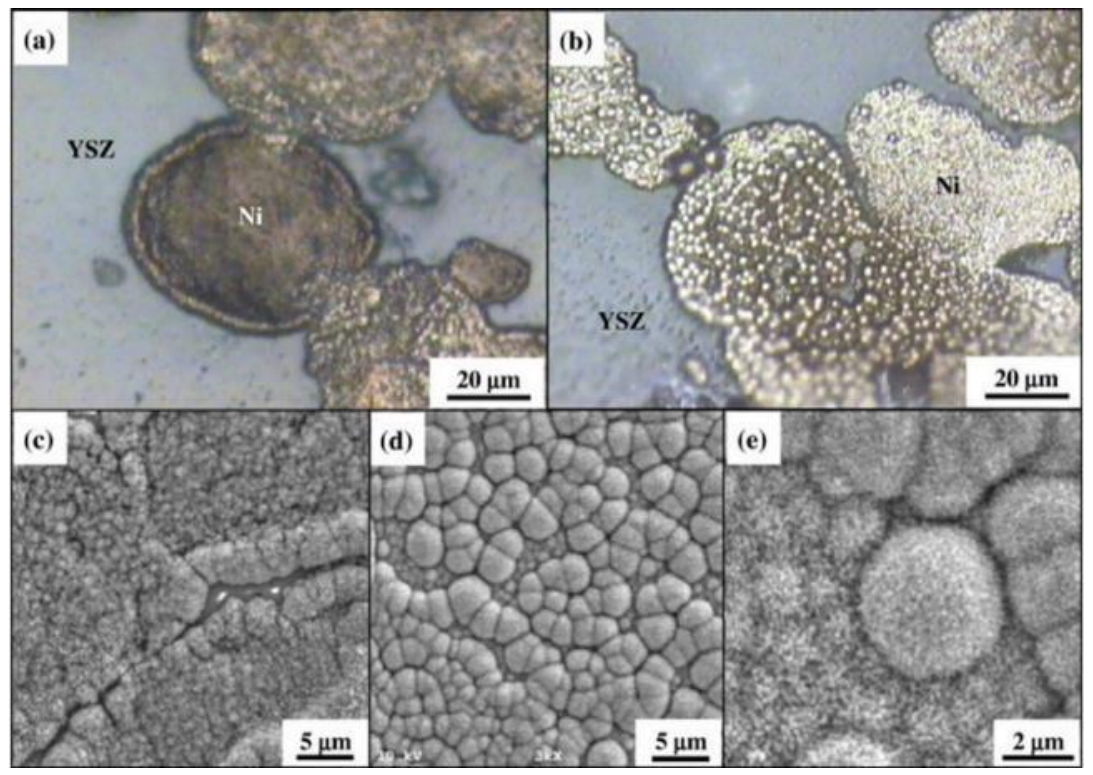

Figure 6. (a-b) Optical microscopy (a, b) and SEM (c, d, e) images of the Ni-YSZ composite after exposure to an $\mathrm{H}_{2} \mathrm{~S}$-containing fuel $\left(50 \mathrm{ppm} \mathrm{H}_{2} \mathrm{~S} / 1.5 \% \mathrm{H}_{2} \mathrm{O} / 48.5 \% \mathrm{~N}_{2} / 50 \% \mathrm{H}_{2}\right)$ at $800{ }^{\circ} \mathrm{C}$ for $48 \mathrm{~h}^{13}$

Moreover, EDX elemental mapping on sulfur poisoned Ni-YSZ composite exhibited the selective corrosion of sulfur on Ni. In Figure 7, the complemented sulfur and zirconium area in the EDX maps indicate that sulfur selectively attacks the nickel in the composite. On the other hand, because of the excellent stability of YSZ, $\mathrm{H}_{2} \mathrm{~S}$ or sulfur do not react with YSZ and the adsorption of sulfur on oxides is usually minimal ${ }^{55}$.

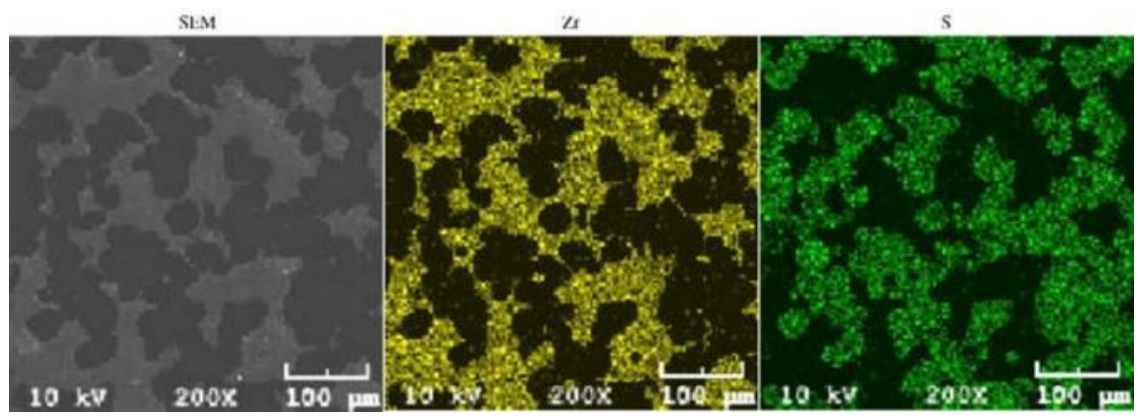

Figure 7. SEM image and EDX elemental maps of the Ni-YSZ composite after exposure to an $\mathrm{H}_{2} \mathrm{~S}$-containing fuel $\left(50 \mathrm{ppm} \mathrm{H}_{2} \mathrm{~S} / 1.5 \%\right.$ $\left.\mathrm{H}_{2} \mathrm{O} / 48.5 \% \mathrm{~N}_{2} / 50 \% \mathrm{H}_{2}\right)$ at $800{ }^{\circ} \mathrm{C}$ for $48 \mathrm{~h} .{ }^{13}$ 


\subsubsection{Volume Change}

Besides carbon deposition and sulfur poisoning, the big $\mathrm{NiO} / \mathrm{Ni}$ volume change in the redox environment and the microstructure change because of $\mathrm{Ni}$ coarsening are two other reasons for the performance degradation. The volume and pore size change in a Ni-YSZ cermet with different Ni:YSZ ratio is listed in Table 1. According to this table, the volume loss of $\mathrm{NiO}$ after reducing is about $40 \mathrm{vol} \%$. Uniformly dispersed pores in bulk $\mathrm{Ni}$ and at $\mathrm{Ni} / \mathrm{YSZ}$ interface ${ }^{56-57}$ are formed to compensate this volume change.

Table 1. Vol\% of Ni-YSZ cermet with different compositions of NiO and YSZ. ${ }^{10}$

\begin{tabular}{ccc|ccc}
\hline \hline \multicolumn{3}{c|}{ Before Reduction (vol\%) } & \multicolumn{3}{c}{ After Reduction (vol\%) } \\
YSZ & NiO & Pore & YSZ & Ni & Pore \\
\hline 91.05 & 8.95 & 0 & 91.05 & 5.262 & 3.688 \\
81.89 & 18.11 & 0 & 81.89 & 10.65 & 7.46 \\
72.51 & 27.49 & 0 & 72.51 & 16.16 & 11.33 \\
62.90 & 37.10 & 0 & 62.90 & 21.8 & 15.30 \\
53.06 & 46.94 & 0 & 53.06 & 27.6 & 19.34 \\
42.98 & 57.02 & 0 & 42.98 & 35.53 & 21.49 \\
32.64 & 67.36 & 0 & 32.64 & 39.6 & 27.76 \\
22.04 & 77.96 & 0 & 22.04 & 45.84 & 32.12 \\
11.06 & 88.84 & 0.1 & 11.06 & 52.23 & 36.71 \\
\hline \hline
\end{tabular}

Mechanism of performance degradation from $\mathrm{Ni}$ volume change in a redox environment is shown in Figure 8. For an as-sintered NiO-YSZ composite, configuration of pores, $\mathrm{NiO}$ and $\mathrm{YSZ}$, as shown in Figure $8 \mathrm{a}^{11}$. Upon reduction, the $\mathrm{Ni}$ particles become rounded and volume reduced, more space is formed in the electrode. During re-oxidation, the Ni particles won't revert to original state but expansion to a new morphology which dominated by the oxidation kinetics. Accompanying a fast and random volume expansion in a certain space, stress is generated in the YSZ matrix and Ni particles. At some weak points, cracks happen, as shown in Figure 8c. When the electrode is reduced for the second time, because of the 
redistribution of $\mathrm{NiO}$ an improved percolating $\mathrm{Ni}$ network will be formed compared with the first reduced state. With repeated redox cycling, more and more cracks are formed in the YSZ network together with a better improved percolating of Ni network and Ni coarsening.

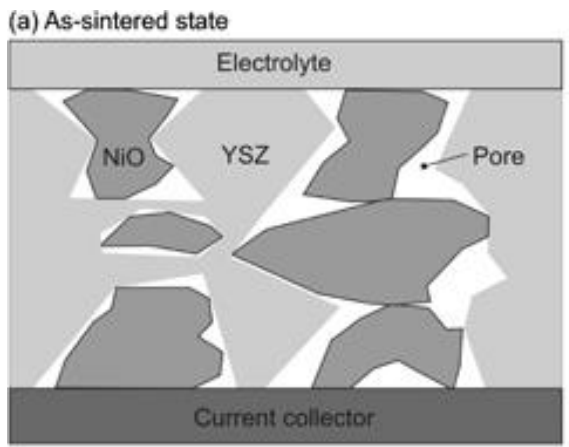

(b) First reduced state
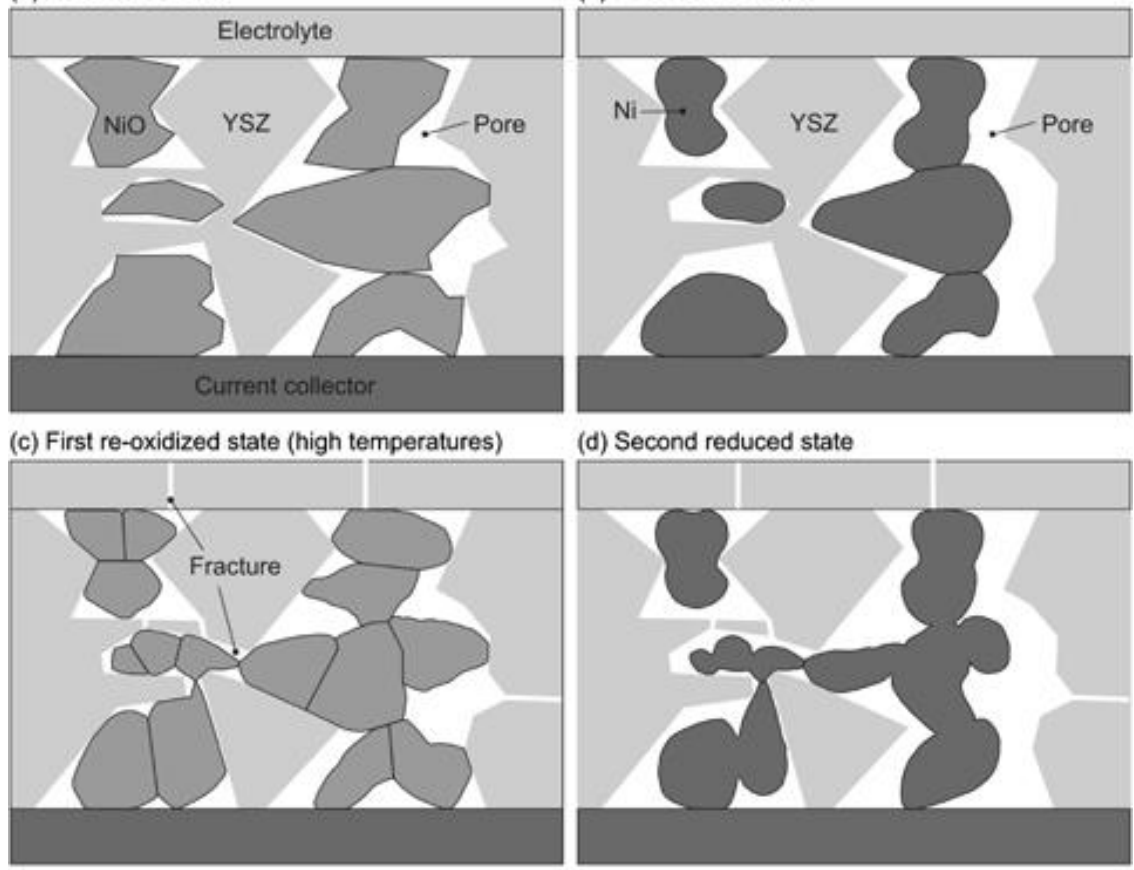

(d) Second reduced state
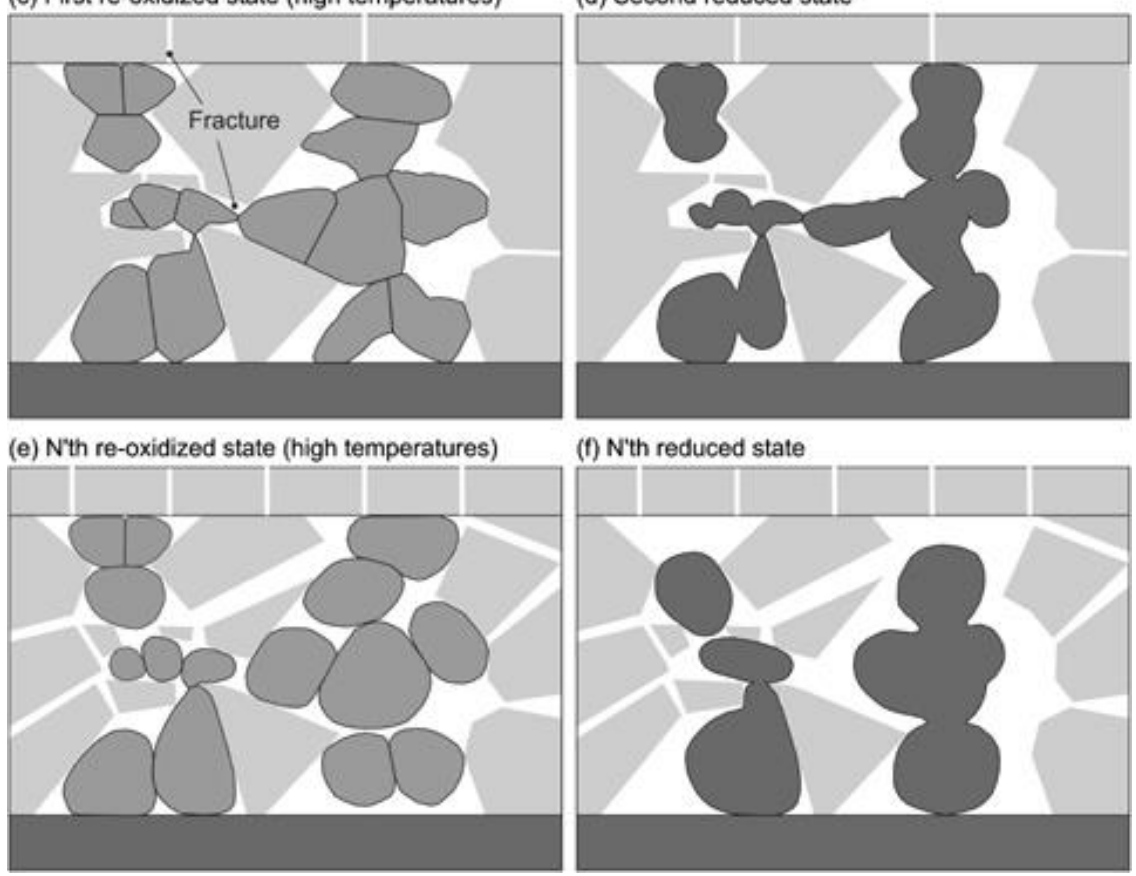

Figure 8. Schematic diagram of the microstructure change in Ni/NiO-YSZ electrode upon successive redox cycling. ${ }^{11}$

\subsection{Perovskite Anodes}

The requirements of high carbon resistance and low sulfur sensitivity bring people to start working on nickel free materials such as copper-based cermet $^{58-60}$, ceria related compounds ${ }^{61-64}$, perovskites ${ }^{65-67}$, and pyrochlores ${ }^{68-70}$. Because of the exceptional structure and flexible composition, perovskites get lots of 
attention in recent years and generate many famous material groups, such as $\mathrm{SrTiO}_{3}$ (STO) related materials ${ }^{71-72}, \mathrm{Sr}_{2} \mathrm{MgMoO}_{6-\delta}(\mathrm{SMM})$ related materials ${ }^{73-74}$ and $\mathrm{Sr}_{2} \mathrm{FeMoO}_{6-\delta}(\mathrm{SFM})$ related materials ${ }^{75-76}$.

\subsubsection{Simple Perovskite Structure}

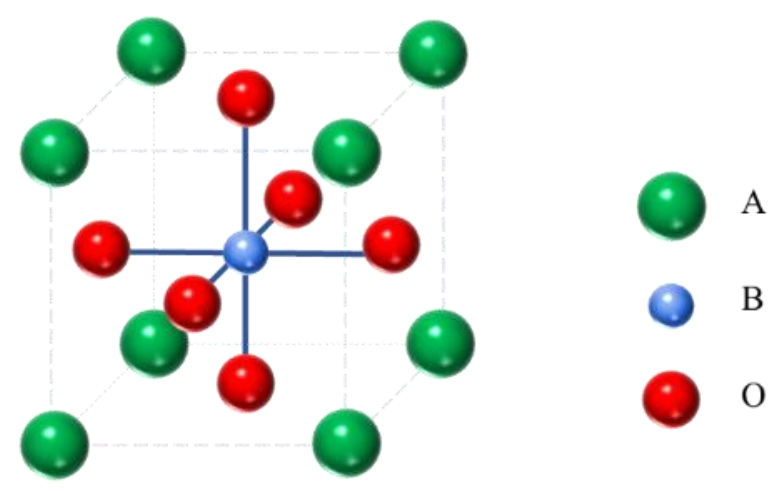

Figure 9. Crystal structure of the perovskite with $\mathrm{ABO}_{3}$ form.

Generally, ideal perovskite is a cubic structure which can be written as $\mathrm{ABO}_{3}$. Most common A site elements are made of alkaline earth metals such as divalent cations $\mathrm{Ca}, \mathrm{Sr} . \mathrm{Ba}, \mathrm{Pb}$ and trivalent cation $\mathrm{La}^{77}$, which usually have a larger size and occupies at the cubic corner (green sites in Figure 9). The preference of divalent cations is because of their larger size compared with trivalent cations and in that case, more Bsite cations can be used. A smaller B-site cation normally comes from transition metal group which occupies at the cubic center site (blue site in Figure 9) and oxygens sit at face center (red sites in Figure 9). In the ideal cubic $\mathrm{ABO}_{3}$ structure, the bond length of A-O and B-O follow the relationship $L_{A-O}=\sqrt{2} L_{B-O}$ based on simple geometry. However, in most cases, the radii of A and B cations don't match this perfectly. Goldschmidt tolerance factor ${ }^{77-78}$, which used to describe the A and B cation mismatch can be written as:

$$
t=\frac{r_{A}+r_{O}}{\sqrt{2}\left(r_{B}+r_{O}\right)}
$$

In this equation, $r_{A}, r_{B}$, and $r_{O}$ are the ionic radii of $\mathrm{A}, \mathrm{B}$, and $\mathrm{O}$, respectively, for perovskites with two or more different A-site or B-site cations, an average radius is used. When $t<1, r_{A}$ is smaller than ideal, the structure compensates the mismatch by tilting the $\mathrm{BO}_{6}$ octahedra; when $t>1, r_{A}$ cation is larger than ideal 
and the strain caused by mismatch cannot be compensated by octahedral tilting. The tolerance factor $t$ within a large number of perovskite materials is summarized in Figure 10.

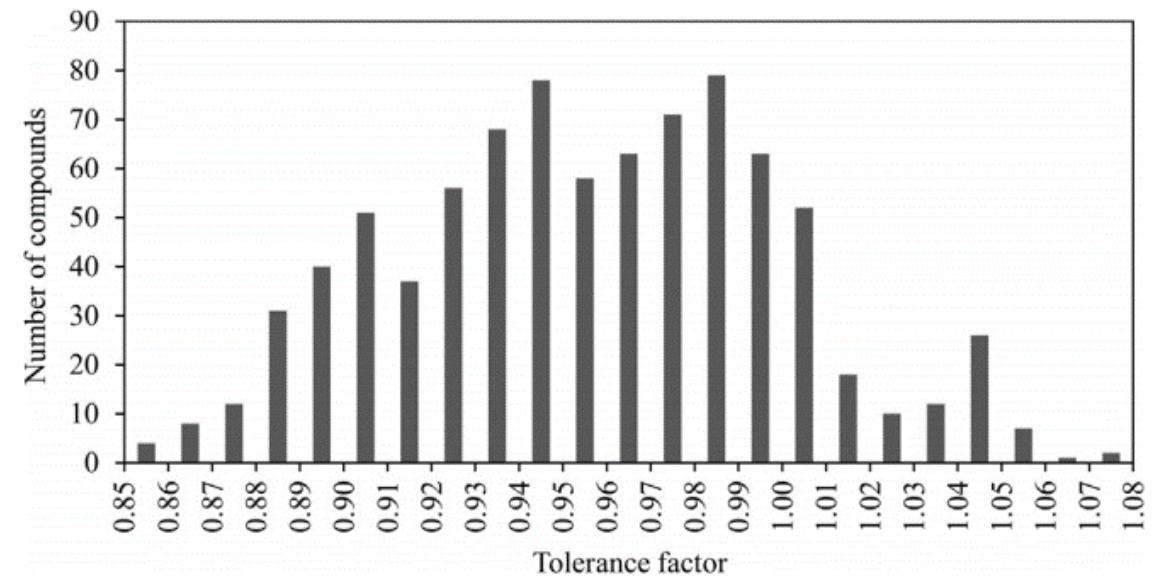

Figure 10. A number of $\mathrm{ABO}_{3}$ compounds reported with different values of tolerance factor $t{ }^{77}$

\subsubsection{Ordered Perovskite Structure}

Cation substitutions are possible on A or B sites of the perovskite structure. The vacancy can be regarded as a kind of substitution on $\mathrm{O}$ sites. Cation substitutions are usually used to build up the perovskite family and to tune the cation ordering which significantly impacts the properties of the material. Rock salt, columnar and layered ordering become the (111), (110) and (001) ordering configurations, respectively (Figure 11). A-site cation ordering provides the same shapes, also shown in Figure $11 .{ }^{79-80} \mathrm{~A}$ special case is that in the ordered perovskite $\mathrm{AA}^{\prime} \mathrm{BB}^{\prime} \mathrm{O}_{6}$, rock-salt ordering of the $\mathrm{B} / \mathrm{B}^{\prime}$ cations and layered ordering of the A/A' cations will coexist. The B' cations move along the c-axis towards the under-bonded anion and away from the over-bonded anion. ${ }^{80}$

Cation ordering is essential to determine the characteristics (i.e., crystal structure and phase stability) and electronic or ionic conductivity of perovskite materials. ${ }^{80-81}$. Generally, B-site-ordering happens easier than A-site ordering. The coordination preference of the B-site cations defines the ordering status of the cations and vacancies when a large number of oxygen vacancies exist. 
Moreover, the ordering of the B-site cations controls the ordering behavior of the A-site cations. The A-site ordering cannot be formed without the existence of B-site ordering. ${ }^{80}$ For example, $\mathrm{NaLaTi}_{2} \mathrm{O}_{6}$ and $\mathrm{NaLaZr}_{2} \mathrm{O}_{6}$ do not show any order, whereas $\mathrm{NaLaMgWO}_{6}$ and $\mathrm{NaLaMnWO}_{6}$ display highly ordered A-site cations. ${ }^{82-83}$ In 1984, NaLaMgWO 6 , an ordered perovskite structure, was reported ${ }^{84}$ Some other examples are $\mathrm{KLaMgWO}_{6}{ }^{85-86}, \mathrm{NaLaCoWO}_{6}$ and $\mathrm{NaLaNiWO}_{6}{ }^{87}, \mathrm{NaLaScNbO}_{6}{ }^{82}, \mathrm{NaNdCoWO}_{6}{ }^{83}, \mathrm{KLaMnWO}_{6}{ }^{83}$ $\mathrm{NaLnMnWO}_{6}(\mathrm{Ln}=\mathrm{La}, \mathrm{Ce}, \mathrm{Pr}, \mathrm{Nd}, \mathrm{Sm}, \mathrm{Gd}, \mathrm{Dy}, \mathrm{Ho})^{83,88}, \mathrm{NaLnMgWO}_{6}(\mathrm{Ln}=\mathrm{Ce}, \mathrm{Pr}, \mathrm{Nd}, \mathrm{Sm}, \mathrm{Eu}, \mathrm{Gd}, \mathrm{Tb}$, Dy, and $\mathrm{Ho})^{83,88}$ and $\mathrm{PrBaCo}_{2} \mathrm{O}_{6}{ }^{89}$.

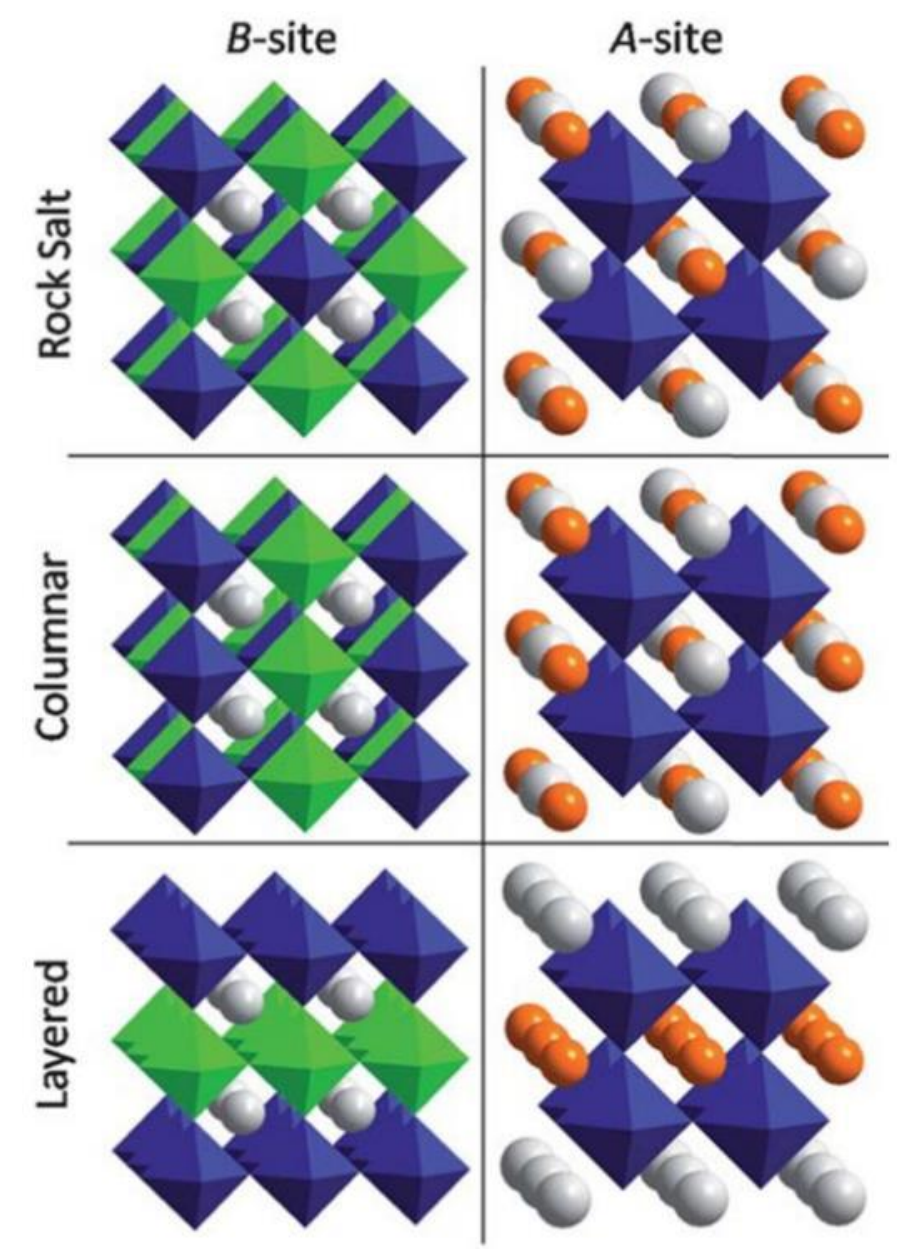

Figure 11. Cation ordering schemes of perovskites. From top to bottom are 0D (rock salt), 1D (columnar ordering) and 2D (layered ordering) for $\mathrm{B}$-site ordering in $\mathrm{A}_{2} \mathrm{BB}^{\prime} \mathrm{X}_{6}$ perovskites (left) and A-site ordering in $\mathrm{AA}^{\prime} \mathrm{B}_{2} \mathrm{X}_{6}$ (right) perovskites. ${ }^{79}$ 


\subsubsection{Potential perovskite anodes}

The conductivity of modified STO can be $100 \mathrm{~S} \mathrm{~cm}^{-1}$ at $800^{\circ} \mathrm{C}$ with proper lanthanum (La) or yttrium (Y) doping on A site ${ }^{90-91}$. This value could reach up to $120 \mathrm{~S} \mathrm{~cm}^{-1}$ with niobium $(\mathrm{Nb})$ doping on $\mathrm{B}$ site $\mathrm{e}^{92}$. Similar modification with manganese $(\mathrm{Mn})$ or gallium $(\mathrm{Ga})$ on $\mathrm{B}$ site are also researched ${ }^{92}$ and achieved high electrical conductivity. Another advantage of STO and related materials is the matched CTE with electrolytes (YSZ is $10-11 \times 10^{-6} \mathrm{~K}^{-1} 93-94$ and LSGM is $10-12 \times 10^{-6} \mathrm{~K}^{-1} 95-97$ ). According to Marina's work ${ }^{98}$, the CTE of undoped $\mathrm{SrTiO}_{3}$ and $\mathrm{La}_{\mathrm{x}} \mathrm{Sr}_{1-\mathrm{x}} \mathrm{TiO}_{3}(\mathrm{x}=0.1-0.4)$ are $10.8 \times 10^{-6} \mathrm{~K}^{-1}$ and $11-12 \times 10^{-6} \mathrm{~K}^{-1}$, respectively. The greatest advantage of doped STO is their high stability. First, doped STO presents good chemical stability at the operation environment (high temperature and low $\mathrm{P}_{\mathrm{O} 2}$ ). Second, they display good resistance to carbon deposition and sulfur poisoning ${ }^{71}$, as well as an attractive $\mathrm{H}_{2} \mathrm{~S}$-induced electrochemical enhancement effect when fuel containing $\mathrm{H}_{2} \mathrm{~S}^{72}$. Third, their good chemical compatibility with YSZ make them are more suitable for large-scale commercialized production. The other two families SMM and SFM are stable with GDC and LSGM but only YSZ can be applied to a commercialized production. Good stability, however, from the other aspect, implies lower electrocatalytic activity and lower electrochemical performance. The inferior performance (less than $\left.100 \mathrm{~mW} \mathrm{~cm}^{-2}\right)^{71,91}$ when utilizing doped LST as an anode in SOFCs limited the application prospect of these materials. Even LST-GDC composite with Ni infiltration can only reach about $300 \mathrm{~mW} \mathrm{~cm}{ }^{-2}$ at $800{ }^{\circ} \mathrm{C}$ in humidified $\mathrm{H}_{2}{ }^{99}$.

Compared with Ni-YSZ anode, double perovskite material SMM yielded a competitive maximum power density as $838 \mathrm{~mW} \mathrm{~cm}^{-2}$ in $\mathrm{H}_{2}$ and $400 \mathrm{~mW} \mathrm{~cm}^{-2}$ in dry $\mathrm{CH}_{4}$ at $800{ }^{\circ} \mathrm{C}$ along with a better sulfur tolerance ${ }^{100-}$ ${ }^{101}$. Low $\mathrm{Mo}^{6+} / \mathrm{Mo}^{5+}$ reduction potential contributes to easier dissociative chemisorption of the fuels on the perovskite surface and good electrochemical performance. In SMM structure, the valence of stratum (Sr) and magnesium $(\mathrm{Mg})$ are both +2 , polyvalent element molybdenum $(\mathrm{Mo})$ shows $+4 /+5 /+6$ at different $\mathrm{P}_{\mathrm{O} 2}$ environment. Because there is no interstitial oxygen in perovskite, only Mo is responsible for oxygen vacancy formation in the structure. Since the vacancy concentration plays an essential role on physical and electrochemical properties ${ }^{50,102}$, substitute partial or entire $\mathrm{Mg}$ with polyvalent elements such as cobalt (Co), 
iron $(\mathrm{Fe})$ and nickel (Ni) are attempted. After substitution, the relation between cation valance and oxygen vacancy concentration is more complicated and probably lead to a faster oxygen exchange kinetics on the surface. In-situ exsolution of Co, Ni and Ni-Mo nanoparticles (NPs) in a strong reducing atmosphere was observed on the surface and grain boundary of $\mathrm{Sr}_{2} \mathrm{CoMoO}_{6}$ and $\mathrm{Sr}_{2} \mathrm{NiMoO}_{6}$. This unique decorated surface is believed to enhance the electrocatalytic activity ${ }^{50}$.
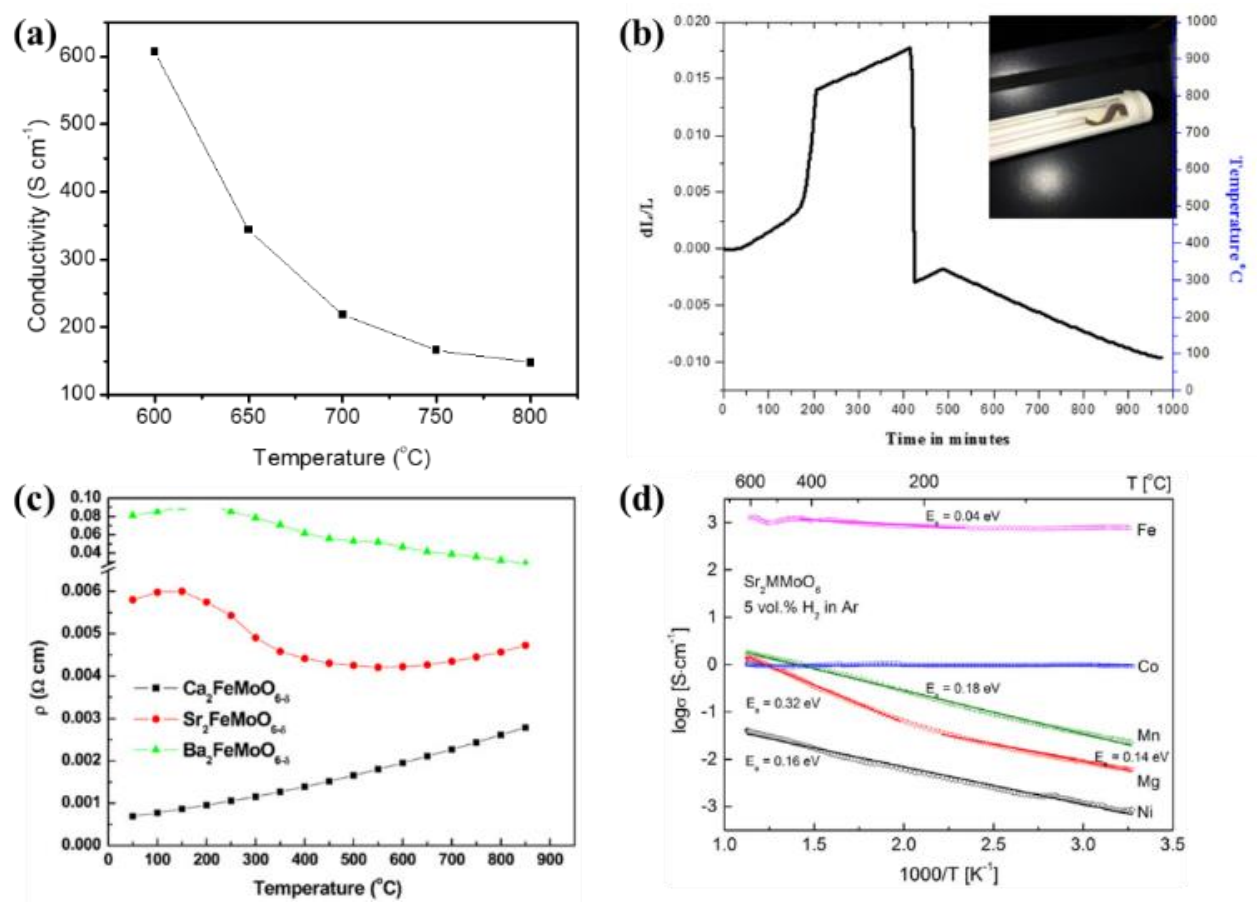

(d)

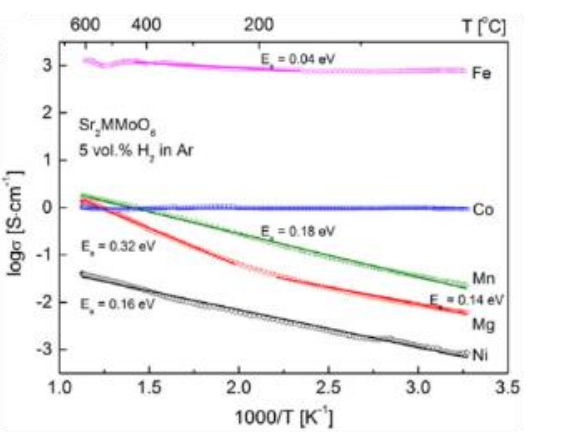

Figure 12. (a) Electrical conductivity of $\mathrm{Sr}_{2} \mathrm{FeMoO}_{6-\delta}$ in $5 \% \mathrm{H}_{2}$, (2) Dilatometry data of $\mathrm{Sr}_{2} \mathrm{FeMoO}_{6-\delta}$ in air, inset is the bar sample after test, (c) Electrical resistance of $\mathrm{Sr}_{2} \mathrm{FeMoO}_{6-\delta}$ and related materials in $\mathrm{H}_{2},{ }^{103}$ (d) Electrical conductivity of $\mathrm{Sr}_{2} \mathrm{FeMoO}_{6-\delta}$ and associated materials in $5 \% \mathrm{H}_{2}{ }^{104}$

Among polyvalent elements, Fe has been extensively investigated to substitute $\mathrm{Mg}$ in SMM. Compositions with different Fe content are researched and achieved good results. When Fe:Mo $=1: 1$, electrical conductivity in forming gas showed nearly metallic behavior with the conductivity of about $150 \mathrm{~S} \mathrm{~cm}^{-1}$ at $800{ }^{\circ} \mathrm{C}$ as shown in Figure 12a and c. Wang ${ }^{105}$ reported the maximum power density of SFM/LSGM/BSCF to be $863.7 \mathrm{~mW} \mathrm{~cm}^{-2}$ with $\mathrm{H}_{2}$ and $604.8 \mathrm{~mW} \mathrm{~cm}^{-2}$ with dry $\mathrm{CH}_{4}$ at $850{ }^{\circ} \mathrm{C}$. Although $\mathrm{Sr}_{2} \mathrm{FeMoO}_{6}$ showed very high power density in both $\mathrm{H}_{2}$ and $\mathrm{CH}_{4}$, this material is only stable in a reducing atmosphere. A thorough and rapid decomposition in the air was reported ${ }^{105-107}$ and observed from our tests as well (Figure 
12b). Through the determination of $\mathrm{Fe}$ and Mo valence states and oxygen stoichiometry in $\mathrm{Sr}_{2} \mathrm{FeMoO}_{6}$, Rager $^{108}$ claimed that the phase stable composition in the air with a maximum Mo solubility is $\mathrm{Sr}_{2} \mathrm{Fe}_{1.34} \mathrm{Mo}_{0.68} \mathrm{O}_{6-\delta}$ and this conclusion was confirmed with the experiment by Wang et al. ${ }^{107}$. A further demonstration of the phase stability of $\mathrm{Sr}_{2} \mathrm{Fe}_{1.5} \mathrm{Mo}_{0.5} \mathrm{O}_{6}(\mathrm{SF} 1.5 \mathrm{M})$ was made by Liu et al. ${ }^{109}$. They use $\mathrm{SF} 1.5 \mathrm{M}$ as both cathode and anode in symmetrical SOFCs. According to their report, the maximum power density of an SF1.5M/LSGM/SF1.5M symmetrical cell was $835 \mathrm{~mW} \mathrm{~cm}^{-2}$ in wet $\mathrm{H}_{2}$ and $230 \mathrm{~mW} \mathrm{~cm}^{-2}$ in $\mathrm{CH}_{4}$ at $900{ }^{\circ} \mathrm{C}$.

\subsubsection{In-situ Exsolution of Perovskite materials}

Though perovskite materials have been extensively studied as alternatives of Ni-YSZ, their electrochemical catalytic activity is generally lower than Ni-YSZ. Surface decoration is an effective technique to improve the catalytic activity of the anode ${ }^{110}$. Perovskite materials with surface-decorated transition metal NPs have shown outstanding potential in energy applications from catalysis to power generation. Unfortunately, when loading metal NPs on the electrode surface with Chemical or physical deposition method ${ }^{111-113}$, aggregation of NPs becomes another issue to induce degradation, especially to the long-term operation ${ }^{114}$.

To address this problem, transition metals (Fe, $\mathrm{Co}$, Ni et al.) are doped into the B-site of the perovskite. In a strong reducing atmosphere at high temperature, doped transition elements may exsolve alone ${ }^{115}$ or with other B-site elements ${ }^{116}$ to form the catalytic metal NPs on the surface. Further, Neagu et al. state that the A-site deficiency created in perovskites $\left(\mathrm{A}_{1-\mathrm{y}} \mathrm{B}_{1-\mathrm{x}} \mathrm{M}_{\mathrm{x}} \mathrm{O}_{3}\right)$ makes the NPs exsolution easier and controllable with more flexible choices of compositions. ${ }^{114}$ Inspired by this, several new materials following this design principle are reported ${ }^{117-120}$.

According to Neagu et al's work, exsolved NPs grow from the parent phase with a socket structure (Figure 13a) which can improve the connection strength between NPs and parent phase ${ }^{115}$. Compared with deposited NPs, the carbon deposition on the surface with exsolved NPs is essentially limited (Figure 13ef). There are two kinds of carbon fiber growth mechanisms on $\mathrm{Ni}$ particles, one is tip-growth and the other 
is base-growth (Figure 13h). In the tip-growth mechanism, carbon dissolves into the Ni lattice while the fiber grows at the metal particle-oxide substrate interface, resulting in the particle uplifting from its original location. Most carbon fibers grow in this way. Because of the strong interaction between the exsolved socketed particle and the parent oxide, the most favorable tip-growth pathway is extremely limited which contribute to a clean surface during the coking test. In addition, this special socketed structure also significantly limited the coarsening and agglomeration of the decorated Ni NPs during long-term utilization. In Figure 13i-1, the exsolved particles behave as if pinned to their original locations and show a level of stability beyond the conventional deposited NPs.
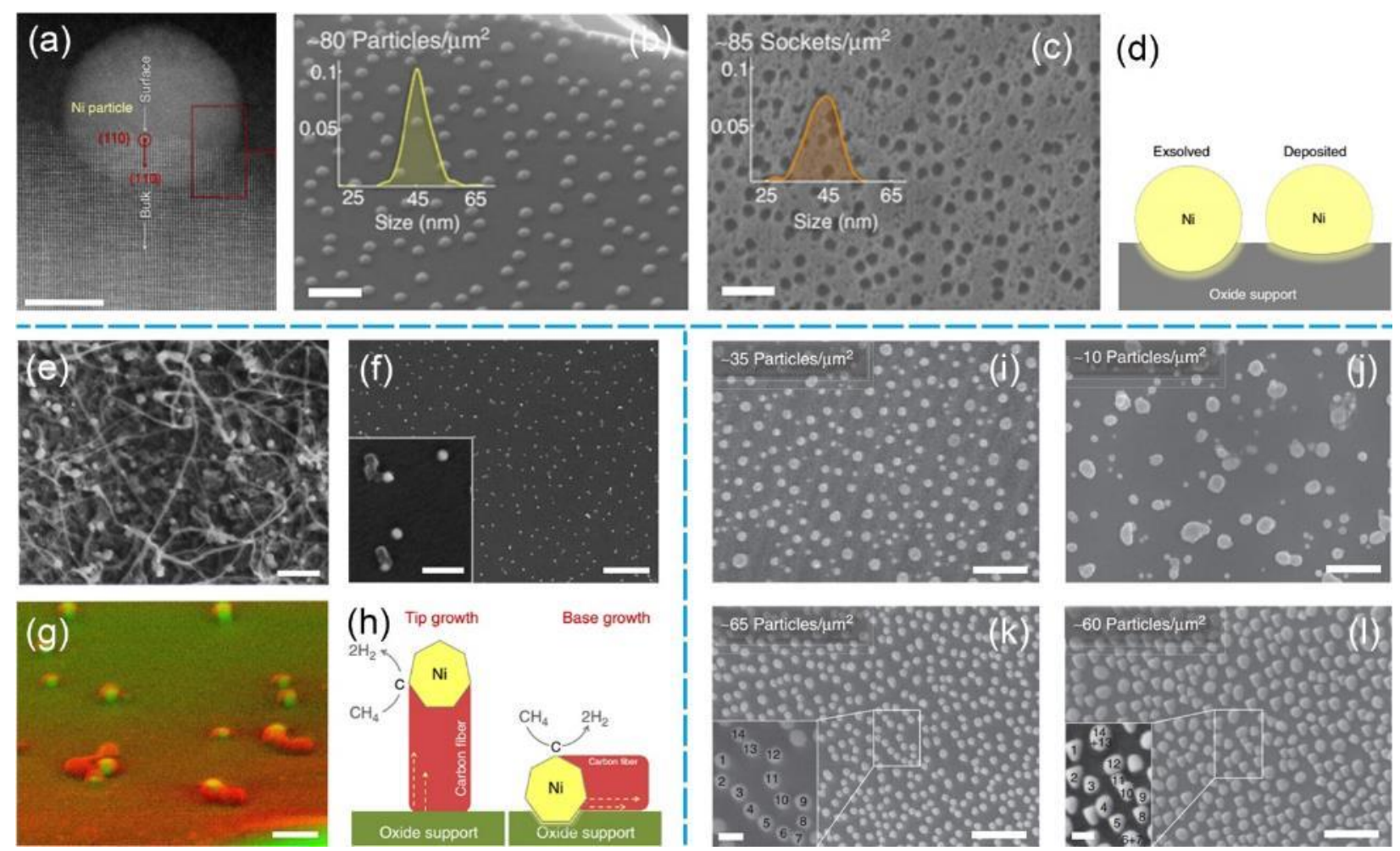

Figure 13. (a-d) Particle-substrate interface on perovskite surface with exsolved Ni particles. (e-h) Carbon deposition on perovskite surface with (e) deposited particles and (f-g) exsolved particles. (i-l) Thermal stability of (i-j) deposited particles and (k-l) exsolved particles. $^{115}$

Studying the exsolution mechanism can help to understand the physical processes of particle growth as well as to control the particle dimensions. Gao et al. ${ }^{121}$ provided an in-depth study of the exsolution process from nucleation step and particle growth step. 
In the classical isothermal nucleation theory, the nucleation rate can be expressed as ${ }^{122-123}$ :

$$
\dot{N}=\frac{C}{\tau} \exp \left(-\frac{\Delta G^{*}+E_{a}}{R T}\right)
$$

Where $\dot{N}$ is the nucleation rate per unit area or volume, $C$ is the nucleation site density, $\tau$ is the characteristic timescale. $\Delta G^{*}$ is the critical free energy, $E_{a}$ is the activation energy. $\Delta G^{*}+E_{a}$ in Eq. (11) can be expressed as:

$$
\begin{gathered}
\Delta G^{*}+E_{a}=\Delta G_{\text {bulk }}^{*}+\Delta G_{\text {interface }}^{*}+\Delta G_{\text {surface }}^{*}+E_{\text {strain }}+E_{\text {diffusion }} \\
\Delta G_{\text {interface }}^{*}=\gamma_{\text {interface }} S_{\text {interface }}^{*} \\
\Delta G_{\text {surface }}^{*}=\gamma_{\text {surface }} S_{\text {surface }}^{*}
\end{gathered}
$$

Where $\gamma$ denotes the surface tension, $S{ }_{\text {interface }}$ corresponds to the solid-solid interface. Gao et al. ${ }^{121}$ state that the nucleation process is strongly influenced by the surface morphology. Therefore, at the grain boundaries and concave sites, a higher particle density is always found. Besides $\Delta G^{*}$, The $E_{a}$ in Eq. (12) will also affect the nucleation process. A smaller $E_{\text {strain }}$ on the surface decided that the surface is more favorable for nucleation rather than bulk ${ }^{124}$. The $E_{\text {diffusion }}$ may vary due to the segregation of the elements and lead to a patterned particle distribution. Nucleation may also be impacted by surface roughness.

According to Gao's analytical model ${ }^{121}$, the growth rate of a spherical particle can be expressed as:

$$
\frac{\mathrm{d} V}{\mathrm{~d} t}=v_{0} S \exp \left(-\frac{E_{a}}{R T}\right) \prod c_{i}^{v_{i}}=v_{0} r^{\alpha} \exp \left(-\frac{E_{S}(r)}{R T}\right) \prod c_{i}^{v_{i}}
$$

The growth of NPs could be controlled by strain-limited exsolution, reaction-limited exsolution, and diffusion-limited exsolution, which can be described as Eq. (15), Eq. (16), and Eq. (17), respectively.

$$
\begin{gathered}
r=r_{\mathrm{s}-\lim }\left(\ln \left(1+\frac{t}{\tau_{\mathrm{s}-\mathrm{lim}}}\right)\right)^{\frac{1}{3}} \\
r=r_{\mathrm{r}-\lim }\left(1-\exp \left(-\frac{t}{\tau_{\mathrm{r}-\mathrm{lim}}}\right)\right)^{\frac{1}{3}}
\end{gathered}
$$




$$
r=r_{\mathrm{d}-\lim }\left(\frac{t}{\tau_{\mathrm{d}-\lim }}\right)^{\frac{1}{6}}
$$

When strain dominates the growth process, larger strain energy will lead to smaller particle size. If the reactant limits the exsolution, a higher doping level contributes to larger particle size. In both situations, particles grow faster in a higher hydrogen particle pressure $\left(\mathrm{P}_{\mathrm{H} 2}\right)$ environment (Figure 14). As to the diffusion limited exsolution, the cation's reduction on the surface is much faster than the cation's diffusion in the bulk. Thus, the particle growth depends on the diffusion rate of cations in the bulk. The concentration of exsolved element is zero near the interface at the bulk side.
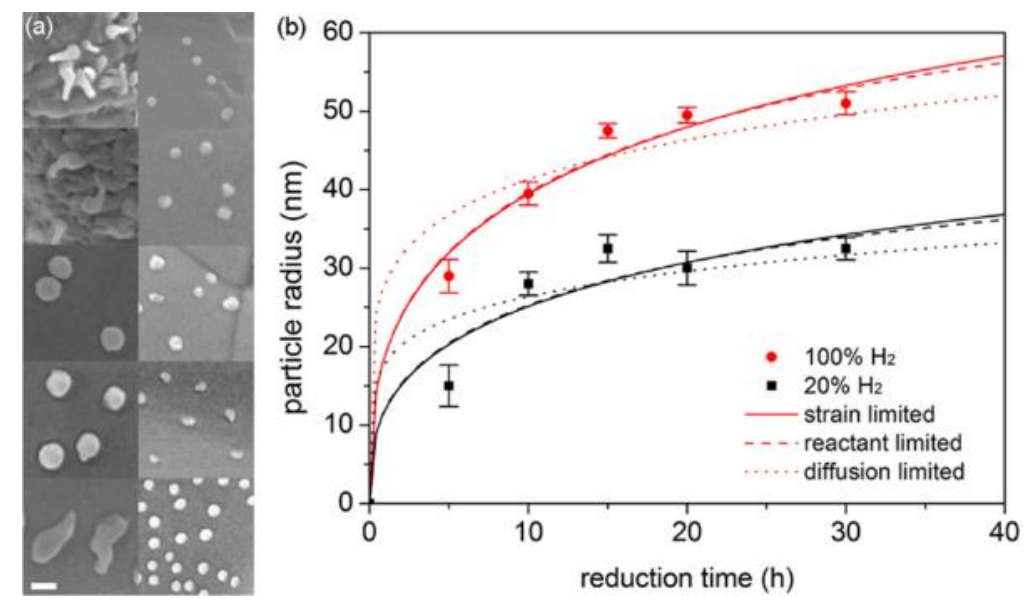

Figure 14. (a) Particles reduced in pure $\mathrm{H}_{2}$ (left) and $20 \% \mathrm{H}_{2}$ (right) for 5, 10, 15, 20, and $30 \mathrm{~h}$. Scale bar is $100 \mathrm{~nm}$. (b) The average particle size with reduction time and the fitting results with three models.

\subsection{Hydrogen Oxidation Reaction Mechanisms}

\subsubsection{HOR Process on Ni-YSZ Anode}

Besides new materials development, a lot of work has been done to understand the mechanism of anodic reactions, especially for hydrogen oxidation reaction on Ni-YSZ anode. Several mechanisms are extensively researched on different rate determining steps (RDS) include adsorption and disassociation of $\mathrm{H}_{2}{ }^{26,125}$, surface diffusion of $\mathrm{H}$ atoms and/or $\mathrm{O}^{2-}$ ions ${ }^{30,125-127}$, electrochemical reaction steps at $\mathrm{TPB}^{125,127-}$ 
${ }^{128}$, catalytic effects of water ${ }^{26,129}$ and others. Briefly, the overall reaction Eq. (3) could occur following steps as:

$$
\begin{array}{ll}
\mathrm{H}_{2}(g)+* \rightarrow \mathrm{H}_{2, N i / Y S Z} * & \text { Adsorption of } \mathrm{H}_{2} \text { on } \mathrm{Ni} \text { or YSZ } \\
\mathrm{H}_{2, N i / Y S Z} * \rightarrow \mathrm{H}_{2, T P B} * & \text { Surface diffusion of } \mathrm{H}_{2} \text { to TPB } \\
\mathrm{H}_{2, T P B} *+\mathrm{O}_{O, Y S Z}^{\times} \rightarrow \mathrm{H}_{2} \mathrm{O}(g)+V_{O, Y S Z}^{*}+2 e_{N i}^{-} & \text {Electrochemical reaction }
\end{array}
$$

Here, $*$ is the active sites on $\mathrm{Ni}$ or YSZ surface for chemisorption. The $\mathrm{H}_{2}$ disassociation step on the $\mathrm{Ni}$ surface is not presented in above steps ${ }^{129}$. Though there is wide recognition of this process, different opinions regard to some reaction details exist ${ }^{10}$. First, locations of electrochemical reaction are not clear, it could symmetrically on Ni and YSZ surface ${ }^{22,125}$ or merely on one surface ${ }^{126-127}$. Second, the diffusion pathways of $\mathrm{H}$ to TPB (surface and/or bulk) and the possible role of interstitial hydrogen and hydroxyl at $\mathrm{Ni} / Y S Z$ interface ${ }^{126-127,} 129$. Third, the catalytic effect of water in reactions ${ }^{26,129}$. Fourth, intermediate species and locations of oxygen ions before water formation.

Three reaction pathways including hydrogen spillover, oxygen spillover and hydrogen interstitial pathways at TPB area are summarized by Bessler et al. ${ }^{130}$ and schematic diagrams with regard to these pathways are shown in Figure 15. (1) In the hydrogen spillover pathway, adsorbed $\mathrm{H}$ atoms move from Ni surface over TPB towards YSZ surface while simultaneously oxidized to $\mathrm{H}^{+}$and give electrons to Ni (Figure $15 \mathrm{a}$ ). $\mathrm{H}^{+}$

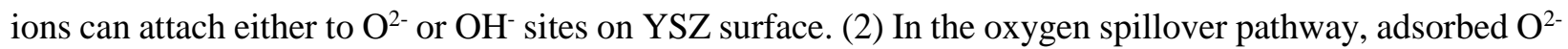
ions move from YSZ surface over TPB towards Ni surface. Electron transfer could happen before, during or after spillover (Figure 15b). Since direct contact of two surfaces is required by hydrogen and oxygen spillover pathways, when TPB is blocked by secondary phases, hydrogen interstitial pathway is a proper substitution to maintain the charge transfer. (3) In hydrogen interstitial pathway, benefited from a relatively high solubility and diffusivity of $\mathrm{H}$ in metal lattice (solubility: $\mathrm{H} / \mathrm{M} \approx 10^{-4}$ in $\mathrm{Ni}, \mathrm{DH} \approx 10^{-5}-10^{-4} \mathrm{~cm}^{2} \mathrm{~s}^{-1}$ in $\mathrm{Ni}$ around $1000 \mathrm{~K})^{129}, \mathrm{H}$ atoms are dissolved in Ni lattice, diffused to Ni/YSZ interface and oxidized there to yield interstitial protons in YSZ lattice (Figure 15c). Based on these, similar pathways such as hydroxyl spillover pathway and chemical reactions on the electrolyte surface pathway are also proposed ${ }^{131}$. All these 
pathways are chemically reasonable in certain conditions. For further investigation, quantitative analysis is needed.

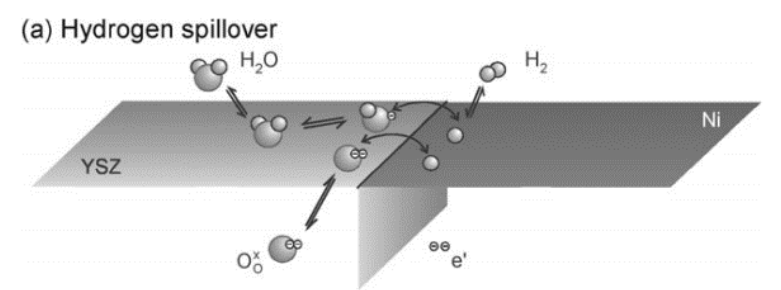

(b) Oxygen spillover

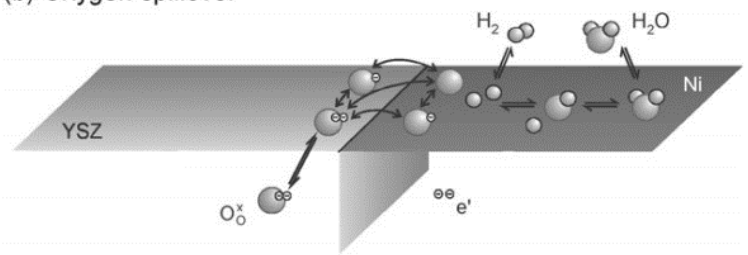

(c) Hydrogen interstitial

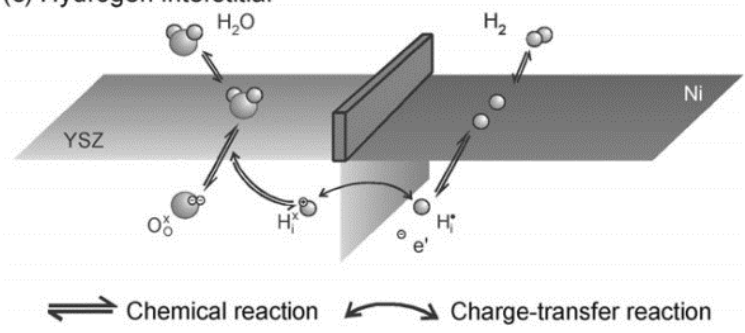

Figure 15. Charge transfer mechanisms at the Ni/YSZ three-phase boundary. The "wall" in panel (c) indicates potential segregated impurities. $^{130}$

\subsubsection{HOR Process on MIEC Anode}

Mixed ionic and electronic conductors (MIECs) are materials in which both the ionic and electronic species carry electricity ${ }^{132}$. In principle, most ionic crystals, like oxides and halides, can be regarded as MIECs because they have both ionic and electronic conductivity. Most perovskite materials applied in SOFC anode (such as $\mathrm{Sr}_{2} \mathrm{MgMoO}_{6-\delta}$ and $\mathrm{Sr}_{2} \mathrm{Fe}_{1.5} \mathrm{Mo}_{0.5} \mathrm{O}_{6-\delta}$ ) are MIEC materials. For this kind of material, reaction active regions are no longer limited to TPB. As shown in Figure 16, fuel oxidation reaction in Ni-YSZ anode can only react at two points marked as red dots. For MIEC materials, benefit from their good ionic conductivity and electrical conductivity, every point on the surface can be regarded as TPB, or in other words reaction zone is expanded to the whole electrode surface (marked as red line). Based on the overall hydrogen oxidation reaction in Eq. (3), model ${ }^{133}$ is established to investigate the electrochemical performance in 
reducing atmosphere. Periodic density functional theory (DFT) calculations are used by Suthirakun et al. ${ }^{134}$ to calculate the free energy profile $(\mathrm{eV})$ for the $\mathrm{HOR}$ on the plane-Mo surface of $\mathrm{Sr}_{2} \mathrm{Fe}_{1.5} \mathrm{Mo}_{0.5} \mathrm{O}_{6}$. According to their calculation, a similar pathway is proposed for $\mathrm{H}_{2}$ oxidation on $\mathrm{Sr}_{2} \mathrm{Fe}_{1.5} \mathrm{Mo}_{0.5} \mathrm{O}_{6}$ surface and displayed in Figure 17. In summary, except surface diffusion which is not emphasized in MIEC anode, there are no other big differences between mechanisms applied in Ni/YSZ and MIEC anodes. $\mathrm{H}_{2} \mathrm{O}$ catalytic effects observed in Ni/YSZ anode are rarely mentioned in MIEC anodes.

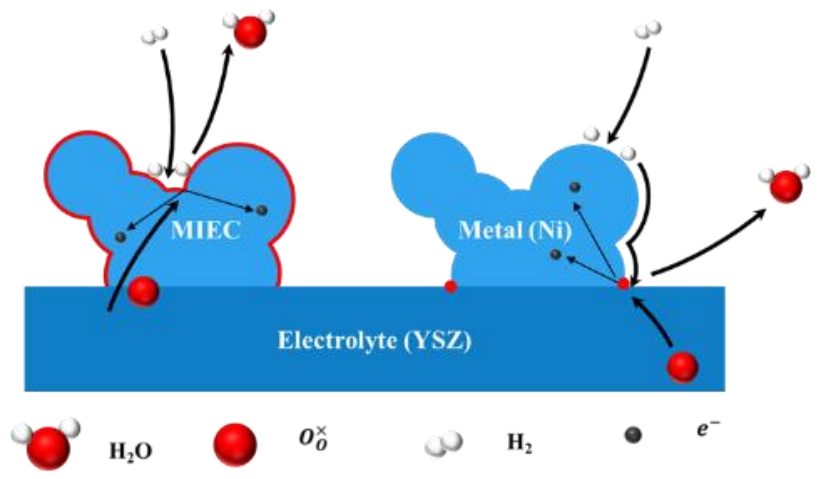

Figure 16. 2PB reaction regions for an MIEC anode (left) and 3PB reaction regions for an electronic-ionic composite anode (right).

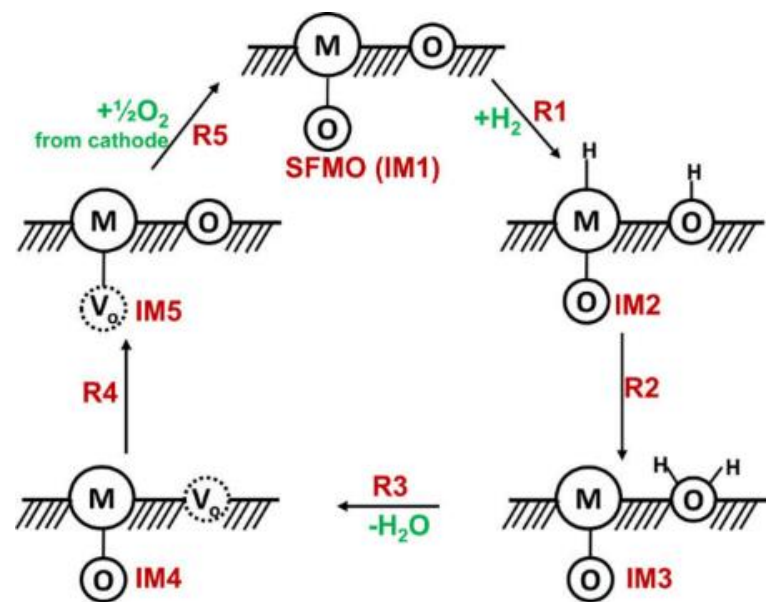

Figure 17. Proposed mechanism for $\mathrm{H}_{2}$ oxidation on $\mathrm{Sr}_{2} \mathrm{Fe}_{1.5} \mathrm{Mo}_{0.5} \mathrm{O}_{6}$ surface. ${ }^{134}$

\subsubsection{Catalytic Effect of $\mathrm{H}_{2} \mathrm{O}$ to HOR Process on Ni-YSZ Anode}

Besides electrochemical reaction at TPB area, the catalytic effect of $\mathrm{H}_{2} \mathrm{O}$ in Ni-YSZ cermet is also investigated. According to Jiang et $a .^{22}$, The effect of $\mathrm{P}_{\mathrm{H} 2 \mathrm{O}}$ to the hydrogen oxidation reaction on 
$\mathrm{Ni}$ /zirconia cermet anodes is first reported in 1989. The further study published by Jiang is based on Ni and Pt porous electrode. From Jiang's work, the reaction rate promotion from $\mathrm{H}_{2} \mathrm{O}$ is only observed on Ni-based electrodes, as shown in Figure 18. Depending on the metal surface evaluation, Jiang claims that there are $\mathrm{O}_{\text {ads }}$ species or suboxide on $\mathrm{Ni}$ electrode surface. Compared with a clean Ni surface, these oxygen species serve as bridges so that adsorbed hydrogen atoms can diffuse from one active site of $\mathrm{O}_{\text {ads }}$ species to another. As the concentration of $\mathrm{O}_{\text {ads }}$ species or suboxide on the Ni surface increase with $\mathrm{P}_{\mathrm{O} 2}$, the rate of such dissociative adsorption/diffusion of hydrogen increases significantly with the water content in $\mathrm{H}_{2}$. For noble metal Pt, however, the formation of such oxygen species on the surface is highly unlikely due to a much higher Gibbs energy. In that case, $\mathrm{H}_{2} \mathrm{O}$ only act as a $\mathrm{P}_{\mathrm{O} 2}$ adjuster apart from the reaction product. $\mathrm{As}_{\mathrm{O} 2}$ in humidified $\mathrm{H}_{2}$ is much higher than in dry $\mathrm{H}_{2}$, the $\mathrm{R}_{\mathrm{p}}$ of $\mathrm{Pt}$ is bigger in $\mathrm{H}_{2}$ with $2 \% \mathrm{H}_{2} \mathrm{O}$.
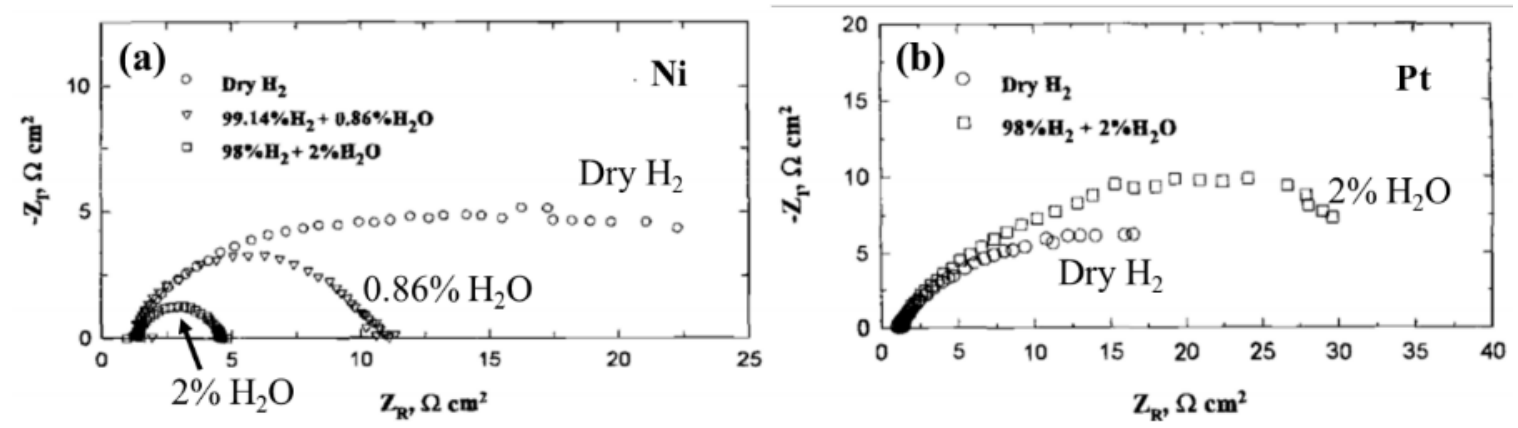

Figure 18. Impedance spectra for $\mathrm{H}_{2}$ oxidation on (a) porous $\mathrm{Ni}$ electrode and (b) porous Pt electrode, at $1000^{\circ} \mathrm{C}$ for different $\mathrm{H}_{2} \mathrm{O} \%$ in $\mathrm{H}_{2}$ gas. ${ }^{22}$

Different from Jiang's mechanism, Bieberle et al. ${ }^{26}$ proposed another mechanism which indicates that $\mathrm{H}_{2} \mathrm{O}$ in $\mathrm{H}_{2}$ gas expanded the diffusion length of $\mathrm{H}$ atoms on the YSZ surface. Figure 19 is the schematic diagram of Bieberle's model utilized to explain the catalytic effect of $\mathrm{H}_{2} \mathrm{O}$ in the hydrogen oxidation reaction. After adsorption and disassociation of $\mathrm{H}_{2}$ on $\mathrm{Ni}$ surface (Figure 19a) and oxidation of $\mathrm{H}$ atom to $\mathrm{H}^{+}$ion (Figure $19 \mathrm{~b}), \mathrm{H}^{+}$is diffused to YSZ surface with help of protonation and deprotonation reactions of the hydroxyl groups on the YSZ surface (Figure 19c-d). This protonation-deprotonation mechanism is unique for a wet fuel-gas atmosphere where the electrochemically active region is enlarged due to a hydroxylated YSZ surface and anode kinetics is facilitated in wet gas. 


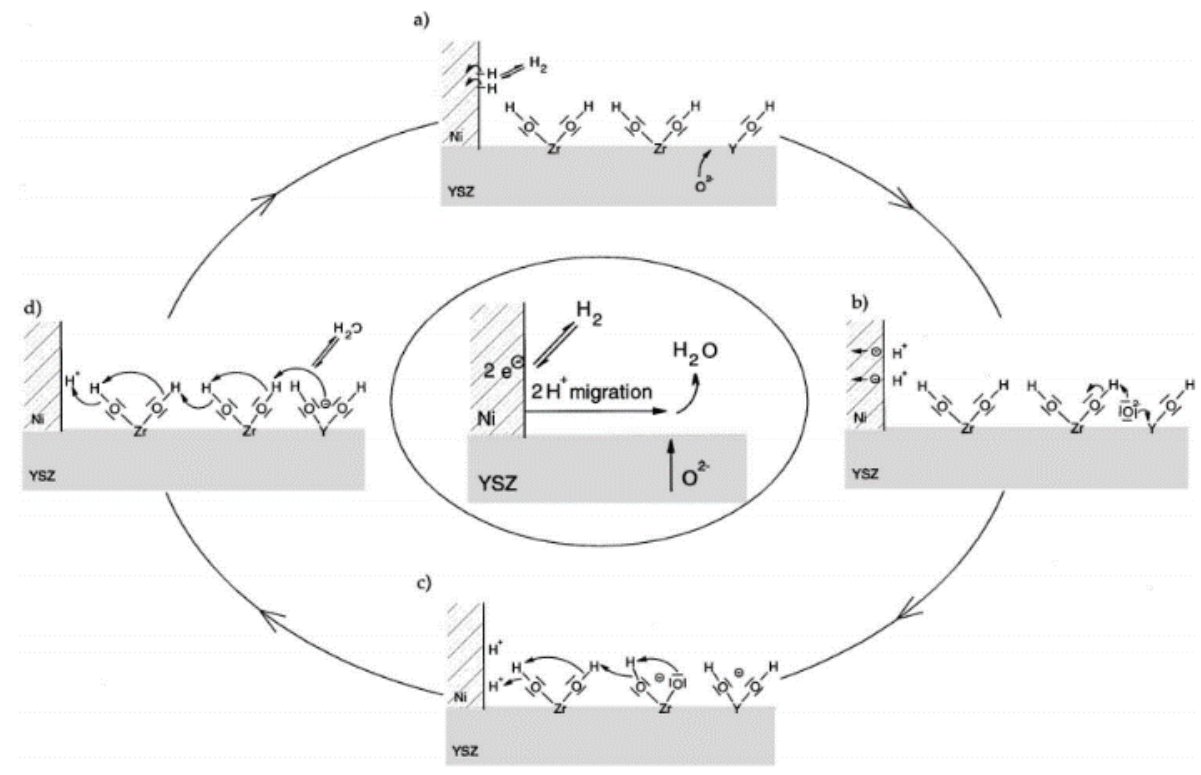

Figure 19. Model for the catalytic effect of the addition of water in the fuel gas atmosphere on the performance of SOFC anodes. ${ }^{26}$

Though both mechanisms are plausible, they are not the whole story yet. First, the worse electrochemical performance of Pt electrode in wet $\mathrm{H}_{2}$ (Figure 18b) cannot be explained by Bieberle's mechanism. Second, if Jiang's mechanism is reasonable, more evidence is needed to prove that in the same $\mathrm{P}_{\mathrm{O} 2}$ condition, the electrochemical performance should be the same no matter how much water content in the gas. In that case, more investigations are desired in this aspect. 


\section{Chapter 2 Research Objectives}

- Develop a Ni-free redox stable ceramic anode material with high performance for SOFC.

- Evaluate the phase stability of the developed material in both air and $\mathrm{H}_{2}, \mathrm{CTE}$, phase and electrical conductivity reversibility in redox environment, the electrochemical performance of symmetrical cell and single cell.

- Verify the conditions required for Fe exsolution and characterize the morphology of exsolved material.

- Demonstrate the long-term stability of LSFM in $\mathrm{H}_{2}$ as well as to characterize the particle growth of LSFM.

- Investigate the effect of exsolution on electrochemical performance.

- Research the catalytic effect of water to hydrogen oxidation reaction process and propose a mechanism to explain this phenomenon. 


\section{Chapter 3 Experimental Methods}

\subsection{Material Synthesis}

The material preparation method is the footstone for repeatable and credible research. Big experimental deviations from different groups based on the same or similar materials are not rare surprising in the literature ${ }^{135-136}$. Although we usually ascribe this difference to the various test environments, different material synthesis routines may also play a crucial role. In this work, all experimental details will be clarified first before data analysis and discussion.

\subsubsection{Sol-gel Preparation (Step 1)}

EDTA-citric acid sol-gel method ${ }^{137}$ was applied as a general material preparation strategy on all anode candidates in this work. Here we take $\mathrm{Sr}_{2} \mathrm{Fe}_{1.5} \mathrm{Mo}_{0.5} \mathrm{O}_{6-\delta}(\mathrm{SF} 1.5 \mathrm{M})$ as an example. A stoichiometric amount of raw materials (Alfa Aesar), $\mathrm{Sr}\left(\mathrm{NO}_{3}\right)_{2}$ and $\mathrm{Fe}\left(\mathrm{NO}_{3}\right)_{3} \cdot 9 \mathrm{H}_{2} \mathrm{O}$, were dissolved in distilled water in one beaker (solution 1). In another beaker, the mixture of ethylenediaminetetraacetic acid (EDTA) (Alfa Aesar) and a suitable amount of ammonia water (Alfa Aesar) was heated and stirred until a clear solution was obtained (solution 2). Solution 2 was mixed into solution 1 and then $\left(\mathrm{NH}_{4}\right)_{6} \mathrm{Mo}_{7} \mathrm{O}_{24} \cdot 4 \mathrm{H}_{2} \mathrm{O}$ (Alfa Aesar) and citric acid (Alfa Aesar) were added one by one. The molar ratio of metal ions : citric acid : EDTA was $1: 1.25$ : 1. The solution was adjusted to $\mathrm{pH}=6$ with ammonia water and held on a hot plate at about $80{ }^{\circ} \mathrm{C}$ for several hours with stirring until gelation occurred. The gel was heated at $200{ }^{\circ} \mathrm{C}$ overnight to drive off the liquid and form porous black ash.

\subsubsection{Organics Elimination (Step 2)}

The black ash was fired at about $500{ }^{\circ} \mathrm{C}$ with intermittent stirring until all organic residues are eliminated. The brick-red precursor was obtained after this low-temperature treatment. Depends on different elements in solution, the color of the precursor after $500{ }^{\circ} \mathrm{C}$ treatment may be different. The brick-red color in our precursor came from the iron oxide. 
This is the most important step during the synthesis process but always be neglected. As abundant EDTA was added into the solution, the organics in precursor must be eliminated thoroughly before a phase formation, especially for a big batch. Otherwise, some carbonized organics will stay in the precursor and form amorphous structures with a metal oxide or change the local condition for the phase formation. Unfortunately, this amorphous structure can't be detected by XRD or observed from SEM images which leads to the neglection. Based on our experiments, the residual organics not only increased the phase formation temperature but also damaged the phase stability of the synthesized materials.

\subsubsection{Phase Formation (Step 3)}

The phase formation temperature was significantly influenced by the purity of the precursor. For SF1.5M precursors with and without organic residues, phase formation temperature and the phase stability of the synthesized materials were compared. The sample without organic elimination process was labeled as sample 1 and the sample with thorough organic elimination process was labeled as sample 2 . For each sample, several calcining temperatures were conducted on precursor that from the same batch. All samples were characterized by XRD and SEM after synthesis and reduction.

Pure perovskite structure was obtained from both samples (Figure 20). Compared with sample 2, however, sample 1 exhibited a higher phase formation temperature as well as a larger particle size (Figure 21a and c). Specifically, the organic residues in precursor increased the phase formation temperature from $1050{ }^{\circ} \mathrm{C}$ to $1200{ }^{\circ} \mathrm{C}$. For a big batch or a small crucible, the oxygen could be insufficient at the bottom to make all organics transfer to $\mathrm{CO}_{2}$, even at a high temperature. In that case, organic residues could form a composite with a metal oxide or may coat on oxide to prevent the incorporation with particles nearby. Since no extra peak was detected by XRD and no secondary phase can be observed from SEM images (Figure 21a), it is conjectured that organic residues could exist as the amorphous carbon. 

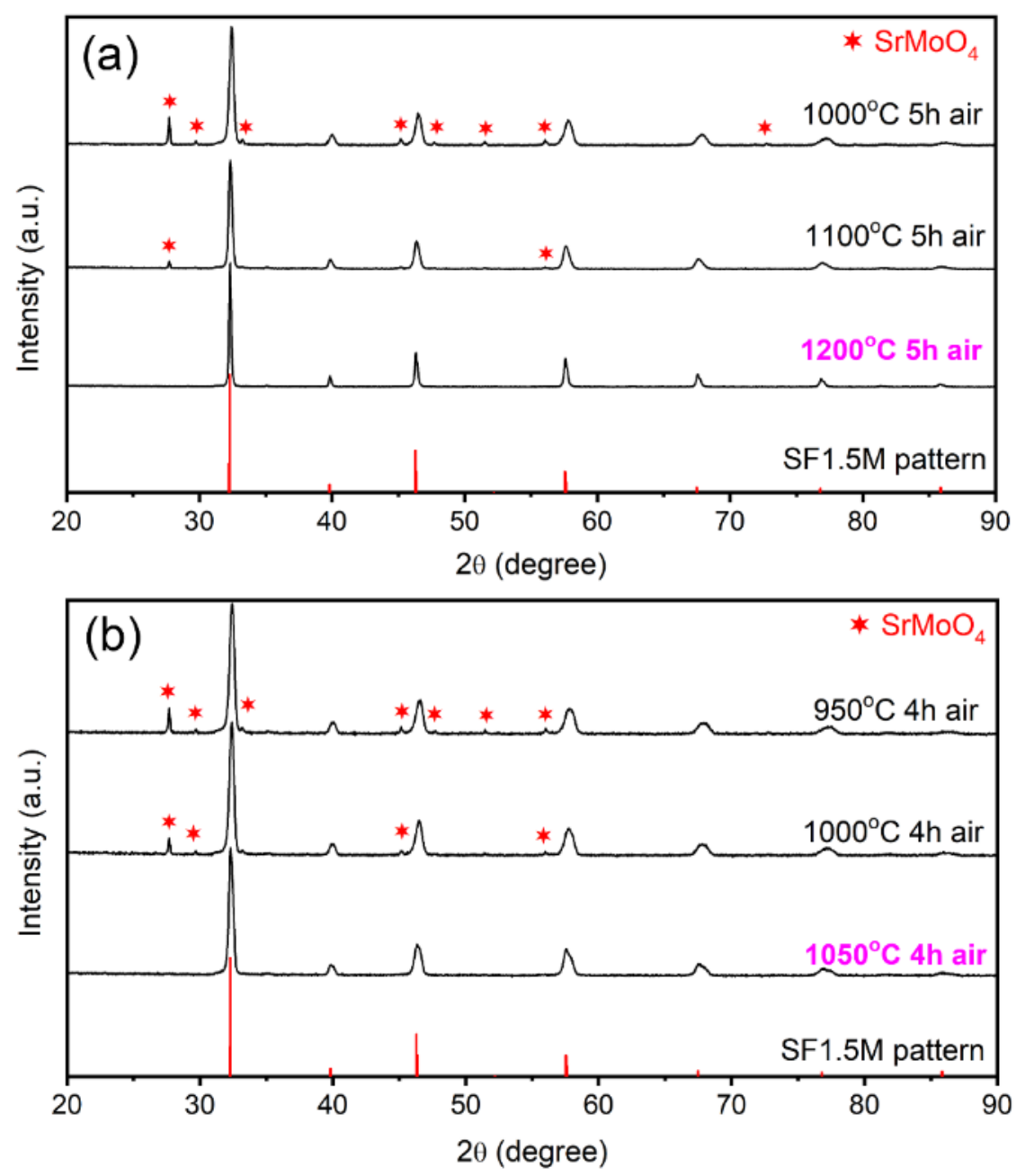

Figure 20. XRD patterns of SF1.5M calcined in air at different temperatures: (a) precursor with organics residues, (b) precursor without organics residues. SF1.5M standard pattern (98-009-6233 from COD) are provided in figures.

Besides the phase formation temperature, the phase stability behavior of the two samples was also different in a reducing atmosphere. SF1.5M has been verified as a very stable perovskite material in both oxidation and reducing atmosphere ${ }^{108,138}$, but sample 1 showed poor stability in $\mathrm{H}_{2}$. As displayed in Figure 22a, two obvious new peaks at about $45^{\circ}$ appeared after $1 \mathrm{~h}$ reduction and a big left shoulder emerged on the main peak (at about $32^{\circ}$ ), which strongly demonstrated a phase change in the reducing atmosphere. Correspondingly, the morphology of SF1.5M powders exhibited a significant change after reduction (Figure 21a-b). Compared with sample 1, the XRD patterns verified the high stability of sample 2 in hydrogen and the SEM images suggested the good microstructure maintenance. 

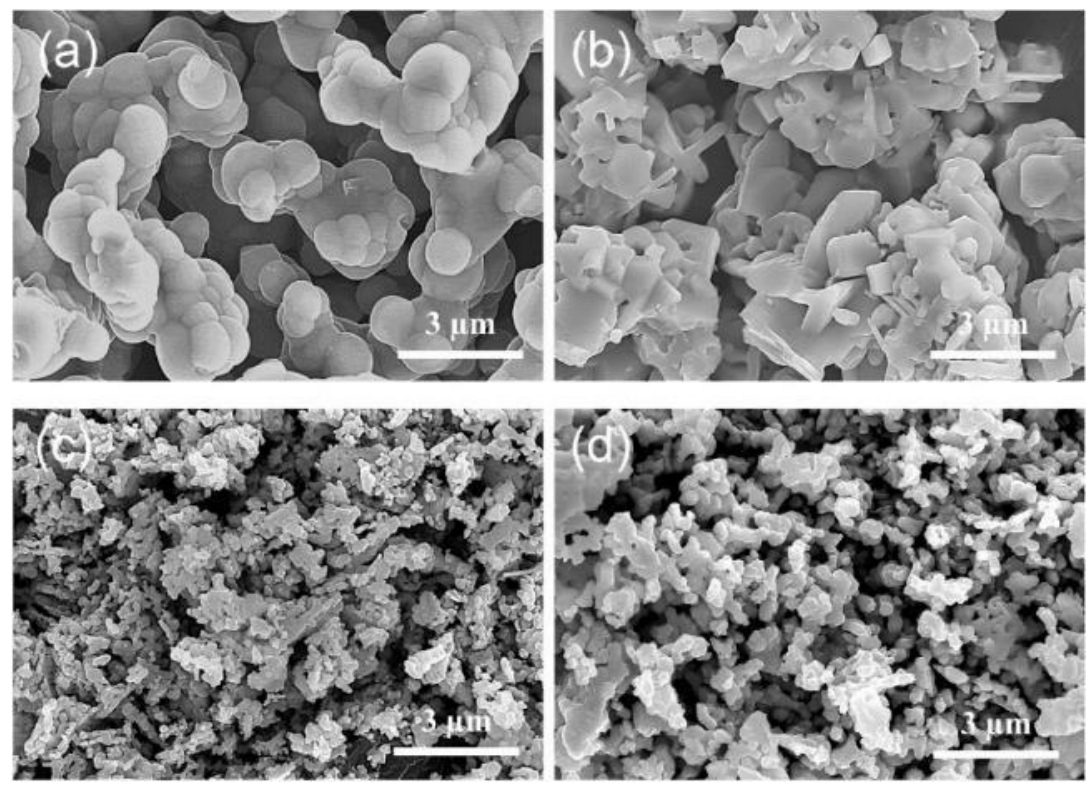

Figure 21. SEM images of SF1.5M powders as synthesized and after reduction. (a-b) Without organics elimination and (c-d) with thorough organic elimination. (a) Synthesized in the air at $1200{ }^{\circ} \mathrm{C}$ for $5 \mathrm{~h}$, (b) reduced in $\mathrm{H}_{2}$ at $800{ }^{\circ} \mathrm{C}$ for $1 \mathrm{~h}$, (c) synthesized in the air at $1050{ }^{\circ} \mathrm{C}$ for $4 \mathrm{~h},(\mathrm{~d})$ reduced in $\mathrm{H}_{2}$ at $800{ }^{\circ} \mathrm{C}$ for $5 \mathrm{~h}$.
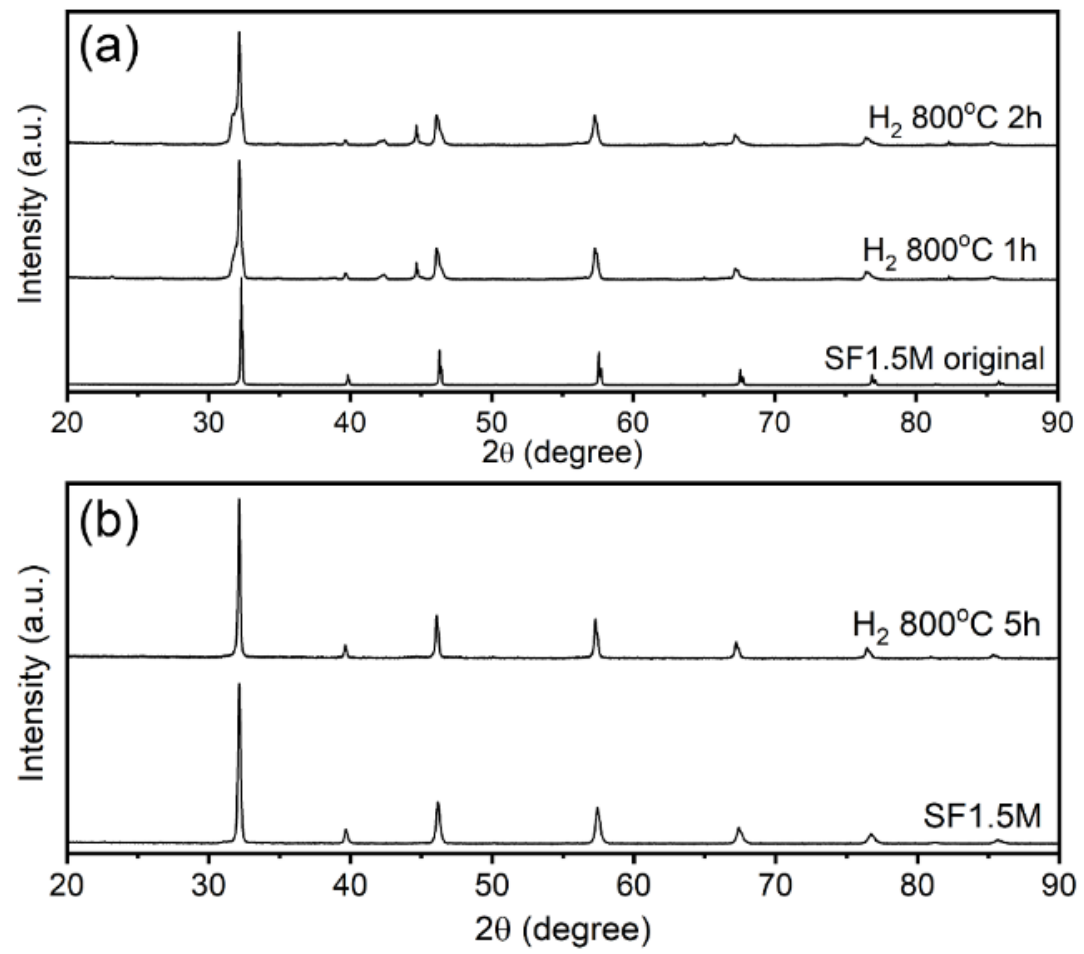

Figure 22. XRD patterns of $\mathrm{SF} 1.5 \mathrm{M}$ reduced in $\mathrm{H}_{2}$ at $800^{\circ} \mathrm{C}$ (a) without organics elimination, (b) with thorough organic elimination. 
Similar synthesis routines with a thorough organic residues elimination process were applied to all materials in this work. $\mathrm{Sr}_{2} \mathrm{FeMoO}_{6-\delta}(\mathrm{SFM})$ and $\mathrm{Pr}_{0.5} \mathrm{Sr}_{1.5} \mathrm{Fe}_{1.5} \mathrm{Mo}_{0.5} \mathrm{O}_{6-\delta}$ (PSFM) were calcined in $5 \% \mathrm{H}_{2}, \mathrm{SF} 1.5 \mathrm{M}$, $\mathrm{Sr}_{2} \mathrm{Fe}_{1.5} \square{ }_{0.1} \mathrm{Mo}_{0.4} \mathrm{O}_{6-\delta}$ and $\mathrm{Sr}_{2} \mathrm{Fe}_{1.9-\mathrm{x}} \mathrm{Co}_{0.1} \mathrm{Mo}_{\mathrm{x}} \mathrm{O}_{6-\delta} \quad(\mathrm{x}=0.3-0.5$, SFCM $)$ were obtained in air, $\mathrm{La}_{0.5} \mathrm{Sr}_{1.5} \mathrm{Fe}_{1.5} \mathrm{Mo}_{0.5} \mathrm{O}_{6-\delta}(\mathrm{LSFM})$ was obtained in $\mathrm{N}_{2}$.

\subsection{Sample Fabrication}

\subsubsection{Bar Sample Fabrication}

Cuboid bar samples were fabricated for dilatometry and four-point DC electrical conductivity measurements. After mixing LSFM with 3 wt\% polyvinyl butyral (PVB, Alfa Aesar) uniformly, the mixtures were pressed into pellets (diameter was $31 \mathrm{~mm}$ ) and sintered at $1250{ }^{\circ} \mathrm{C}$ for $4 \mathrm{~h}$ in $\mathrm{N}_{2}$. Bar samples were cut from the sintered pellets with a diamond saw blade and polished with sandpaper to achieve a cuboid shape and smooth surfaces. The length of the bar sample after treatment was about $2 \mathrm{~cm}$.

Before cutting, the porosity of the sintered pellet was measured with Archimedes' Principle. First, the weight of dry pellet in the air was measured with analytical balance (A\&D GH-202) and the average value was noted as $\mathrm{M}_{1}$. Second, immersed the pellet in water in a beaker and put the beaker in a vacuum chamber for several minutes to eject air in the pellet. The weight of saturated pellet was measured again in water and the average weight was noted as $\mathrm{M}_{2}$. The real volume of the pellet can be calculated as $V=\frac{M_{1}-M_{2}}{\rho_{\text {water }}}$. Here, $\rho_{\text {water }}=1 \mathrm{~g} \mathrm{~cm}^{-3}$ is the density of water. Also, the theoretical volume of the pellet can be obtained as $V_{0}=$ $\pi r^{2} h$. Here, $r$ is the radius and $h$ is the thickness of the pellet. Hence, the porosity $(\phi)$ of the pellet can be written as:

$$
\phi=\left(1-\frac{V}{V_{0}}\right) \times 100 \%
$$

After sintering, the porosity of all samples was equal to or less than $5 \%$. 


\subsubsection{Symmetrical Cell Fabrication}

In this work, symmetrical cells with an LSGM electrolyte were fabricated by the screen-printing method. LSGM pellets (diameter is $16 \mathrm{~mm}$ ) were sintered at $1400{ }^{\circ} \mathrm{C}$ in the air for $4 \mathrm{~h}$. The diameter of the sintered electrolyte discs was about $13 \mathrm{~mm}$. Electrode slurry was screen-printed on both sides of the electrolyte symmetrically with an active area of $0.7 \mathrm{~cm}^{2}$, followed by sintering at $1150{ }^{\circ} \mathrm{C}$ in the air (for $\mathrm{SF} 1.5 \mathrm{M}$ ) or argon (for LSFM) for $2 \mathrm{~h}$ to achieve a good interface connection and a porous electrode (Figure 23). Silver current collectors with gold leads were applied on both sides of the symmetrical cells.
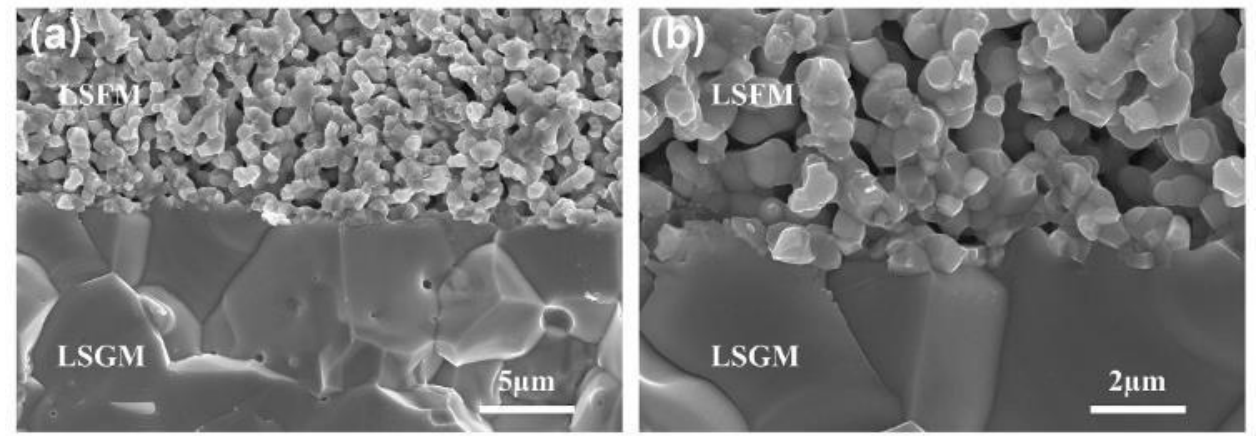

Figure 23. (a) and (b) Cross-section SEM images of LSGM/LSFM interface after sintering at $1150{ }^{\circ} \mathrm{C}$ for $2 \mathrm{~h}$ in $\mathrm{N}_{2}$.

\subsubsection{Single Cell Fabrication}

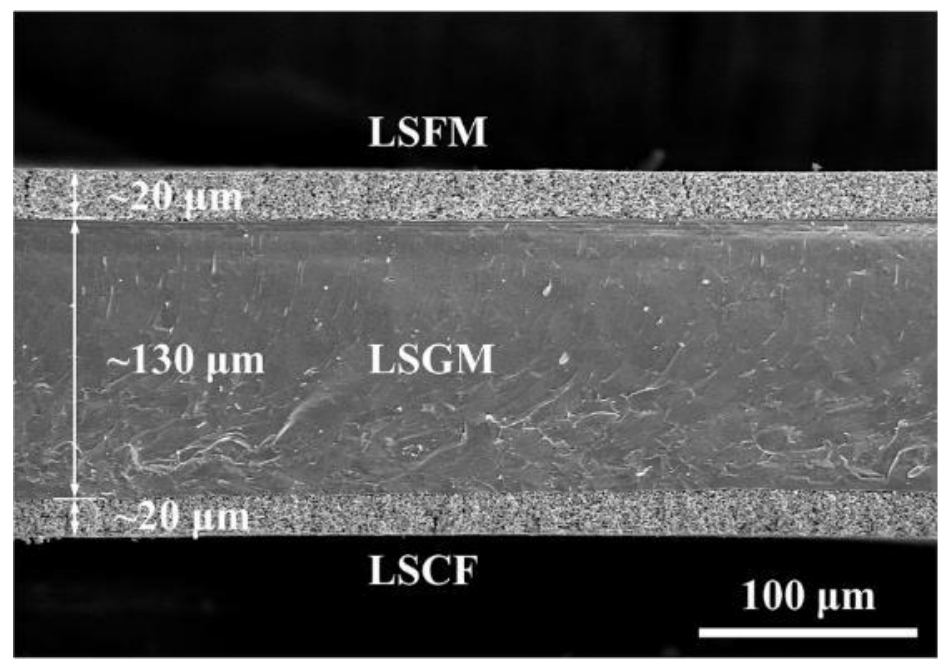

Figure 24. Cross section of LSCF/LSGM/LSFM single cell. 
Electrolyte supported single cell LSCF/LSGM/LSFM was utilized in this work. LSCF $\left(\left(\mathrm{La}_{0.6} \mathrm{Sr}_{0.4}\right)_{0.95} \mathrm{Co}_{0.2} \mathrm{Fe}_{0.8} \mathrm{O}_{3-\delta}\right.$, fuelcellmaterials) cathode paste and LSFM anode paste were printed on dense LSGM (about $130 \mu \mathrm{m}$ thick, Figure 24) by the screen-printing method. The active area of cathode and anode were $0.3 \mathrm{~cm}^{2}$ and $0.7 \mathrm{~cm}^{2}$, respectively. After electrode printing, the cell was sintered at $1150{ }^{\circ} \mathrm{C}$ in $\mathrm{N}_{2}$ for $2 \mathrm{~h}$. The thickness of the porous electrodes was about $20 \mu \mathrm{m}$ (Figure 24). Silver current collectors and gold leads were applied on both sides of the cell.

\subsection{Material Structure Characterization}

\subsubsection{XRD, SEM, TEM and EDS}

Composition of the synthesized powders was characterized by X-ray Diffraction (XRD, PANalytical X'pert PRO) with $\mathrm{Cu}$ Ka radiation. Scanning Electron Microscopy (SEM, JEOL JSM-7600F), Transmission Electron Microscopy (TEM) and Energy Dispersive X-Ray Spectroscopy (EDS) were utilized separately or together to observe the microstructure and elements distribution of the powders and cells.

\subsubsection{Rietveld Refinement of XRD Results}

The Rietveld refinement of the LSFM crystal structure was performed with software TOPAS Academic v6. The instrument profile and detector zero were obtained from the refinement of an external silicon standard. The background was modeled using a fifth order polynomial function, the peak shape was modeled using the modified Thompson-Cox-Hastings pseudo-Voigt function ${ }^{139}$. The peak broadening was modeled by crystallite size function. The initial structural model was from the Crystallography Open Database (COD), \#96-154-2033 ${ }^{140}$. The site occupancies of the elements (La, Sr, Fe, Mn) were from the nominal chemical composition.

\subsubsection{Synchrotron X-ray diffraction and Rietveld Refinement}

The powder X-ray diffraction pattern of the totally reduced LSFM sample (in $\mathrm{H}_{2}$ at $1200{ }^{\circ} \mathrm{C}$ for $2 \mathrm{~h}$ ) was collected at the powder diffraction beamline at the Australian Synchrotron ${ }^{141}$, using an X-ray wavelength 
of $\lambda=0.590746 \AA$. The powdered sample was loaded in a glass capillary $(0.3 \mathrm{~mm}$ outer diameter and 0.01 mm wall thickness) and measured under the Debye-Scherrer geometry with a high-resolution position sensitive Mythen detector. Fast spin $(60 \mathrm{rpm})$ of the capillary was maintained during data collection in order to minimize possible preferred orientation effects and to improve particle statistics.

Rietveld refinement was carried out using software TOPAS Academic v6. The background was modeled using a ninth-order polynomial function. The wavelength, instrument profile, and detector zero were obtained from the refinement of $\mathrm{L} \mathrm{LaB}_{6}$ standard (NIST SRM 660b). User-defined empirical functions considering both Gaussian and Lorentzian contributions were used to fit the instrumental profile. The peak broadening of the phases was modeled by the crystallite size function. The initial structural models were from the Crystallography Open Database (COD), \#96-100-8054 for the Ruddlesden-Popper (RP) phase ${ }^{142}$, and \#96-110-0109 for the Fe-Mo alloy phase. For the RP phase, the site occupancies of Sr, La, Fe, and Mo were refined considering the total occupancy as 1.0 for $\mathrm{Sr}$ and La (Wyckoff position: 4e), and Fe and Mo (Wyckoff position: 2a). Site occupancies of the O sites were fixed to 1.0. For the Fe-Mo alloy phase, the site occupancies of $\mathrm{Fe}$ and Mo were refined considering their total as 1.0. Once good refinement was achieved, as indicated by low values of the weighted-profile R-value $\left(R_{w p}\right)$ and goodness of fit $\left(\chi^{2}\right)^{143}$, the percentages of the involved crystalline phases were calculated by ${ }^{144}$,

$$
W_{p}=(S Z M V)_{p} / \Sigma_{i}(S Z M V)_{i}
$$

where $W_{p}$ is the relative weight percentage of phase $p, S$ the scale factor, $Z$ the number of formula units per unit cell, $M$ the molecular weight of the formula unit, and $V$ the volume of the unit cell. $i$ represents each phase in the mixture.

\subsubsection{XPS}

X-ray Photoelectron Spectroscopy (XPS) was applied to analyze the elemental composition and valence states on the surface. As a very surface sensitive characterization method, the detection depth of XPS is about $10 \mathrm{~nm}$. 


\subsubsection{Dilatometry Test}

The expansion behavior of materials at high temperature was characterized by a simple push rod type dilatometer (Netzsch DIL 402C, push rod type). The sample was heated in the air from room temperature to $800{ }^{\circ} \mathrm{C}$ at a rate of $3{ }^{\circ} \mathrm{C} \mathrm{min}^{-1}$, followed by two $5 \% \mathrm{H}_{2}$-air redox cycles with each cycle lasting for $10 \mathrm{~h}$. A cooling rate of $3{ }^{\circ} \mathrm{C} \min ^{-1}$ was used as the sample cooled in air.

\subsection{Electrical and Electrochemical Characterization}

\subsubsection{Four-point DC Method Conductivity Measurement}

The electrical conductivity was measured by four-point DC method at $800{ }^{\circ} \mathrm{C}$ for two to three $5 \% \mathrm{H}_{2}$-air redox cycles. The soaking time for each atmosphere was $6 \sim 8 \mathrm{~h}$ until the conductivity value was stable. Gold leads were fixed on the sample by silver paste.

\subsubsection{Electrical Conductivity Relaxation (ECR)}

The ECR measurement was carried out on bar sample by four-point DC method at $800{ }^{\circ} \mathrm{C}$ over the $\mathrm{P}_{\mathrm{O} 2}$ from $1.7 \times 10^{-18}$ (humidified $1 \% \mathrm{H}_{2}-99 \% \mathrm{~N}_{2}$ ) to $4.3 \times 10^{-21}$ (humidified $20 \% \mathrm{H}_{2}-80 \% \mathrm{~N}_{2}$ ). ECR in the dry reducing atmosphere was also investigated as needed. For all conditions with humidified gas, $\mathrm{P}_{\mathrm{O} 2}$ change follow the rule $\Delta \log \mathrm{P}_{02} \leq 0.6$. The total flow rate of mixed gas was fixed at $100 \mathrm{sccm}$. The measured surface exchange coefficient $\left(\mathrm{k}_{\mathrm{ex}}\right)$ and chemical diffusion coefficient $\left(\mathrm{D}_{\text {chem }}\right)$ were written as a function of equilibrium state $\mathrm{P}_{\mathrm{O} 2}$. The schematic structure of the home-made ECR chamber is presented in Figure 25. The chamber consisted of a $10 \mathrm{~cm}$ length quartz tube with $1 \mathrm{~cm}$ inner diameter, intake tube, and exit tube. Mica (orange parts in Figure 25) was applied for chamber sealing. To avoid temperature and pressure disturbing near the gas inlet point (right side), the sample was kept at the left side of the chamber. The collected ECR curves were fitted by MATLAB with equation ${ }^{145}$ : 


$$
\begin{aligned}
\frac{\sigma(t)-\sigma(0)}{\sigma(\infty)-\sigma(0)}= & 1-\sum_{m=1}^{\infty} \sum_{n=1}^{\infty} \sum_{p=1}^{\infty} \frac{2 L_{\beta}^{2} \exp \left(-\beta_{m}^{2} D_{c h e m} t / x^{2}\right)}{\beta_{m}^{2}\left(\beta_{m}^{2}+L_{\beta}^{2}+L_{\beta}\right)} \\
& \times \frac{2 L_{\gamma}^{2} \exp \left(-\gamma_{n}^{2} D_{\text {chem }} t / y^{2}\right)}{\gamma_{n}^{2}\left(\gamma_{n}^{2}+L_{\gamma}^{2}+L_{\gamma}\right)} \times \frac{2 L_{\phi}^{2} \exp \left(-\phi_{p}^{2} D_{\text {chem }} t / z^{2}\right)}{\phi_{p}^{2}\left(\beta_{p}^{2}+L_{\phi}^{2}+L_{\phi}\right)}
\end{aligned}
$$

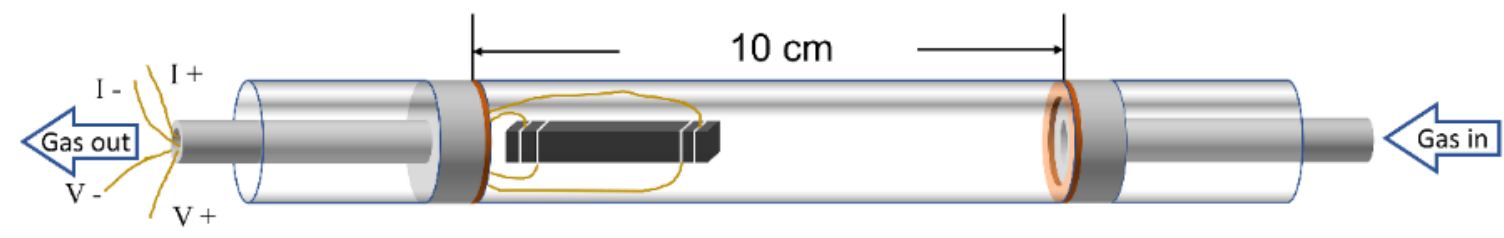

Figure 25. Schematic structure of home-made ECR chamber.

Before testing on LSFM, calibration of the whole ECR system was made with $\left(\mathrm{La}_{0.6} \mathrm{Sr}_{0.4}\right)_{0.95} \mathrm{Co}_{0.2} \mathrm{Fe}_{0.8} \mathrm{O}_{3}$ $\delta$ (LSCF) dense bar sample to ensure the accuracy and reliability of the ECR test. In order to investigate the relationship between chamber length and flush time, two lengths of test chamber were evaluated with the same LSCF sample, one is $3 \mathrm{~cm}$ (Figure 26a) and the other is $10 \mathrm{~cm}$ (Figure 26b). The inner diameter for both chambers was $1 \mathrm{~cm}$. The total flow rate of mixed gas was fixed at $100 \mathrm{sccm}$ and the gas was switched from 0.05 to 0.06 atm of $\mathrm{O}_{2}$ for all tests. According to den Otter's work ${ }^{146}$, flush time $\left(\tau_{f}\right)$ is the characteristic time needed for new gas to flush the reactor chamber, a less flush time is the requirement for more accurate fitting. This parameter can be written as:

$$
\tau_{f}=\frac{V_{r}}{\Phi_{v, t o t}} \times \frac{T_{S T P}}{T_{r}}
$$

In this equation, $\Phi_{v, \text { tot }}$ is the flow rate of gas, $V_{r}$ and $T_{r}$ represent the reactor volume and temperature, respectively, $T_{S T P}$ denotes the room temperature. 
(a)

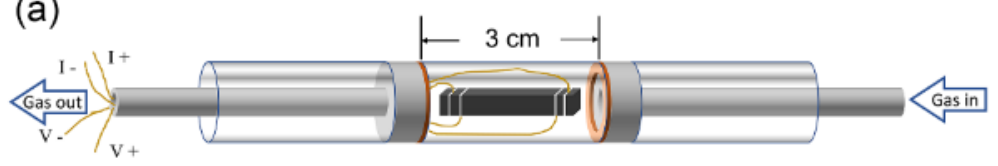

(b)
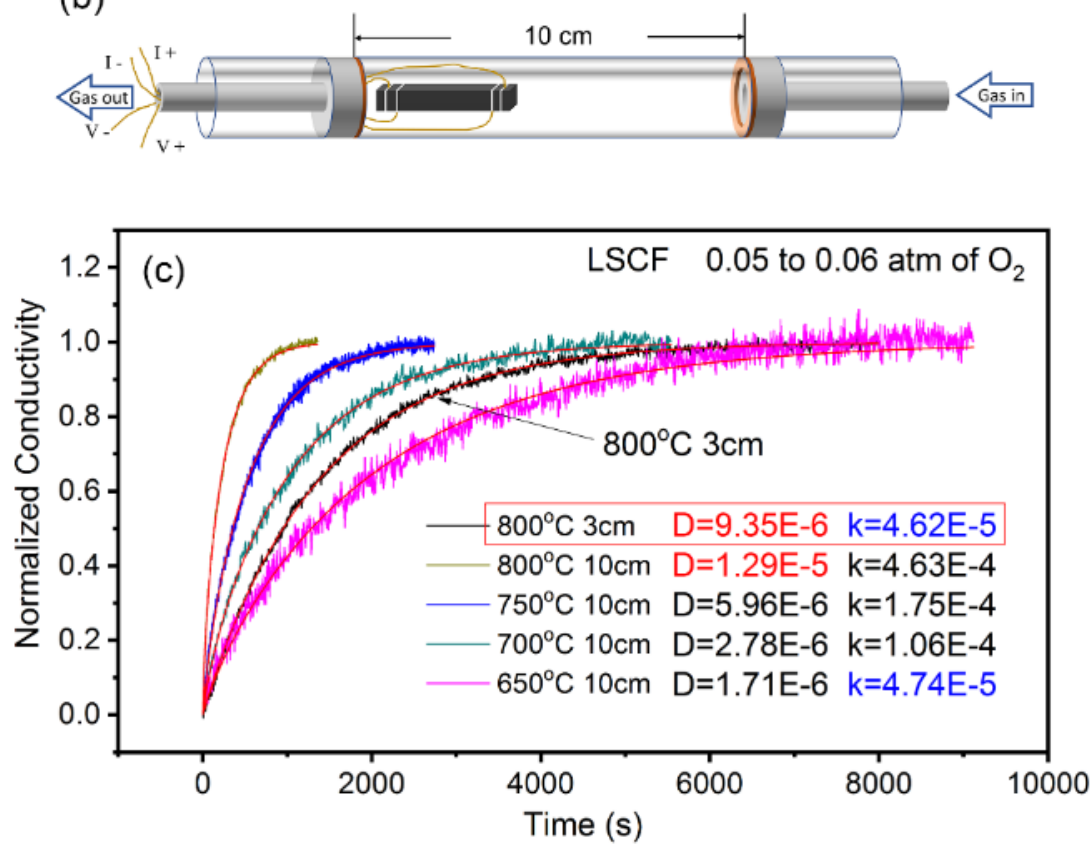

Figure 26. Schematic structure of ECR holder with (a) $3 \mathrm{~cm}$ chamber, (b) $10 \mathrm{~cm}$ chamber. (c) Normalized ECR data of LSCF measured with different chamber lengths at different temperatures. $\mathrm{P}_{\mathrm{O} 2}$ was switched from 0.05 to 0.06 atm for all tests in (c).

When other parameters are constant, a shorter chamber or in other words, a smaller $V_{r}$, means a less flush time. At $800{ }^{\circ} \mathrm{C}$, however, the equilibrium process was much slower in the $3 \mathrm{~cm}$ chamber and both $\mathrm{D}_{\text {chem }}$ and $k_{e x}$ were reduced. This relaxation process was affected by either too fast gas flow on the surface or lower gas temperature. To demonstrate this assumption, the same sample was tested again in $10 \mathrm{~cm}$ chamber from 650 to $800{ }^{\circ} \mathrm{C}$ with the same $\mathrm{P}_{\mathrm{O} 2}$ change. From fitting data listed in Figure 26c, the $\mathrm{D}_{\text {chem }}$ value got in $3 \mathrm{~cm}$ chamber was a little bit lower than that tested at $800{ }^{\circ} \mathrm{C}$ in $10 \mathrm{~cm}$ chamber (marked as red in Figure 26c), however the $\mathrm{k}_{\mathrm{ex}}$ value got in $3 \mathrm{~cm}$ chamber was about one order magnitude lower than that tested at $800{ }^{\circ} \mathrm{C}$ in $10 \mathrm{~cm}$ but more close to the value obtained at $650{ }^{\circ} \mathrm{C}$ (marked as blue in Figure 26c). This result indicated that the slow equilibrium process in the shorter chamber was influenced by both surface and bulk factors. A lower sample temperature slowed down the bulk diffusion and an ultra-fast flow rate near gas 
inlet point (right side) was more likely to clean all gas molecules attached on the surface rather than supply molecules for reaction with sample thus suppressed the oxygen exchange on the surface and lower the equilibrium process. To avoid the temperature and pressure disturbing near the gas inlet point, the $10 \mathrm{~cm}$ chamber was applied on all ECR tests in this work and samples were kept at the left side of the chamber, as shown in Figure 26b. The flush time was about 1-2 seconds without bubbler or 3-5 seconds when included bubbler into the system. The $\mathrm{D}_{\text {chem }}$ and $\mathrm{k}_{\mathrm{ex}}$ value of LSCF tested at $800{ }^{\circ} \mathrm{C}$ in $10 \mathrm{~cm}$ chamber are in the same order with reported values ${ }^{147}$.

\subsubsection{Electrochemical Impedance Spectroscopy (EIS)}

Electrochemical Impedance Spectroscopy (EIS) was carried out on symmetrical cells at open circuit condition over $10^{5}$ to $10^{-2} \mathrm{~Hz}$ frequency range with $10 \mathrm{mV}$ perturbation. All electrochemical experiments were performed using an AUTOLAB PGSTAT302N potentiostat/galvanostat (Metrohm, Netherlands) controlled by NOVA 1.11 software. Zview software was used for impedance spectra analysis and fitting. For the symmetrical cell, the area specific resistance (ASR) can be calculated as:

$$
\mathrm{ASR}=\frac{1}{2}\left(\mathrm{R}_{\mathrm{p}, \mathrm{m}} \times \mathrm{A}\right)
$$

Where, $\mathrm{R}_{\mathrm{p}, \mathrm{m}}$ is the polarization resistance measured from the raw EIS data, $\mathrm{A}$ is the active region area of one side, the unit of the ASR is $\Omega \mathrm{cm}^{2}$. For the EIS fitting, inductance (L) is involved into the equivalent circuit to mimic a more realistic electrochemical process. This inductance is subtracted in the following data discussion. In the experiments for in-situ exsolution investigation, cells were heated up to $800{ }^{\circ} \mathrm{C}$ in $\mathrm{N}_{2}$ and switched to $\mathrm{H}_{2}$ when the temperature was stable. Then impedance spectrums were recorded every 30 min. For other experiments, prereduction in humidified $\mathrm{H}_{2}$ at $800{ }^{\circ} \mathrm{C}$ for $3 \mathrm{~h}$ was carried out before electrochemical tests. At each target temperature, the cell was soaked for 30 to $60 \mathrm{~min}$ before measurement to ensure a steady state of cells. 


\subsubsection{Distribution of Relaxation Time (DRT)}

The MATLAB program code applied for DRT analysis was developed by Ciucci ${ }^{148}$ based on the Tikhonov regularization method. The regularization parameter was $1 \times 10^{-3}$ for all ERT analysis.

\subsubsection{Single Cell Test}

For the single cell test, $97 \% \mathrm{H}_{2}-3 \% \mathrm{H}_{2} \mathrm{O}$ as fuel flowed on the anode side and air as the oxidant flowed on the cathode side. The flow rates on both sides were $100 \mathrm{sccm}$. Current-Voltage (I-V) curves were recorded at $700{ }^{\circ} \mathrm{C}, 750{ }^{\circ} \mathrm{C}$, and $800{ }^{\circ} \mathrm{C}$, respectively.

\subsection{DFT Computational Model and Methods}

Spin-polarized DFT calculations are performed with the Vienna Ab-initio Simulation Package ${ }^{149-150}$ using the Perdew-Burke-Ernzerhof (PBE) exchange-correlation functional ${ }^{151-152}$, the Projector Augmented Wave (PAW) method ${ }^{153}$. To correct for the self-interaction error inherent to standard DFT for describing the energetics of transition metal perovskites, an on-site Hubbard term $\mathrm{U}-\mathrm{J}$ equal to $4.0 \mathrm{eV}$ is applied to the open-shell d electrons of $\mathrm{Fe}^{134,154-155}$, whereas no U-J parameter is applied to the d shell of Mo ${ }^{134,155}$. Bulk SF1.5M calculations are performed using 40-atom pseudocubic supercells with coordinates of atoms taken from those of the low-temperature phases as initial atomic positions for relaxation, in order to restore rotation and distortion of transition-metal-oxygen octahedra in the adopted supercells ${ }^{154-155}$. To provide a magnetic environment more similar to the application relevant high-temperature paramagnetic state than the antiferromagnetic ground state, ${ }^{154}$ all calculations were performed in the ferromagnetic state in order to use a consistent and tractable set of magnetic structures.

The (001) surfaces are simulated using the 9-layer $2 \times 2$ symmetric $(001) \mathrm{BO}_{2}$ terminated slabs (containing 92 atoms for the perfect $\mathrm{BO}_{2}$ slabs with no $\mathrm{O}$ vacancies) based on the relaxed bulk structure ${ }^{156-157}$. To reduce the complexity of surface adsorption configurations at the presence of surface $\mathrm{O}$ vacancy for highlighting the slab nonstoichiometry effect (Fermi level shift at various $\delta$ ), $\mathrm{O}$ vacancies are placed in the slab layers 
below the $\mathrm{BO}_{2}$ termination to maintain the surface configuration during $\mathrm{HOR}$. The top surface layer $\mathrm{O}$ vacancies are formed either in the intermediate and final states of the HOR or in the dry surface model with a pre-existed surface $\mathrm{O}$ vacancy for comparison with the hydrated surface model. More details of the DFT methods, the ab initio thermodynamic approaches ${ }^{154}$, as well as slab model configurations for the various oxygen nonstoichiometry, cation arrangement, and surface configurations of the intermediate states in the HOR energy landscapes, are provided in the Supporting Information. 


\section{Chapter 4 Modification Strategy and Performance of SFM-Based Materials}

As the widely used anode material in Solid-Oxide Fuel Cells, Ni-YSZ possesses: (1) attractive catalytic activity for hydrogen oxidation reaction ${ }^{37}$; (2) good electronic and ionic conductivity (around $10^{2}-10^{3} \mathrm{~S} \mathrm{~cm}^{-}$ ${ }^{1}$ at $600-1000{ }^{\circ} \mathrm{C}$ in $\left.\mathrm{H}_{2}\right)^{38-39}$; (3) lower cost than platinum (Pt), praseodymium (Pr) and other precious metals. However, the nature of Ni displays some drawbacks which are very difficult to overcome. First, the volume expansion of the oxidation from $\mathrm{Ni}\left(6.589 \mathrm{~cm}^{3} \mathrm{~mol}^{-1}\right)$ to $\mathrm{NiO}\left(11.198 \mathrm{~cm}^{3} \mathrm{~mol}^{-1}\right)$ is about $70 \%{ }^{56}$; this gives rise to extra mechanical stress leading to cracks and fuel leakage and finally causing damage to the entire stack. Second, severe carbon deposition and sulfur poisoning on $\mathrm{Ni}$ are responsible for the rapid performance decay when hydrocarbon fuels are applied as fuel gas ${ }^{12-13,47}$. Therefore, Ni-free materials, especially perovskite structure materials, which reveal smaller volume change, higher resistance to carbon deposition and good catalytic activity, have been researched in recent years as potential anode candidates. Many deeply investigated perovskites are derived from $\mathrm{Sr}_{2} \mathrm{MgMoO}_{6-\delta}$ which proposed by Goodenough $e t$ $a .^{73,100}$. Based on this material, single valent cation $\mathrm{Mg}^{2+}$ is partially or totally replaced with multivalent cation $\mathrm{Fe}^{2+/ 3+}$ in order to create redox couple $\mathrm{Fe}^{2+}+\mathrm{Mo}^{6+} \leftrightarrow \mathrm{Fe}^{3+}+\mathrm{Mo}^{5+}$. More electronic carriers, as well as oxygen vacancies, are generated from this replacement and a novel electrochemical performance is expected $^{75,109,158}$.

In this chapter, $\mathrm{Sr}_{2} \mathrm{FeMoO}_{6-\delta}(\mathrm{SFM})$ and related compositions will be discussed. To develop new Ni-free materials with good redox reversibility, proper CTE and decent electrochemical performances, different modification strategies are applied on SFM. Along with physical and electrochemical performance, the influence of different elements doping will also be investigated. 


\subsection{Doping Strategy}

The promising performance of SFM has been published by Wang ${ }^{105}$. The maximum power density of SFM/LSGM/BSCF single cell reached $863.7 \mathrm{~mW} \mathrm{~cm}^{-2}$ with $\mathrm{H}_{2}$ and $604.8 \mathrm{~mW} \mathrm{~cm}^{-2}$ with dry $\mathrm{CH}_{4}$ at $850{ }^{\circ} \mathrm{C}$. Although SFM shows high conductivity and great power density in $\mathrm{H}_{2}$, its terrible stability in the air is unacceptable (Figure 12b). By the determination of Fe and Mo valence states and the oxygen stoichiometry in SFM, Rager ${ }^{108}$ claimed that the phase stable composition in the air with a maximum Mo solubility is $\mathrm{Sr}_{2} \mathrm{Fe}_{1.34} \mathrm{Mo}_{0.68} \mathrm{O}_{6-\delta}$ and this conclusion was confirmed with the experiment by Wang's group ${ }^{107}$. With proper composition adjustment, $\mathrm{Sr}_{2} \mathrm{Fe}_{1.5} \mathrm{Mo}_{0.5} \mathrm{O}_{6}(\mathrm{SF} 1.5 \mathrm{M})$ was developed by Liu et al. ${ }^{109}$ and has been verified as a stable material in both air and $\mathrm{H}_{2}$. The maximum power density of symmetrical cell $\mathrm{SF} 1.5 \mathrm{M} / \mathrm{LSGM} / \mathrm{SF} 1.5 \mathrm{M}$ reaches $835 \mathrm{~mW} \mathrm{~cm}^{-2}$ in wet $\mathrm{H}_{2}$ and $230 \mathrm{~mW} \mathrm{~cm}^{-2}$ in $\mathrm{CH}_{4}$ at $900{ }^{\circ} \mathrm{C}$.

Based on this composition, a further investigation of CTE and redox reversibility was carried out with different elements doping. The first effort was Co doping on B site and the second effort was La doping on A site. The main purpose of Co doping was to improve the catalytic effect on the electrode surface and to induce some in-situ metal NP exsolution. Unfortunately, the phase stability of SF1.5M in $\mathrm{H}_{2}$ was ruined by light B-site Co doping. Though the electrical conductivity was improved in the air with Co-doping, the low electrical conductivity and poor phase stability in $\mathrm{H}_{2}$ prevented the application of Co-doped compositions as anode materials.

The second effort was devoted to improving the crystal stability in the fuel cell's operation conditions. We hypothesize that the thermal and chemical expansion behaviors may be influenced by metal-oxygen (M-O) bond strength in the perovskite crystal structure. Increasing the bond strength of M-O bond can probably stabilize the crystal lattice and reduce the expansion. Though no work has been done to demonstrate this hypothesis, similar idea and phenomenon have been mentioned in the literature. Forbess et al. discussed the effect of M-O bond strength on the transition temperature and the activation energy of La-doped material $\mathrm{Sr}_{1-\mathrm{x}} \mathrm{La}_{\mathrm{x}} \mathrm{Bi}_{2} \mathrm{Nb}_{2} \mathrm{O}_{9}{ }^{159}$. Due to the larger bond strength of $\mathrm{La}-\mathrm{O}$ bond $\left(799 \pm 4 \mathrm{KJ} \mathrm{mol}^{-1}\right.$ at $\left.\mathrm{RT}\right)$ than $\mathrm{Sr}-\mathrm{O}$ 
bond $\left(425.5 \pm 16.7 \mathrm{KJ} \mathrm{mol}^{-1}\right.$ at $\left.\mathrm{RT}\right)$, the substitution of $\mathrm{La}^{3+}$ into $\mathrm{Sr}^{2+}$ sites enhanced the stability of the crystal structure. In addition, Y.S. Chou et al. ${ }^{160}$ investigated the mechanical and thermal properties of $\mathrm{La}_{1-}$ ${ }_{\mathrm{x}} \mathrm{Sr}_{\mathrm{x}} \mathrm{Cr}_{0.2} \mathrm{Fe}_{0.8} \mathrm{O}_{3}$ (x=0.2 to 0.8) as a cathode. According to Chou's work, the CTE increase with Sr content, or in other words, CTE is decreased by a higher La content, the average CTE values are listed in Table 2. Also, La was introduced in $\mathrm{Sr}_{2} \mathrm{MgMoO}_{6-\delta}$ by Goodenough et al. and achieved a good performance in natural gas $^{101}$. Therefore, we envisage that the modification of A-site metal elements by substituting partial Sr with La in the perovskite structure may improve the resistance of the material to environment-induced thermal and chemical expansions.

Table 2. Average CTE of sintered $\mathrm{La}_{1-\mathrm{x}} \mathrm{Sr}_{\mathrm{x}} \mathrm{Cr}_{0.2} \mathrm{Fe}_{0.8} \mathrm{O}_{3}$ ceramics. ${ }^{160}$

\begin{tabular}{ccc}
\hline Composition & $\begin{array}{c}\text { Average CTE } \\
\left(10^{-6} \mathrm{~K}^{-1}\right)\end{array}$ & $\begin{array}{c}\text { Temperature range } \\
\left({ }^{\circ} \mathrm{C}\right)\end{array}$ \\
\hline $\mathrm{La}_{0.8} \mathrm{Sr}_{0.2} \mathrm{Cr}_{0.2} \mathrm{Fe}_{0.8} \mathrm{O}_{3}$ & 9.43 & $\mathrm{RT}$ to $\sim 300$ \\
$\mathrm{La}_{0.6} \mathrm{Sr}_{0.4} \mathrm{Cr}_{0.2} \mathrm{Fe}_{0.8} \mathrm{O}_{3}$ & $\mathbf{1 2 . 0}$ & $\sim \mathbf{3 0 0}$ to $\mathbf{1 1 0 0}$ \\
\hline \multirow{2}{*}{$\mathrm{La}_{0.4} \mathrm{Sr}_{0.6} \mathrm{Cr}_{0.2} \mathrm{Fe}_{0.8} \mathrm{O}_{3}$} & 12.3 & $\mathrm{RT}$ to $\sim 690$ \\
& $\mathbf{1 7 . 0}$ & $\sim \mathbf{6 9 0}$ to 1100 \\
\hline & 12.9 & $\mathrm{RT}$ to $\sim 560$ \\
$\mathrm{La}_{0.2} \mathrm{Sr}_{0.8} \mathrm{Cr}_{0.2} \mathrm{Fe}_{0.8} \mathrm{O}_{3}$ & $\mathbf{2 2 . 2}$ & $\sim \mathbf{5 6 0}$ to $\mathbf{1 1 0 0}$ \\
\hline & 13.9 & $\mathrm{RT}$ to $\sim 715$ \\
& $\mathbf{3 3 . 6}$ & $\sim \mathbf{7 1 5}$ to $\sim \mathbf{8 5 0}$ \\
& 17.9 & $\sim 850$ to 1100 \\
\hline \hline
\end{tabular}

In $\mathrm{ABO}_{3}$ perovskite structure, the average B-site valence state is four in case of an $\mathrm{A}^{2+}$ cation and for B'B' combination it could be $\mathrm{B}^{\prime+4} / \mathrm{B}^{\prime \prime+4}, \mathrm{~B}^{\prime+3} / \mathrm{B}^{\prime{ }^{+5}}, \mathrm{~B}^{\prime+2} / \mathrm{B}^{\prime{ }^{+6}}$ and $\mathrm{B}^{\prime+1} / \mathrm{B}^{\prime++}$. When $\mathrm{A}$ cation is trivalent, such as $\mathrm{La}^{3+}$, the average $\mathrm{B}$-site valence state become three and the combination groups are $\mathrm{B}^{9+3} / \mathrm{B}^{\prime+3}, \mathrm{~B}^{+2} / \mathrm{B}^{\prime+4}$

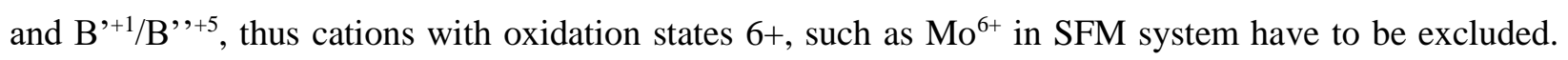
Consideration of the balance between $\mathrm{La}^{3+}$ and $\mathrm{Mo}^{5+/ 6+}$ and the equivalent valence of cations and anions, $\mathrm{La}_{0.5} \mathrm{Sr}_{1.5} \mathrm{Fe}_{1.5} \mathrm{Mo}_{0.5} \mathrm{O}_{6-\delta}$ (LSFM) is chosen as the optimal composition in this paper. All electrical and electrochemical performances are based on this formula. 
In the following sections, phase redox stability, expansion behavior and conductivity properties of candidates were investigated, and results were listed in Table 3. Depends on remarkable properties, LSFM is chosen as the optimum candidate and is further investigated in the following chapters.

Table 3. Stability, reversibility, conductivity and CTE data of candidates.

\begin{tabular}{|c|c|c|c|c|c|}
\hline Materials & $\begin{array}{l}\text { Phase Stability } \\
\text { in } \mathbf{H}_{2} \\
\end{array}$ & $\begin{array}{c}\text { Phase Stability } \\
\text { in air } \\
\end{array}$ & $\begin{array}{c}\text { Redox } \\
\text { Reversibility }\end{array}$ & $\begin{array}{c}\text { Conductivity at } 800^{\circ} \mathrm{C} \text { in } \\
5 \% \mathrm{H}_{2}(\mathrm{~S} / \mathrm{cm})\end{array}$ & $\begin{array}{c}\text { CTE } \\
\left(10^{-6} K^{-1}\right) \\
\end{array}$ \\
\hline $\mathrm{Sr}_{2} \mathrm{FeMoO}_{6-\delta}(\mathrm{SFM})$ & $V$ & X & X & $\sim 150$ & 14 \\
\hline $\mathrm{Sr}_{2} \mathrm{Fe}_{1.5} \mathrm{Mo}_{0.5} \mathrm{O}_{6-\delta}(\mathrm{SF} 1.5 \mathrm{M})$ & $\sqrt{ }$ & $\sqrt{ }$ & $x$ & 20 & 17.12 \\
\hline $\mathrm{Sr}_{2} \mathrm{Fe}_{1.5} \mathbf{C o}_{0.1} \mathrm{Mo}_{0.4} \mathrm{O}_{6-\delta}(\mathrm{SFCM})$ & X & $\sqrt{ }$ & $\sqrt{x}$ & 7 & 20.39 \\
\hline $\mathbf{L a}_{0.5} \mathrm{Sr}_{1.5} \mathrm{Fe}_{1.5} \mathrm{Mo}_{0.5} \mathrm{O}_{6-\delta}$ (LSFM) & $\sqrt{ }$ & $\sqrt{ }$ & $\sqrt{ }$ & 23 & 15.01 \\
\hline
\end{tabular}

\subsection{Phase Formation and Stability}

\subsubsection{Phase Stability of SF1.5M}

In order to achieve good redox reversibility, the phase stability in both oxidizing and reducing atmosphere is critical. First, the phase stability of SFM, SF1.5M, SFCM, and LSFM was investigated. Among four candidates, SF1.5M and LSFM exhibited credible phase stability in $\mathrm{H}_{2}$ and air at high temperature. As discussed in section 3.1.3, SF1.5M is a good candidate as both cathode and anode ${ }^{108,138}$. The XRD patterns and SEM images of SF1.5M before and after reduction can be found from Figure 22b and Figure 21c-d.

\subsubsection{Phase Formation and Stability of LSFM}

The calcination condition of the LSFM was investigated and the obtained phases were characterized by XRD. Figure 27a displayed the XRD patterns of LSFM calcined in air, $5 \% \mathrm{H}_{2}-95 \% \mathrm{~N}_{2}$ and $\mathrm{N}_{2}$, respectively. Pure LSFM with perovskite structure is obtained in $\mathrm{N}_{2}$ (Figure 27a and Figure 28). According to Rietveld refinement (Figure 27b and Table 4), the as-prepared pure LSFM shows a cubic structure (Pm-3m space group) with $\mathrm{a}=\mathrm{b}=\mathrm{c}=3.93584(2) \AA$ and $\alpha=\beta=\gamma=90^{\circ}\left(\mathrm{R}_{\mathrm{wp}}=4.61 \%, \chi^{2}=1.56, \mathrm{R}_{\mathrm{p}}=3.38 \%\right)$. In $5 \% \mathrm{H}_{2}-95 \% \mathrm{~N}_{2}$, the synthesized material is far from the perovskite structure. According to the XRD data analysis, the calcined powder is composed of pure metal iron (Fe, JCPDS No. 06-0696) and several kinds of metal oxides such 
as $\mathrm{LaSrFeO}_{4}$ (JCPDS No. 71-1745), $\mathrm{Sr}_{3} \mathrm{Fe}_{2} \mathrm{O}_{6}$ (JCPDS No. 82-0426) and $\mathrm{SrMoO}_{3}$ (JCPDS No. 81-0640), as marked in Figure 27a. The crystal structure of the powder calcined in air showed more similarity to a cubic perovskite structure except for several impurity peaks corresponding to $\mathrm{SrMoO}_{4}$ (JCPDS No. 080482) and $\mathrm{LaFeO}_{3}$ (JCPDS No. 75-0541).
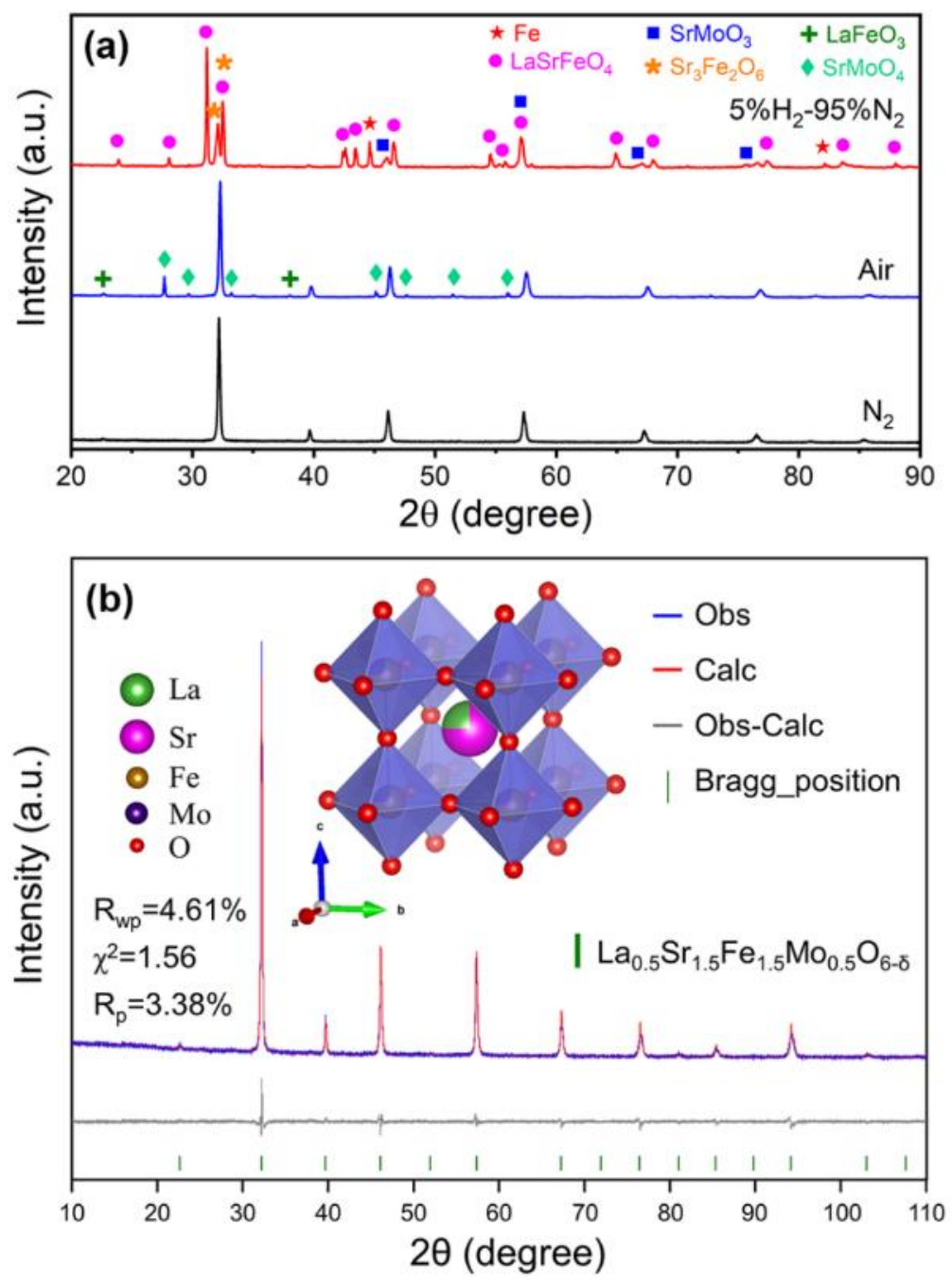

Figure 27. (a) XRD patterns of LSFM calcined in $5 \% \mathrm{H}_{2}$, air, and $\mathrm{N}_{2}$, respectively. (b) XRD pattern with Rietveld refinement result of LSFM calcined in $\mathrm{N}_{2}$. Crystal structure of LSFM is shown in the inset. 

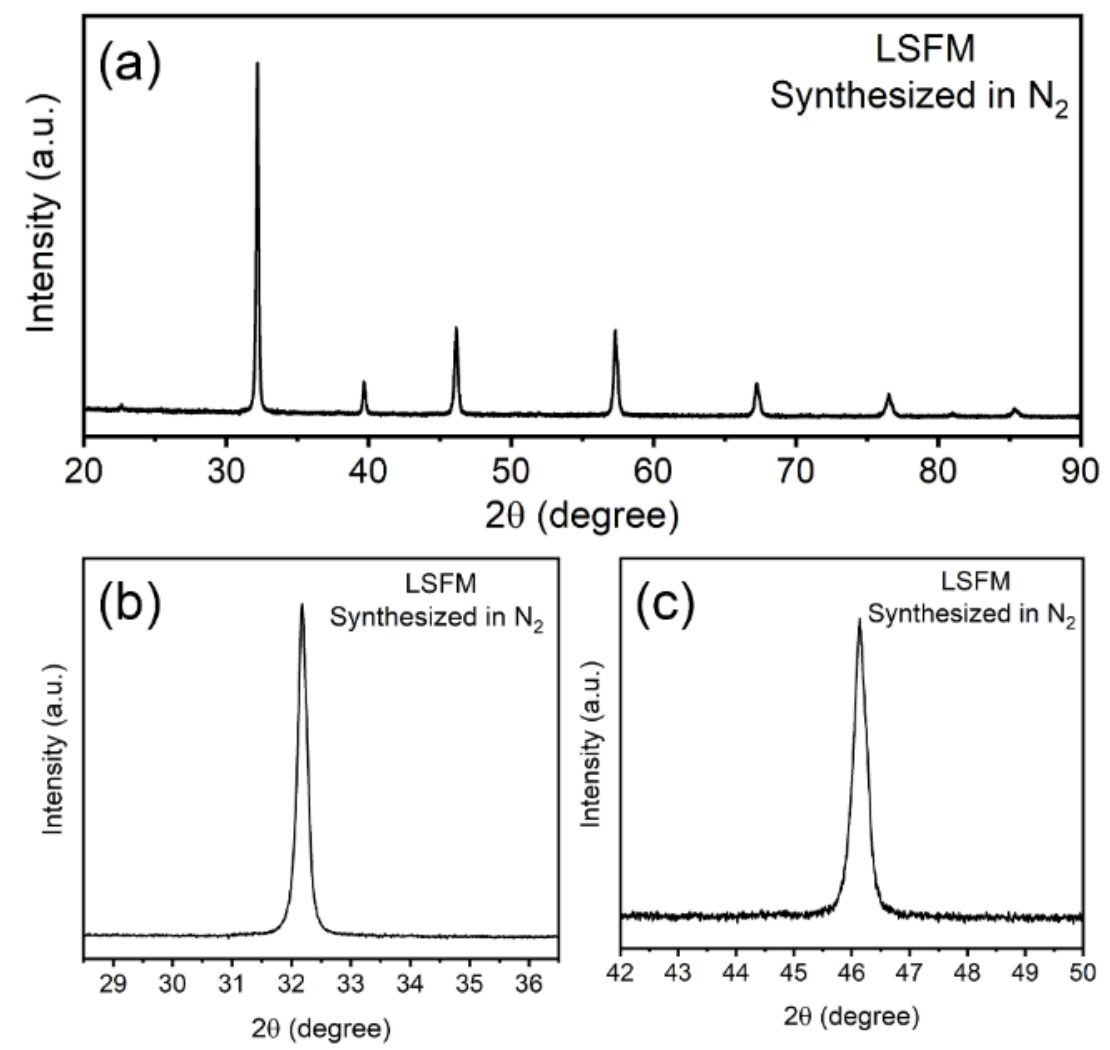

Figure 28. (a) XRD pattern of LSFM synthesized in N2. (b) XRD main peak at $32^{\circ}$. (c) XRD main peak at $46^{\circ}$.

Table 4. The final refined structure parameters.

\begin{tabular}{cccccc}
\hline \hline Atom & $\mathrm{x}$ & $\mathrm{y}$ & $\mathrm{z}$ & Occupancy & $\mathrm{B}\left(\AA^{2}\right)$ \\
\hline $\mathrm{La}(1 \mathrm{~b})$ & 0.5 & 0.5 & 0.5 & 0.25 & 0.728 \\
$\mathrm{Sr}(1 \mathrm{~b})$ & 0.5 & 0.5 & 0.5 & 0.75 & 0.728 \\
$\mathrm{Fe}(1 \mathrm{a})$ & 0 & 0 & 0 & 0.75 & 0.508 \\
$\mathrm{Mo}(1 \mathrm{a})$ & 0 & 0 & 0 & 0.25 & 0.508 \\
$\mathrm{O}(3 \mathrm{~d})$ & 0.5 & 0 & 0 & 1.00 & 1.834 \\
\hline \hline
\end{tabular}

According to the literature ${ }^{75,161}, \mathrm{SF} 1.5 \mathrm{M}$ pure phase is usually obtained in air. The difference of synthesis atmospheres between LSFM and SF1.5M probably come from the different valence states of $\mathrm{La}^{3+}$ and $\mathrm{Sr}^{2+}$. The reaction between oxygen gas and defects in LSFM can be expressed as: 


$$
\frac{1}{2} \mathrm{O}_{2}(g)+V_{O}^{\ddot{*}}+2 M_{M}{ }^{\prime}=\mathrm{O}_{O}^{\times}+2 M_{M}^{\times}
$$

Here, $M$ presents B-site cations $\mathrm{Fe}$ and Mo. $M_{M}^{\prime}$ corresponds to $\mathrm{Fe}^{2+}$ and $\mathrm{Mo}^{5+}, M_{M}^{\times}$corresponds to $\mathrm{Fe}^{3+}$ and $\mathrm{Mo}^{6+}$. When partially replacing divalent cation $\mathrm{Sr}^{2+}$ by trivalent cation $\mathrm{La}^{3+}$, oxygen vacancy concentration decreases to maintain the electrical neutrality. If $\mathrm{B}$-site cations are assumed to be $\mathrm{Fe}^{3+} / \mathrm{Fe}^{4+}$ and $\mathrm{Mo}^{6+}$ in air, the theoretical value of $\delta$ become 0 or negative which is unfavorable to perovskite phase formation. Thus, a lower $\mathrm{P}_{\mathrm{O} 2}$ environment (such as $\mathrm{N}_{2}$ or Ar) would be preferred to push the Reaction (21) backward and produce some oxygen vacancies. Nevertheless, a reducing atmosphere (such as $5 \% \mathrm{H}_{2}$ ) would go too far to reduce cations into metal (such as $\mathrm{Fe}$ ) and metal oxides which are more stable in a reducing environment. Based on the XRD results, LSFM synthesized in $\mathrm{N}_{2}$ would be used in the following tests.

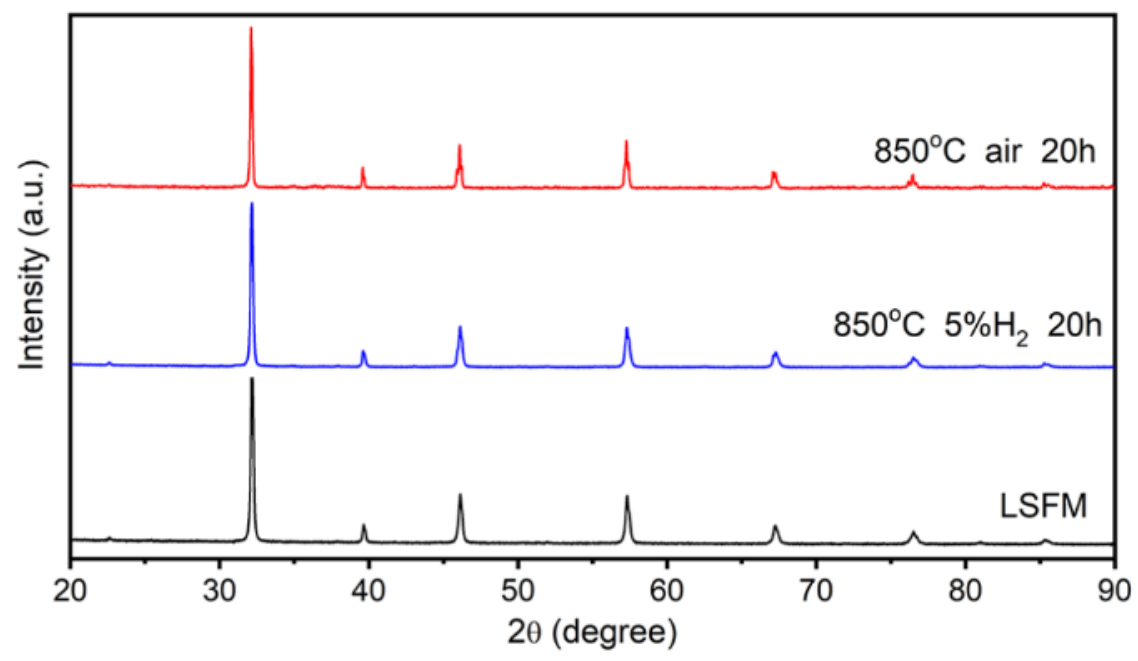

Figure 29. XRD patterns of LSFM pure phase following heat treatment at $850{ }^{\circ} \mathrm{C}$ for $20 \mathrm{~h}$ in air and $5 \% \mathrm{H}_{2}$.

Although calcined in $\mathrm{N}_{2}$, the synthesized LSFM exhibited good phase stability in both oxidizing and reducing atmospheres. Figure 29 shows the XRD patterns of pure LSFM powder before and after heat treatment at $850{ }^{\circ} \mathrm{C}$ for $20 \mathrm{~h}$ in air and forming gas, respectively. Compared with the original XRD pattern, no new peaks are observed for both samples after $20 \mathrm{~h}$ heat treatment. This demonstrated good phase stability of LSFM over a long time in both reducing and oxidizing atmospheres and presented a high 
potential for redox stability. The good phase stability of LSFM is responsible for the high reversibility of electronic conductivity under multiple redox cycles.

Compared with SF1.5M, an in-situ Fe NPs exsolution was observed in LSFM. This exsolution only occurs at a high temperature $\left(\right.$ such as $800{ }^{\circ} \mathrm{C}$ ) in a high hydrogen partial pressure environment such as dry or humidified $\mathrm{H}_{2}$. In a low hydrogen partial pressure environment, most Fe cations are stable in the lattice, no metal Fe can be detected by XRD, as shown in Figure 29. The details of the in-situ Fe exsolution will be discussed in chapter 5 .

\subsubsection{Phase Stability of SFM}
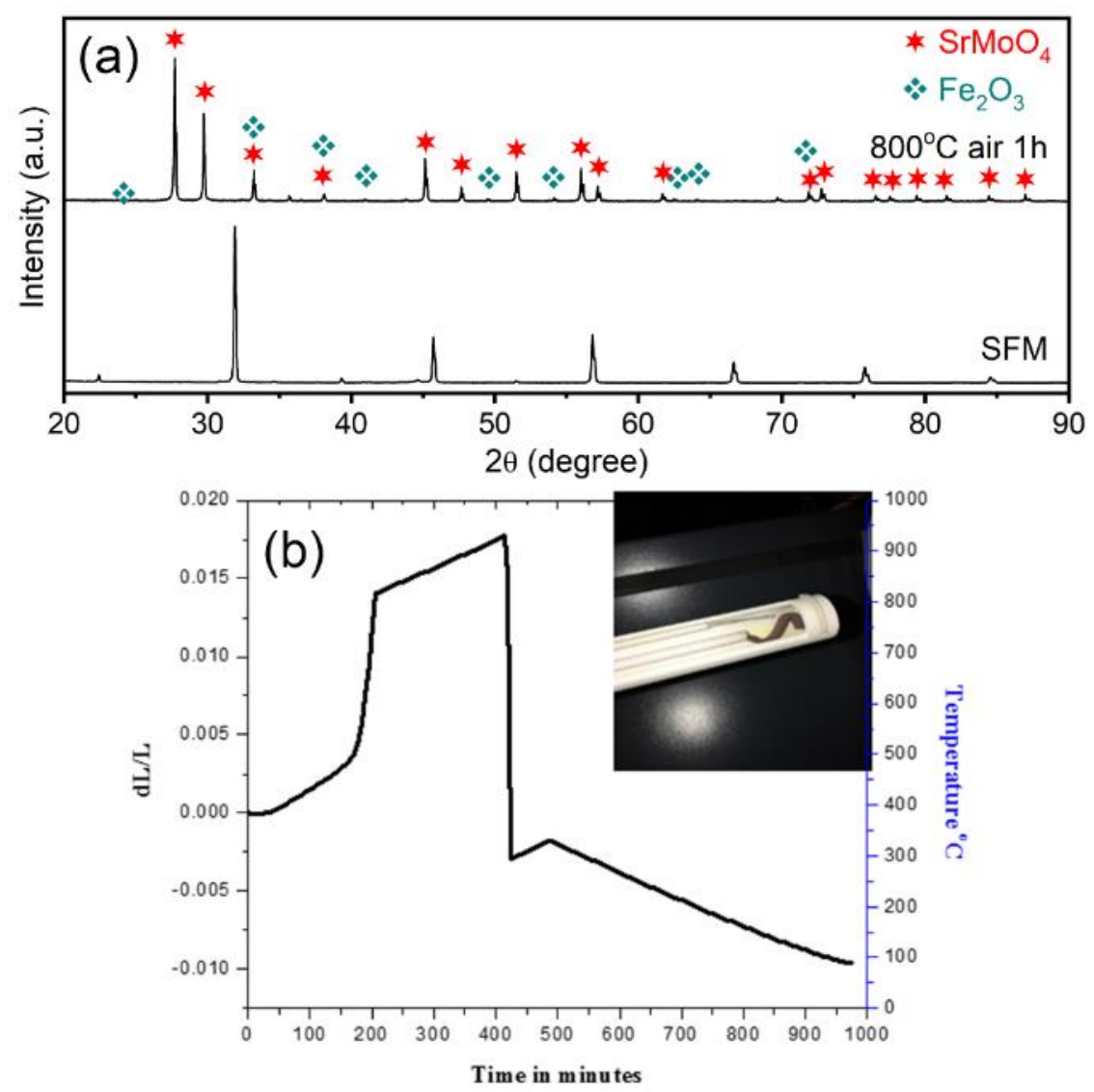

Figure 30. (a) XRD patterns of SFM as synthesized in $5 \% \mathrm{H}_{2}$ and oxidized in air, (b) Dilatometry data of SFM heated up in the air, inset is the bar sample after dilatometry test. 
As mentioned previously, SFM can only be synthesized and applied in reducing atmosphere. In this work, pure SFM was obtained in $5 \% \mathrm{H}_{2}-95 \% \mathrm{~N}_{2}$ forming gas at $1300{ }^{\circ} \mathrm{C}$, as shown in Figure 30a. Unfortunately, this composition is very unstable in air and will quickly decompose into $\mathrm{SrMoO}_{4}$ and $\mathrm{Fe}_{2} \mathrm{O}_{3}$ in the air which has been proved by XRD (Figure 30a) and dilatometry result (Figure 30b).

\subsubsection{Phase Stability of SFCM}
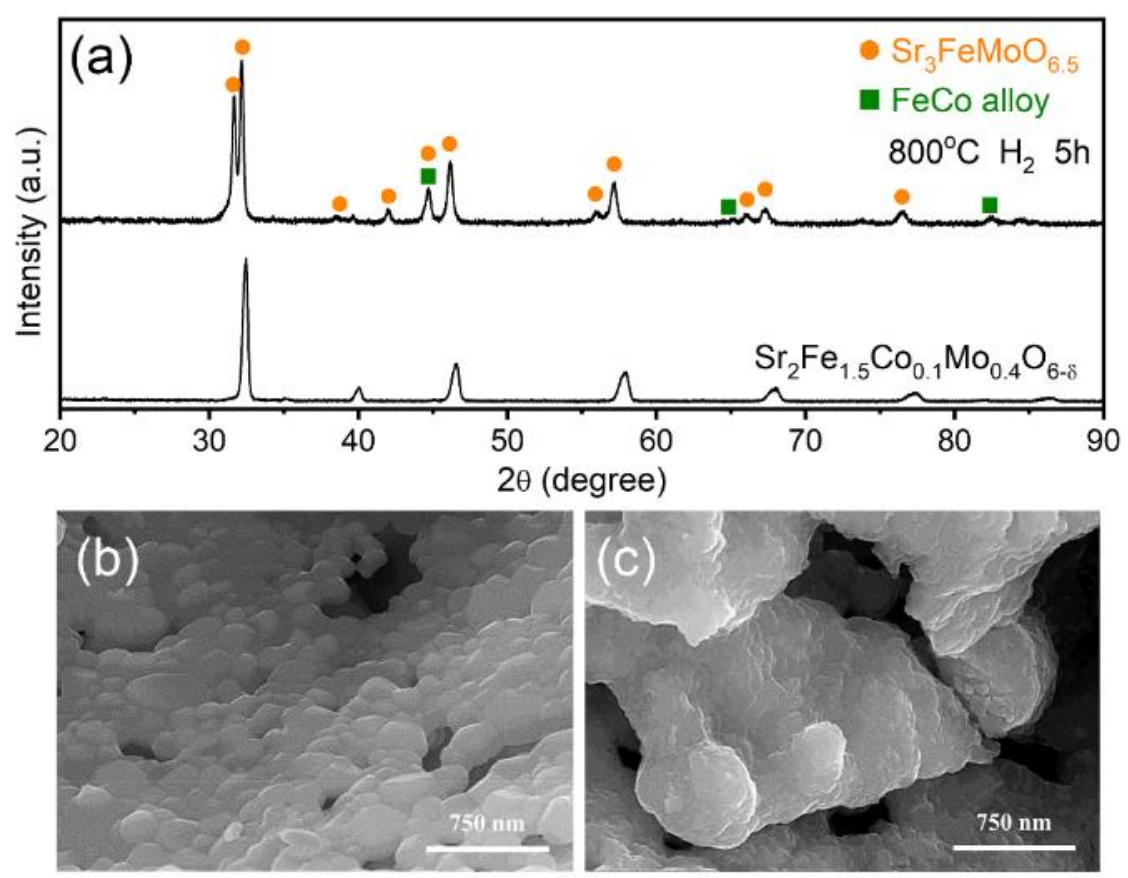

Figure 31. (a) XRD patterns of $\mathrm{Sr}_{2} \mathrm{Fe}_{1.5} \mathrm{Co}_{0.1} \mathrm{Mo}_{0.4} \mathrm{O}_{6-\delta}$ (SFCM) as synthesized and reduced in $\mathrm{H}_{2}$, (b) SEM image of SFCM as synthesized, (c) SEM image of SFCM reduced in $\mathrm{H}_{2}$.

Another unstable composition is Co doped SFCM. Perovskite SFCM was successfully synthesized in air and presented great stability in air. However, after reducing in $\mathrm{H}_{2}$ at $800{ }^{\circ} \mathrm{C}$ for several hours, a large-scale phase transition from perovskite $\left(\mathrm{Sr}_{2} \mathrm{Fe}_{1.5} \mathrm{Co}_{0.1} \mathrm{Mo}_{0.4} \mathrm{O}_{6-\delta}\right)$ to Ruddlesden-Popper (RP) phase $\left(\mathrm{Sr}_{3} \mathrm{FeMoO}_{6.5}\right)$ and Fe-Co alloy was detected by XRD (Figure 31a). SEM images in Figure 31b-c suggest that there is an obvious morphology change together with this phase transition during the reduction process. In Figure $31 \mathrm{~b}$ the synthesized SFCM powders present small and uniform particles, the grain size is about 200-300 $\mathrm{nm}$ and grain boundaries can be observed clearly. After reduction, all grain boundaries disappeared, only a big 
chunk with the irregular shape and rough surface can be observed from Figure 31c. Similar phase transitions are reported on anode materials $\mathrm{Pr}_{0.4} \mathrm{Sr}_{0.6} \mathrm{Co}_{0.2} \mathrm{Fe}_{0.7} \mathrm{Ni}_{0.1} \mathrm{O}_{3-\delta}{ }^{162}, \quad \mathrm{Sr}_{2} \mathrm{FeMo}_{0.65} \mathrm{Ni}_{0.35} \mathrm{O}_{6-\delta}{ }^{163}$ and $\mathrm{La}_{0.6} \mathrm{Sr}_{0.4} \mathrm{Fe}_{0.8} \mathrm{Ni}_{0.2} \mathrm{O}_{3-\delta}{ }^{116}$. Though the decent electrochemical performance and the good sulfur tolerance are reported on some of these materials, it is difficult to achieve good redox reversibility with the large-scale phase transition.

\subsection{Thermal and Chemical Expansion Behavior}

Except for SFM, thermal expansion and chemical expansion behaviors of other three compositions (SF1.5M, SFCM, and LSFM) as well as similar materials with different Fe:Mo ratios were analyzed by dilatometry method. In this test, dense bar samples were heated up to and stabilized at $800{ }^{\circ} \mathrm{C}$ in the air followed by two redox cycles. For each redox cycle, gas switched from air to $5 \% \mathrm{H}_{2}$ and then switched back to air. In each atmosphere, the sample was soaked for $5 \mathrm{~h}$. After two redox cycles, the testing system was cooled down to the room temperature (RT) in air. In Figure 32, graphs were plotted with the same y-axis range to compare the CTE directly. Red horizontal lines marked the expansion of materials at $800{ }^{\circ} \mathrm{C}$ in the air before and after each redox cycle. Average CTE from RT to $800{ }^{\circ} \mathrm{C}$ of SF1.5M, SFCM, and LSFM were $17.12 \times 10^{-6}$ $\mathrm{K}^{-1}, 20.39 \times 10^{-6} \mathrm{~K}^{-1}$, and $15.01 \times 10^{-6} \mathrm{~K}^{-1}$, respectively.
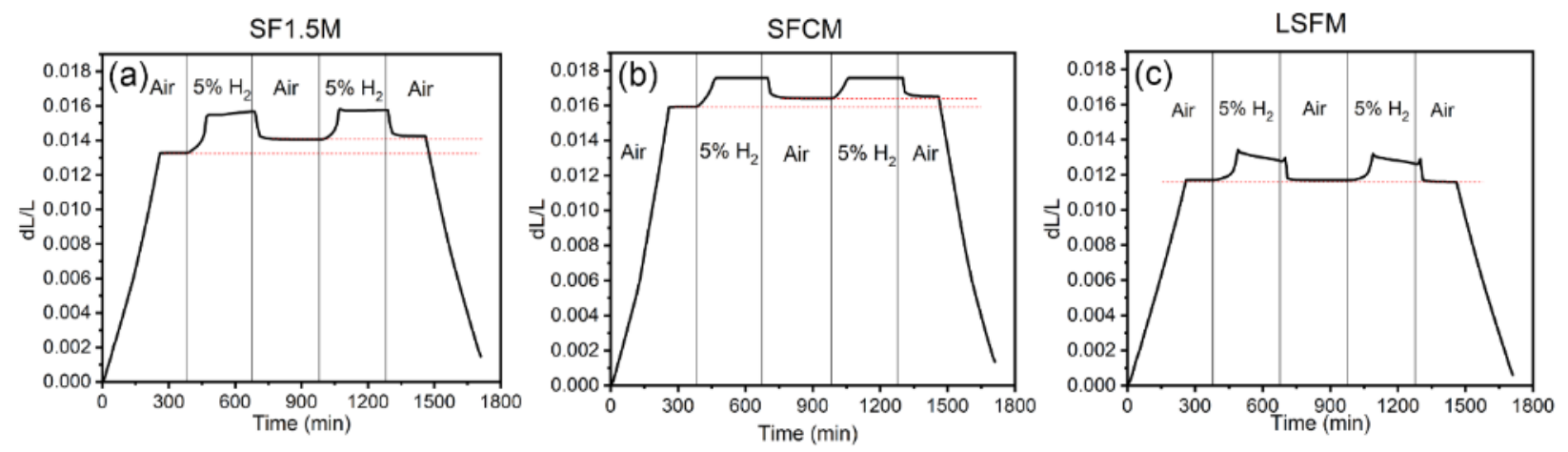

Figure 32. Dilatometry results of (a) SF1.5M, (b) SFCM and (c) LSFM from RT to $800{ }^{\circ} \mathrm{C}$ in air and two redox cycles in air and $5 \% \mathrm{H}_{2}$. 
Compared with SF1.5M in Figure 32a, the thermal expansion behavior was accelerated by Co (Figure 32b) but depressed by La (Figure 32c). As mentioned before, the different CTE may relate to the different metaloxygen (M-O) bond strength between Fe-O, Mo-O, and Co-O as well as Sr-O and La-O. In order to further verify this hypothesis, CTE of some similar compositions was measured and listed in Table 5. For Sr-FeMo compositions set $\left(\mathrm{Fe}_{1.4} \mathrm{Mo}_{0.6}, \mathrm{Fe}_{1.5} \mathrm{Mo}_{0.5}\right.$ and $\left.\mathrm{Fe}_{1.6} \mathrm{Mo}_{0.4}\right)$ and $\mathrm{Sr}-\mathrm{Fe}-\mathrm{Co}-\mathrm{Mo}$ compositions set $\left(\mathrm{Fe}_{1.4} \mathrm{Co}_{0.1} \mathrm{Mo}_{0.5}, \mathrm{Fe}_{1.5} \mathrm{Co}_{0.1} \mathrm{Mo}_{0.4}\right.$ and $\left.\mathrm{Fe}_{1.6} \mathrm{Co}_{0.1} \mathrm{Mo}_{0.3}\right)$, CTE showed a downtrend with Mo content increment. This trend suggested a stronger Mo-O bond strength than the Fe-O bond (Mo-O > Fe-O) in the crystal structure. This conclusion was also verified in the literature ${ }^{155,164-165}$. In order to analyze the bond strength between Mo-O and Co-O, compositions with the same Fe content were put together, as shown in "Co replace Mo" columns in Table 5. The higher CTE of Co-containing samples in all three sets revealed a stronger Mo-O bond strength than the Co-O bond (Mo-O > Co-O). Similarly, for the bond strength between Fe-O and Co-O, compositions with the same Mo content were put together, as shown in "Co replace Fe" column in Table 5. As CTE values of Co-containing samples were always bigger, we can draw the conclusion that the $\mathrm{Fe}-\mathrm{O}$ bond possessed a stronger strength than $\mathrm{Co}-\mathrm{O}$ bond $(\mathrm{Fe}-\mathrm{O}>\mathrm{Co}-\mathrm{O})$. In summary, for B-site cations the M-O bond strength followed the relationship: Mo-O > Fe-O > Co-O.

Table 5. Effect of Co on CTE change in $\mathrm{Sr}_{2} \mathrm{Fe}_{1+\mathrm{x}} \mathrm{Mo}_{1-\mathrm{x}} \mathrm{O}_{6-\delta}(\mathrm{x}=0.4-0.6)$

\begin{tabular}{|c|c|c|c|c|c|}
\hline CTE & \multicolumn{3}{|c|}{ Co replace Mo } & \multicolumn{2}{|c|}{ Co replace Fe } \\
\hline \multirow{2}{*}{ Without Co } & $\mathrm{Fe}_{1.4} \mathbf{M o}_{0.6}$ & $\mathrm{Fe}_{1.5} \mathbf{M o}_{0.5}$ & $\mathrm{Fe}_{1.6} \mathbf{M o}_{0.4}$ & $\mathrm{Fe}_{1.5} \mathbf{M o}_{0.5}$ & $\mathrm{Fe}_{1.6} \mathrm{Mo}_{0.4}$ \\
\hline & 16.10 & 17.12 & 19.85 & 17.12 & 19.85 \\
\hline \multirow{2}{*}{ With Co } & $\mathrm{Fe}_{1.4} \mathrm{Co}_{0.1} \mathrm{Mo}_{0.5}$ & $\mathrm{Fe}_{1.5} \mathrm{Co}_{0.1} \mathrm{Mo}_{0.4}$ & $\mathrm{Fe}_{1.6} \mathrm{Co}_{0.1} \mathrm{Mo}_{0.3}$ & $\mathrm{Fe}_{1.4} \mathrm{Co}_{0.1} \mathrm{Mo}_{0.5}$ & $\mathrm{Fe}_{1.5} \mathrm{Co}_{0.1} \mathrm{Mo}_{0.4}$ \\
\hline & 18.06 & 20.39 & 21.08 & 18.06 & 20.39 \\
\hline
\end{tabular}

Compared with the original $\mathrm{Sr}-\mathrm{O}$ bond, La introduced a stronger $\mathrm{M}-\mathrm{O}$ bond into the structure. $\mathrm{La}_{\mathrm{x}} \mathrm{Sr}_{2}$ ${ }_{x} \mathrm{Fe}_{1.5} \mathrm{Mo}_{0.5} \mathrm{O}_{6-\delta}$ compositions with different La contents ( $\mathrm{x}=0,0.5$ and 1 ) were synthesized and evaluated by the dilatometry method. With the increase of La content, the CTE decreased from $17.12 \times 10^{-6} \mathrm{~K}^{-1}$ (in $\mathrm{SF} 1.5 \mathrm{M}$ ) to $13.28 \times 10^{-6} \mathrm{~K}^{-1}$ (in La $\mathrm{SFM}$ ), as shown in Figure 33 . When $1 / 2$ of the strontium is replaced, this 
value dropped to $13.3 \times 10^{-6} \mathrm{~K}^{-1}\left(\mathrm{LaSrFe}_{1.5} \mathrm{Mo}_{0.5} \mathrm{O}_{6-\delta}\right)$ which is very close to that reported for LSGM (10$12 \times 10^{-6} \mathrm{~K}^{-195-97}$ ). Based on this experimental result, La provided an obvious limitation to the thermal expansion (Figure 34).

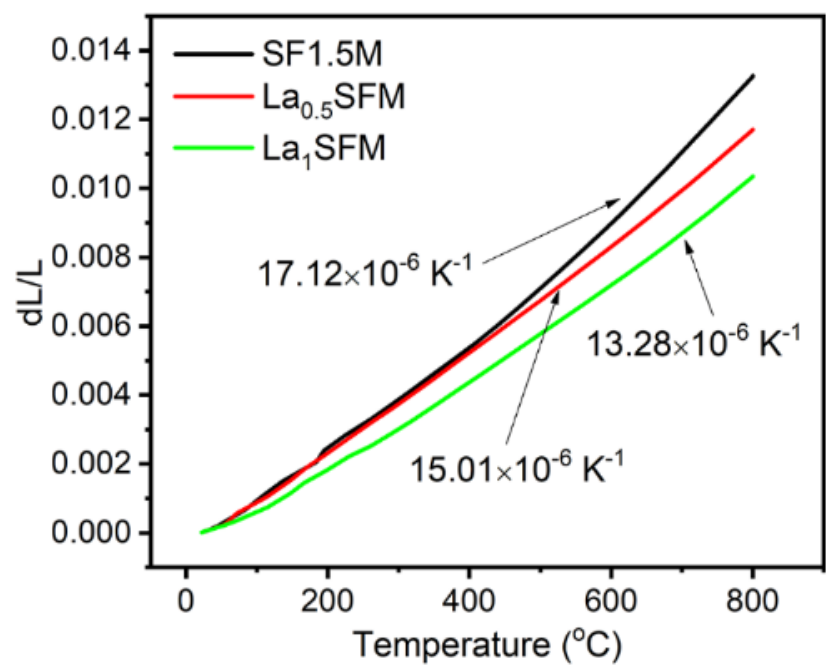

Figure 33. Effect of La on thermal expansion behavior.

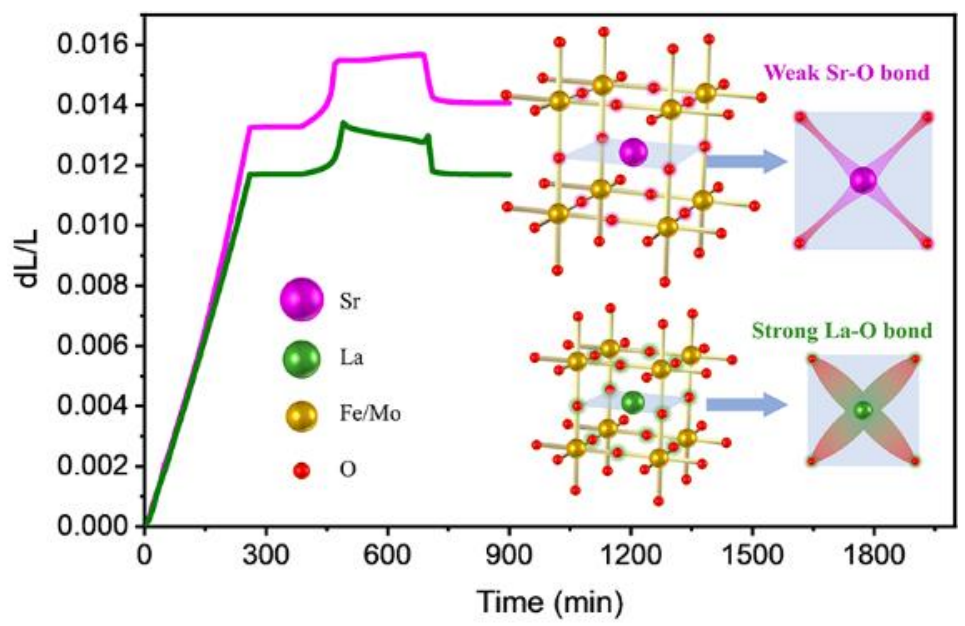

Figure 34. Thermal expansion and chemical expansion behavior of LSFM (green line) and SF1.5M (purple line). Crystal structure of the two materials can be found from inset.

On the other hand, with lanthanum doping the lattice stability in a redox environment is also improved.

Figure 35a-b shows the dilatometry behavior of LSFM and SF1.5M during redox cycling. Compared with SF1.5M, LSFM presents smaller volume change under redox environment and better reversibility during 
two redox cycles. For SF1.5M, the volume in the air before and after redox cycles is a clear ladder shape. After each expansion-contraction cycle, some volume expansion remains which can be easily observed in Figure 35b. In contrast, the lanthanum doped sample shows no expansion remnant (Figure 35a). This excellent chemical expansion reversibility benefits from the high structural stability and good phase stability of LSFM (Figure 34).
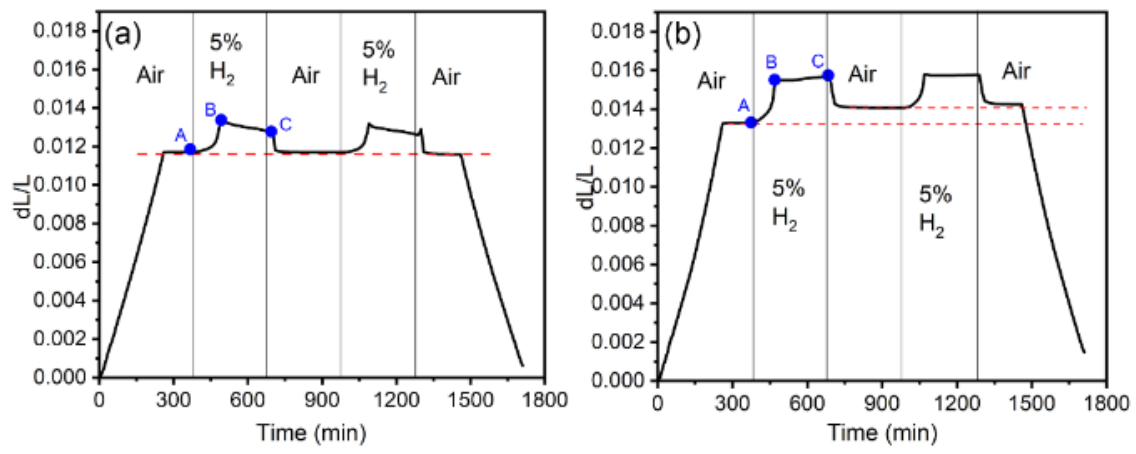

Figure 35. Dilatometry behavior of (a) LSFM and (b) SF1.5M from room temperature to $800{ }^{\circ} \mathrm{C}$ in the air followed by two redox cycles at $800^{\circ} \mathrm{C}$.

Moreover, different chemical expansion behaviors of LSFM and SF1.5M in 5\% $\mathrm{H}_{2}$ are noticed. LSFM exhibits milder chemical expansion and slight contraction when soaked in $5 \% \mathrm{H}_{2}$, while $\mathrm{SF} 1.5 \mathrm{M}$ presents bigger chemical expansion and extra expansion in $5 \% \mathrm{H}_{2}$. Chemical expansion is the result of two competing processes, lattice contraction around oxygen vacancies and lattice expansion from the increase of cation radius. In general, the quantity of cation radius increment is much larger and leading to a net expansion ${ }^{166}$. For perovskite structure, subtle symmetry changes during expansion ${ }^{167}$ and the degree of electronic charge localization will also contribute to the chemical expansion behavior.

Compared with SF1.5M, more B-site cations in LSFM would be reduced to a lower valence state after switching the gas from air to $5 \% \mathrm{H}_{2}$ (from A to B in Figure 35). As the cation radius increment dominates the expansion behavior, a bigger chemical expansion in LSFM is expected. However, a milder chemical expansion is observed from our dilatometry test. Specifically, the volume expansion in SF1.5M from A to B is $0.2216 \%$ (as shown in Figure 35b). This value increased to $0.2409 \%$ (from A to C) after reduction for 
5 h. For LSFM (as shown in Figure 35a), the volume change from A to B is $0.1706 \%$ which is smaller than $\mathrm{SF} 1.5 \mathrm{M}$. After $5 \mathrm{~h}$ reduction, this value dropped to $0.1062 \%$ (from A to C). Based on this experimental phenomenon, a stronger M-O bond probably also contribute to a smaller chemical expansion (from A to B) and stronger maintenance respect to the original structure (point A) (Figure 34). Considering the different radius of $\mathrm{La}^{3+}$ and $\mathrm{Sr}^{2+}$, the smaller $\mathrm{La}^{3+}(117.2 \mathrm{pm})$ can make more space for octahedral tilting and structure distortion than $\mathrm{Sr}^{2+}(132 \mathrm{pm})$. Thus, it is more likely for La-doped compositions to perform a structure contraction during relaxation (From B to C). This conclusion is consistent with our experimental observations on La-doped compositions ( $\mathrm{La}_{0.5} \mathrm{Sr}_{1.5} \mathrm{Fe}_{1.5} \mathrm{Mo}_{0.5} \mathrm{O}_{6-\delta}$ and $\mathrm{LaSrFe}_{1.5} \mathrm{Mo}_{0.5} \mathrm{O}_{6-\delta}$ ). Both samples exhibited similar volume contraction behavior in reducing atmosphere (Figure 36).
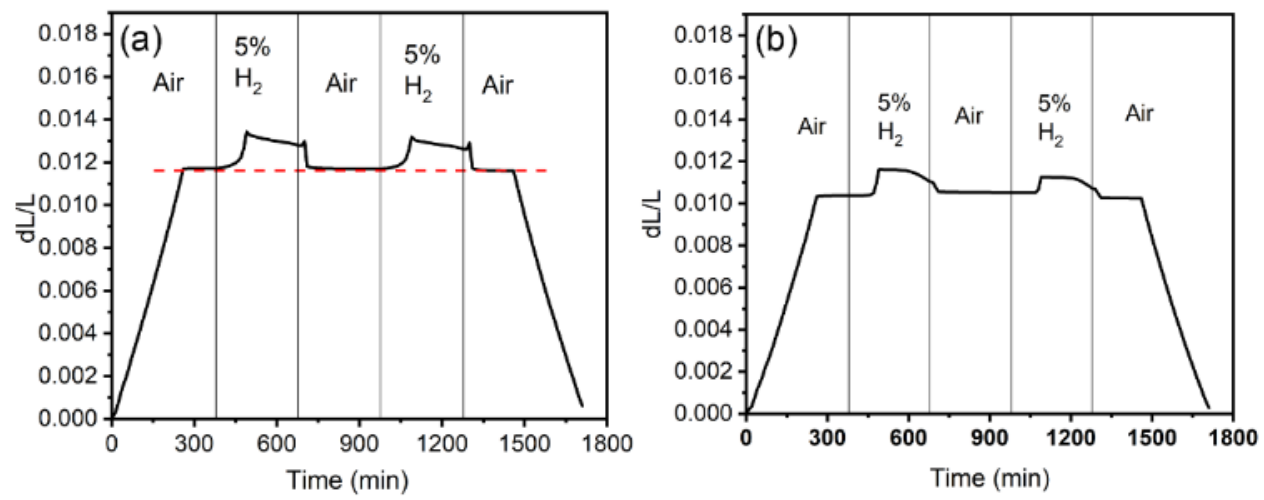

Figure 36. Dilatometry behavior of (a) LSFM and (b) $\mathrm{LaSrFe}_{1.5} \mathrm{Mo}_{0.5} \mathrm{O}_{6-\delta}$ from room temperature to $800{ }^{\circ} \mathrm{C}$ in the air followed by two redox cycles at $800{ }^{\circ} \mathrm{C}$.

In the macroscopic view, the appropriate thermal expansion and mild chemical expansion of LSFM can help to avoid the poor internal connections and micro-cracks in stacks and maintain the electrical and electrochemical performance during redox cycling. In that case, the good dilatometry performance may also contribute to the excellent reversibility of the electrical conductivity.

\subsection{Electrical Performance in Redox Cycling}

The electrical conductivity of SF1.5M, SFCM, and LSFM and their similar compositions (with different Fe:Mo ratios) were investigated here under a redox environment. The influence of Fe:Mo ratio, Co or La 
doping on conductivity reversibility are discussed then. Graphs presented in Figure 37a-c suggest that for $\mathrm{Sr}_{2} \mathrm{Fe}_{1+\mathrm{x}} \mathrm{Mo}_{1-\mathrm{x}} \mathrm{O}_{6-\delta}(\mathrm{x}=0.4,0.5,0.6)$ : (1) higher conductivities in both air and forming gas corresponds to a higher Fe content. (2) All compositions exhibit a higher conductivity in the reducing atmosphere. (3) Slight degradation can be observed from the first to the second redox cycle, especially for conductivity in $5 \% \mathrm{H}_{2}$. The expansion residue shown in Figure 32 would bring some microcracks into the bulk and lead to the conductivity decay. The conductivities of Co-doped compositions $\operatorname{Sr}_{2} \mathrm{Fe}_{1+\mathrm{x}} \mathrm{Co}_{0.1} \mathrm{Mo}_{1-\mathrm{x}-0.1} \mathrm{O}_{6-\delta}(\mathrm{x}=0.4,0.5,0.6)$ (Figure 37d-f), however, display an opposite trend: (1) with Fe content increase, the conductivity in both air and $5 \% \mathrm{H}_{2}$ falls off. (2) A small amount of Co-doping totally flipped over the relationship of conductivities between air and $5 \% \mathrm{H}_{2}$. More specifically, conductivity is dramatically increased in the air but limited in $\mathrm{H}_{2}$. This implies the enhancement of Co element to the electrochemical performance in the oxidation environment which may explain the extensive utilization of Co element in cathode materials ${ }^{168-}$ ${ }^{171}$. (3) Considerable conductivity drop in the second redox cycle is largely ascribed to the obvious phase change. As displayed in Figure 31a,c-d, the massive phase transition, and morphology change will lead to big stress in the dense sample which is the main reason for microcracks. when re-oxidized in air, the microcracks and insulative metal oxides come from Fe-Co alloy will partially or totally kill the conductivity performance. It is foreseeable that after several redox cycles the conductivity performance, as well as electrochemical performance of SFCM, will be destroyed. 

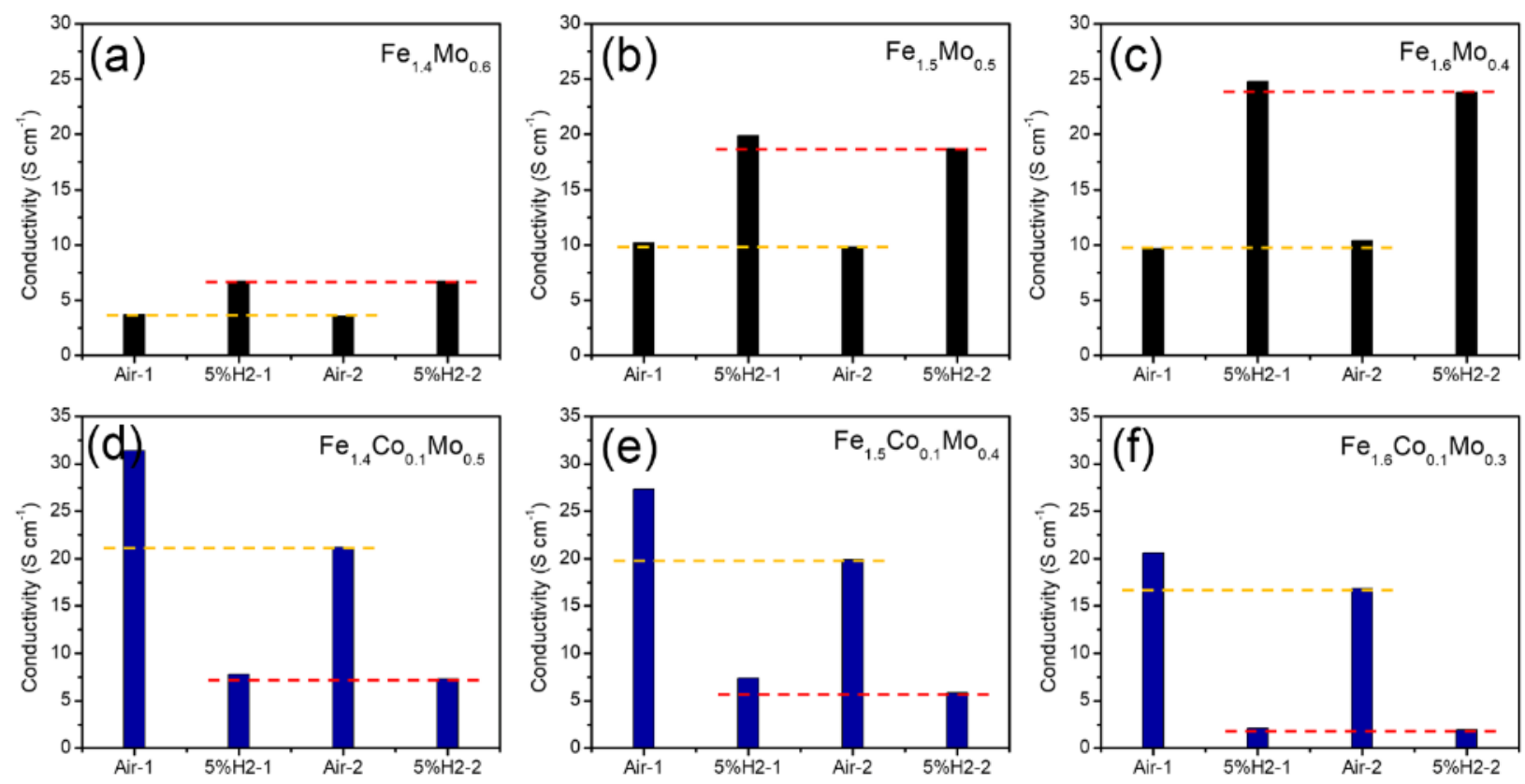

Figure 37. The conductivity of compositions without (a-c) and with (d-f) Co doping in two redox cycles.

By contrast, LSFM possesses a high conductivity in $5 \% \mathrm{H}_{2}$ and excellent reversibility under redox cycling. No degradation is observed in three redox cycles and a slight increase in both air and forming gas can be clearly seen in Figure 38. In the forming gas, a very similar conductivity value between LSFM and SF1.5M demonstrates that the conductivity performance in the reducing atmosphere is maintained with La-doping. In view of the previous conclusion about phase stability, thermal expansion, and chemical expansion, we have reasons to believe that this outstanding electrical performance because of the positive influence of La on phase stability, unit cell stability and electrical conductivity in $\mathrm{H}_{2}$. So far, the La-doped composition satisfied all requirements to a redox stable anode material. In the following sections, we will focus on this material and further explore the electrochemical performance and HOR mechanism. 


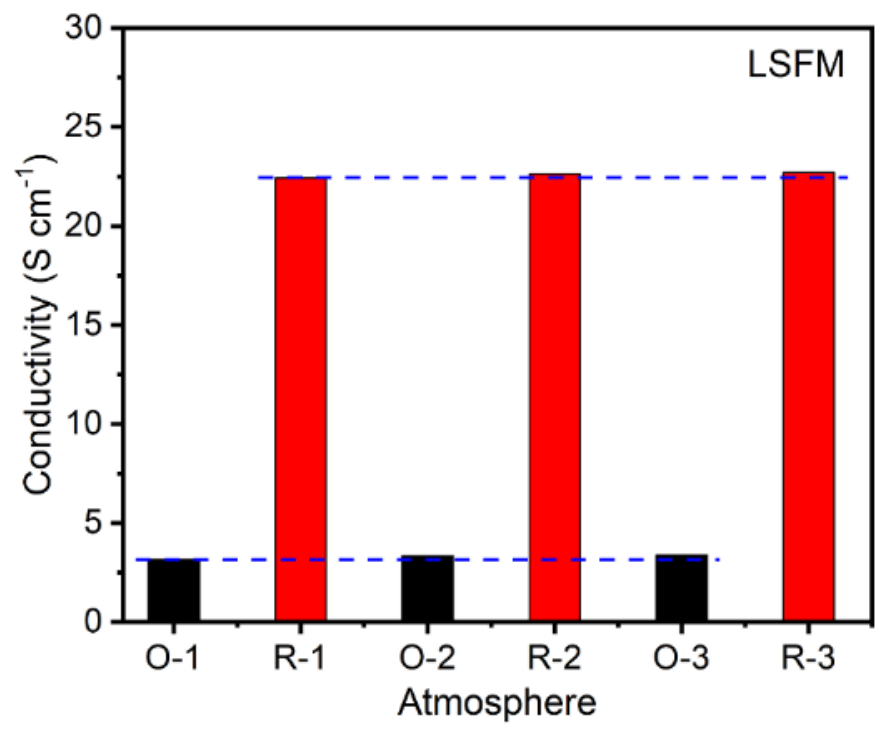

Figure 38. The conductivity of LSFM in three redox cycles.

\subsection{Chemical Compatibility of LSFM}

Previous literature has reported that $\mathrm{Sr}_{2} \mathrm{FeMoO}_{6}{ }^{103,105}, \mathrm{Sr}_{2} \mathrm{Fe}_{1.5} \mathrm{Mo}_{0.5} \mathrm{O}_{6}{ }^{109,}, 138$ and other similar compositions are all utilized with LSGM as the electrolyte. In this work, the chemical compatibility of LSFM with electrolytes under sintering condition (at $1150{ }^{\circ} \mathrm{C}$ in $\mathrm{N}_{2}$ for $2 \mathrm{~h}$ ) and operation condition (at $800{ }^{\circ} \mathrm{C}$ in $\mathrm{H}_{2}$ for $10 \mathrm{~h}$ ) are verified, respectively. First, mixture pellets were sintered at $1150{ }^{\circ} \mathrm{C}$ in nitrogen for $2 \mathrm{~h}$ and XRD patterns after treatment are shown in Figure 39a-c. The XRD pattern reveals that LSFM is very unstable with YSZ. During the sintering process, LSFM reacts severely with YSZ and decomposes into several oxides in a short time. The main peak of LSFM which should be at around $32.1^{\circ}$ disappeared after sintering. Besides YSZ, $\mathrm{SrMoO}_{4}, \mathrm{SrZrO}_{3}$, and $\mathrm{LaFeO}_{3}$ are also detected. LSFM shows perfect compatibility with both GDC and LSGM, as shown in Figure 39b-c. Based on this result, the chemical compatibility of LSFM with GDC and LSGM at operating condition $\left(800{ }^{\circ} \mathrm{C}, \mathrm{H}_{2}\right)$ are further evaluated. Mixture pellets of LSFM+GDC and LSFM+LSGM were sintered at $800{ }^{\circ} \mathrm{C}$ in hydrogen for $10 \mathrm{~h}$. Both GDC and LSGM exhibit good chemical compatibility with LSFM in hydrogen (Figure 39d-e). These results guarantee a clear electrode/electrolyte interface as well as a clean LSFM-GDC composite electrode during sintering and 
operation process. Based on the favorable compatibility with LSFM, LSGM will be applied as the electrolyte without GDC barrier layer.
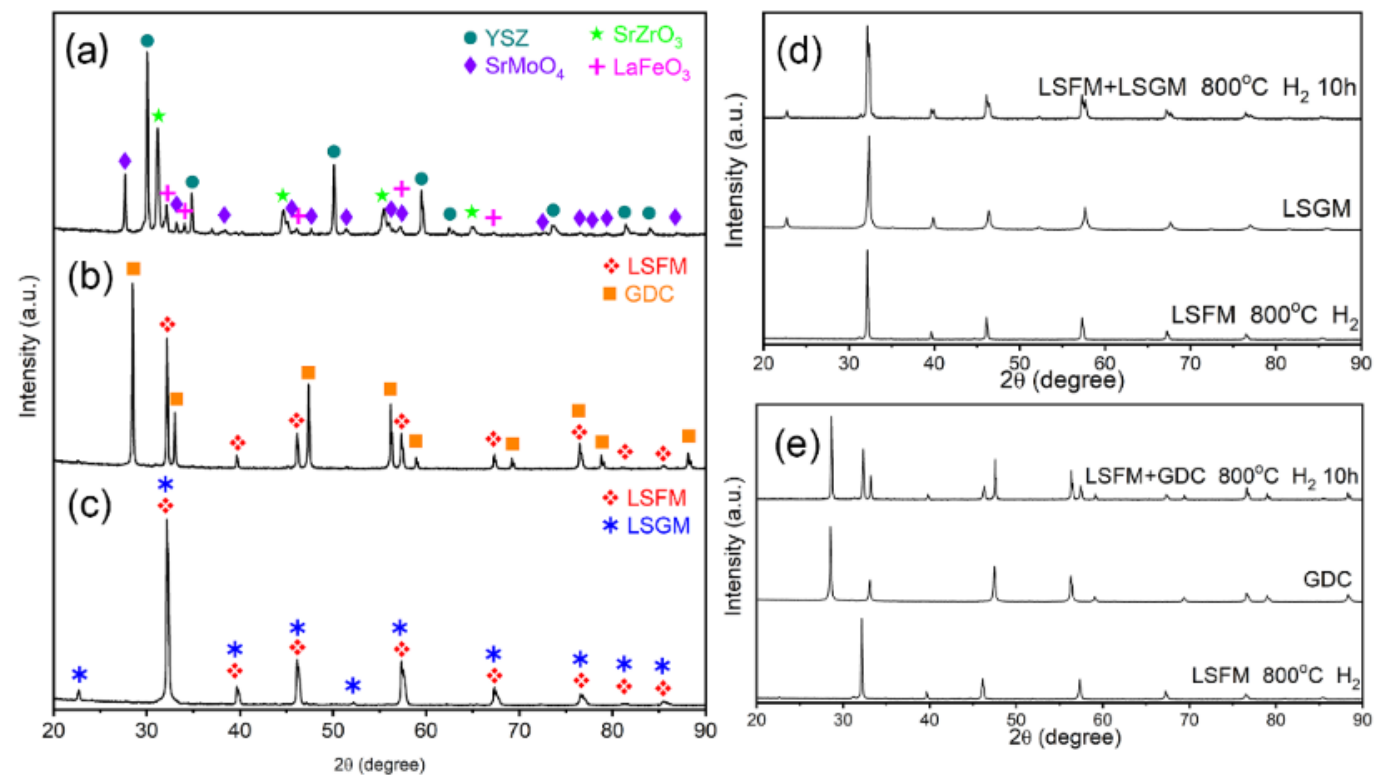

Figure 39. XRD patterns of (a) LSFM + YSZ, (b) LSFM + GDC, (c) LSFM + LSGM mixtures sintered at $1150{ }^{\circ} \mathrm{C}$ in $\mathrm{N}_{2}$ for $2 \mathrm{~h}$ and (d) LSFM+GDC, (e) LSFM+LSGM mixtures sintered at $800{ }^{\circ} \mathrm{C}$ in $\mathrm{H}_{2}$ for $10 \mathrm{~h}$.

\subsection{Electrochemical Performance of LSFM}

\subsubsection{Symmetrical Cell Performance}

After screen printing and sintering, the thickness of the porous electrode is about $30 \mu \mathrm{m}$ (Figure 40a). As reported by Watanabe et al. ${ }^{172}$ and Xiong et al. ${ }^{173}$, platinum can dramatically promote a cell's electrochemical performance. Specifically, the vaporization of platinum will take place above $600{ }^{\circ} \mathrm{C} . \mathrm{PtO}_{2}$, as vapor species, will be reduced to metal again and redeposit on the electrode surface. During this vaporization-deposition process, platinum prefers to deposit around the TPBs area and contributes to an attractive performance due to its excellent catalytic ability. According to Xiong's work, this vaporizationdeposition phenomenon has been confirmed by the long-term experiments in which the deposition of platinum around the TPBs is observed by elemental mappings on the cross section of LSF/ScSZ interface. In order to avoid extra performance promotion from platinum, the silver current collector was applied to all 
cells in this work. The morphology of the silver current collector after sintering at $800{ }^{\circ} \mathrm{C}$ is given in Figure 40b. The silver current collector is porous and uniform which leaves enough space for fuel (wet $\left.\mathrm{H}_{2}\right)$ to saturate the electrode while also allowing the product $\left(\mathrm{H}_{2} \mathrm{O}\right)$ to leave the electrode.
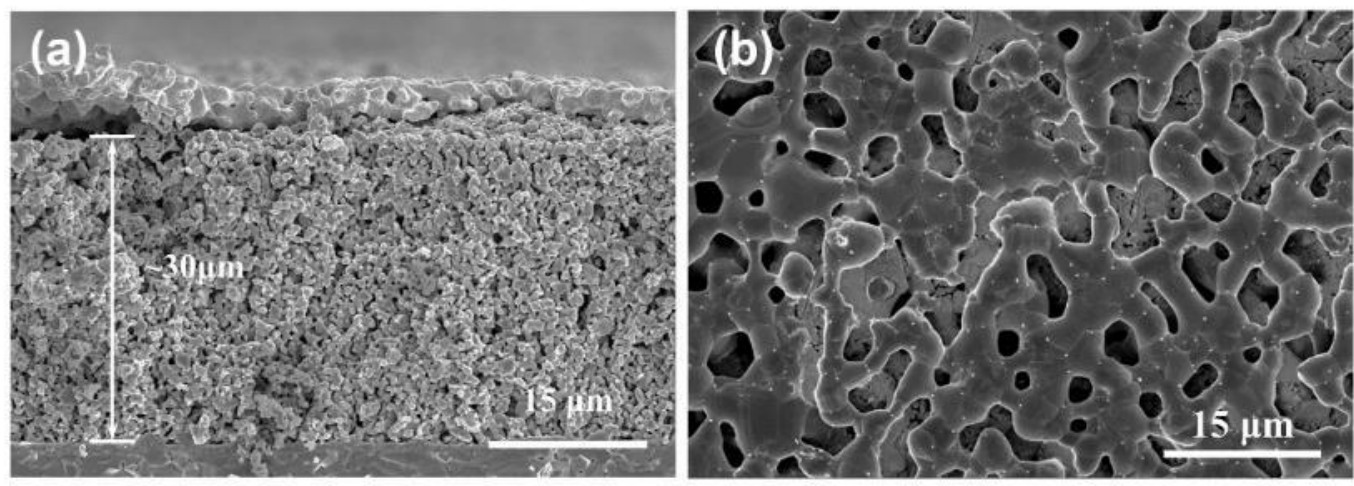

Figure 40. SEM images of (a) the cross section of LSFM/LSGM/LSFM symmetrical cell, (b) the porous Ag current collector.

The polarization resistance $\left(\mathrm{R}_{\mathrm{p}}\right)$ of anode material in SOFCs is an effective parameter to assess the catalytic activity on the hydrogen oxidation reaction (HOR). Figure 41a is the Nyquist plot of LSFM/LSGM/LSFM symmetrical cell from $700{ }^{\circ} \mathrm{C}$ to $800{ }^{\circ} \mathrm{C}$ in wet $\mathrm{H}_{2}$. An attractive polarization resistance is obtained at 800 ${ }^{\circ} \mathrm{C}$ as $0.16 \Omega \mathrm{cm}^{2}$. This performance is prominent compared with that of $\operatorname{Sr}_{2} \mathrm{Fe}_{1.5} \mathrm{Mo}_{0.5} \mathrm{O}_{6-\delta}, \mathrm{Sr}_{1.9} \mathrm{MgMoO}_{6-\delta}$ and other ceramic anodes published in recent years and also competitive with that of ceramic+SDC composite anodes, as shown in Table 6. The activation energy ( $\left.E_{a}\right)$ of LSFM is $1.2 \mathrm{eV}$ (Figure 41b). This value is comparable with similar ceramic materials, such as $\mathrm{Sr}_{2} \mathrm{Fe}_{1.5} \mathrm{Mo}_{0.5} \mathrm{O}_{6-\delta}(1.07 \mathrm{eV})^{161}, \mathrm{Ba}_{2} \mathrm{PrMoO}_{6-\delta}$ $(1.09 \mathrm{eV})^{174}, \mathrm{Sr}_{2} \mathrm{Mg}\left(\mathrm{Mo}_{0.8} \mathrm{Nb}_{0.2}\right) \mathrm{O}_{6-\delta}(1.16 \mathrm{eV})^{74}, \mathrm{Ba}_{2} \mathrm{NdMoO}_{6-\delta}(1.19 \mathrm{eV})^{174}$ and $\mathrm{Sr}_{2} \mathrm{FeTi}_{0.75} \mathrm{Mo}_{0.25} \mathrm{O}_{6-\delta}(1.27$ $\mathrm{eV})^{76}$. 

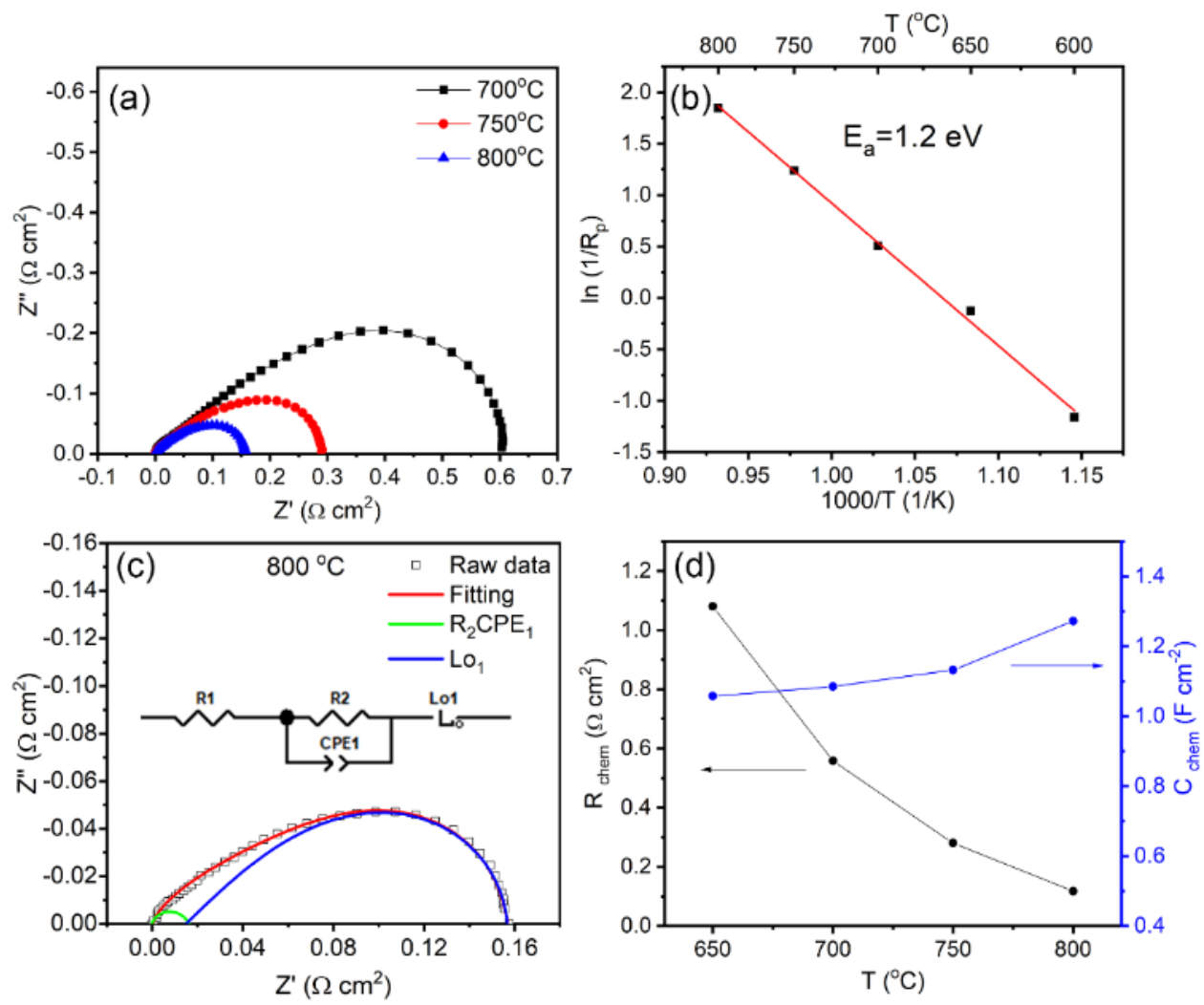

Figure 41. Symmetrical cell LSFM/LSGM/LSFM tested in wet $\mathrm{H}_{2}$ from 600 to $800{ }^{\circ} \mathrm{C}$ : (a) Nyquist plots of impedance from 700 to $800{ }^{\circ} \mathrm{C}$. the ohmic resistance $\mathrm{R}_{1}$ is subtracted from the impedance plot. (b) Arrhenius plot and activation energy. (c) Raw data and fitting line at $800{ }^{\circ} \mathrm{C}$. The equivalent circuit is shown in the inset. (d) $R_{\text {chem }}$ and $C_{\text {chem }}$ as a function of temperature.

Table 6. Comparison of polarization resistance of ceramic anodes in wet $\mathrm{H}_{2}$.

\begin{tabular}{cccc}
\hline \hline Material & $\mathrm{R}_{\mathrm{p}}\left(\Omega \mathrm{cm}^{2}\right)$ & Temperature $\left({ }^{\circ} \mathrm{C}\right)$ & Ref. \\
\hline $\mathrm{SF} 1.5 \mathrm{M}$ & 0.356 & 800 & 161 \\
$\mathrm{SF} 1.5 \mathrm{M}$ & 0.27 & 800 & 109 \\
$\mathrm{Sr}_{1.9} \mathrm{MgMoO}_{6-\delta}$ & 0.32 & 800 & 175 \\
$\mathrm{La}_{0.75} \mathrm{Sr}_{0.25} \mathrm{Cr}_{0.5} \mathrm{Mn}_{0.5} \mathrm{O}_{3}$ & 0.26 & 900 & 176 \\
$\mathrm{Gd}_{2} \mathrm{Ti}_{1.4} \mathrm{Mo}_{0.6} \mathrm{O}_{7}$ & 0.2 & 950 & 177 \\
$\mathrm{LSFM}^{\mathrm{S}}$ & 0.16 & 800 & This work \\
$\mathrm{YSZ}+\mathrm{SF} 1.5 \mathrm{M}$ (infiltration) & 0.235 & 800 & 107 \\
$\mathrm{SF} 1.5 \mathrm{M}+20 \%-50 \% \mathrm{SDC}$ & 0.16 & 800 & 161 \\
$\mathrm{SF} 1.5 \mathrm{M}+\mathrm{SDC}$ & 0.15 & 800 & 178 \\
\hline \hline
\end{tabular}


As shown in Figure 41a, the impedance spectroscopy of LSFM symmetrical cell is a half-tear-drop-shaped impedance which is composed of a diagonal of about $45^{\circ}$ at the high-frequency region and followed by a semi-circle at the low-frequency region. The half-tear-drop-shaped impedance arises from a co-limitation of surface oxygen exchange and oxygen bulk diffusion in oxygen reduction reaction (ORR) or hydrogen oxidation reaction (HOR). This phenomenon is first reported based on ORR and then reviewed by Adler ${ }^{179}$. When electrode presents a facile solid-state diffusion and the electrochemical process is only limited by the oxygen exchange at surface, the impedance is composed of several semicircles and can be fitted by equivalent circuits such as $R_{s}\left(R_{1} C_{1}\right)\left(R_{2} C_{2}\right)$. However, if solid-state diffusion is slowed down or surface oxygen exchange rate is promoted, at some point the electrochemical process will be co-limited by the surface reaction and the bulk diffusion. In that case, the impedance will transform from a semicircle shape to a half-tear-drop shape. This co-limitation process can be described as:

$$
\begin{gathered}
Z_{\text {chem }}=\frac{R_{\text {chem }}}{\sqrt{1+\left(j \omega t_{\text {chem }}\right)^{\alpha}}} \\
C_{\text {chem }}=\frac{t_{\text {chem }}}{R_{\text {chem }}} \\
f=\frac{\left(-\partial \mu_{O_{2}} / \partial \delta\right)}{R T} \\
C_{\text {chem }}=\frac{4 F^{2}}{R T} \frac{(1-\varepsilon) l_{\delta}}{f V_{m}}=\frac{4 F^{2}(1-\varepsilon) l_{\delta}}{V_{m}}\left(-\frac{\partial \mu_{O_{2}}}{\partial \delta}\right)^{-1}
\end{gathered}
$$

Where $Z_{c h e m}$ is the chemical impedance co-limited by surface oxygen exchange and solid-state diffusion. $R_{\text {chem }}$ is the characteristic resistance from the chemical reaction. $t_{\text {chem }}$ is the characteristic time. $f$ is a thermodynamic factor reflecting the ease with which to change the stoichiometry $(\delta)$ in a given change of $\mathrm{P}_{\mathrm{O} 2} . \varepsilon$ is the porosity of the electrode. $l_{\delta}$ is the characteristic "utilization" length which indicates the thickness of the active region in a porous electrode, normally at a range of several micrometers. $V_{m}$ is the molar volume of the electrode. $C_{\text {chem }}$ is the chemical capacitance related to the bulk oxidation/reaction of the material and usually very large. As shown by Kawada et al. ${ }^{180}$, for a very thin $(1.5 \mu \mathrm{m}) \mathrm{La}_{0.6} \mathrm{Sr}_{0.4} \mathrm{CoO}_{3-\delta}$ 
mixed-conducting film the chemical capacitance is about $0.1-1 \mathrm{~F} \mathrm{~cm}^{-2}$. This value is about three orders larger than the oxygen adsorption and transport dominated pseudocapacitance of $\mathrm{Pt}\left(\sim 10^{-3} \mathrm{~F} \mathrm{~cm}^{-2}\right)$ and five orders larger than the interfacial polarization capacitance of the Pt/YSZ interface $\left(10^{-6}-10^{-5} \mathrm{~F} \mathrm{~cm}^{-2}\right)$.
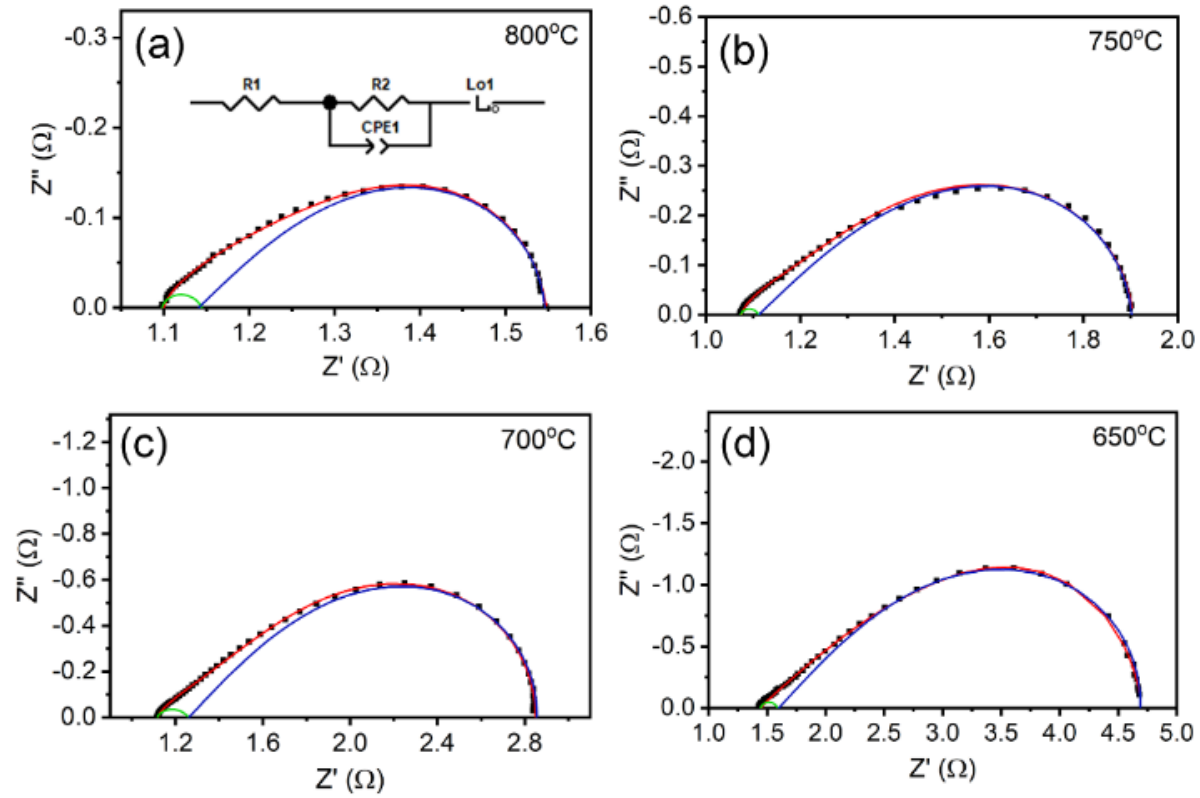

Figure 42. Nyquist plot of LSFM symmetrical cell (black dots) and fitting lines obtained in humidified $\mathrm{H}_{2}$ at (a) $800{ }^{\circ} \mathrm{C}$, (b) 750 ${ }^{\circ} \mathrm{C}$, (c) $700{ }^{\circ} \mathrm{C}$ and (d) $650{ }^{\circ} \mathrm{C}$.

From the view of oxygen diffusion in the bulk and oxygen exchange at surface, HOR is similar to ORR. In that case, we applied the co-limited theory on the anode. Impedances of LSFM symmetrical cell are fitted well (Figure 41c) with $\mathrm{R}_{1}\left(\mathrm{R}_{2} \mathrm{CPE}_{1}\right) \mathrm{Lo}_{1}$ equivalent circuit (inset in Figure $41 \mathrm{c}$ ). $\mathrm{R}_{1}$ presents ohmic resistance from electrolyte resistance and electrode ohmic resistance ${ }^{107}$ (subtracted from the impedance plot). The green semicircle (Figure 41c and Figure 42) in the high-frequency region corresponds to the oxygen ion transfer process at the electrode/electrolyte interface $\left(\mathrm{R}_{2} \mathrm{CPE}_{1}\right)^{181-182}$. The blue half-tear-drop curve (Figure 41c and Figure 42) in the low-frequency region presents the oxygen bulk diffusion and surface chemical exchange (gas adsorption, dissociation, and oxygen exchange) co-limited process $\left(\mathrm{Lo}_{1}\right)^{179,183-184} . R_{\text {chem }}$ and $C_{c h e m}$ as a function of temperature are plotted in Figure $41 \mathrm{~d}$. As expected, $R_{\text {chem }}$ decreases as the temperature increases, which implies faster surface kinetics at a higher temperature. Chemical capacitance $C_{\text {chem }}$ 
calculated from fitting result is very large $\left(1-1.3 \mathrm{~F} \mathrm{~cm}^{-2}\right)$ which accords with Kawada's result. ${ }^{180}$. From the proportional relationship between $C_{c h e m}$ and $l_{\delta}\left(C_{c h e m} \propto l_{\delta}\right)$ from Eq. (25), the increase of $C_{c h e m}$ with temperature illustrates an expansion of active region in the porous electrode. Furthermore, the size of the active region is estimated. Calculated from Rietveld refinement, the molar volume $V_{m}$ of this material is $73.41 \mathrm{~cm}^{3} \mathrm{~mol}^{-1}$. According to the literature ${ }^{145,185-186}$, the thermodynamic factor $f$ is estimated as 10 , and the porosity of the electrode $\varepsilon$ is 0.5 . From Eq. (25) the size of the active region $l_{\delta}$ is about $4.5 \mu \mathrm{m}$ at $800{ }^{\circ} \mathrm{C}$ and consistent with the typical values $(3-5 \mu \mathrm{m})^{179}$. This value demonstrates that a large portion of the electrode surface is active for HOR, which indicates some level of ionic conductivity, a good catalytic activity and a sufficient electrical conductivity of LSFM.

\subsubsection{Single Cell Performance}

Full cell performance of the LSFM single phase anode was evaluated on an LSGM electrolyte- supported cell operated in humidified hydrogen from 700 to $800{ }^{\circ} \mathrm{C}$. LSCF single phase was applied as the cathode. Current-Voltage (I-V) and Current-Power density (I-P) curves are shown in Figure 43. The open circuit voltages $(\mathrm{OCV})$ are 1.09-1.10 V at operating temperatures. Such high values, which are very close to the theoretical OCV $\left(1.10 \mathrm{~V} \text { at } 800{ }^{\circ} \mathrm{C} \text { and } 1.12 \mathrm{~V} \text { at } 700{ }^{\circ} \mathrm{C} \text { in humidified } \mathrm{H}_{2}\right)^{187}$ calculated from the Nernst equation, confirm a well-formed dense LSGM electrolyte and good sealing of the cell. The maximum power density $\left(\mathrm{P}_{\max }\right)$ achieved at 700,750 and $800{ }^{\circ} \mathrm{C}$ are 329,693 and $1156 \mathrm{~mW} \mathrm{~cm}{ }^{-2}$, respectively. To the best of our knowledge, this value is higher than cells employing undoped $\operatorname{Sr}_{2} \mathrm{Fe}_{1.5} \mathrm{Mo}_{0.5} \mathrm{O}_{6-\delta}(\mathrm{SF} 1.5 \mathrm{M})$ single phase or SF1.5M+GDC/YSZ composite as anodes reported to date and can be comparable to the performance of many other promising ceramic anodes under similar conditions (Table 7). The high electrical conductivity and good electrochemical performance are responsible for high power density. 


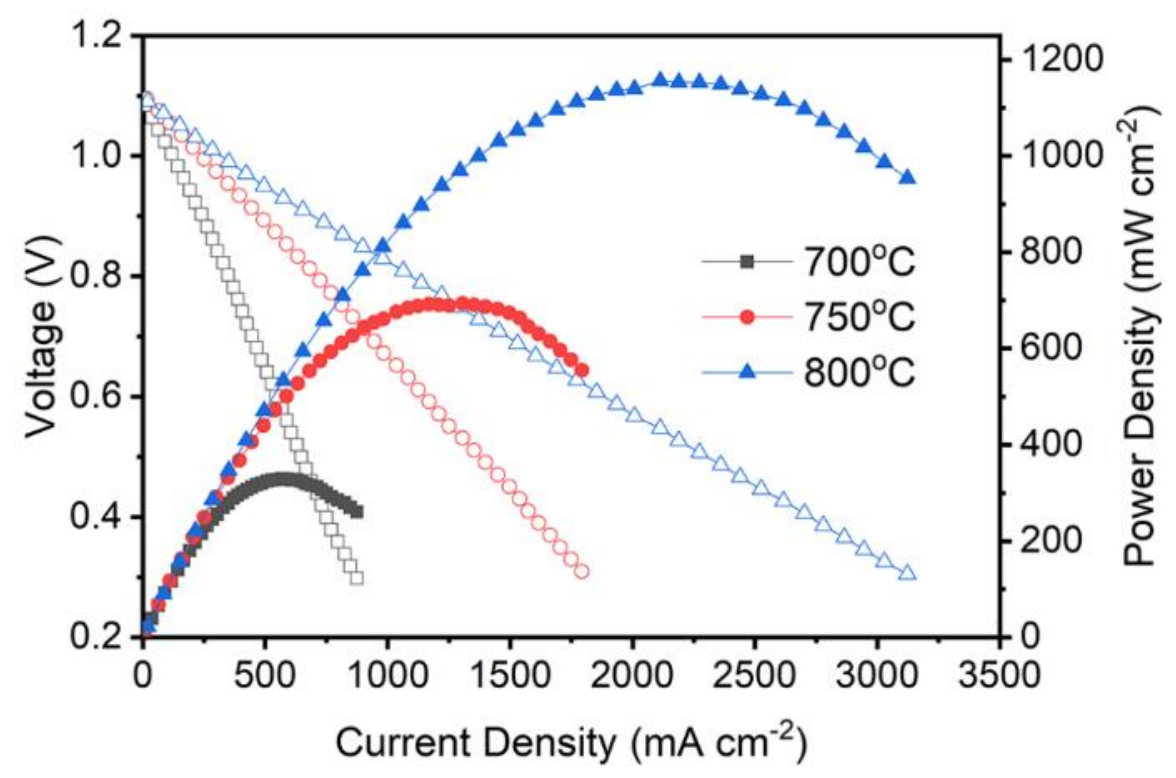

Figure 43. Voltage (open symbols) and power density (filled symbols) as a function of current density for an electrolytesupported single cell LSCF/LSGM/LSFM under humidified $\mathrm{H}_{2}$ from $700{ }^{\circ} \mathrm{C}$ to $800^{\circ} \mathrm{C}$.

It should be noted that the power density of BSCF/LSGM/SFM single cell in humidified $\mathrm{H}_{2}$ at $800{ }^{\circ} \mathrm{C}$ is about $600 \mathrm{~mW} \mathrm{~cm}^{-2}$, much lower than LSCF/LSGM/LSFM single cell tested in the same condition. Exclude any fact in cell fabrication and any difference from the cathode which could affect the cell performance, the electrochemical performance of LSFM can be approximately considered similar, if not much better than SFM. Considering the huge difference of conductivity between LSFM $\left(23 \mathrm{~S} \mathrm{~cm}^{-1}\right)$ and SFM $\left(150 \mathrm{~S} \mathrm{~cm}^{-1}\right)$, it seems that conductivity is not that critical to an excellent power density. Maybe influenced by Ni-YSZ cermet anode which displays the conductivity of about $10^{2}-10^{3} \mathrm{~S} \mathrm{~cm}^{-1}$ in $\mathrm{H}_{2}$, a lot of literature emphasized the importance of conductivity, especially electrical conductivity, to an anode material ${ }^{50,188}$. Also, a lot of work has been down to improve the conductivity of anode materials, such as LST and related compositions. Based on our research on LSFM, 10-20 S cm$~_{-1}$ seems to be enough to support a favorable power density. More efforts should be focused on how to improve the ionic conductivity and catalytic activity of anode candidates. For an MIEC anode, a proper ionic conductivity and matched surface catalytic activity can expand the reaction zone from electrolyte/electrode interface to the whole anode surface which would improve the utilization of anode and achieve a decent cell performance. 
Table 7. The maximum power density of anode materials with wet $\mathrm{H}_{2}$ at $800{ }^{\circ} \mathrm{C}$.

\begin{tabular}{|c|c|c|c|}
\hline Material & Cathode & $\mathrm{P}_{\max }\left(\mathrm{mW} \mathrm{cm} \mathrm{cm}^{-2}\right)$ & Ref. \\
\hline \multirow{6}{*}{$\mathrm{SF} 1.5 \mathrm{M}$} & $\mathrm{La}_{0.6} \mathrm{Sr}_{0.4} \mathrm{Co}_{0.2} \mathrm{Fe}_{0.8} \mathrm{O}_{3-\delta}$ & 291 & 189 \\
\hline & $\mathrm{Ba}_{0.5} \mathrm{Sr}_{0.5} \mathrm{Co}_{0.8} \mathrm{Fe}_{0.2} \mathrm{O}_{3-\delta}$ & 520 & 190 \\
\hline & $\mathrm{SF} 1.5 \mathrm{M}$ & 500 & 109 \\
\hline & $\mathrm{SF} 1.5 \mathrm{M}$ & 500 & 191 \\
\hline & $\mathrm{SF} 1.5 \mathrm{M}$ & 530 & 75 \\
\hline & $\mathrm{Sr}_{2} \mathrm{Fe}_{1.4} \mathrm{Ni}_{0.1} \mathrm{Mo}_{0.5} \mathrm{O}_{6-\delta}$ & 260 & 192 \\
\hline $\mathrm{SF} 1.5 \mathrm{M}+\mathrm{SDC}$ & $\mathrm{SF} 1.5 \mathrm{M}+\mathrm{SDC}$ & 500 & 193 \\
\hline YSZ+SF1.5M (infiltration) & $\begin{array}{c}\mathrm{YSZ}+\mathrm{La}_{0.6} \mathrm{Sr}_{0.4} \mathrm{Fe}_{0.9} \mathrm{Sc}_{0.1} \mathrm{O}_{3-\delta} \\
\text { (infiltration) }\end{array}$ & 462 & 107 \\
\hline YSZ+SF1.5M (infiltration) & YSZ+SF1.5M (infiltration) & 1030 & 194 \\
\hline $\mathrm{Sr}_{2} \mathrm{FeMoO}_{6-\delta}$ & $\mathrm{Ba}_{0.5} \mathrm{Sr}_{0.5} \mathrm{Co}_{0.8} \mathrm{Fe}_{0.2} \mathrm{O}_{3-\delta}$ & 600 & 105 \\
\hline $\mathrm{Sr}_{2} \mathrm{CoMoO}_{6-\delta}$ & \multirow{2}{*}{$\mathrm{SrCo}_{0.8} \mathrm{Fe}_{0.2} \mathrm{O}_{3}$} & 735 & \multirow{2}{*}{135} \\
\hline $\mathrm{Sr}_{2} \mathrm{NiMoO}_{6-\delta}$ & & 500 & \\
\hline $\mathrm{Sr}_{2} \mathrm{NiMoO}_{6-\delta}$ & $\mathrm{Ba}_{0.5} \mathrm{Sr}_{0.5} \mathrm{Co}_{0.8} \mathrm{Fe}_{0.2} \mathrm{O}_{3-\delta}$ & 595 & 136 \\
\hline $\mathrm{Sr}_{2} \mathrm{Fe}_{1.4} \mathrm{Ni}_{0.1} \mathrm{Mo}_{0.5} \mathrm{O}_{6-\delta}$ & $\mathrm{Sr}_{2} \mathrm{Fe}_{1.4} \mathrm{Ni}_{0.1} \mathrm{Mo}_{0.5} \mathrm{O}_{6-\delta}$ & 530 & 192 \\
\hline$(\mathrm{PrBa})_{0.95}\left(\mathrm{Fe}_{0.9} \mathrm{Nb}_{0.1}\right)_{2} \mathrm{O}_{5+\delta}$ & $\mathrm{PrBaCO}_{2} \mathrm{O}_{5+\delta}$ & 1050 & 195 \\
\hline $\mathrm{Pr}_{0.5} \mathrm{Ba}_{0.5} \mathrm{MnO}_{3}$ & $\begin{array}{c}\mathrm{NdBa}_{0.5} \mathrm{Sr}_{0.5} \mathrm{Co}_{1.5} \mathrm{Fe}_{0.5} \mathrm{O}_{5+\delta}+ \\
\mathrm{Ce}_{0.9} \mathrm{Gd}_{0.1} \mathrm{O}_{2-\delta}\end{array}$ & 1070 & 196 \\
\hline LSFM & $\left(\mathrm{La}_{0.6} \mathrm{Sr}_{0.4}\right)_{0.95} \mathrm{Co}_{0.2} \mathrm{Fe}_{0.8} \mathrm{O}_{3-\delta}$ & 1156 & This work \\
\hline
\end{tabular}

\subsection{Summary}

In this chapter, four compositions SFM, SF1.5M, SFCM, and LSFM are synthesized and investigated in order to develop a novel Ni-free ceramic anode material with excellent redox stability and good electrochemical performance.

In order to qualify a redox-stable material, phase stability in air and forming gas are studied. Except for SFM, the other three samples exhibit some stability. SF1.5M and LSFM display a good perovskite structure maintenance during redox cycles. A small amount of Co, however, dominate the phase stability of SFCM 
in $\mathrm{H}_{2}$ and result in a large-scale phase transition from perovskite to Ruddlesden-Popper phase. Combined with conductivity results in air and forming gas, element Co indicates an oxygen preference behavior which means Co prefer to contribute to a better performance in the oxidizing atmosphere rather than the reducing atmosphere.

Dilatometry technique is applied to examine the thermal expansion and chemical expansion behaviors of candidates. Except for SFM, all other three materials, and their related compositions exhibit normal behavior during heat up and subsequent redox cycles. Based on SF1.5M, Co-doped compositions display a higher CTE while La-doped compositions display a lower CTE. Different Fe:Mo ratio also contributes to CTE change. By thoughtful discussion, we reach the conclusion that in researched compositions, the M-O bond strength follows the relationship as $\mathrm{Mo}-\mathrm{O}>\mathrm{Fe}-\mathrm{O}>\mathrm{Co}-\mathrm{O}$ on B-site and La-O > Sr-O on A-site. In that case, the lower CTE, the smaller chemical expansion in $\mathrm{H}_{2}$ as well as the excellent volume reversibility during redox cycles should all benefit from the stronger La-O bond.

For electrical conductivity performance in a redox cycling, phase stability, volume reversibility and the contribution to electron cloud configuration of different metal elements should be involved. Both SF1.5M and LSFM exhibit high conductivity in forming gas and good reversibility in the redox environment. The slight conductivity decay of SF1.5M in second redox cycle probably because of microcracks formed by big chemical expansion in the first redox cycle. Compare with SF1.5M, LSFM presents a comparable conductivity in forming gas and perfect reversibility in three redox cycles. This demonstrates that La is neutral to an electrical conductivity performance but promotes the conductivity reversibility by providing a more stable crystal structure and a higher resistance to chemical expansion during redox cycling.

The half-tear-drop-shaped impedance spectra of LSFM symmetrical cell indicates that LSFM is a good MIEC material which possesses both high oxygen diffusion in bulk and fast oxygen exchange rate on surface. The perfect match of these two aspects expanded the reaction active zone from electrolyte/electrode interface to a large surface area with the thickness of several or even dozens of microns which depends on the thermal factor of LSFM, which the exact number is not sure yet. The maximum power density of 
LSCF/LSGM/LSFM single cell reaches $1156 \mathrm{~mW} \mathrm{~cm}^{-2}$ in humidified $\mathrm{H}_{2}$ at $800{ }^{\circ} \mathrm{C}$. This competitive performance benefits from high electrical conductivity, great ionic conductivity, and decent surface catalytic activity. 


\section{Chapter 5 In-situ Exsolution on LSFM and Promotion to the Electrochemical Performance}

The Solid-Oxide Fuel Cell (SOFC) is a clean energy conversion device which has become a promising technology to deal with serious energy issues and has received much attention over the last several decades 3,172, 197-198. In recent years, perovskite materials have emerged as promising anode candidates due to their notable performance, such as satisfactory electric and/or ionic conductivity, mild volume change during redox, and great resistance to carbon deposition and sulfur poisoning ${ }^{71-72}$. Nevertheless, the catalytic activity of perovskite materials is deficient compared with metals ( $\mathrm{Fe}, \mathrm{Co}, \mathrm{Ni})$.

Surface decoration is a useful and practical strategy to bridge this performance gap. As a commonly applied modification method on ceramics, the surface decoration is mainly committed to increase the number of active sites in a reaction zone and enhance the catalytic activity for a faster electrochemical reaction. One well-known surface decoration method is infiltration which can modify almost all ceramic materials with metals ( $\mathrm{Ni}^{199}, \mathrm{Cu}^{200}, \mathrm{Cu}-\mathrm{Ni}$ alloy ${ }^{201}$, etc. $)$ and oxides $\left(\mathrm{CeO}_{2}{ }^{8}, \mathrm{La}_{0.4875} \mathrm{Ca}_{0.0125} \mathrm{Ce}_{0.5} \mathrm{O}_{2-\delta}{ }^{9}\right.$ and so on). However, nonuniform distribution of infiltrated nanoparticles (NPs), coarsening of metal NPs and carbon deposition on metal NPs in hydrocarbon fuels largely impact performance stability ${ }^{115}$ in a short or long term SOFC operation. In view of these drawbacks, in-situ exsolution is proposed as an advanced surface modification concept which devoted to the high thermal stability of exsolved metal NPs and efficient applications ${ }^{115-116,}$ 162-163, 202. According to Neagu et al's work, exsolved NPs grow from the parent phase with a socket structure which can improve the connection strength between NPs and parent phase ${ }^{115}$. Benefit from this special structure, coarsening and agglomeration of exsolved metal particles are predominantly restrained during long-term utilization. For Ni particles, socket structure and a strong Ni-parent phase connection can also limit the tip growth pathway of carbon nanotubes and enhance the resistance to carbon coking. Though insitu exsolution has been reported in perovskite materials, the exsolution-dissolution reversibility of 
exsolved NPs in a redox environment has not been discussed. The exsolution process and the related electrochemical performance change along the way are still unclear.

\subsection{Exsolution Characterization}

\subsubsection{Exsolution Condition and Morphology}

Most metal exsolution happens in a strong reducing atmosphere (dry or humidified $\mathrm{H}_{2}$ ) at high temperature (normally higher than $700{ }^{\circ} \mathrm{C}$ ) and this rule is also applicable to LSFM. As shown in Figure 44, the XRD pattern of LSFM upon the $20 \mathrm{~h}$ reduction in $5 \% \mathrm{H}_{2}$ at $850{ }^{\circ} \mathrm{C}$ (Figure $44 \mathrm{~b}$ ) is the same with the synthesized material (Figure 44a). This result proved the good phase stability of LSFM in a low $\mathrm{P}_{\mathrm{H} 2}$ environment and guaranteed the accuracy and repeatability of ECR tests on LSFM in a low $\mathrm{P}_{\mathrm{H} 2}$ range. When LSFM powder was further subjected to a $5 \mathrm{~h}$ reduction in the pure $\mathrm{H}_{2}$ at $800{ }^{\circ} \mathrm{C}$, two minor new peaks can be detected by XRD (Figure 44c). The peak at $44.7^{\circ}$ corresponds to metal Fe (marked with a red star, JCPDS No. 06-0696), the one at $31.2^{\circ}$ may correspond to a $\mathrm{K}_{2} \mathrm{NiF}_{4}$-type structure composition (marked as purple diamond, according to Yang's report ${ }^{162}$ ).

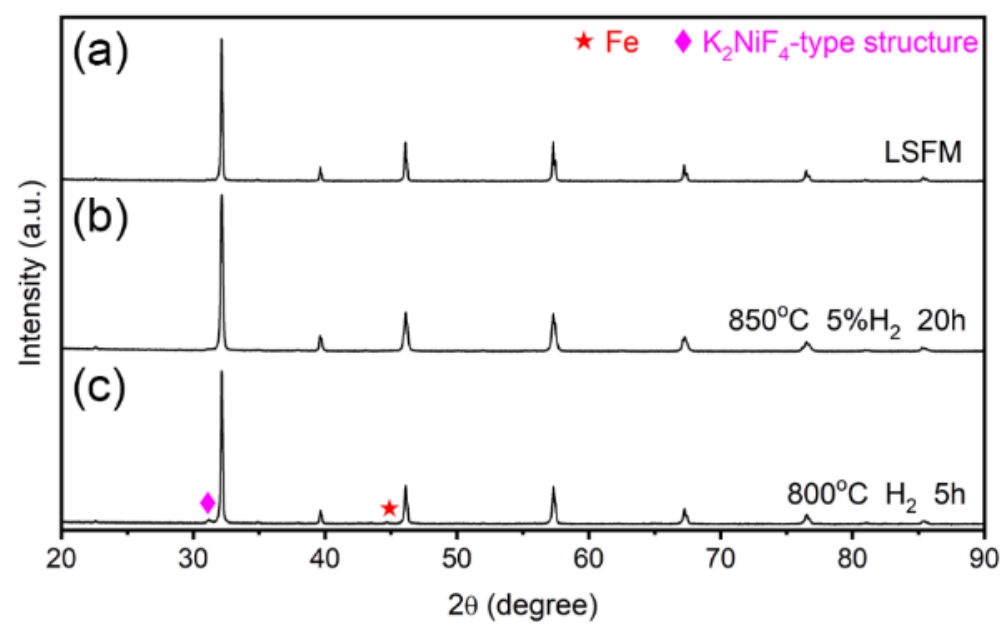

Figure 44. XRD patterns of LSFM: (a) as synthesized, (b) reduced in $5 \% \mathrm{H}_{2}$ at $850{ }^{\circ} \mathrm{C}$ for $20 \mathrm{~h}$ and (c) reduced in $\mathrm{H}_{2}$ at $800{ }^{\circ} \mathrm{C}$ for $5 \mathrm{~h}$. 
Besides XRD, SEM and XPS analysis were conducted upon as-synthesized and reduced LSFM powders to evaluate the morphology change as well as the surface composition evolution during the exsolution. Figure 45 included the SEM images of LSFM powder before and after reduction. Before reduction, the grain size is about $400 \mathrm{~nm}$, the grain boundaries are clear and smooth (Figure 45a). This morphology is maintained well during the reduction (Figure $45 \mathrm{~b}$ ) which indicates good main phase stability in $\mathrm{H}_{2}$. Exsolved NPs uniformly distributed on LSFM powder surface with an average particle size of $100 \mathrm{~nm}$. The average size of exsolved particles on different materials is about $50-150 \mathrm{~nm}$ from the literature ${ }^{114-115,121,124}$. Because of the faster diffusion rate of atoms along grain boundaries, most exsolved particles emerge along or near the grain boundaries.

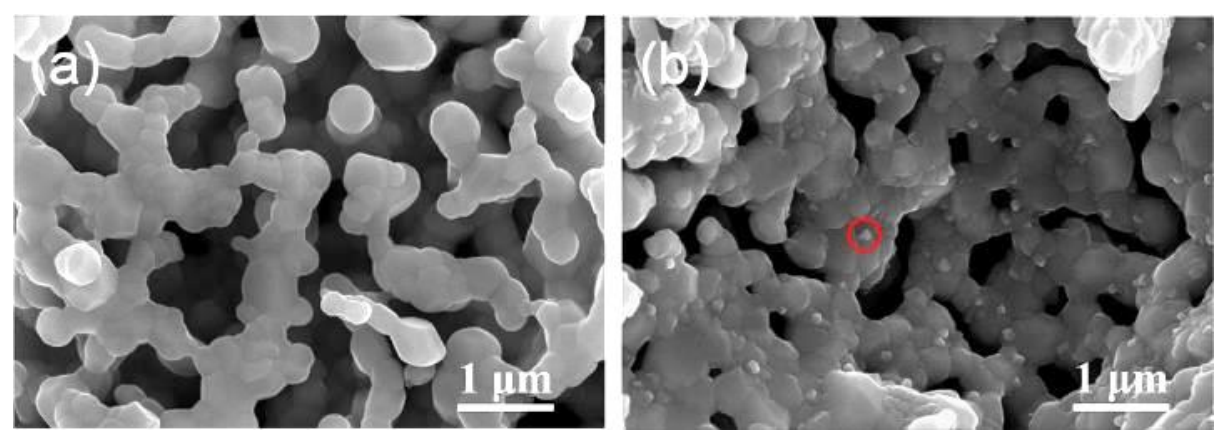

Figure 45. SEM of LSFM powders (a) as synthesized, (b) reduced in $\mathrm{H}_{2}$ at $800{ }^{\circ} \mathrm{C}$ for $5 \mathrm{~h}$.

\subsubsection{Identification of Phase Transition}

In order to analysis the surface condition change during reduction, ex-situ XPS analysis is carried out on LSFM powders before and after reduction treatment. $284.8 \mathrm{eV}$ is the reference value for $\mathrm{C}-\mathrm{C} / \mathrm{C}-\mathrm{H}$. The $\mathrm{Fe} 2 \mathrm{p}$ spectrum of synthesized LSFM is dominated by $\mathrm{Fe}^{3+}$ (Figure $46 \mathrm{a}$ ). After reducing in $\mathrm{H}_{2}$ at $800{ }^{\circ} \mathrm{C}$ for $5 \mathrm{~h}$, part of the $\mathrm{Fe}^{3+}$ cations are reduced to $\mathrm{Fe}^{2+}$ corresponding to the grown-up of $\mathrm{Fe}^{2+}$ peaks and the shrinkage of $\mathrm{Fe}^{3+}$ peaks. The new peak at around 706.2 eV (marked with a red star in Figure 46a) is assigned to $\mathrm{Fe}^{0}$ and indicates the existence of metal $\mathrm{Fe}$ after reducing. Similarly, according to Mo3d spectra in Figure 46b, $\mathrm{Mo}^{6+}$ cations are also partially reduced to $\mathrm{Mo}^{5+}$ in $\mathrm{H}_{2}$. However, no metal Mo was detected by XPS. 

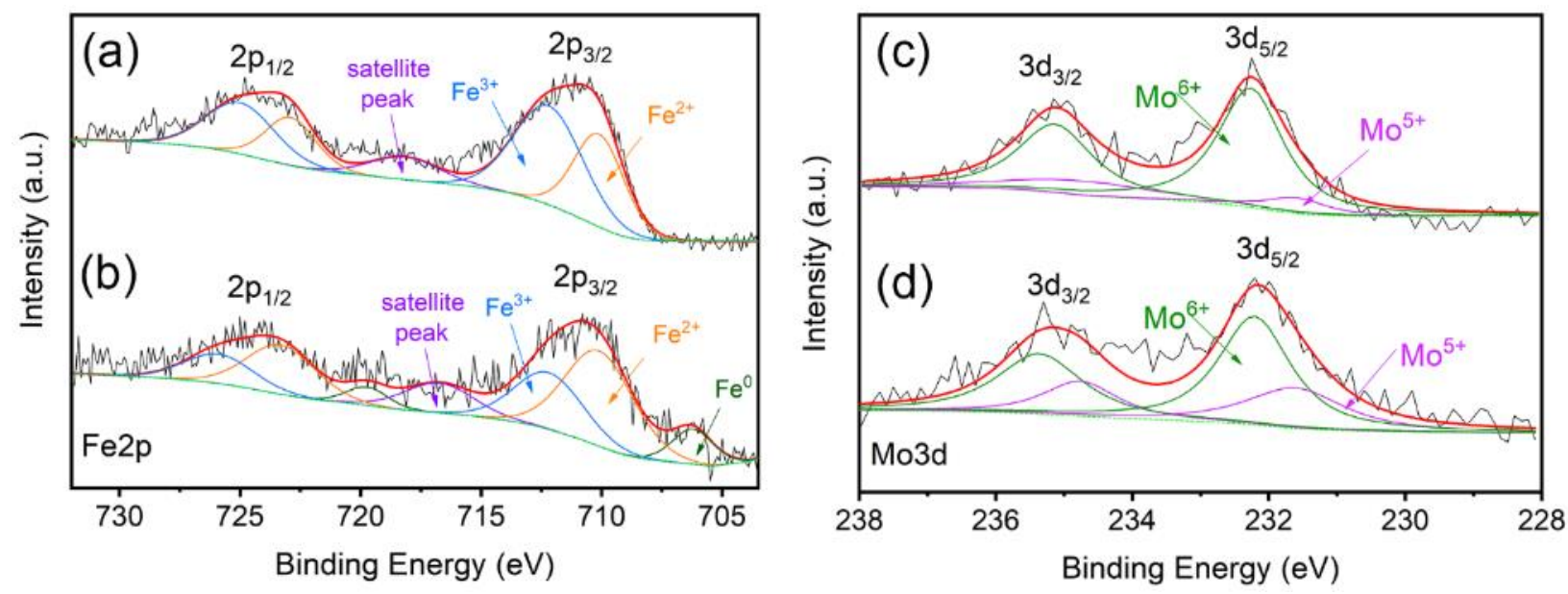

Figure 46. (a-b) Fe2p and (c-d) Mo3d spectra of LSFM. Spectra in (a, c) are collected from as-synthesized powders, spectra in (b, d) are collected after reduction in $\mathrm{H}_{2}$ at $800{ }^{\circ} \mathrm{C}$ for $5 \mathrm{~h}$.
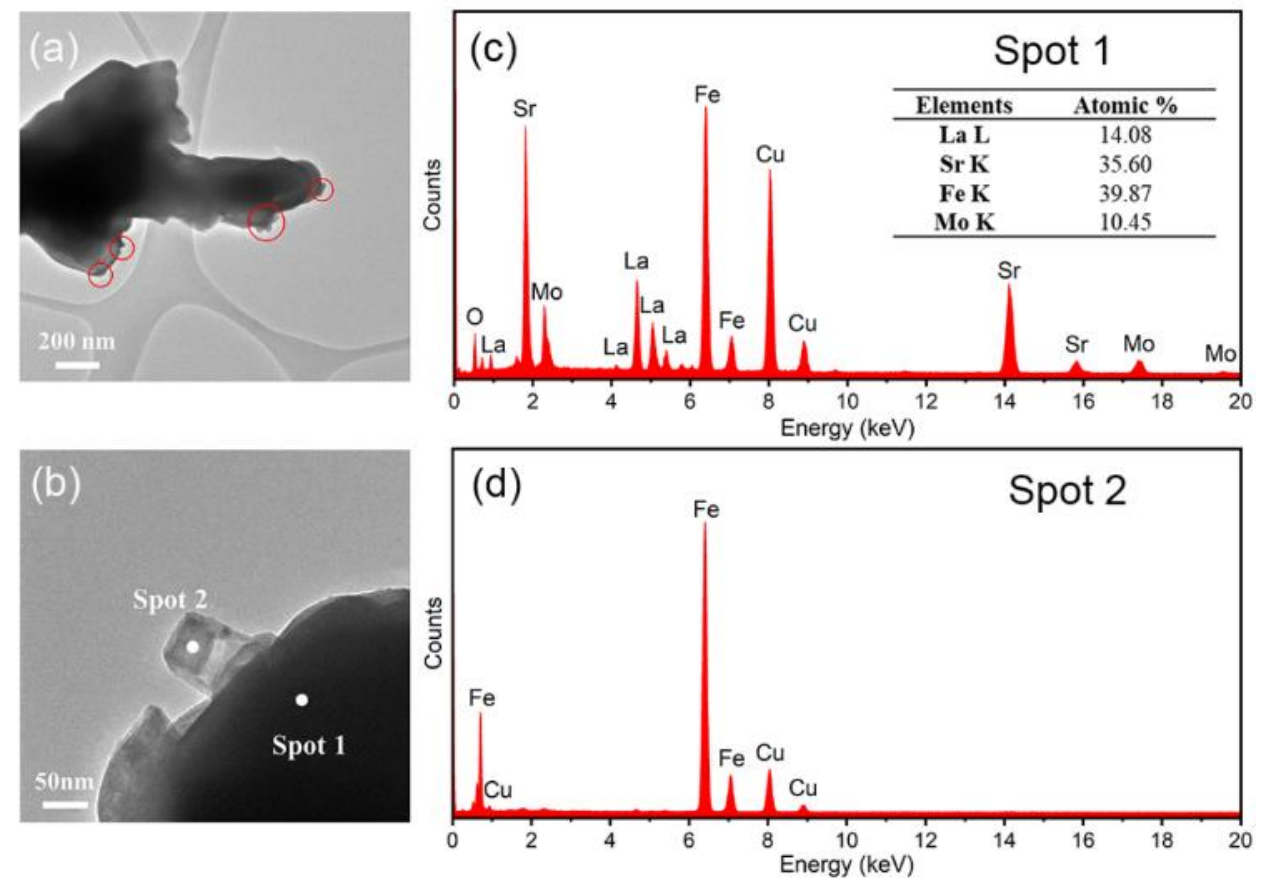

Figure 47. (a-b) TEM bright field images of LSFM with exsolved particles; (c) EDS plot and atomic concentration of the bulk; (d) EDS plot of the exsolved particle.

In order to eliminate the signal interference from the bulk and directly identify the composition of exsolved NPs, TEM and EDS would be the best choice. EDS spot analysis results on bulk (spot 1 in Figure 47b) and exsolved NP (spot 2 in Figure 47b) are given in Figure 47c-d. The atomic ratio of La:Sr:Fe:Mo on spot 1 is 
approximately 1:3:3:1 which is consistent with the composition of LSFM $\left(\mathrm{La}_{0.5} \mathrm{Sr}_{1.5} \mathrm{Fe}_{1.5} \mathrm{Mo}_{0.5} \mathrm{O}_{6-\delta}\right)$. On exsolved particle (spot 2), a strong Fe peak and the absence of $\mathrm{La}, \mathrm{Sr}, \mathrm{Mo}$, O elements suggest that the exsolved NP is pure Fe. A Cu signal belongs to the TEM Cu grid. Based on XPS and TEM results, we can safely say that after reducing in $\mathrm{H}_{2}$ at $800{ }^{\circ} \mathrm{C}$ for $5 \mathrm{~h}$, the exsolved NPs are pure Fe.
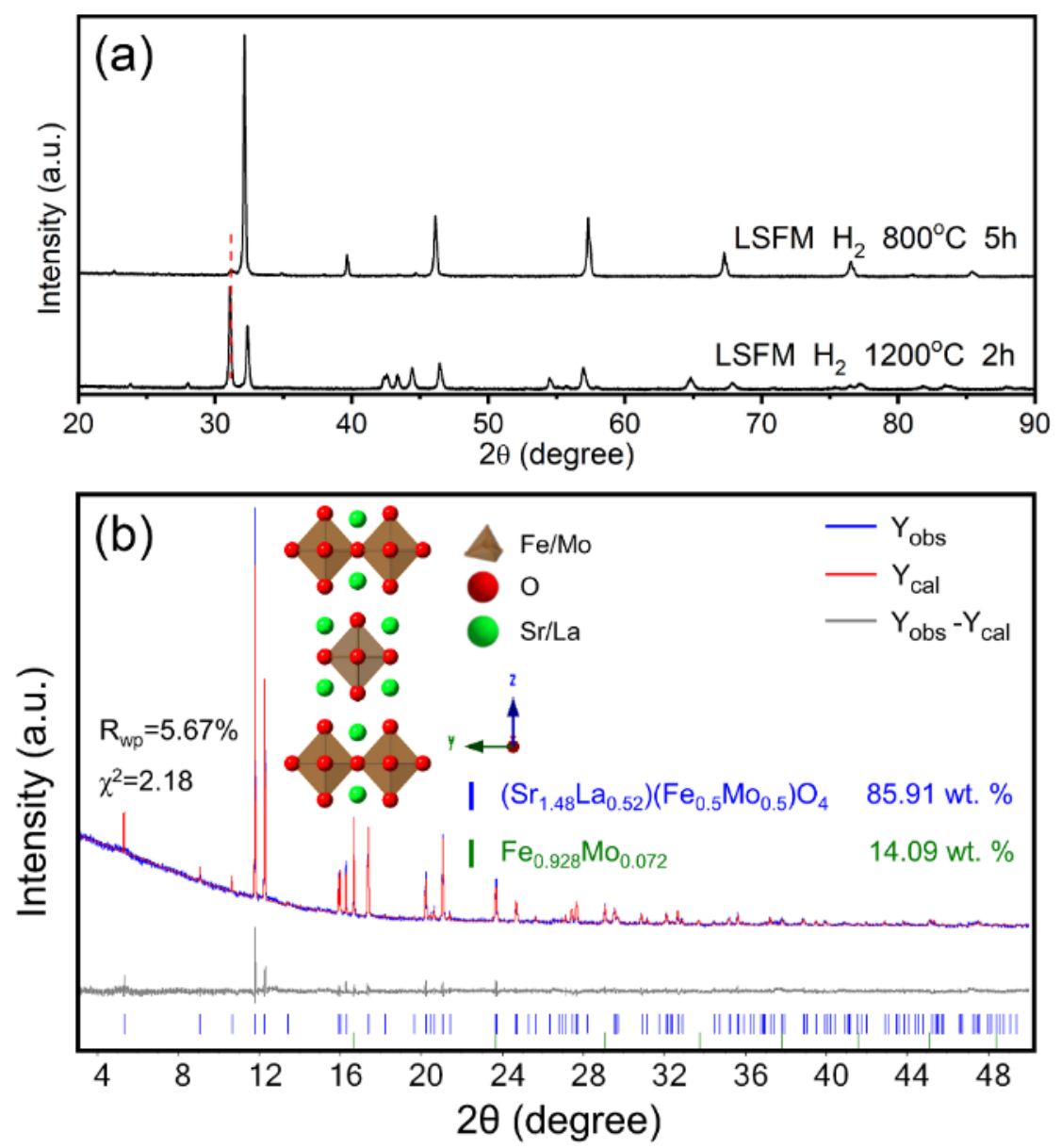

Figure 48. (a) XRD patterns of LSFM with partial $\left(\mathrm{H}_{2}, 800{ }^{\circ} \mathrm{C} 5 \mathrm{~h}\right)$ and total phase transition $\left(\mathrm{H}_{2}, 1200{ }^{\circ} \mathrm{C} 2 \mathrm{~h}\right)$, (b) Synchrotron XRD and Rietveld refinement of LSFM after total phase transition.

To identify the $\mathrm{K}_{2} \mathrm{NiF}_{4}$-type structure composition detected in Figure 44c, a thorough phase transition of LSFM was conducted in $\mathrm{H}_{2}$ at $1200{ }^{\circ} \mathrm{C}$ for $2 \mathrm{~h}$. The treated powder was then characterized by EDS, XRD $(\mathrm{Cu} \mathrm{K} \alpha)$ and synchrotron XRD. In EDS analysis, all the elements can be detected and the atomic ratio of La:Sr:Fe:Mo is close to 1:3:3:1 (Figure 49a). After reducing in $\mathrm{H}_{2}$ at $1200{ }^{\circ} \mathrm{C}$ for $2 \mathrm{~h}$, the XRD pattern of LSFM (Figure 48a) is very different from a perovskite structure. The main peak of the totally reduced 
LSFM (reduced at $1200{ }^{\circ} \mathrm{C}$ ) overlap the tiny peak of the partially reduced LSFM (reduced at $800{ }^{\circ} \mathrm{C}$ ) at $31.2^{\circ}$. As no peak splitting can be observed from the synchrotron XRD pattern, the totally reduced sample should contain only one RP phase and one metal phase. Depending on the Rietveld refinement, the 1200 ${ }^{\circ} \mathrm{C}$ reduced sample contains RP phase $\mathrm{La}_{0.52} \mathrm{Sr}_{1.48} \mathrm{Fe}_{0.5} \mathrm{Mo}_{0.5} \mathrm{O}_{4}$ and metal alloy $\mathrm{Fe}_{0.928} \mathrm{Mo}_{0.072}$ (Figure 48b), the moral ratio of two components is $0.51: 0.49$, close to $1: 1$. After converting the synchrotron data to the corresponding $\mathrm{Cu} \mathrm{K} \alpha$ radiation, the two XRD patterns show a great match (Figure 49b).
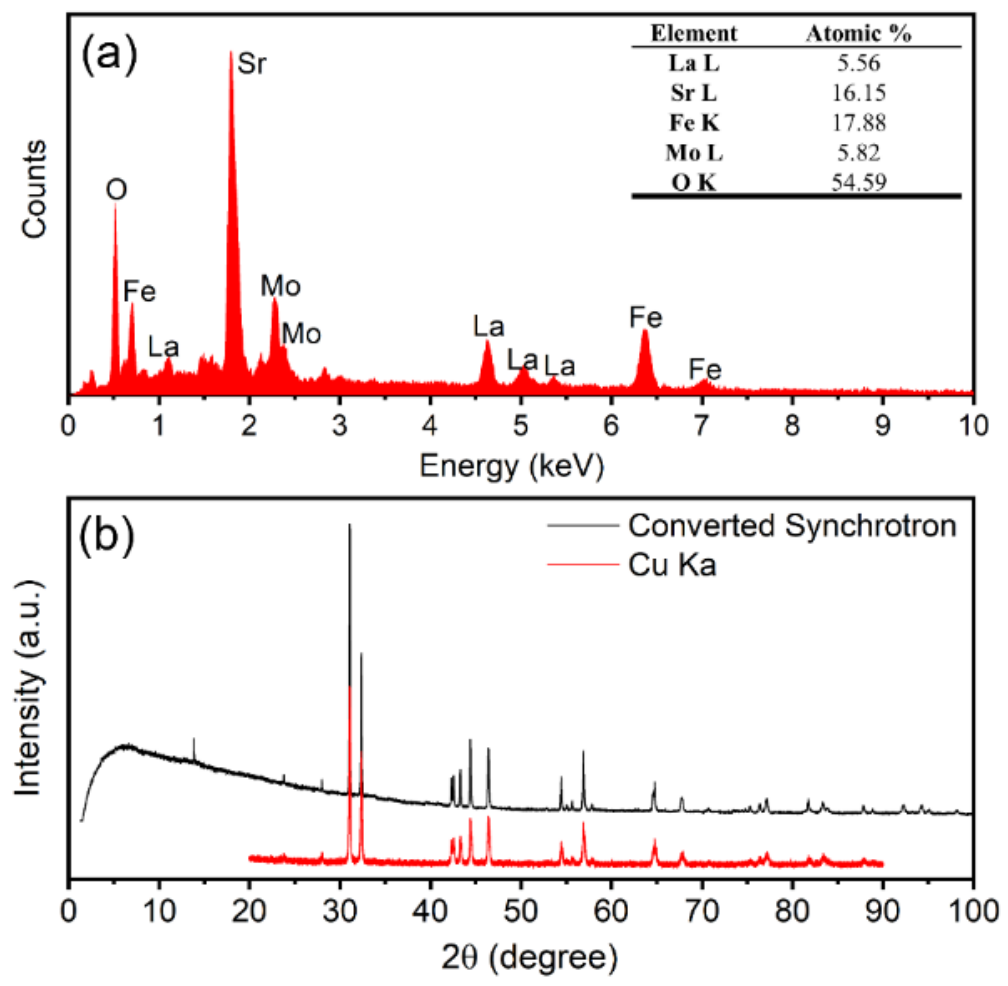

Figure 49. LSFM powder that reduced in $\mathrm{H}_{2}$ at $1200{ }^{\circ} \mathrm{C}$ for $2 \mathrm{~h}$, (a) EDS spectrum and the atomic ratio of elements in reduced LSFM, (b) Converted synchrotron pattern and $\mathrm{Cu} \mathrm{K \alpha}$ pattern of reduced LSFM.

\subsubsection{Phase Evolution}

Based on the experimental results discussed above, we can roughly describe the phase transition of LSFM in $\mathrm{H}_{2}$ at $1200^{\circ} \mathrm{C}$ as:

$$
\mathrm{La}_{0.5} \mathrm{Sr}_{1.5} \mathrm{Fe}_{1.5} \mathrm{Mo}_{0.5} \mathrm{O}_{6-\delta} \stackrel{\mathrm{H}_{2} 1200{ }^{\circ} \mathrm{C}}{\longrightarrow} \mathrm{Fe}+\mathrm{La}_{0.5} \mathrm{Sr}_{1.5} \mathrm{Fe}_{0.5} \mathrm{Mo}_{0.5} \mathrm{O}_{4}
$$

For the different degrees of partial phase transition, it can be generally expressed as: 


$$
\mathrm{La}_{0.5} \mathrm{Sr}_{1.5} \mathrm{Fe}_{1.5} \mathrm{Mo}_{0.5} \mathrm{O}_{6-\delta} \stackrel{\mathrm{H}_{2}}{\longrightarrow} \underset{\frac{2}{n+1}}{\mathrm{Fe}}+\mathrm{La}_{0.5} \mathrm{Sr}_{1.5} \mathrm{Fe}_{1.5-\frac{2}{n+1}} \mathrm{Mo}_{0.5} \mathrm{O}_{6-\delta}
$$

Here, $n$ can be any positive integer. The A-site and B-site cation ratio is $(n+1) / n$, follow the general RP phase formula $\mathrm{A}_{\mathrm{n}+1} \mathrm{~B}_{\mathrm{n}} \mathrm{X}_{3 \mathrm{n}+1}$. When $n=1$, Eq. (27) is equal to Eq. (26) and indicates a total phase transition. When $n=+\infty$, exsolution is absent, and the crystal structure is pure perovskite.

\subsubsection{Exsolution Induced by "Valence Excess" and "Co-Fe Cooperation"}

The ideal in-situ exsolution is a process to achieve the evenly decorated surface with better catalytic activity and higher thermal stability than the infiltration method. Depending on the formula, perovskites can be divided into two types: the A-site deficient perovskite $\mathrm{A}_{1-\alpha} \mathrm{BO}_{3-\delta}$ and the stoichiometric perovskite $\mathrm{ABO}_{3-\delta}$. The exsolution processes of these materials are summarized by Neagu as Eq. (28) and Eq. (29), respectively 114 .

$$
\begin{gathered}
\mathrm{A}_{1-\alpha} \mathrm{BO}_{3-\delta} \rightarrow(1-\alpha) \mathrm{ABO}_{3-\delta^{\prime}}+\alpha \mathrm{B} \\
\mathrm{ABO}_{3-\delta} \rightarrow(1-\alpha) \mathrm{ABO}_{3-\delta^{\prime \prime}}+\alpha \mathrm{B}+\alpha \mathrm{AO}
\end{gathered}
$$

Compared with the stoichiometric composition, A-site deficiency leads to an extra driving force to trigger the B-site exsolution. Inspired by this idea, a large number of A-site deficient perovskites are investigated. Table 8 summarized some A-site deficient and stoichiometric perovskite with their main phase stability after exsolution.

Compositions from Table 8 are generally modified from several limited perovskite families, such as $\operatorname{La}_{x} \operatorname{Sr}_{1-}$ ${ }_{x} \mathrm{TiO}_{3-\delta}(\mathrm{LST})$ and $\mathrm{Sr}_{2} \mathrm{Fe}_{1.5} \mathrm{Mo}_{0.5} \mathrm{O}_{6-\delta}(\mathrm{SF} 1.5 \mathrm{M})$. These original materials provide a stable backbone in $\mathrm{H}_{2}$ for new compositions and minor exsolution $(\leq 15 \%$ on B-site) while guaranteeing a stable perovskite structure after exsolution. An interesting discovery from Table 8 is that $20 \% \mathrm{Ni}$ on the $\mathrm{B}$-site $\left(\mathrm{La}_{0.6} \mathrm{Sr}_{0.4} \mathrm{Fe}_{0.8} \mathrm{Ni}_{0.2} \mathrm{O}_{3}\right.$ -

§) leads to minor decomposition, but a severe phase change is observed from compositions with $20 \%$ Co $\left(\mathrm{Pr}_{0.4} \mathrm{Sr}_{0.6} \mathrm{Co}_{0.2} \mathrm{Fe}_{0.7} \mathrm{Nb}_{0.1} \mathrm{O}_{3-\delta}\right.$ and $\left.\mathrm{Pr}_{0.4} \mathrm{Sr}_{0.6} \mathrm{Co}_{0.2} \mathrm{Fe}_{0.7} \mathrm{Mo}_{0.1} \mathrm{O}_{3-\delta}\right)$. This probably is because of the cooperative exsolution of Co and Fe. When exsolving from perovskite, Co can somehow trigger a massive Fe exsolution 
along with it and collapse the parent structure. This Co-Fe cooperative exsolution is also observed from the $\mathrm{SF} 1.5 \mathrm{M}$ based composition. In Figure 50, the XRD patterns indicate that SF1.5M is not only stable in $\mathrm{H}_{2}$ (Figure 50a) but can also tolerate 5\% vacancy on B-site (Figure 50b). Because of this high stability, Nidoped SF1.5M ( $\mathrm{Sr}_{1.9} \mathrm{Fe}_{1.5} \mathrm{Mo}_{0.4} \mathrm{Ni}_{0.1} \mathrm{O}_{6-\delta}$, Table 8) exhibits excellent stability in $\mathrm{H}_{2}{ }^{203}$. However, when filling this $5 \%$ vacancy with Co, severe phase transitions from the perovskite to the RP phase are detected by XRD from the stoichiometric (Figure 50c) and A-site deficient compositions (Figure 50d).

Table 8. Perovskite materials and the phase stability after exsolution.

\begin{tabular}{|c|c|c|c|c|}
\hline Formula & Material & Exsolved Metal & Impurity & Ref. \\
\hline \multirow{9}{*}{$\mathrm{A}_{1-\alpha} \mathrm{BO}_{3-\delta}$} & $\mathrm{La}_{0.4} \mathrm{Sr}_{0.4} \mathrm{Sc}_{0.9} \mathrm{Ni}_{0.1} \mathrm{O}_{3-\delta}$ & $\mathrm{Ni}$ & No & 121 \\
\hline & $\mathrm{La}_{0.9} \mathrm{Mn}_{0.9} \mathrm{Pt}_{0.075} \mathrm{Ni}_{0.025} \mathrm{O}_{3-\delta}$ & $\mathrm{Pt}_{3} \mathrm{Ni}$ & No & 204 \\
\hline & $\mathrm{Sr}_{1.9} \mathrm{Fe}_{1.5} \mathrm{Mo}_{0.4} \mathrm{Ni}_{0.1} \mathrm{O}_{6-\delta}$ & $\mathrm{NiFe}$ & No & 203 \\
\hline & $\mathrm{La}_{0.52} \mathrm{Sr}_{0.28} \mathrm{Ti}_{0.94} \mathrm{Ni}_{0.06} \mathrm{O}_{3-\delta}$ & $\mathrm{Ni}$ & No & 114 \\
\hline & $\mathrm{La}_{0.4} \mathrm{Sr}_{0.4} \mathrm{Ti}_{0.97} \mathrm{Ni}_{0.03} \mathrm{O}_{3-\delta}$ & $\mathrm{Ni}$ & No & 124 \\
\hline & $\mathrm{La}_{0.4} \mathrm{Sr}_{0.4} \mathrm{Ti}_{0.94} \mathrm{Fe}_{0.06} \mathrm{O}_{2.97}$ & $\mathrm{Fe}$ & No & 117 \\
\hline & $\mathrm{La}_{0.6} \mathrm{Sr}_{0.3} \mathrm{Cr}_{0.85} \mathrm{Fe}_{0.15} \mathrm{O}_{3-\delta}$ & $\mathrm{Fe}$ & No & 202 \\
\hline & $\left(\mathrm{La}_{0.75} \mathrm{Sr}_{0.25}\right)_{0.95}\left(\mathrm{Cr}_{0.8} \mathrm{Ni}_{0.2}\right)_{0.95} \mathrm{Ni}_{0.05} \mathrm{O}_{3}$ & $\mathrm{Ni}$ & No & 205 \\
\hline & $\left(\mathrm{La}_{0.75} \mathrm{Sr}_{0.25}\right)_{0.85}\left(\mathrm{Cr}_{0.5} \mathrm{Fe}_{0.5}\right)_{0.85} \mathrm{Fe}_{0.15} \mathrm{O}_{3}$ & $\mathrm{Fe}$ & No & 206 \\
\hline \multirow{9}{*}{$\mathrm{ABO}_{3-\delta}$} & $\mathrm{La}_{0.3} \mathrm{Sr}_{0.7} \mathrm{Ti}_{0.94} \mathrm{Ni}_{0.06} \mathrm{O}_{3+\delta}$ & $\mathrm{Ni}$ & No & 114 \\
\hline & $\mathrm{La}_{\mathrm{x}} \mathrm{Sr}_{1-\mathrm{x}} \mathrm{Ti}_{1-\mathrm{y}} \mathrm{Ni}_{\mathrm{y}} \mathrm{O}_{3-\delta}(\mathrm{y}<0.1)$ & $\mathrm{Ni}$ & No & 207 \\
\hline & $\mathrm{La}_{0.5} \mathrm{Sr}_{0.5} \mathrm{Ti}_{0.75} \mathrm{Ni}_{0.25} \mathrm{O}_{3-\delta}$ & $\mathrm{Ni}$ & Minor & 208 \\
\hline & $\mathrm{Sr}_{2} \mathrm{Fe}_{1.3} \mathrm{Ni}_{0.2} \mathrm{Mo}_{0.5} \mathrm{O}_{6-\delta}$ & $\mathrm{Fe}-\mathrm{Ni}$ & Minor & 209 \\
\hline & $\mathrm{La}_{0.6} \mathrm{Sr}_{0.4} \mathrm{Fe}_{0.8} \mathrm{Ni}_{0.2} \mathrm{O}_{3-\delta}$ & $\mathrm{Fe}-\mathrm{Ni}$ & Minor & 116 \\
\hline & $\mathrm{Sr}_{2} \mathrm{FeNi}_{0.35} \mathrm{Mo}_{0.65} \mathrm{O}_{6-\delta}$ & $\mathrm{Fe}-\mathrm{Ni}$ & Severe & 163 \\
\hline & $\mathrm{Pr}_{0.4} \mathrm{Sr}_{0.6} \mathrm{Co}_{0.2} \mathrm{Fe}_{0.7} \mathrm{Nb}_{0.1} \mathrm{O}_{3-\delta}$ & $\mathrm{Co}-\mathrm{Fe}$ & Severe & 162 \\
\hline & $\mathrm{Pr}_{0.4} \mathrm{Sr}_{0.6} \mathrm{Co}_{0.2} \mathrm{Fe}_{0.7} \mathrm{Mo}_{0.1} \mathrm{O}_{3-\delta}$ & $\mathrm{Co}-\mathrm{Fe}$ & Severe & 210 \\
\hline & $\mathrm{Pr}_{0.4} \mathrm{Sr}_{0.6} \mathrm{Co}_{0.2} \mathrm{Fe}_{0.7} \mathrm{Mo}_{0.1} \mathrm{O}_{3-\delta}$ & $\mathrm{Co}-\mathrm{Fe}$ & Severe & 211 \\
\hline \multirow{5}{*}{$\begin{array}{l}\text { SF1.5M } \\
\text { Family }\end{array}$} & $\mathrm{Sr}_{2} \mathrm{Fe}_{1.5} \mathrm{Mo}_{0.5} \mathrm{O}_{6-\delta}$ & No & No & \multirow{5}{*}{$\begin{array}{l}\text { This } \\
\text { work }\end{array}$} \\
\hline & $\mathrm{Sr}_{2} \mathrm{Fe}_{1.5} \square_{0.1} \mathrm{Mo}_{0.4} \mathrm{O}_{6-\delta}$ & No & No & \\
\hline & $\mathrm{Sr}_{2} \mathrm{Fe}_{1.5} \mathrm{Co}_{0.1} \mathrm{Mo}_{0.4} \mathrm{O}_{6-\delta}$ & $\mathrm{Co}-\mathrm{Fe}$ & Severe & \\
\hline & $\mathrm{Sr}_{1.9} \mathrm{Fe}_{1.5} \mathrm{Co}_{0.1} \mathrm{Mo}_{0.4} \mathrm{O}_{6-\delta}$ & $\mathrm{Co}-\mathrm{Fe}$ & Severe & \\
\hline & $\mathrm{La}_{0.5} \mathrm{Sr}_{1.5} \mathrm{Fe}_{1.5} \mathrm{Mo}_{0.5} \mathrm{O}_{6-\delta}$ & $\mathrm{Fe}$ & Minor & \\
\hline
\end{tabular}



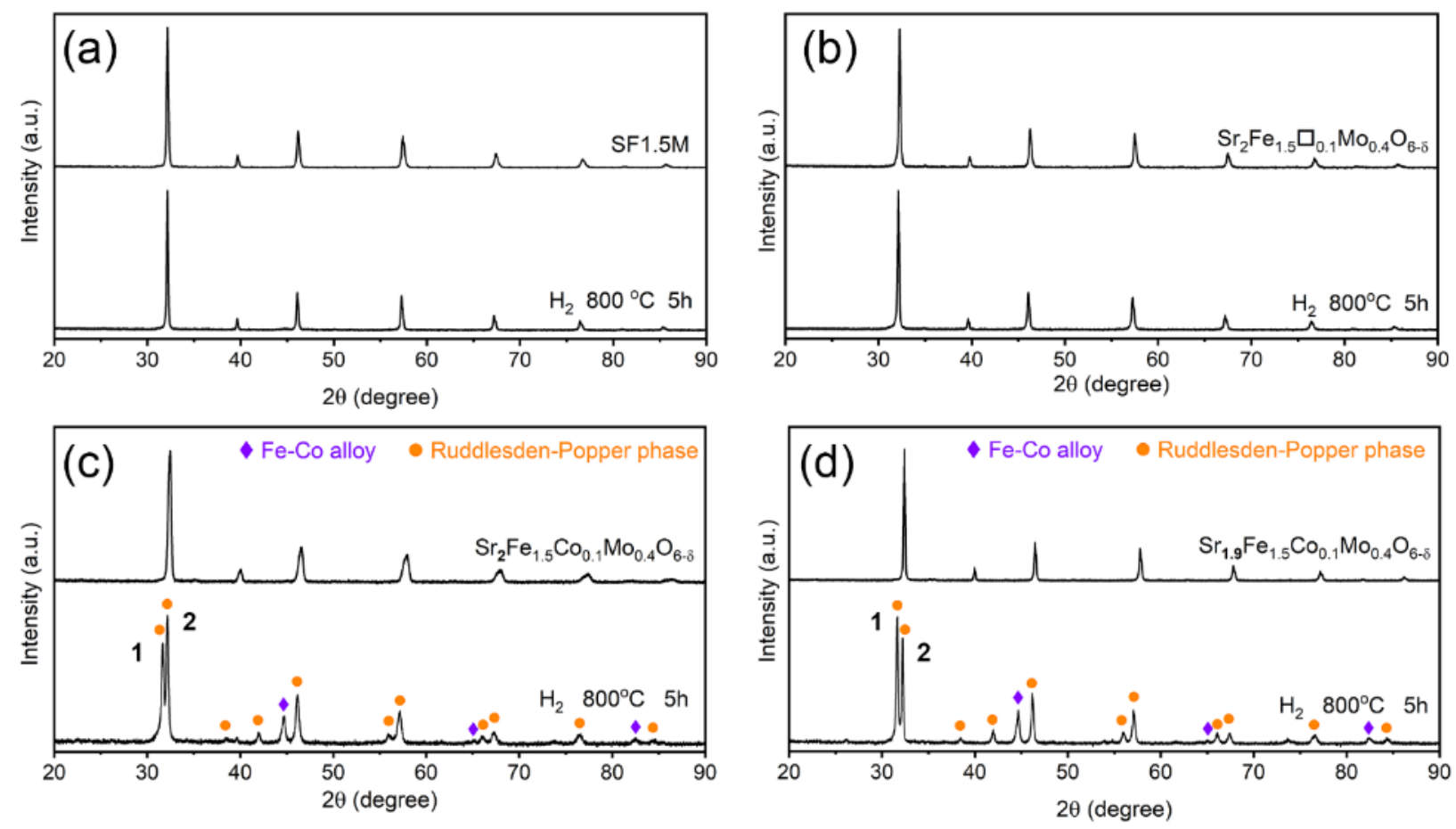

Figure 50. XRD patterns of materials as synthesized and reduced in $\mathrm{H}_{2}$ at $800{ }^{\circ} \mathrm{C}$ for 5 h. (a) $\mathrm{SF} 1.5 \mathrm{M}$, (b) $\mathrm{Sr}_{2} \mathrm{Fe}_{1.5} \square_{0.1} \mathrm{Mo}_{0.4} \mathrm{O}_{6-\delta}$, (c) $\mathrm{Sr}_{2} \mathrm{Fe}_{1.5} \mathrm{Co}_{0.1} \mathrm{Mo}_{0.4} \mathrm{O}_{6-\delta}$, and (d) $\mathrm{Sr}_{1.9} \mathrm{Fe}_{1.5} \mathrm{Co}_{0.1} \mathrm{Mo}_{0.4} \mathrm{O}_{6-\delta}$.

Besides A-site deficiency and Co-Fe cooperative action, "valence excess" is another inducement of exsolution. Unlike the A-site deficiency, the valence excess introduces extra exsolution driving force by increasing the valence state of some single valent elements, such as replacing partial $\mathrm{Sr}^{2+}$ by $\mathrm{La}^{3+}$ in $\mathrm{SF} 1.5 \mathrm{M}$ to produce LSFM. Because $\mathrm{Sr}^{2+}$ and $\mathrm{La}^{3+}$ have a single valence that cannot be reduced to a lower valence state in $\mathrm{H}_{2}$, the excessive valence introduced by $\mathrm{La}^{3+}$ prefers to be compensated by a lower B-site valence to avoid the higher oxygen vacancy formation energy at the bigger $\delta$ condition. Since $\mathrm{Fe}^{2+}$ is easier to be reduced to the metal than $\mathrm{Mo}^{4+/ 5+}$, pure Fe exsolution is formed and detected at $800{ }^{\circ} \mathrm{C}$. If the system cannot be compensated when all available Fe cations are reduced to the metal, some Mo cations may also be reduced to the metal to form an Fe-Mo alloy in an extremely strong reducing environment (i.e., $1200{ }^{\circ} \mathrm{C}$ $\mathrm{H}_{2}$ ). Thus, the Fe-Mo alloy is detected from the thoroughly reduced LSFM by synchrotron XRD. 


\subsection{Stability and Reversibility}

\subsubsection{Long-term Stability}

According to the previous discussion, the Fe exsolution from LSFM has been verified in $\mathrm{H}_{2}$ at $800{ }^{\circ} \mathrm{C}$. This in-situ exsolution seems to mainly occur in the first few hours and then further decomposition will be dramatically restrained. To clarify this, the LSFM powder which had been subjected to $5 \mathrm{~h}$ reduction in pure $\mathrm{H}_{2}$ at $800{ }^{\circ} \mathrm{C}$ was further calcined under the same conditions for another $100 \mathrm{~h}$. As shown in Figure 51a-c, the XRD peaks correspond to Fe and RP phase in LSFM subjected to $100 \mathrm{~h}$ reduction are not obviously intensified in comparison with those of the counterpart subject to $5 \mathrm{~h}$ reduction. Both samples maintain the major phase of perovskite LSFM similar to the prime LSFM synthesized in $\mathrm{N}_{2}$. The SEM images in Figure 51d-e also prove the high similarity of exsolution particles in LSFM upon 5 and $100 \mathrm{~h}$ reduction. The Fe exsolution and phase transition of LSFM powder are much weakened compared to the significant phase decomposition of other perovskite materials with the similar structures such as $\mathrm{Sr}_{2} \mathrm{Fe}_{1.5} \mathrm{Co}_{0.1} \mathrm{Mo}_{0.4} \mathrm{O}_{6-\delta}$ (Figure 31a in Section 2.4.2), $\mathrm{Sr}_{2} \mathrm{FeMo}_{0.65} \mathrm{Ni}_{0.35} \mathrm{O}_{6-\delta}{ }^{163}, \mathrm{La}_{0.6} \mathrm{Sr}_{0.4} \mathrm{Fe}_{0.8} \mathrm{Ni}_{0.2} \mathrm{O}_{3-\delta}{ }^{116}$ and $\operatorname{Pr}_{0.4} \mathrm{Sr}_{0.6} \mathrm{Co}_{0.2} \mathrm{Fe}_{0.7} \mathrm{Nb}_{0.1} \mathrm{O}_{3-\delta}{ }^{162}$, which usually have severe metal exsolution and phase transformation in $\mathrm{H}_{2}$ at the similar temperatures. Thus, the perovskite material LSFM demonstrates the high phase stability against $\mathrm{H}_{2}$ reduction at the cell operating temperature. 

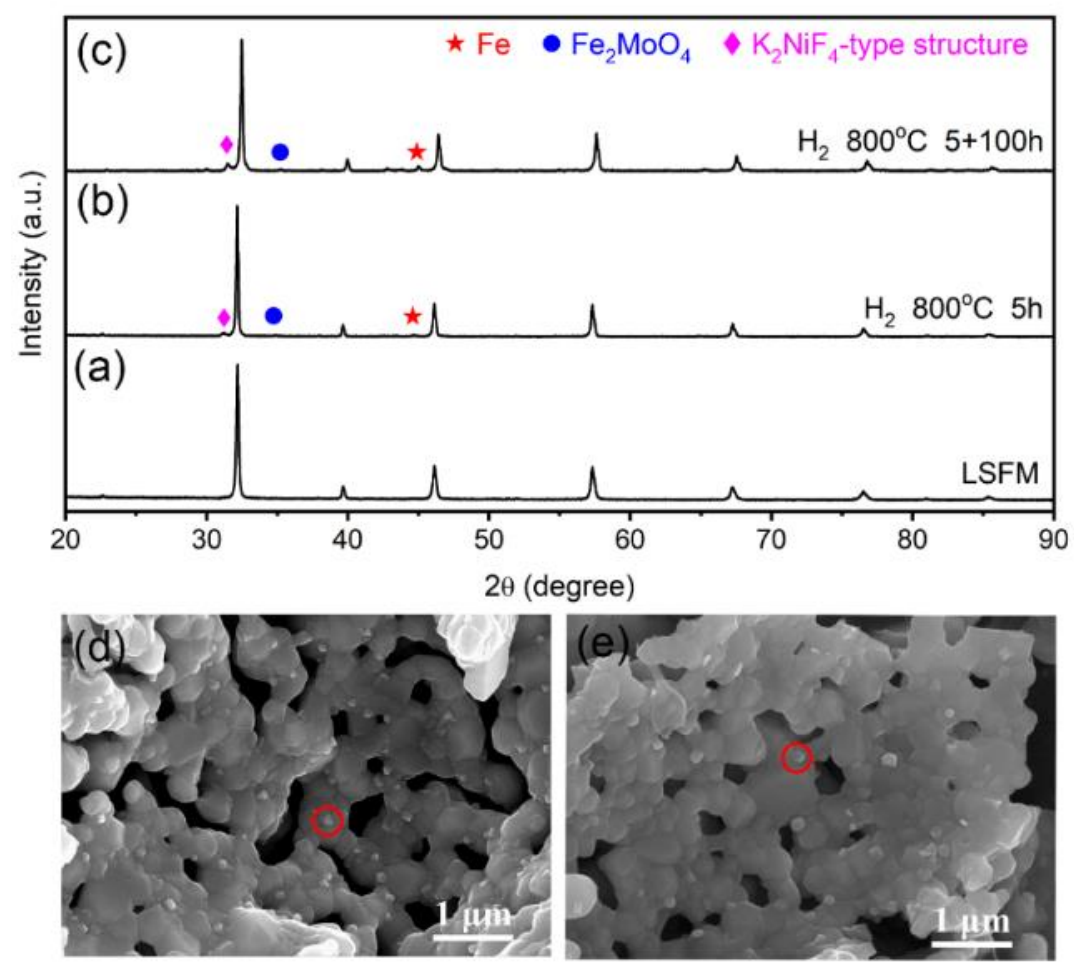

Figure 51. (a-c) Phase stability of LSFM in $\mathrm{H}_{2}$ at $800{ }^{\circ} \mathrm{C}$ for (a) $0 \mathrm{~h}$, (b) $5 \mathrm{~h}$ and (c) $105 \mathrm{~h}$. (d, e) SEM images of LSFM powders reduced for (d) $5 \mathrm{~h}$ and (e) $105 \mathrm{~h}$.

\subsubsection{Phase Reversibility Under the Redox Condition}

It is interesting to find that the exsolution and dissolution of Fe NPs are reversible during a redox cycle. After $5 \mathrm{~h}$ reduction in $\mathrm{H}_{2}$ at $800{ }^{\circ} \mathrm{C}$, the same LSFM powders were subjected to oxidation in the air at 800 ${ }^{\circ} \mathrm{C}$ for $1 \mathrm{~h}$. As shown in Figure 52b, tiny peaks at $31.2^{\circ}$ and $44.7^{\circ}$ disappeared after $1 \mathrm{~h}$ oxidation. The XRD pattern of re-oxidized LSFM shows a high similarity with the synthesized phase (Figure 44a). 

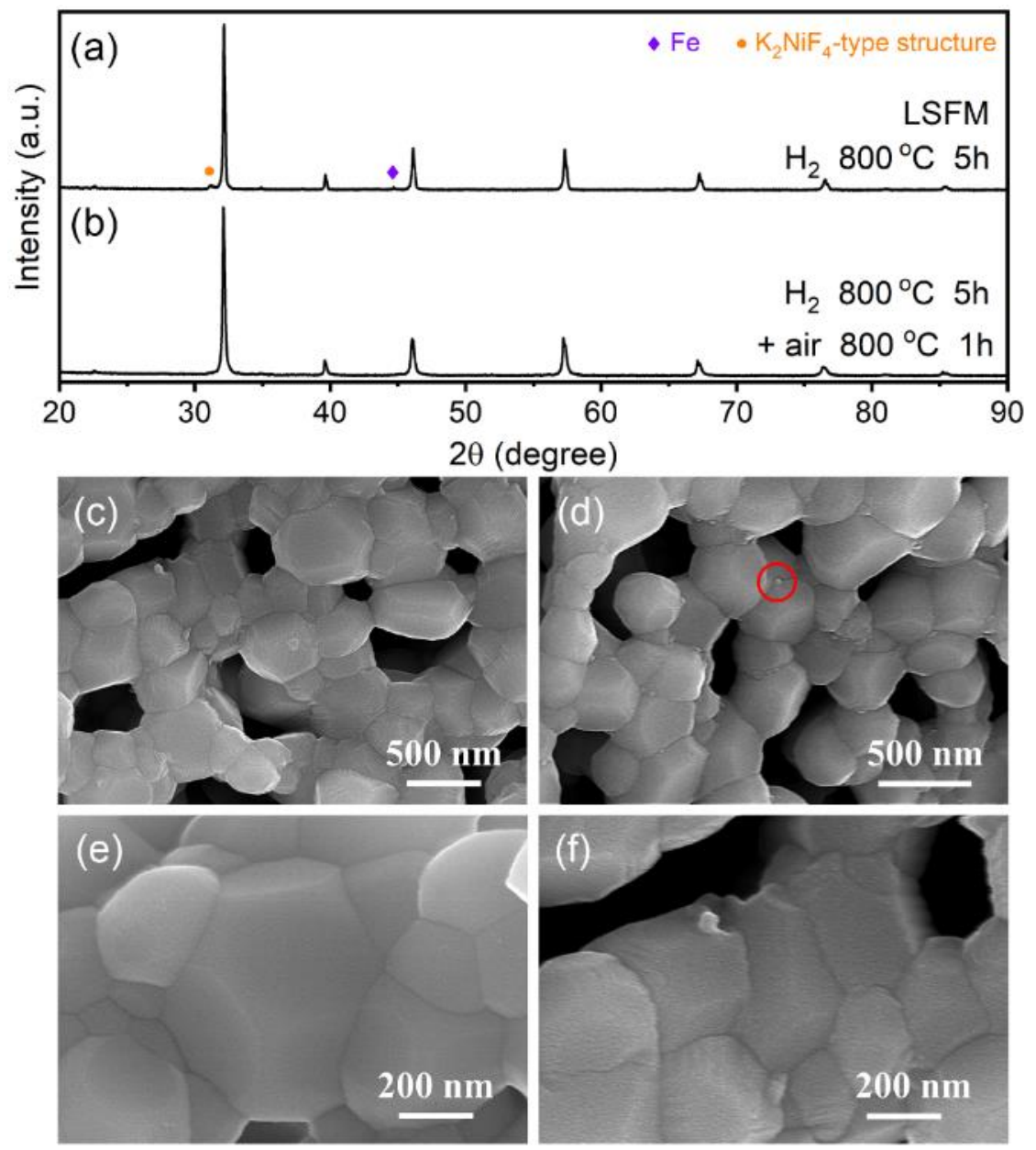

Figure 52. XRD patterns of LSFM powder (a) after reduction in $\mathrm{H}_{2}$ at $800{ }^{\circ} \mathrm{C}$ for $5 \mathrm{~h}$ and (b) after re-oxidization in air at $800{ }^{\circ} \mathrm{C}$ for $1 \mathrm{~h}$. (c-d) SEM images of LSFM after 1 h oxidation (c) without Fe residual, and (d) with Fe residual. (e) Surface and grain boundary morphology of synthesized LSFM. (f) Surface and grain boundary morphology of LSFM after one redox cycle.

Strictly speaking, the XRD pattern in Figure 52b can only demonstrate the disappearance of crystallized Fe after oxidation. To verify the dissolution of Fe, the morphology of LSFM powder after oxidation was characterized by SEM. The clean surface and clear grain boundaries in Figure 52c confirm that Fe NPs is dissolved into the perovskite phase in an oxidation environment. Meanwhile, minor iron oxide residuals are also observed at grain boundaries from the same sample (Figure 52d) which verifies a faster Fe diffusion channel along grain boundaries. 
Before and after redox, the morphology changes at the grain boundary and the nearby surface are evident as displayed in Figure 52e-f. In Figure 52e, the grain boundary of LSFM particles before the reduction is clear and straight, and the particle surface is smooth and uniform. After re-oxidation, though particle shape is maintained, a clear wave-shaped grain boundary and surface can be observed in the high magnification SEM image (Figure 52f). This new morphology implies a reversible phase evolution process during redox cycles:

$$
\begin{aligned}
& \mathrm{La}_{0.5} \mathrm{Sr}_{1.5} \mathrm{Fe}_{1.5} \mathrm{Mo}_{0.5} \mathrm{O}_{6-\delta} \stackrel{\mathrm{H}_{2}}{\longleftrightarrow} \mathrm{Fe}_{x}+\mathrm{La}_{0.5} \mathrm{Sr}_{1.5} \mathrm{Fe}_{1.5-x} \mathrm{Mo}_{0.5} \mathrm{O}_{6-\delta} \\
& \stackrel{\mathrm{O}_{2}}{\longleftrightarrow} \mathrm{La}_{0.5} \mathrm{Sr}_{1.5} \mathrm{Fe}_{1.5} \mathrm{Mo}_{0.5} \mathrm{O}_{6-\delta}
\end{aligned}
$$

This attractive property makes LSFM as a potential candidate material in redox stability required fuel cells.

\subsection{Accelerated Surface Kinetics with Fe Exsolution}

\subsubsection{In Low Pн2 Environment}

In this work, the surface kinetics and bulk diffusion change result from exsolution are investigated by electrical conductivity relaxation (ECR) in the low $\mathrm{P}_{\mathrm{H} 2}$ range (humidified $1 \%-20 \% \mathrm{H}_{2}$ ) and by electrochemical impedance spectroscopy (EIS) in the high $\mathrm{P}_{\mathrm{H} 2}$ atmosphere (humidified $\mathrm{H}_{2}$ ). At low $\mathrm{P}_{\mathrm{H} 2}$ range, the high phase stability of LSFM has been verified in Section 4.2.2 (Figure 29). The stable perovskite phase and the ideal conductivity change curve after an abrupt $\mathrm{P}_{\mathrm{H} 2}$ change lead to repeatable and credible ECR results.

To evaluate the influence of exsolution on electrochemical performance, ECR was conducted in low $\mathrm{P}_{\mathrm{H} 2}$ environment, before and after Fe exsolution (overnight in humidified $\mathrm{H}_{2}$ at $800{ }^{\circ} \mathrm{C}$ ). The ECR fitting results before (black symbols) and after (red symbols) exsolution are presented in Figure 53b-c. The 5\% error tolerance map defines the sensitivity of $k_{\text {ex }}$ and $D_{\text {chem }}$ in a certain error range and indicates the reliability of the fitting result. Error bars in Figure 53b-c are extracted from "error map with 5\% tolerance" (Figure 53a inset and Figure 54) and indicate the $\mathrm{k}_{\mathrm{ex}}$ or $\mathrm{D}_{\text {chem }}$ range between $\mathrm{A}$ and $\mathrm{B}$ in an "error map with $5 \%$ tolerance" 
(Figure 53a inset). Error bars can be used to reveal the accuracy and reliability of obtained $\mathrm{k}_{\mathrm{ex}}$ and $\mathrm{D}_{\text {chem }}$ values.
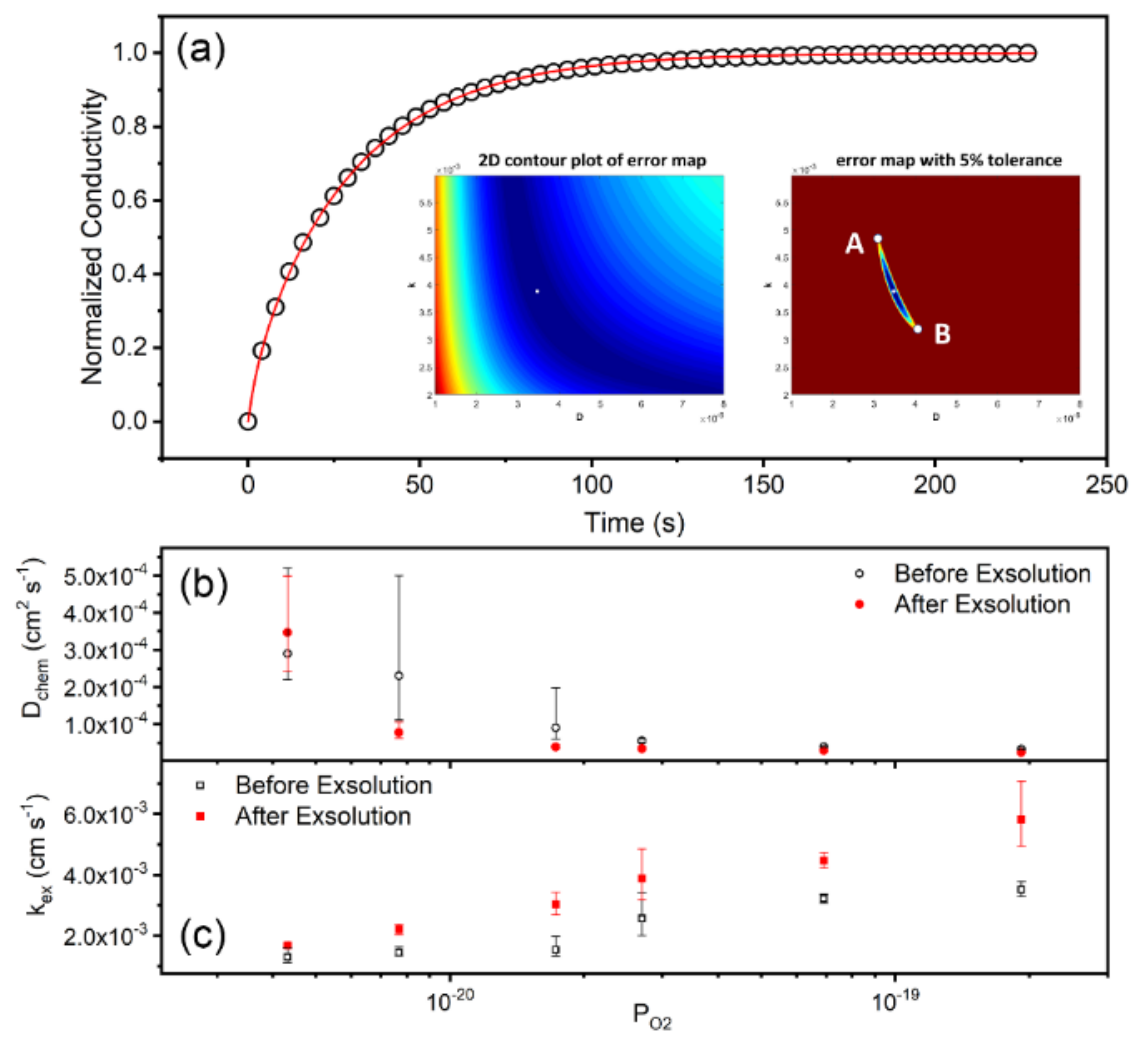

Figure 53. ECR fitting results of LSFM bar sample at $800{ }^{\circ} \mathrm{C}$ in humidified $\mathrm{H}_{2}$. (a) Raw data (open circle) and the fitting result (solid line) from $5 \% \mathrm{H}_{2}$ to $8 \% \mathrm{H}_{2}$ after total reduction. 2D contour plot of error map and error map with $5 \%$ tolerance are shown in the inset. (b) $\mathrm{D}_{\text {chem }}$ and (c) $\mathrm{k}_{\mathrm{ex}}$ before and after total reduction as a function of equilibrium state oxygen partial pressure.

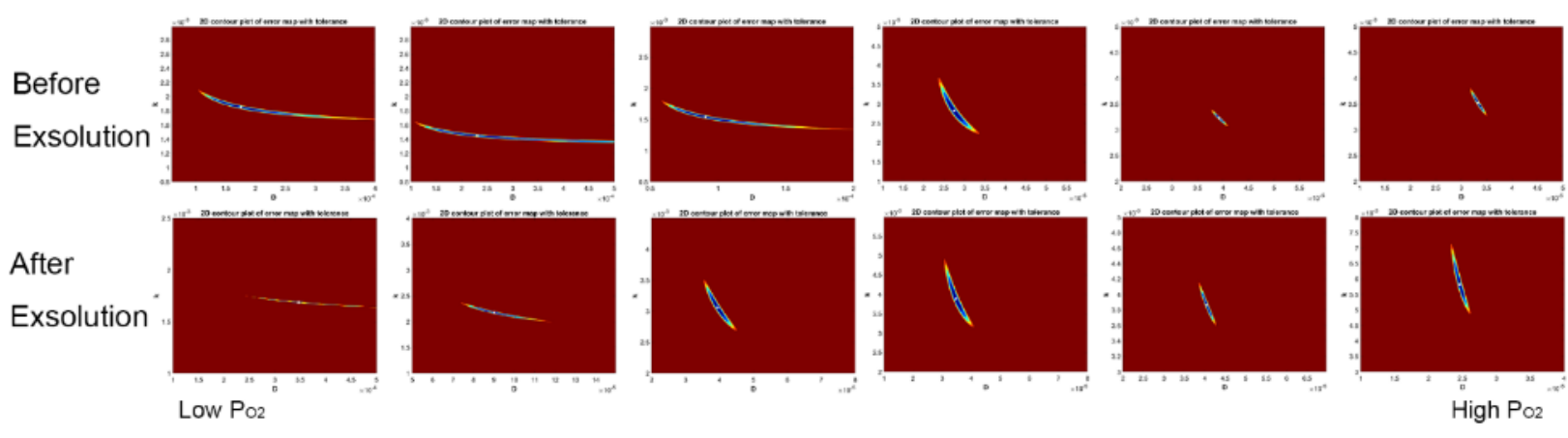

Figure 54. 5\% tolerance error maps of all ECR fitting results. 
From Figure 53c, a clear $\mathrm{k}_{\mathrm{ex}}$ increment (about 1.5 to 2 times) can be observed after exsolution. This enhancement implies a faster surface oxygen exchange rate and a promoted surface reaction kinetics with the presence of exsolved NPs on the surface. For the bulk diffusion in Figure 53b, the closely matched $\mathrm{D}_{\text {chem }}$ values at the high $\mathrm{P}_{\mathrm{O} 2}$ side and the big error bars at the low $\mathrm{P}_{\mathrm{O} 2}$ side suggest that, in this experiment, the exsolution has a minor effect on $\mathrm{D}_{\text {chem. }}$. As is known, $\mathrm{D}_{\text {chem }}$ reflects the oxygen transport capability of the material and is affected by crystal structure. At a certain $\mathrm{P}_{\mathrm{O} 2}$ change (a certain $\mathrm{P}_{\mathrm{O} 2}$ value in Figure 53b), a similar $\mathrm{D}_{\text {chem }}$ value before and after exsolution indicates the well-maintained crystal structure of the material and demonstrates that exsolution and surface phase transition in LSFM won't block ionic diffusion in the bulk.

Overall, with the exsolution of Fe NPs, more active sites are provided on the electrode surface which results in a faster surface electrochemical process. Meanwhile, the well-maintained perovskite structure in LSFM ensures sufficient ionic conductivity during the hydrogen oxidation reaction.

\subsubsection{In High $\mathbf{P}_{\mathrm{H} 2}$ Environment}

In the ECR assumptions, the conductivity change is proportional to the stoichiometry change $(\Delta \delta)$ and the $\Delta \delta$ is ruled by an ideal surface oxygen exchange $\left(k_{\text {ex }}\right)$ and bulk chemical diffusion $\left(D_{\text {chem }}\right)^{212}$, which can be described as Eq. (19). On that account, high phase stability during the test is required for the credible $\mathrm{k}_{\mathrm{ex}}$ and $D_{\text {chem. }}$ However, as verified above, LSFM undergoes exsolution and slight phase transition in the high $\mathrm{P}_{\mathrm{H} 2}$ environment. Therefore, the EIS method is employed in this work to monitor the performance change of the LSFM/LSGM/LSFM symmetrical cells during the Fe exsolution process in the high $\mathrm{P}_{\mathrm{H} 2}$ environment $\left(3 \% \mathrm{H}_{2} \mathrm{O}-97 \% \mathrm{H}_{2}\right)$. The symmetrical cell is heated up in $\mathrm{N}_{2}$. When the temperature is stable at $800{ }^{\circ} \mathrm{C}$, test gas is switched to humidified $\mathrm{H}_{2}$. Impedance spectra are then recorded every 30 minutes until a constant polarization resistance value is obtained. 

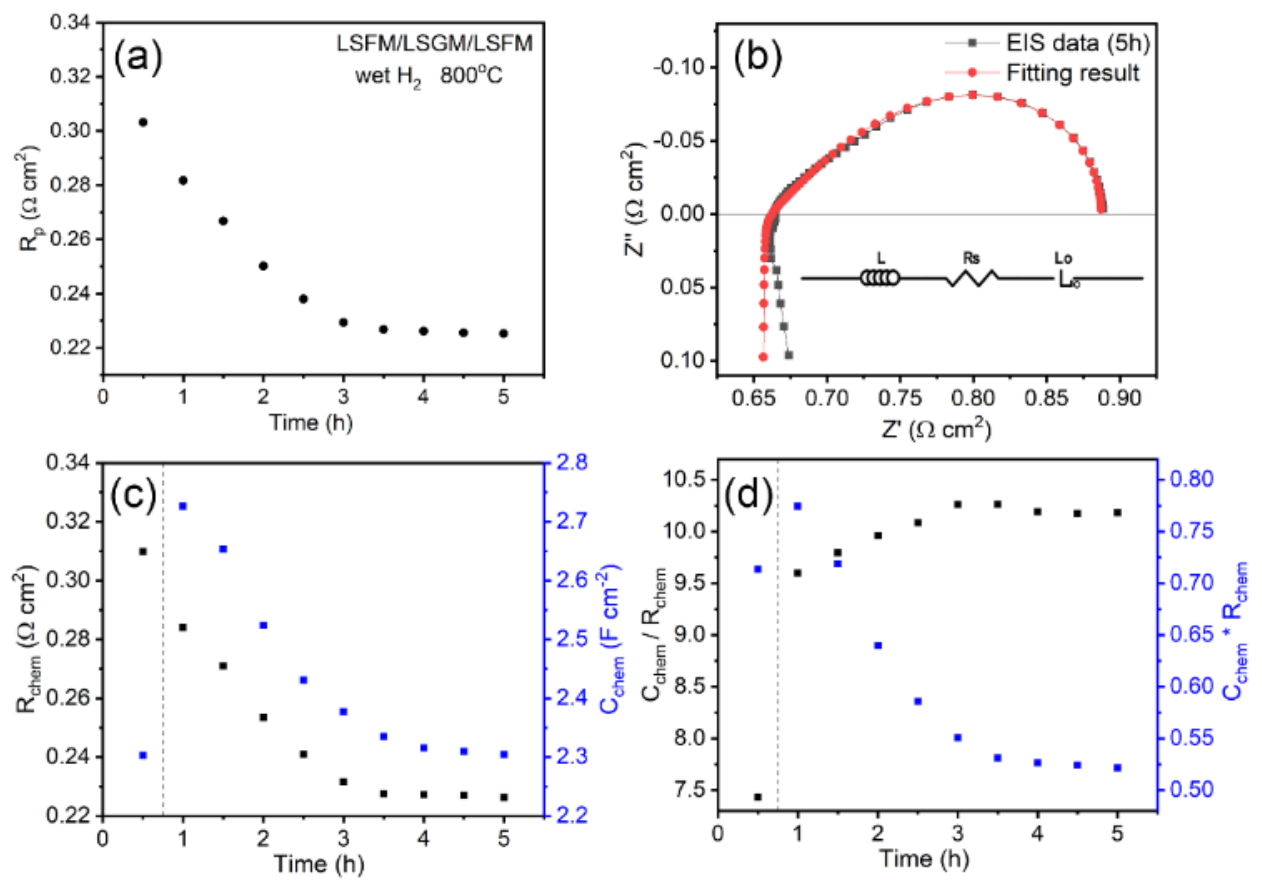

Figure 55. LSFM/LSGM/LSFM symmetrical cell tested at $800{ }^{\circ} \mathrm{C}$ in humidified $H_{2}$. (a) $R_{p}$ as a function of soaking time. (b) Nyquist plot (black) and the fitting result (red) at $5 \mathrm{~h}$. Inset is the corresponding equivalent circuit. (c) $R_{\text {chem }}$ and $C_{\text {chem }}$ as a function of soaking time. (d) $C_{\text {chem }} / R_{\text {chem }}$ (proportional to effective ionic conductivity $\sigma_{i, e f f}$ ) and $C_{c h e m} * R_{c h e m}$ (proportional to surface areaspecific resistance $R_{\text {surf }}$ ) as a function of soaking time.

As shown in Figure 55a, the $\mathrm{R}_{\mathrm{p}}$ exhibits a linear decrease in the first 3 hours and then reaches a constant value. In contrast, the parallel sample SF1.5M does not show exsolution in $\mathrm{H}_{2}$ and its symmetrical cell does not exhibit this reduction in $\mathrm{R}_{\mathrm{p}}$ (Figure 56). Figure 55a reflects the Fe exsolution-ceasing process on LSFM in a strong reducing atmosphere, confirming the promotion of exsolution on the HOR process. 

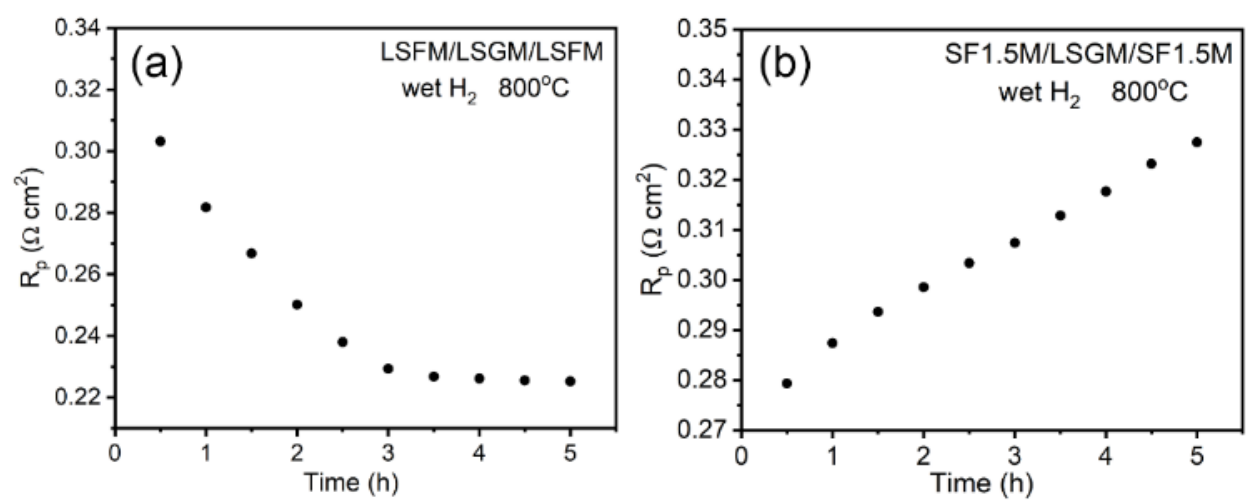

Figure 56. Polarization resistance of (a) LSFM, (b) SF1.5M symmetrical cells tested in humidified $\mathrm{H}_{2}$ at $800{ }^{\circ} \mathrm{C}$ as a function of soaking time.

According to Adler's investigation ${ }^{179,184}$, the half-tear-drop-shaped impedance spectrum (Figure 55b) suggests an oxygen bulk diffusion and surface chemical exchange co-limited electrochemical process which can be well-fitted by a de Levie Pore element (Lo). Thus, the equivalent circuit LRsLo (inset of Figure 55b) is applied for impedance fitting. In this equivalent circuit, $\mathrm{L}$ is the inductance, $\mathrm{Rs}$ is the ohmic resistance from the electrolyte, Lo presents the oxygen bulk diffusion and surface chemical exchange co-limited process. The Lo element can be described as Eq. (22) ${ }^{213}$ :

$$
Z_{\text {chem }}=\frac{R_{\text {chem }}}{\sqrt{1+\left(j \omega t_{\text {chem }}\right)^{\alpha}}}
$$

where $Z_{\text {chem }}$ is the chemical impedance,

$R_{\text {chem }}$ is the characteristic resistance,

$\alpha$ denotes the non-ideal behavior. The fitting result of all data are given in Table 9. Based on Adler's work ${ }^{179}, R_{\text {chem }}$ and $C_{\text {chem }}$ can be written as:

$$
\begin{gathered}
R_{\text {chem }}=2 \sqrt{\frac{R_{\text {surf }}}{\sigma_{i, e f f} a}} \\
C_{\text {chem }}=\frac{4 F^{2}}{R T} \frac{(1-\varepsilon) l_{\delta}}{f V_{m}}=\frac{4 F^{2}}{R T} \frac{(1-\varepsilon)}{f V_{m}} \sqrt{\frac{\sigma_{i, e f f} R_{\text {surf }}}{a}}
\end{gathered}
$$


where $C_{\text {chem }}$ is the chemical capacitance,

$R_{\text {surf }}$ is the area-specific resistance, reflecting the oxygen exchange resistance at the LSFM surface,

$\sigma_{i, e f f}$ is the effective ionic conductivity, and can be expressed as $\sigma_{i, e f f}=(1-\varepsilon) \sigma_{i} / \tau$,

$\varepsilon$ is the porosity,

$\tau$ is the tortuosity,

$a$ is the surface area,

$f$ is the thermodynamic factor,

$l_{\delta}$ is the characteristic "utilization" length,

$V_{m}$ is the molar volume.

Table 9. Fitting results of EIS data from 0.5 to $5 \mathrm{~h}$.

\begin{tabular}{cccccc}
\hline \hline Time & $\mathrm{R}_{\text {chem }}$ & $\mathrm{C}_{\text {chem }}$ & $\alpha$ & $\mathrm{C}_{\text {chem }} / \mathrm{R}_{\text {chem }}$ & $\mathrm{C}_{\text {chem }} * \mathrm{R}_{\text {chem }}$ \\
& $\Omega \mathrm{cm}^{2}$ & $\mathrm{~F} \mathrm{~cm}^{-2}$ & $/$ & $/$ & / \\
\hline $0.5 \mathrm{~h}$ & 0.310 & 2.303 & 1.041 & 7.434 & 0.714 \\
$1 \mathrm{~h}$ & 0.284 & 2.726 & 1.033 & 9.598 & 0.774 \\
$1.5 \mathrm{~h}$ & 0.271 & 2.653 & 1.031 & 9.793 & 0.719 \\
$2 \mathrm{~h}$ & 0.253 & 2.524 & 1.027 & 9.961 & 0.640 \\
$2.5 \mathrm{~h}$ & 0.241 & 2.431 & 1.022 & 10.086 & 0.586 \\
$3 \mathrm{~h}$ & 0.232 & 2.377 & 1.019 & 10.262 & 0.551 \\
$3.5 \mathrm{~h}$ & 0.228 & 2.336 & 1.015 & 10.263 & 0.531 \\
$4 \mathrm{~h}$ & 0.227 & 2.316 & 1.014 & 10.190 & 0.526 \\
$4.5 \mathrm{~h}$ & 0.227 & 2.310 & 1.014 & 10.174 & 0.524 \\
$5 \mathrm{~h}$ & 0.226 & 2.305 & 1.013 & 10.180 & 0.522 \\
\hline \hline
\end{tabular}



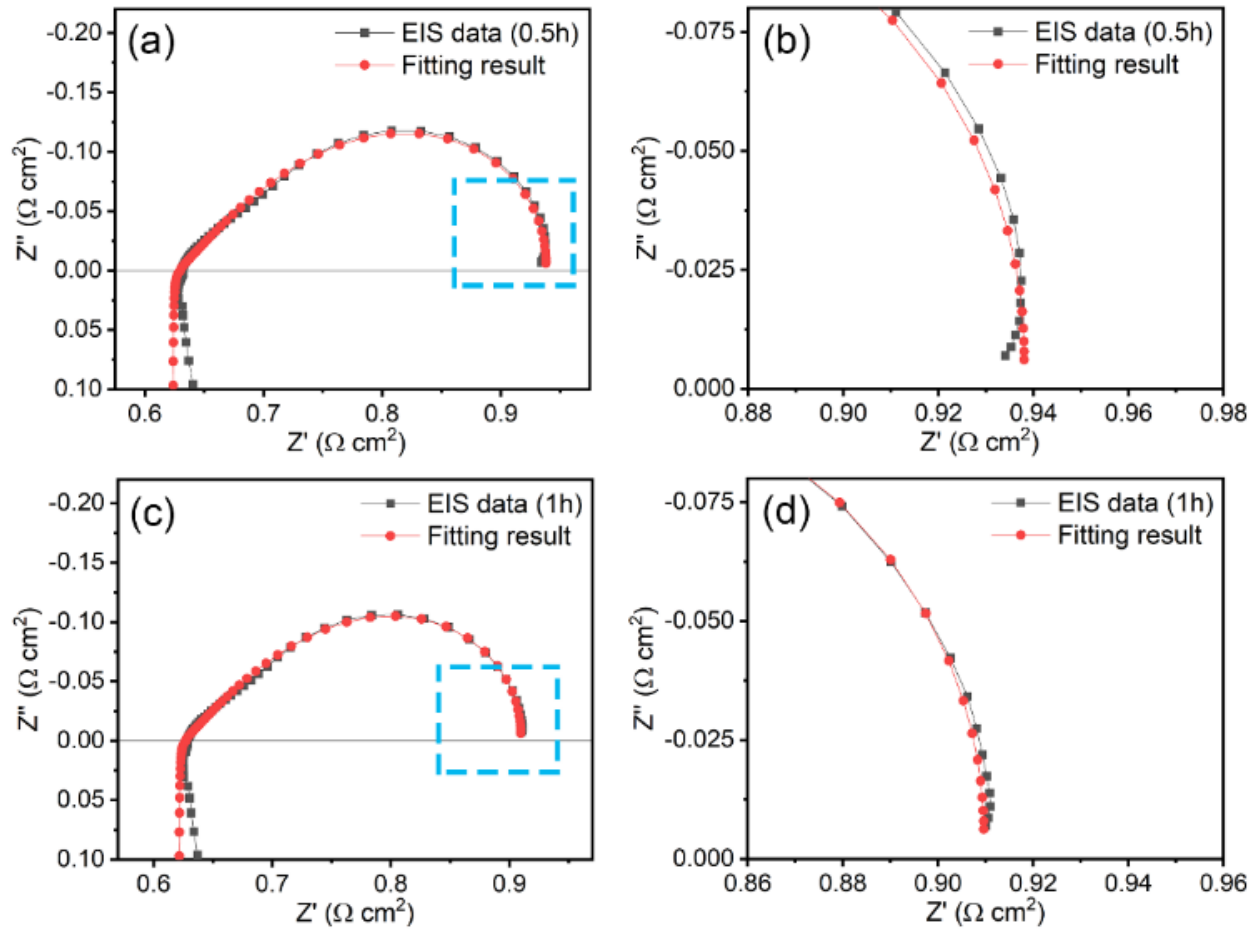

Figure 57. Nyquist plots (black) and fitting results (red) of LSFM/LSGM/LSFM symmetrical cell tested at $800{ }^{\circ} \mathrm{C}$ in humidified $\mathrm{H}_{2}$ after (a-b) $0.5 \mathrm{~h}$ reduction and (c-d) $1 \mathrm{~h}$ reduction.

At $0.5 \mathrm{~h}$, an unusual impedance curl at the low-frequency side (Figure 57a-b) indicates an unstable electrochemical process in the cell. This instability is responsible for the abnormal fitting results in Figure $55 \mathrm{c}-\mathrm{d}$ at $0.5 \mathrm{~h}$. After about $1 \mathrm{~h}$ soak time, the overlapped EIS spectrum with the fitted line (Figure 57c-d) suggests a stable electrochemical process and reveals that the fitting results in Figure 55c-d from $1 \mathrm{~h}$ to $5 \mathrm{~h}$ are reliable. Starting from $1 \mathrm{~h}$, both $R_{\text {chem }}$ and $C_{\text {chem }}$ present a clear reducing trend with time (Figure 55c). Since $R_{\text {chem }}$ and $C_{\text {chem }}$ are dominated by more than one parameter, the relationship between $R_{\text {surf }}$ and $\sigma_{i, e f f}$ with $R_{\text {chem }}$ and $C_{\text {chem }}$ will be more helpful. From Eq. (31) and Eq. (32), it can be shown:

$$
\begin{gathered}
\frac{C_{\text {chem }}}{R_{\text {chem }}}=\frac{2 F^{2}}{R T} \frac{(1-\varepsilon)}{f V_{m}} \sigma_{i, e f f} \\
C_{\text {chem }} \times R_{\text {chem }}=\frac{8 F^{2}}{R T} \frac{(1-\varepsilon)}{a f V_{m}} R_{\text {surf }}
\end{gathered}
$$


When the only concern is the electrochemical change with time at a certain temperature in a certain $\mathrm{P}_{\mathrm{O} 2}$ environment, $\varepsilon, V_{m}$, and T are constant. Thus, Eq. (33) and Eq. (34) can be simplified as Eq. (35) and Eq. (36), respectively:

$$
\begin{gathered}
\frac{C_{\text {chem }}}{R_{\text {chem }}} \propto \frac{\sigma_{i, \text { eff }}}{f} \\
C_{\text {chem }} \times R_{\text {chem }} \propto \frac{R_{\text {surf }}}{f}
\end{gathered}
$$

Here, the thermodynamic factor $f$ illustrates the difficulty of changing the stoichiometry $(\delta)$ for a given $\mathrm{P}_{\mathrm{O} 2}$ change. According to the literature ${ }^{179}, f \approx 1$ implies an easy change of the stoichiometry and $f>>1$ implies a more difficult change of the stoichiometry. During the exsolution process, $f$ should present a rising trend in the first 3 hours and gradually stabilize to a constant value. Therefore, from Figure 55d, it can be seen that $\sigma_{i, \text { eff }}$ increased with time during exsolution. The trend of $R_{\text {surf }}$, however, is complicated due to the absence of an $f$ value.

In brief, the in-situ exsolution is favorable to a promoted electrochemical performance. Exsolved Fe NPs mainly accelerate the HOR kinetics at the surface. The high phase stability of LSFM limited the Fe exsolution and phase change in the first few hours. The well-maintained perovskite structure guaranteed an acceptable ionic conductivity.

\subsubsection{The Influence of Exsolution on Surface and Bulk Properties}

To more clearly observe the influence of $R_{\text {surf }}, \sigma_{i, e f f}$ and $f$ on the electrochemical process during exsolution, the same EIS data are analyzed by the distribution of relaxation time (DRT) method. In DRT, the peak position of the $\mathrm{n}^{\text {th }}$ peak is equal to its corresponding equivalent circuit element's characteristic frequency, and the polarization resistance can be described as ${ }^{214}$ :

$$
Z_{p o l}(\omega)=R_{p o l} \int_{0}^{\infty} \frac{\gamma(\tau)}{1+j \omega \tau} \mathrm{d} \tau ; \quad \int_{0}^{\infty} \gamma(\tau) \mathrm{d} \tau=1
$$


where $Z_{p o l}$ is the total polarization resistance,

$R_{p o l}$ is the total ohmic resistance of the equivalent circuit,

$\tau$ is the relaxation time,

$\frac{\gamma(\tau)}{1+j \omega \tau}$ is the fraction of the overall polarization between relaxation time $\tau$ and $\tau+\mathrm{d} \tau$. If $S_{n}$ represents the peak area of the $\mathrm{n}^{\text {th }}$ peak in DRT, a proportional relation is seen between the peak area and the polarization resistance of the $\mathrm{n}^{\text {th }}$ peak, as shown in Eq. (38). Here, $\tau_{n, i}$ and $\tau_{n, f}$ denote the relaxation time range of the $\mathrm{n}^{\text {th }}$ peak, and $Z_{p o l}$ is the polarization resistance of the $\mathrm{n}^{\text {th }}$ peak.

$$
S_{n} \propto \int_{\tau_{n, i}}^{\tau_{n, f}} \frac{\gamma(\tau)}{1+j \omega \tau} \mathrm{d} \tau \propto Z_{p o l, n}(\omega)
$$
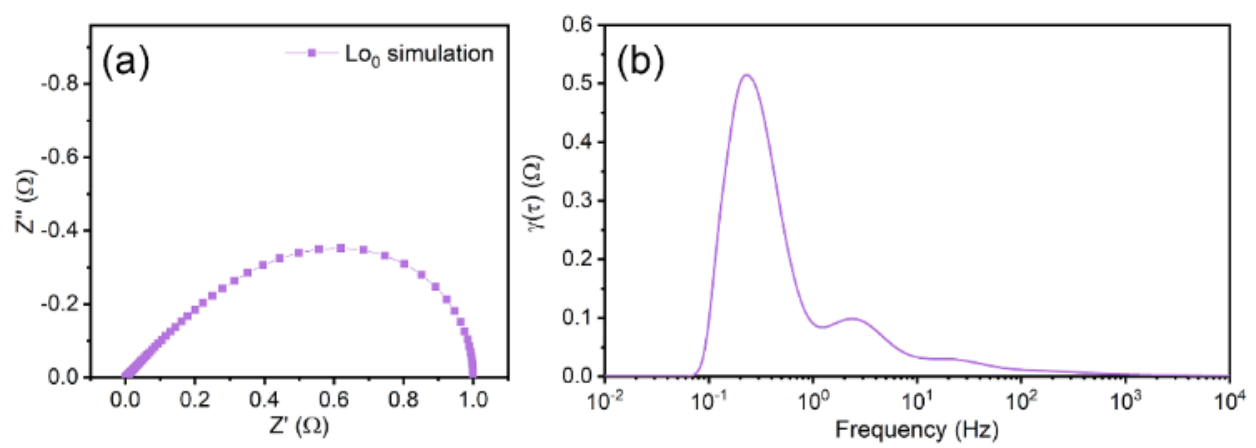

Figure 58. (a) Impedance simulation of the standard Lo element. (b) DRT result of the standard Lo element.

Different from the RQ element which corresponds to a symmetrical single peak ${ }^{215}$, the DRT result of Lo element is a multi-peak spectrum, as shown in Figure 58b. Figure 58a is the impedance spectrum of standard Lo element:

$$
Z(\omega)=\frac{1}{\sqrt{1+(j \omega)^{1}}}
$$

Considering the co-limited characteristic of the Lo element, it may not be appropriate to simply assign these peaks to the different electrochemical processes and interpret the effect of exsolution, accordingly. To 
clearly understand the DRT spectrum and better interpret the influence of exsolution, the values of $R_{\text {surf }}$, $\sigma_{i, e f f}$, and $f$ are estimated:

From Table 9, we know that at $5 \mathrm{~h}, R_{\text {chem }}=0.226 \Omega \mathrm{cm}^{2}, C_{\text {chem }}=2.305 \mathrm{~F} \mathrm{~cm}^{-2}$.

Assume porosity $\varepsilon \approx 0.5$, thermodynamic factor $f \approx 10^{137}$.

$\mathrm{F}=96485 \mathrm{C} \mathrm{mol}^{-1}, \mathrm{R}=8.314 \mathrm{~J}(\mathrm{~K} \mathrm{~mol})^{-1}, \mathrm{~T}=1073 \mathrm{~K}, V_{m}=73.41 \mathrm{~cm}^{3} \mathrm{~mol}^{-1} 137$.

(1) For the "utilization" length:

$C_{\text {chem }}=\frac{4 F^{2}}{R T} \frac{(1-\varepsilon) l_{\delta}}{f V_{m}}$

$l_{\delta}=\frac{R T}{4 F^{2}} \frac{f V_{m}}{(1-\varepsilon)} C_{c h e m}=\frac{8.314 \times 1073}{4 \times 96485^{2}} \times \frac{10 \times 73.41}{(1-0.5)} \times 2.305 \mathrm{~cm} \approx 10 \mu \mathrm{m}$

(2) For the surface area:

From Figure 45, the particle size of synthesized LSFM is about $400 \mathrm{~nm}$. Assume all LSFM particles are ideal sphere, thus, the surface area $\left(\mathrm{S}_{0}\right)$ and volume $\left(\mathrm{V}_{0}\right)$ of one ideal particle are:

$S_{0}=4 \pi r^{2}=4 \times 3.14 \times(200 \mathrm{~nm})^{2}=5.024 \times 10^{5} \mathrm{~nm}^{2}$

$V_{0}=\frac{4}{3} \pi r^{3}=\frac{4}{3} \times 3.14 \times(200 \mathrm{~nm})^{3}=3.35 \times 10^{7} \mathrm{~nm}^{3}$

In the LSFM symmetrical cell, the active area (A) of LSFM symmetrical cell is about $0.5 \mathrm{~cm}^{2}$, so, the volume of active $\operatorname{LSFM}\left(\mathrm{V}_{\text {total }}\right)$ can be calculated as:

$V_{\text {total }}=A l_{\delta}(1-\varepsilon)=0.5 \mathrm{~cm}^{2} \times 10 \mu \mathrm{m} \times(1-0.5)=2.5 \times 10^{17} \mathrm{~nm}^{3}$

Therefore, the surface area $(a)$ is roughly equal to:

$a=\frac{V_{\text {total }}}{V_{0}} S_{0}=\frac{2.5 \times 10^{17}}{3.35 \times 10^{7}} \times 5.024 \times 10^{5} \mathrm{~nm}^{2}=3.75 \times 10^{15} \mathrm{~nm}^{2} \approx 40 \mathrm{~cm}^{2}$

(3) For $R_{\text {surf }}$ and $\sigma_{i, e f f}$ : 


$$
\begin{aligned}
\frac{C_{\text {chem }}}{R_{\text {chem }}}= & \frac{2 F^{2}}{R T} \frac{(1-\varepsilon)}{f V_{m}} \sigma_{\text {i,eff }} \\
\sigma_{\text {i,eff }}= & \frac{\frac{C_{\text {chem }}}{R_{\text {chem }}}}{\frac{2 F^{2}}{R T} \frac{(1-\varepsilon)}{f V_{m}}}=\frac{\frac{2.305}{0.226}}{\frac{2 \times 96485^{2}}{8.314 \times 1073} \times \frac{(1-0.5)}{10 \times 73.41}} S \mathrm{~cm}^{-1}=0.007 \mathrm{~S} \mathrm{m^{-1 }} \\
R_{\text {chem }} & =2 \sqrt{\frac{R_{\text {surf }}}{\sigma_{i, e f f} a}} \\
\frac{R_{\text {surf }}}{\sigma_{i, \text { eff }}}= & \frac{a}{4}\left(R_{\text {chem }}\right)^{2}=\frac{40}{4} \times 0.226^{2}=0.5 \\
R_{\text {surf }} & =0.0035 \Omega \mathrm{cm}^{2}
\end{aligned}
$$

Therefore, at $5 \mathrm{~h}, R_{\text {surf }}=0.0035 \Omega \mathrm{cm}^{2}, \sigma_{i, e f f}=0.007 \mathrm{~S} \mathrm{~cm}^{-1}$ and $f \approx 10$. Based on this result, the various values of $R_{\text {surf }}, \sigma_{i, e f f}$, and $f$ are listed in Table 10 . Figure 59 shows the results of this parametric study as well as the influence of $R_{\text {surf }}, \sigma_{i, e f f}$, and $f$ on the electrochemical process.

Table 10. Parameters setting of $R_{\text {surf }}, \sigma_{i, e f f}$, and $f$.

\begin{tabular}{ccccccc}
\hline \hline & Parameters & Fitting 1 & Fitting 2 & Fitting 3 & Fitting 4 & Fitting 5 \\
\hline \multirow{2}{*}{ I } & $\boldsymbol{R}_{\text {surf }}$ & $\mathbf{0 . 0 0 1 5}$ & $\mathbf{0 . 0 0 2 5}$ & $\mathbf{0 . 0 0 3 5}$ & $\mathbf{0 . 0 0 4 5}$ & $\mathbf{0 . 0 0 5 5}$ \\
& $\sigma_{i, \text { eff }}$ & 0.007 & 0.007 & 0.007 & 0.007 & 0.007 \\
& $f$ & 10 & 10 & 10 & 10 & 10 \\
\hline \multirow{2}{*}{ II } & $R_{\text {surf }}$ & 0.0035 & 0.0035 & 0.0035 & 0.0035 & 0.0035 \\
& $\boldsymbol{\sigma}_{i, \text { eff }}$ & $\mathbf{0 . 0 0 5}$ & $\mathbf{0 . 0 0 6}$ & $\mathbf{0 . 0 0 7}$ & $\mathbf{0 . 0 0 8}$ & $\mathbf{0 . 0 0 9}$ \\
& $f$ & 10 & 10 & 10 & 10 & 10 \\
\hline \multirow{2}{*}{ III } & $R_{\text {surf }}$ & 0.0035 & 0.0035 & 0.0035 & 0.0035 & 0.0035 \\
& $\sigma_{i, e f f}$ & 0.007 & 0.007 & 0.007 & 0.007 & 0.007 \\
& $\boldsymbol{f}$ & $\mathbf{6}$ & $\mathbf{8}$ & $\mathbf{1 0}$ & $\mathbf{1 2}$ & $\mathbf{1 4}$ \\
\hline \multirow{2}{*}{ IV } & $R_{\text {surf }}$ & 0.0035 & 0.0035 & 0.0035 & 0.0035 & 0.0035 \\
& $\boldsymbol{\sigma}_{i, \text { eff }}$ & $\mathbf{0 . 0 0 5}$ & $\mathbf{0 . 0 0 6}$ & $\mathbf{0 . 0 0 7}$ & $\mathbf{0 . 0 0 8}$ & $\mathbf{0 . 0 0 9}$ \\
& $\boldsymbol{f}$ & $\mathbf{6}$ & $\mathbf{8}$ & $\mathbf{1 0}$ & $\mathbf{1 2}$ & $\mathbf{1 4}$ \\
\hline \hline
\end{tabular}



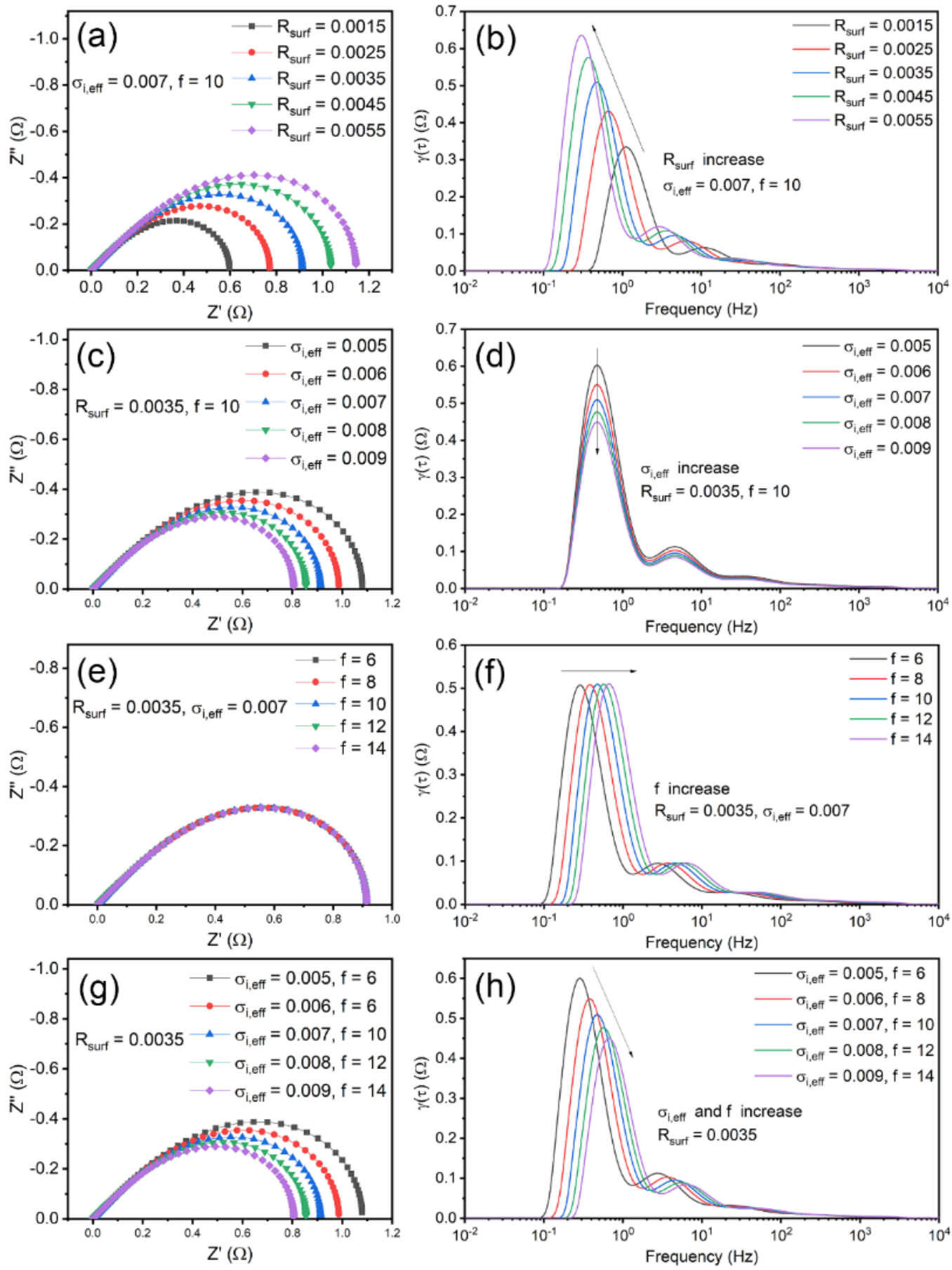

Figure 59. Simulated Lo element and corresponding DRT fitting spectra based on Table 10. (a-b) Increased $R_{\text {surf }}$ with fixed $\sigma_{i, e f f}$ and $f\left(\sigma_{i, e f f}=0.007, f=10\right)$. (c-d) Increased $\sigma_{i, e f f}$ with fixed $R_{\text {surf }}$ and $f\left(R_{\text {surf }}=0.0035, f=10\right)$. (e-f) increased $f$ with fixed $R_{\text {surf }}$ and $\sigma_{i, e f f}\left(R_{\text {surf }}=0.0035, \sigma_{i, e f f}=0.007\right) .(\mathrm{g}-\mathrm{h})$ Increased $\sigma_{i, e f f}$ and $f$ with fixed $R_{\text {surf }}\left(R_{\text {surf }}=0.0035\right)$.

In the condition I, $R_{\text {surf }}$ increased from $0.0015 \Omega \mathrm{cm}^{2}$ to $0.0055 \Omega \mathrm{cm}^{2}$ while $\sigma_{i, e f f}$ and $f$ are constant. As expected, the $\mathrm{R}_{\mathrm{p}}$ shows a clear growing trend with $R_{\text {surf }}$ increasing (Figure $59 \mathrm{a}$ ). However, it is interesting 
to notice that both peak position and peak area in Figure $59 \mathrm{~b}$ are influenced by varied $R_{\text {surf }}$. When $R_{\text {surf }}$ increases, the peak position moves to the low-frequency direction and the peak area grows. Figure 59b suggests that a reduced surface reaction resistance $R_{\text {surf }}$ contributes to faster reaction kinetics as well as smaller polarization resistance. The condition I is very similar to the experimental data, as shown in Figure 60.
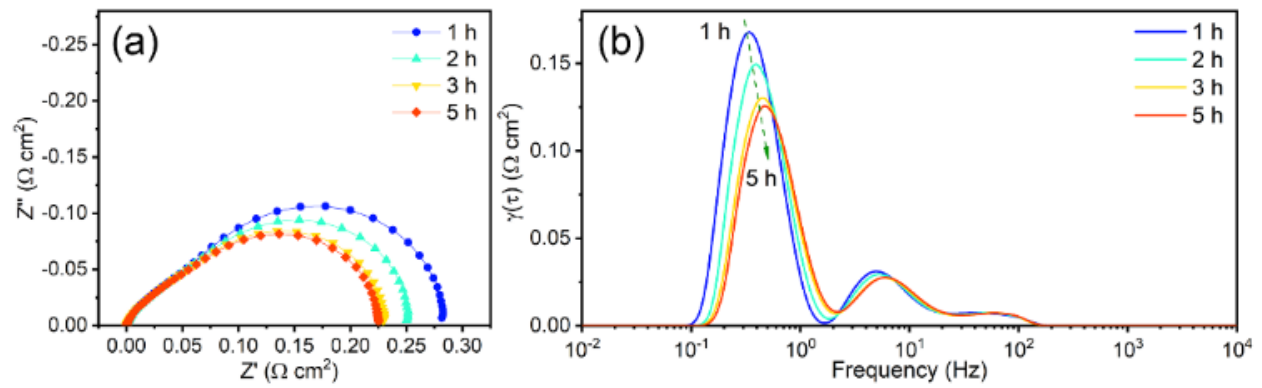

Figure 60. (a) Nyquist plots of LSFM/LSGM/LSFM symmetrical cell at $800{ }^{\circ} \mathrm{C}$ in humidified $\mathrm{H}_{2}$ for $1 \mathrm{~h}, 2 \mathrm{~h}, 3 \mathrm{~h}$, and $5 \mathrm{~h}$. In this graph, inductance (L) and ohmic resistance $\left(\mathrm{R}_{\mathrm{s}}\right)$ are subtracted from the plot. (b) The corresponding DRT spectra.

In condition II, when only $\sigma_{i, e f f}$ changes, the higher $\sigma_{i, e f f}$ also contributes to a smaller $\mathrm{R}_{\mathrm{p}}$, as shown in Figure 59c. However, in DRT fitting (Figure 59d), this drop in $\mathrm{R}_{\mathrm{p}}$ only leads to the change of peak intensity without any influence on the peak position. In condition III, opposite of condition II, a bigger $f$ pushes the DRT peak to the high-frequency direction while keeping the peak intensity the same (Figure 59f). This DRT spectra correspond to overlapping Nyquist plots, as shown in Figure 59e. Compared with $R_{\text {surf, }} \sigma_{i, e f f}$ and $f$ can only control one aspect of DRT spectrum, either peak intensity or peak position. Among them, $\sigma_{i, \text { eff }}$ can affect $\mathrm{R}_{\mathrm{p}}$ while no visible difference can be observed from a Nyquist plot with varying $f$.

Therefore, considering the influence of $f$ combined with $\sigma_{i, e f f}$, a similar trend to Figure 60 is obtained, as shown in Figure 59g-h (Condition IV). Thus, to achieve the performance improvement in Figure 60a, three variations of parameters are possible: 1) a decrease in $\left.R_{\text {surf }}, 2\right)$ an increase in $\sigma_{i, e f f}$ and $f$, and 3) a decrease in $R_{\text {surf }}$ plus an increase in $\sigma_{i, e f f}$ and $f$. The ECR test demonstrated a clear enhancement of $\mathrm{k}_{\mathrm{ex}}$ (in other words, a decrease of $R_{\text {surf }}$ ) after exsolution, and from the EIS analysis, the increment of $\sigma_{i, \text { eff }}$ and $f$ during exsolution 
are verified. Therefore, it is likely that a decrease in $R_{\text {surf }}$ plus an increase in $\sigma_{i, \text { eff }}$ and $f$ work together during the exsolution to achieve performance development, as shown in Figure 55a.

\subsection{Summary}

In this chapter, the exsolution of Fe NPs in $\mathrm{H}_{2}$, the reversibility of exsolution and the electrochemical performance related to exsolution are investigated based on LSFM. With the influence of $\mathrm{La}^{3+}$ on A-site, Fe NPs are exsolved with an average size of $120 \mathrm{~nm}$ after reducing LSFM in $\mathrm{H}_{2}$ at $800{ }^{\circ} \mathrm{C}$ for $5 \mathrm{~h}$. After about $3 \mathrm{~h}$ reducing treatment, the exsolution slows down and the material reaches a new equilibrium which demonstrated by the good phase stability in the following 100 hours treatment. On the other hand, when reoxidize LSFM in air, within about 1 hour, most Fe NPs are disappeared, a clear but waved grain boundary and grain surface indicate a reversible phase evolution. This makes LSFM an excellent potential candidate for redox applications

In a reducing atmosphere, in-situ exsolution leads to faster kinetics at the surface and higher ionic conductivity in the bulk. Based on ECR analysis, Fe exsolution leads to faster surface kinetics which comes from the great catalytic activity of Fe NPs. Meanwhile, the EIS result demonstrates the increased ionic conductivity during the exsolution process. Therefore, "excess valence" is a simple and effective strategy to obtain a uniform surface decoration and better electrochemical performance which is promising for the development of SOFC. 


\section{Chapter 6 The Role of Water in Hydrogen Oxidation Reaction}

In solid oxide fuel cells (SOFCs), there are two kinds of widely used anodes. One is traditional Ni-based composite anodes such as Ni-YSZ ${ }^{10}$, the other is ceramic anode such as perovskite structure anodes ${ }^{174,181}$. Due to the significant electrochemical performance improvement of Ni-based anode in humidified $\mathrm{H}_{2}{ }^{125}$, ${ }^{216}$, steam vapor has been universally supplied with $\mathrm{H}_{2}$ to Ni-YSZ anode ${ }^{29,217}$. A few researchers dedicated to this topic and proposed several suppositions based on their experimental results. Jiang et al. claim that in humidified gas, $\mathrm{O}_{\mathrm{ads}}$ species or suboxides form on the Ni surface. ${ }^{22}$ Compared with a clean Ni surface, adsorbed hydrogen atoms diffuse faster on oxygen species. Enough amount of oxygen species can serve as a fast hydrogen diffusion channel network on the Ni surface and significantly enhance the surface electrochemical activity. On the contrary, Bieberle's model suggests that the improved electrochemical performance in humidified gas comes from an expanded hydrogen diffusion length on the YSZ surface. ${ }^{26}$ In this model, hydroxyl groups formed in humidified gas expanded the hydrogen diffusion length on the YSZ surface via the protonation-deprotonation mechanism and facilitated the anode kinetics. However, both mechanisms can be only applicable in specific conditions. Bieberle's theory is incapable of explaining the inert effect of $\mathrm{H}_{2} \mathrm{O}$ on a Pt-YSZ electrode while Jiang's mechanism is meaningless in a Ni-free system.

With the rise of ceramic anodes, humidified $\mathrm{H}_{2}$ is also employed in many ceramic anodes ${ }^{107,196,218}$, although the verification of the $\mathrm{H}_{2} \mathrm{O}$ catalytic effect on ceramics has never been published. For a pure ceramic anode, in consideration of the absence of $\mathrm{Ni}$ and the broad solid-gas two-phase boundary on mixed ionic and electronic conductors (MIECs), such as $\mathrm{Sr}_{2} \mathrm{Fe}_{1.5} \mathrm{Mo}_{0.5} \mathrm{O}_{6-\delta}(\mathrm{SF} 1.5 \mathrm{M})^{155}$, the mechanisms in Ni-YSZ system mentioned above are unsuitable or insufficient to explain the whole story towards the pure ceramic anode. Moreover, in terms of the hydrogen oxidation reaction (HOR) (Eq. 3), additional steam vapor will increase the product $\left(\mathrm{H}_{2} \mathrm{O}\right)$ concentration and push the Eq. (3) backward, which could significantly slow down the electrochemical process on the anode side. 


$$
\mathrm{H}_{2}(g)+O_{O}^{\times}=\mathrm{H}_{2} \mathrm{O}(g)+V_{O}^{\ddot{*}}+2 e^{-}
$$

Here, $\mathrm{O}_{O}^{\times}, V_{O}$ and $e^{-}$denote lattice oxygen, oxygen vacancy, and electron, respectively. Some literature reported the HOR investigation on ceramic anode based on Eq. (3), but the influence of $\mathrm{H}_{2} \mathrm{O}$ is neglected, from both calculation ${ }^{134,219}$ and experimental aspects ${ }^{133}$.

In this chapter, we demonstrated the catalytic effect of $\mathrm{H}_{2} \mathrm{O}$ on $\mathrm{HOR}$ based on $\mathrm{Sr}_{2} \mathrm{Fe}_{1.5} \mathrm{Mo}_{0.5} \mathrm{O}_{6-\delta}(\mathrm{SF} 1.5 \mathrm{M})$ and related perovskite materials with electrical conductivity relaxation (ECR) and electrochemical impedance spectroscopy (EIS) method. In both low and high $\mathrm{P}_{\mathrm{H} 2}$ environment, a faster HOR process was observed in humidified gas. The experimental data analysis indicates that $\mathrm{H}_{2} \mathrm{O}$ mainly contribute to a faster surface reaction process. This hypothesis is further verified by DFT based thermodynamic modeling. As moderate steam vapor can increase the oxygen chemical potential and hydrate the surfaces of the ceramic material, the modeling results demonstrate the beneficial effects of humidity on the HOR reactions as results of (a) smaller $\delta$ and (b) formation surface hydroxyl groups, both of which lower reaction energy of the HOR processes.

As the first step of the $\mathrm{H}_{2} \mathrm{O}$ catalytic effect study, we will only focus on pure perovskite structure in this chapter. SF1.5M is tested in both high and low $\mathrm{P}_{\mathrm{H} 2}$ environment due to the high stability in $\mathrm{H}_{2}$ (Figure 22). For other perovskite compositions: $\mathrm{La}_{0.5} \mathrm{Sr}_{1.5} \mathrm{Fe}_{1.5} \mathrm{Mo}_{0.5} \mathrm{O}_{6-\delta}(\mathrm{LSFM})$ and $\mathrm{Pr}_{0.5} \mathrm{Sr}_{1.5} \mathrm{Fe}_{1.5} \mathrm{Mo}_{0.5} \mathrm{O}_{6-\delta}$ (PSFM), insitu exsolution were observed (Figure 44 and Figure 61) in the high $\mathrm{P}_{\mathrm{H} 2}$ environment. So, the ECR and EIS tests on LSFM and PSFM are conducted in low $\mathrm{P}_{\mathrm{H} 2}$ environments to avoid the exsolution during tests. 


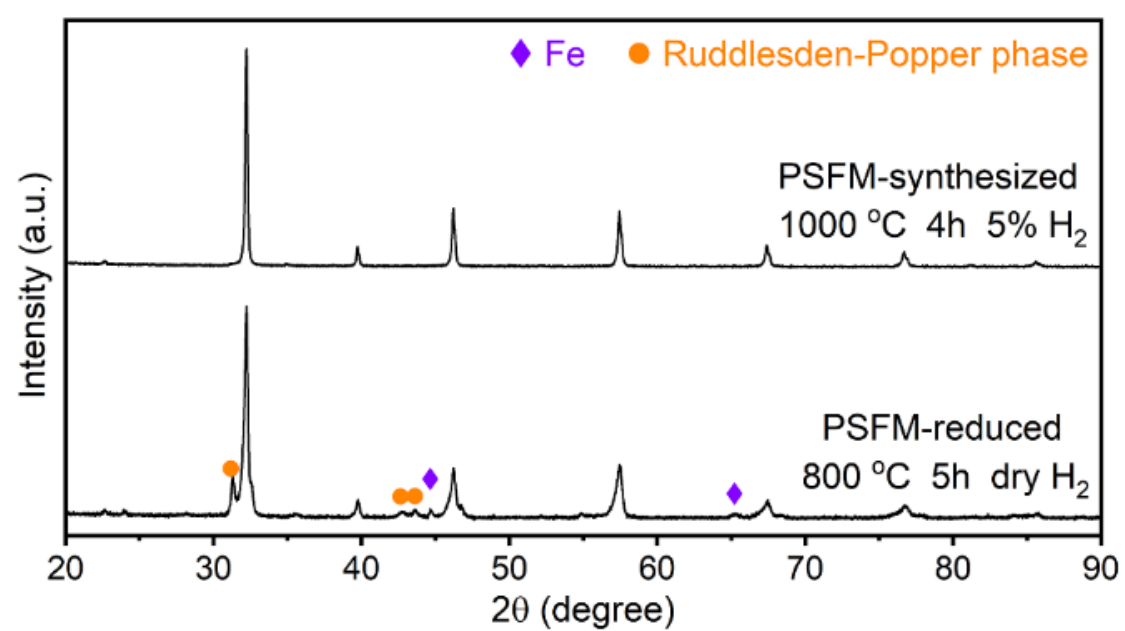

Figure 61. XRD patterns of PSFM synthesized in the $5 \% \mathrm{H}_{2}$ at $1000{ }^{\circ} \mathrm{C}$ for $4 \mathrm{~h}$ and reduced in dry $\mathrm{H}_{2}$ at $800{ }^{\circ} \mathrm{C}$ for $5 \mathrm{~h}$.

\subsection{Catalytic Effect of $\mathrm{H}_{2} \mathrm{O}$ to $\mathrm{HOR}$}

\subsubsection{Accelerated surface process in humidified gas (ECR)}

Electrical Conductivity Relaxation (ECR) is an intuitive method to compare the equilibrium rate of ceramic materials from one $\mathrm{P}_{\mathrm{O} 2}$ environment to another. It is also an effective way to extract the surface and bulk electrochemical information from a simple test. In this section, ECR is employed to compare the response behavior of SF1.5M to the gas change with or without $\mathrm{H}_{2} \mathrm{O}$ in a low $\mathrm{P}_{\mathrm{H} 2}$ condition (from $5 \% \mathrm{H}_{2}$ to $10 \% \mathrm{H}_{2}$ ). Theoretically speaking, a dry $\mathrm{H}_{2}-\mathrm{N}_{2}$ mixed gas provides a lower $\mathrm{P}_{\mathrm{O} 2}$ environment which leads to a higher oxygen vacancy concentration and a higher oxygen ion diffusion rate $\left(\mathrm{D}_{\text {chem }}\right)$ in bulk. Besides, the more significant $\mathrm{P}_{\mathrm{O} 2}$ difference from $\mathrm{P}_{\mathrm{H} 2}-1$ to $\mathrm{P}_{\mathrm{H} 2}-2$ result in a stronger driving force for oxygen exchange $\left(\mathrm{k}_{\mathrm{ex}}\right)$ at the surface. Therefore, a faster equilibrium process is expected. 

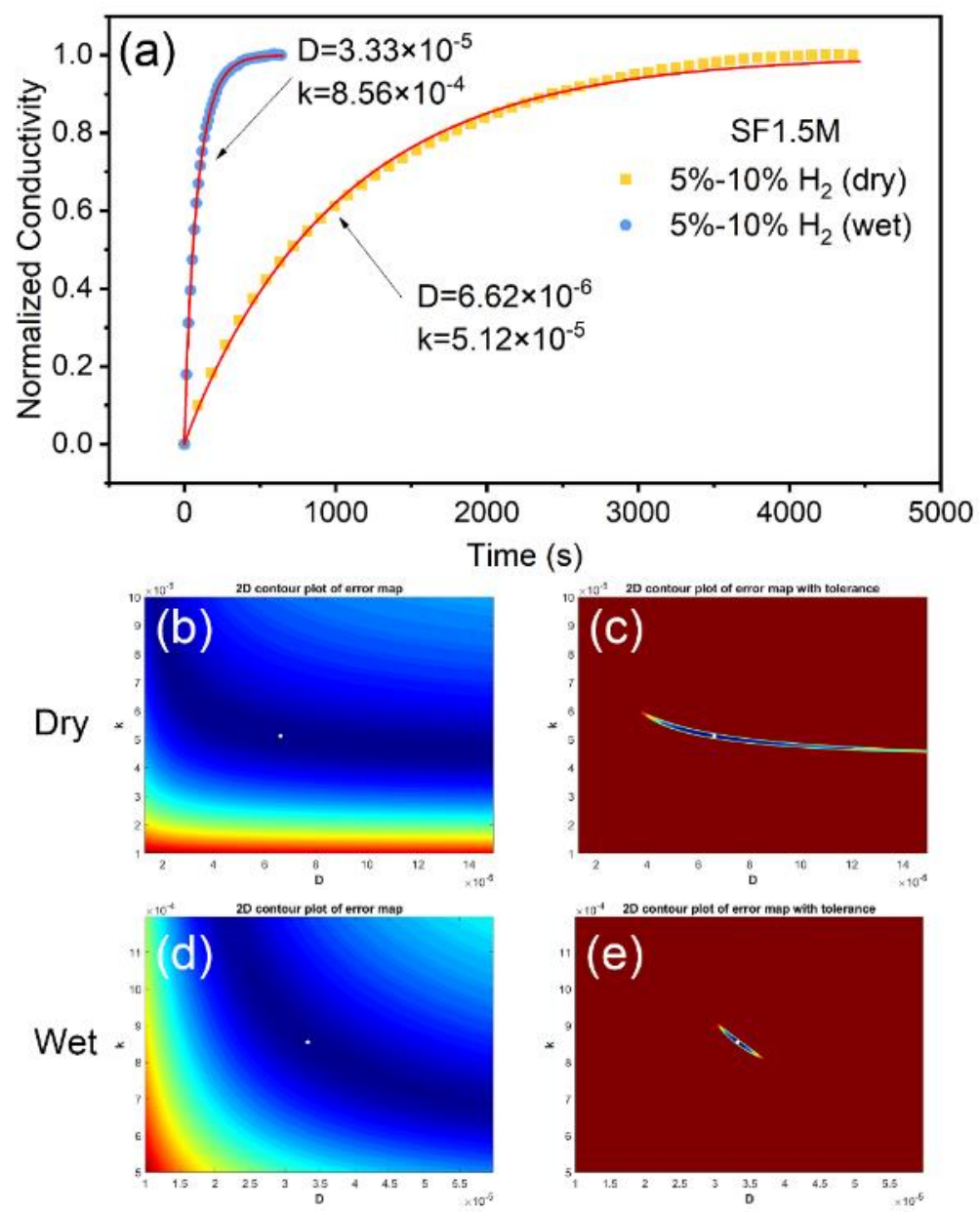

Figure 62. (a) ECR raw data and fitting results of SF1.5M bar sample at $800{ }^{\circ} \mathrm{C}$ in the dry (yellow) and wet (blue) gas mixture from $5 \% \mathrm{H}_{2}$ to $10 \% \mathrm{H}_{2} .2 \mathrm{D}$ error map in dry (b) and wet (d) gas, error map with $5 \%$ tolerance in dry (c) and wet (e) gas are also given.

Contrary to the expectation that when switching the gas from $5 \% \mathrm{H}_{2}$ to $10 \% \mathrm{H}_{2}$, a much faster equilibrium process is observed in humidified gas (Figure 62a). The value of $k_{e x}$ in the humidified gas is about one order of magnitude larger than that in the dry gas (Figure 62a). Considering the small error of $\mathrm{k}_{\mathrm{ex}}$ values (about \pm

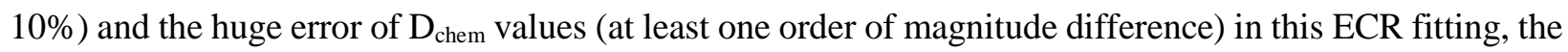
$\mathrm{k}_{\mathrm{ex}}$ values are reliable. In view of error maps from ECR fitting, we believe the equilibrium process in dry gas is mainly limited by a slow surface process. From Figure 62c, the error map with 5\% tolerance exhibits a long and almost horizontal narrow area. This shape means that when the $\mathrm{D}_{\text {chem }}$ and $\mathrm{k}_{\mathrm{ex}}$ value approaching to the optimum solution (white point in Figure 62c), the fitting result is mainly dominated by the fixed $\mathrm{k}_{\mathrm{ex}}$ 
value along with the more flexible $\mathrm{D}_{\text {chem }}$ value, which indicates the rate-determining step in the dry gas is the slow surface reaction process. Comparatively, the similar $\mathrm{D}_{\text {chem }}$ and $\mathrm{k}_{\mathrm{ex}}$ range in Figure $62 \mathrm{e}$ suggests a co-limited process in humidified gas. Similar results are also observed from perovskite materials LSFM and PSFM (Figure 63 and Figure 64). This leads to the conclusion that in a dry environment at low $\mathrm{P}_{\mathrm{H} 2}$ condition, the electrochemical reaction on the anode side is limited by a slow surface process.
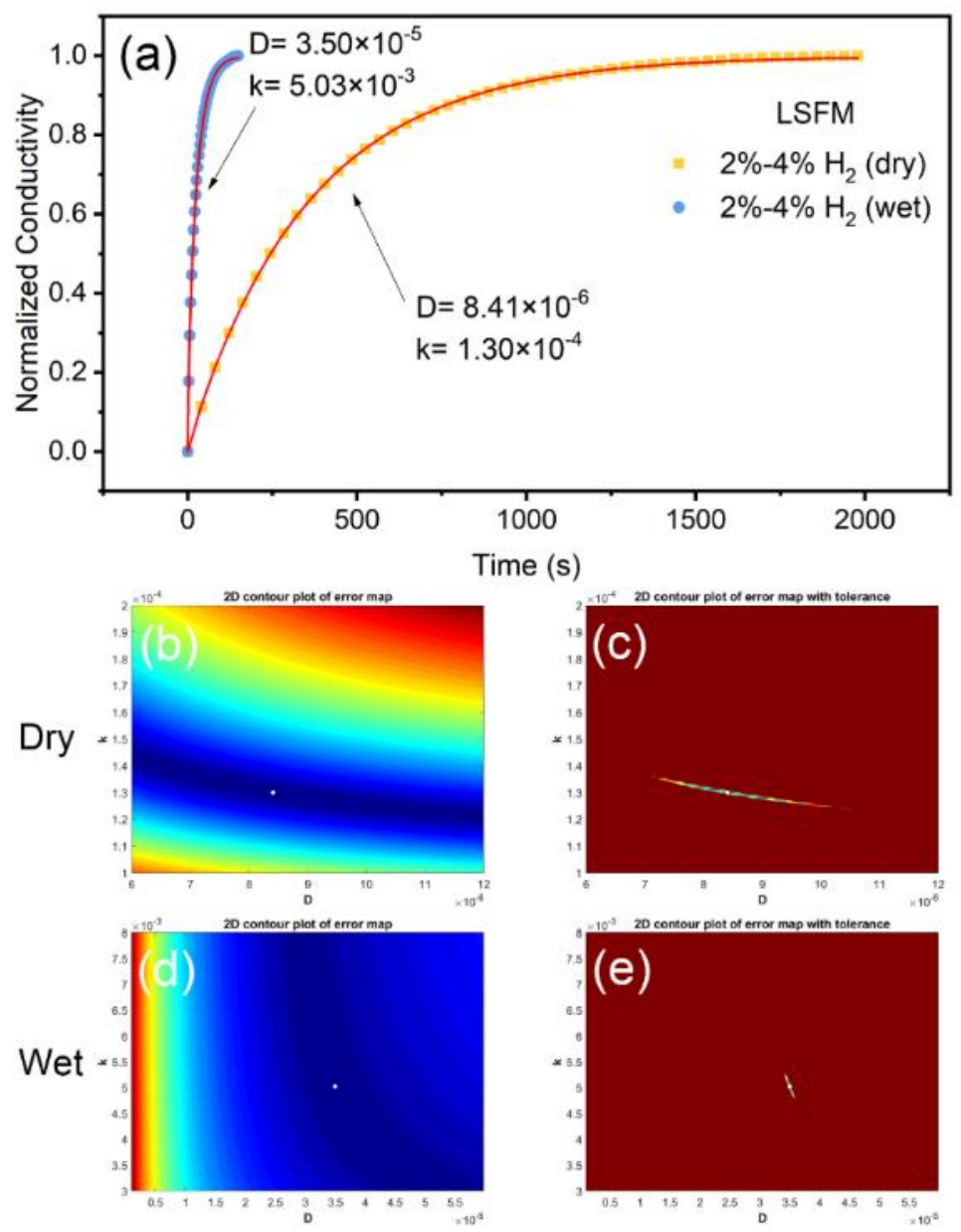

Figure 63. (a) ECR raw data and fitting results of the fresh LSFM bar sample (no exsolution) at $800^{\circ} \mathrm{C}$ in the dry (yellow) and wet (blue) gas mixture from $2 \% \mathrm{H}_{2}$ to $4 \% \mathrm{H}_{2} .2 \mathrm{D}$ error map in dry (b) and wet (d) gas, error map with $5 \%$ tolerance in dry (c) and wet (e) gas are also given. 

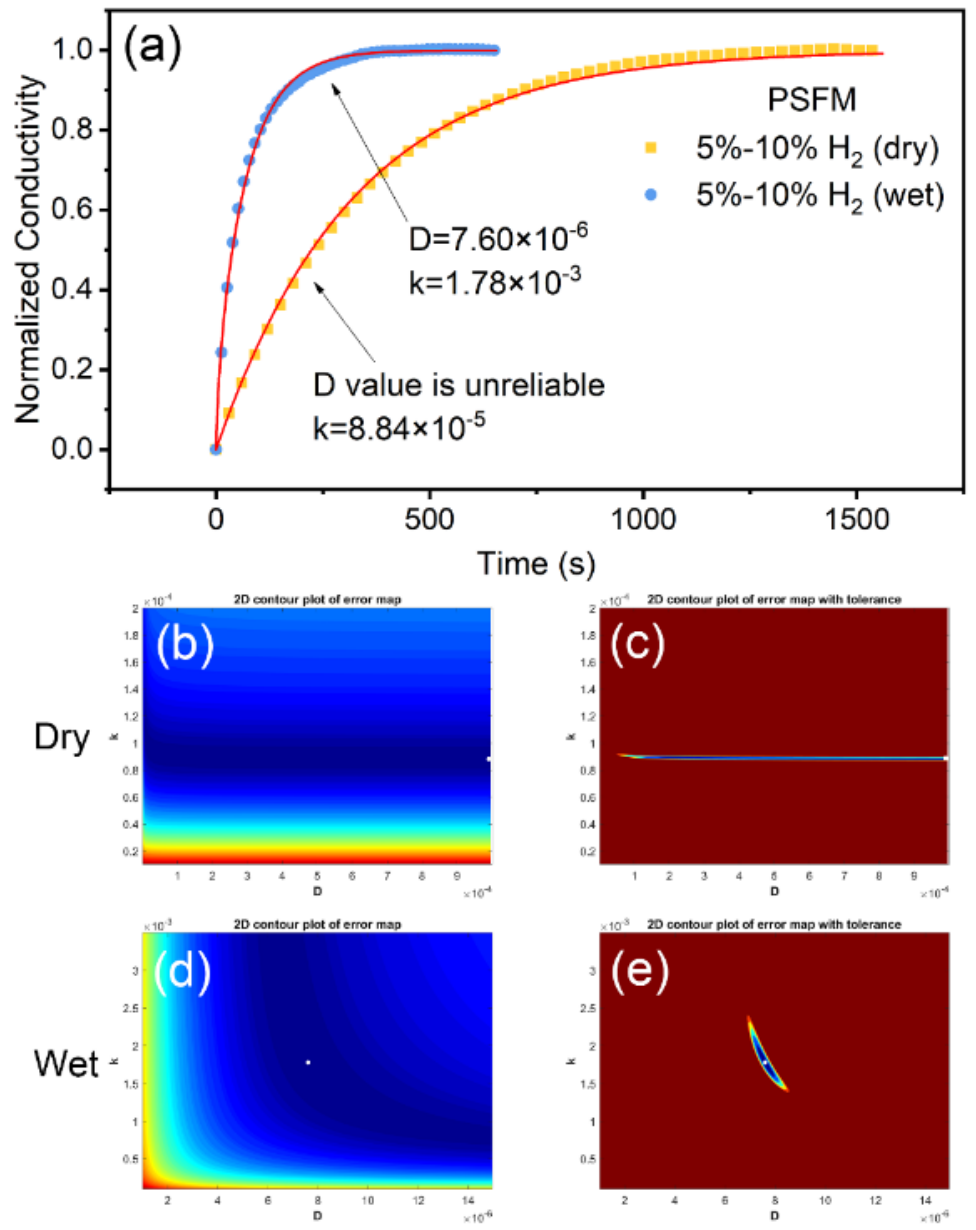

Figure 64. (a) ECR raw data and fitting results of fresh PSFM bar sample (no exsolution) at $800{ }^{\circ} \mathrm{C}$ in the dry (yellow) and wet (blue) gas mixture from $5 \% \mathrm{H}_{2}$ to $10 \% \mathrm{H}_{2}$. 2D error map in dry (b) and wet (d) gas, error map with $5 \%$ tolerance in dry (c) and wet (e) gas are also given.

\subsubsection{Accelerated Surface Process in humidified gas (EIS)}

To further simulate a fell cell operation condition, EIS is performed on LSGM electrolyte supported symmetrical cells. Given the great chemical stability of SF1.5M in $\mathrm{H}_{2}$, the same SF1.5M/LSGM/SF1.5M symmetrical cell is tested in $\mathrm{H}_{2}$ and $5 \% \mathrm{H}_{2}$ with and without steam, respectively. For other perovskite materials, their symmetrical cells are tested in dry and wet $5 \% \mathrm{H}_{2}$. As shown in Figure 65 and Figure 66, 
all symmetrical cells exhibit a smaller polarization resistance $\left(\mathrm{R}_{\mathrm{p}}\right)$ in the humidified environments than that in the dry gas.
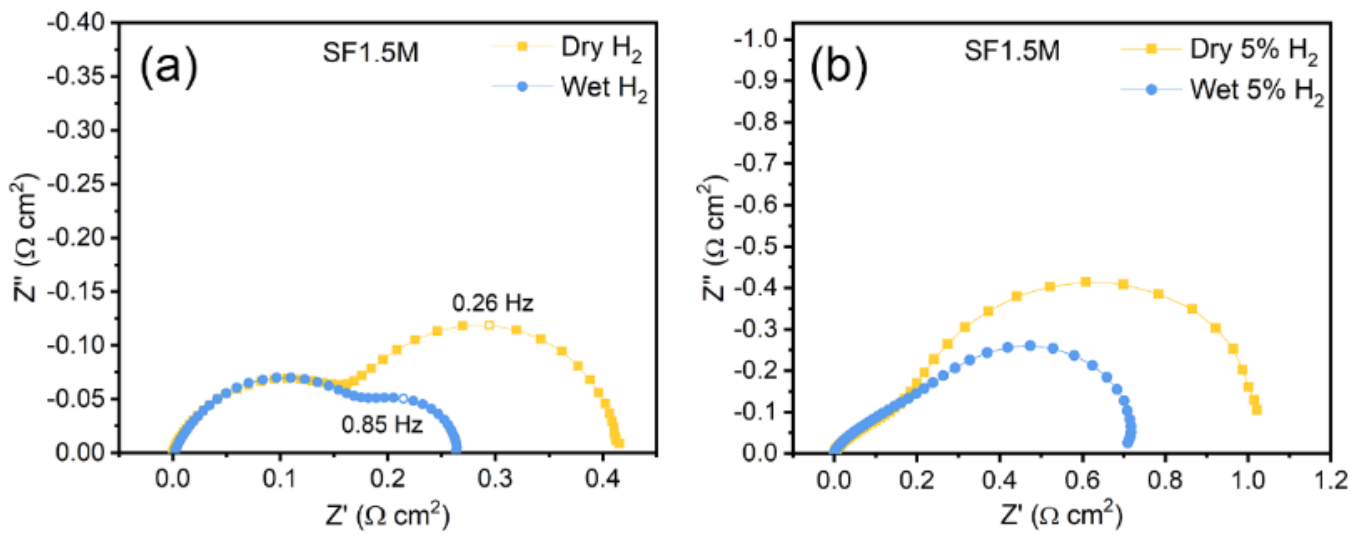

Figure 65. Nyquist plots of the symmetrical cell SF1.5M/LSGM/SF1.5M obtained at $800{ }^{\circ} \mathrm{C}$ in dry and humidified (a) $\mathrm{H}_{2}$, (b) $5 \% \mathrm{H}_{2}$.
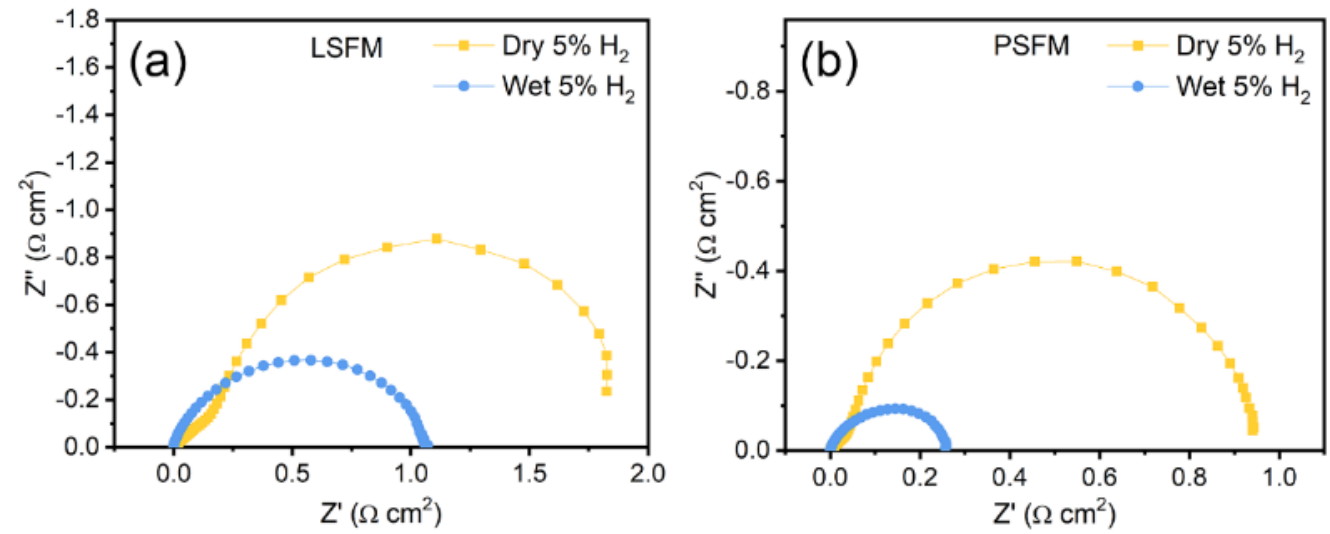

Figure 66. Nyquist plots of the symmetrical cell (a) LSFM/LSGM/LSFM, (b) PSFM/LSGM/PSFM obtained at $800{ }^{\circ} \mathrm{C}$ in dry and humidified $5 \% \mathrm{H}_{2}$.

In the pure $\mathrm{H}_{2}$ (Figure 65a), the impedance spectra of SF1.5M symmetrical cell are made of two arcs, the high-frequency arc corresponds to the charge transfer process and the low-frequency arc corresponds to the surface process ${ }^{181-182}$. As presented in Figure $65 \mathrm{a}$, the overlap of two spectra at high-frequency range suggests a similar charge transfer process in different gases and implies that $\mathrm{H}_{2} \mathrm{O}$ has no obvious effect on the charge transfer process. At low-frequency range, a much smaller arc can be observed in humidified $\mathrm{H}_{2}$ together with the increased characteristic frequency, which rises from $0.26 \mathrm{~Hz}\left(\operatorname{dry~} \mathrm{H}_{2}\right)$ to $0.85 \mathrm{~Hz}\left(\mathrm{wet}_{2}\right)$. 
This evident change reveals a promoted surface kinetics with the help of $\mathrm{H}_{2} \mathrm{O}$ in high $\mathrm{P}_{\mathrm{H} 2}$ environment. This conclusion is consistent with our ECR result.

\subsection{HOR Mechanism and the Role of $\mathrm{H}_{2} \mathrm{O}$}

\subsubsection{Rate-determining Steps on SF1.5M Surfaces}

The surface HOR processes can be divided into several reaction steps, such as hydrogen dissociative adsorption (Eq. (40)), hydrogen diffusion (Eq. (41)), $\mathrm{H}_{2} \mathrm{O}$ plus surface oxygen vacancy formation (reaction between hydrogen and lattice oxygen to produce $\mathrm{H}_{2} \mathrm{O}$ and surface oxygen vacancy) (Eq. (42)), desorption of $\mathrm{H}_{2} \mathrm{O}$ from surface ${ }^{133-134}$ (Eq. (43)). Where * denotes the adsorption sites on the surface, subscribe "ad" indicates the adsorbed atoms or molecules, $\mathrm{H}_{\mathrm{ad}, 2 \mathrm{~PB}}$ and $\mathrm{H}_{\mathrm{ad}, 3 \mathrm{~PB}}$ present the adsorbed hydrogen at the solidgas two-phase boundary and solid-solid-gas triple-phase boundary, respectively.

$$
\begin{gathered}
H_{2}(g)+2 * \leftrightarrow 2 H_{a d} \\
H_{a d, 2 P B} \leftrightarrow H_{a d, 3 P B} \\
2 H_{a d}+O_{O}^{\times} \leftrightarrow H_{2} O_{a d}+V_{O}^{*}+2 e^{-} \\
H_{2} O_{a d} \leftrightarrow H_{2} O(g)+*
\end{gathered}
$$

Guided from the distinct ECR and EIS responses between the dry and wet conditions, a hypothesis is proposed for the increase of HOR activity of SF1.5M upon increasing humidity of the $\mathrm{H}_{2}$ gas. Benefit from the sufficient ionic and electrical conductivity, HOR area on SF1.5M is expanded to the solid-gas twophase boundary on the electrode. Thus, hydrogen diffusion (Eq. (41)) should not be the rate-determining step. Also, desorption of $\mathrm{H}_{2} \mathrm{O}$ (Eq. (43)) is unlikely to be the rate-determining step in the dry gas. Therefore, the added $\mathrm{H}_{2} \mathrm{O}$ could be beneficial to the surface catalytic processes such as the hydrogen dissociative adsorption (Eq. (40)) and the reactions between hydrogen and lattice oxygen on the surface (Eq. (42)).

The HOR intermediate state of the $\mathrm{H}_{2} \mathrm{O}$ plus surface $\mathrm{O}$ vacancy formation was previously reported to be the rate determined step for $\mathrm{HOR}$ on the $(001) \mathrm{FeO}_{2}$ terminated surfaces, whereas the HOR on the surface 
Mo-site of the mixed (001) $\mathrm{BO}_{2}$ surfaces ( $\mathrm{B}=\mathrm{Fe}$ and $\mathrm{Mo}$ ) is controlled by the $\mathrm{H}_{2}$ dissociation step, when the fuel cells are operated near the open circuit voltage or under the low applied voltage conditions. ${ }^{134}$ In the following discussions, we will focus on the perovskite (001) surface models to examine the effect of humidity on the HOR on the SF1.5M surfaces.

\subsubsection{Effect of Slab Non-stoichiometry on HOR Reaction Energy}

Although $\mathrm{H}_{2} \mathrm{O}(\mathrm{g})$ is on the product side of the HOR (Eq. (3)), which intuitively suggests a likelihood of suppressing the forward HOR reaction upon increasing humidity in the $\mathrm{H}_{2}$ gas, the oxygen nonstoichiometry of SF1.5M (the activity of $\mathrm{O}_{O}^{\times}$) is also influenced by the added humidity, i.e., the lattice $\mathrm{O}_{O}^{\times}$activity is increased $\left(V_{O}^{*}\right.$ or $\delta$ is decreased) near the SF1.5M surfaces when adding the humidity. It is noted that following the concept of the chemical potential for the $\mathrm{O}$ lattice building unit ${ }^{220}$, the effect of increasing lattice $0_{O}^{\times}$activity is accompanied with the decreased $V_{O}^{*}$ activity. Therefore, the activities of the $0_{O}^{\times}$and $V_{O}^{*}$ species in the HOR equation cannot be separately discussed when referring to the oxygen chemical potential. Consequently, the electron chemical potential (Fermi level) near the SF1.5M surfaces is also decreased at lower $\delta^{221}$, which contributes to the free energy decrease on the right-hand side of Eq. (3). Overall, both the increased lattice $\mathrm{O}_{O}^{\times}$activity on the reactant side (which also simultaneously accounts for decreased $V_{O}^{*}$ activity on the product side following the concept of the $\mathrm{O}$ lattice building unit) and decreased electron chemical potential on the product side compete with the $\mathrm{H}_{2} \mathrm{O}$ activity effect in the forward reaction of $\mathrm{HOR}$ upon adding humidity.

In Figure 67, the HOR reaction energy landscapes for the $\mathrm{SF} 1.5 \mathrm{M}(001) \mathrm{BO}_{2}$ terminated surface under the dry condition (solid lines $-\mathrm{T}=1000 \mathrm{~K}, \mathrm{P}_{\mathrm{H} 2}=0.05$ bar, and $\mathrm{P}_{\mathrm{H} 2 \mathrm{O}}=0.0001$ bar) and the wet condition (dashed lines $-\mathrm{T}=1000 \mathrm{~K}, \mathrm{P}_{\mathrm{H} 2}=0.10 \mathrm{bar}$, and $\mathrm{P}_{\mathrm{H} 2 \mathrm{O}}=0.03$ bar $)$ are presented. These two analyses were performed for considering the $\mathrm{H}_{2} \mathrm{O} / \mathrm{H}_{2}$ gas phase chemical potential differences between the dry and wet conditions at a given slab (subsurface) $\delta$. Note that there is no surface hydration reaction involved in Figure 67's calculations and $\mathrm{H}_{2} \mathrm{O}$ is only regarded as a product. The effect of increasing $\mathrm{P}_{\mathrm{H} 2}$ in the wet condition vs. the 
dry condition is found to cause slight energy reduction of the first three intermediate states (I1, I2, and I3) by about $0.06 \mathrm{eV}$. On the other hand, it can be seen that more significant change of the HOR energy landscapes at different nonstoichiometry values $(\delta=0,0.25,0.50$ and 0.75$)$, where a lower energy is needed for the plateau state (I3) of HOR on the SF1.5M surfaces at lower $\delta$. It is also noted that the $\mathrm{H}_{2}$ dissociative adsorption can occur either on two surface O-sites (I2 - HatO\&HatO) or on one surface M-site plus one surface O-site (I1 - HatM\&HatO), and their relative stability can be switched at different $\delta$ : the HatO\&HatO state is lower in energy at $\delta=0$ and 0.25 whereas the HatM\&HatO state is lower in energy at $\delta=0.5$ and 0.75. For the HOR processes, the configuration of higher energy between the HatO\&HatO and HatO\&HatM states can be bypassed for the $\mathrm{H}_{2}$ dissociative adsorption step, as indicated by the dashed line arrows in Figure 67. Beyond the $\mathrm{H}_{2}$ dissociative adsorption step, the $\mathrm{H}_{2} \mathrm{O}$ plus surface oxygen vacancy formation step (Surf_Vo\& $\mathrm{H}_{2} \mathrm{OatM}$ ) can be found to be the intermediate state possessing the highest energy in the HOR energy landscape for $\delta=0.25-0.75$. Such results are consistent with Suthirakun et al. for the SF1.5M (001) B surfaces simulated at $\delta=0.625 .{ }^{134}$ Therefore, considering the energy of Surf_Vo\& $\mathrm{H}_{2} \mathrm{OatM}$ (I3) state relative to the initial surface state in the HOR energy landscape, that the plateau state $-\mathrm{I} 3\left(\mathrm{H}_{2} \mathrm{OatM} \&\right.$ Surf_ $\mathrm{V}_{\mathrm{O}}$ ) is higher in energy at $\delta=0.75$ and becomes lower when decreasing $\delta$ of the slab indicate the HOR activities can be increased at lower $\delta$ near the SF1.5M surfaces. Overall, the HOR reaction energy landscapes are found to be more significantly influenced by the SF1.5M slab non-stoichiometry value $(\delta)$ than the $\mathrm{H}_{2} \mathrm{O} / \mathrm{H}_{2}$ gas phase thermodynamic effect at fixed $\delta$, indicating the near surface $\delta$ change in response to the added humidity in the $\mathrm{H}_{2}$ gas can result in greater enhancement to the HOR activities. 


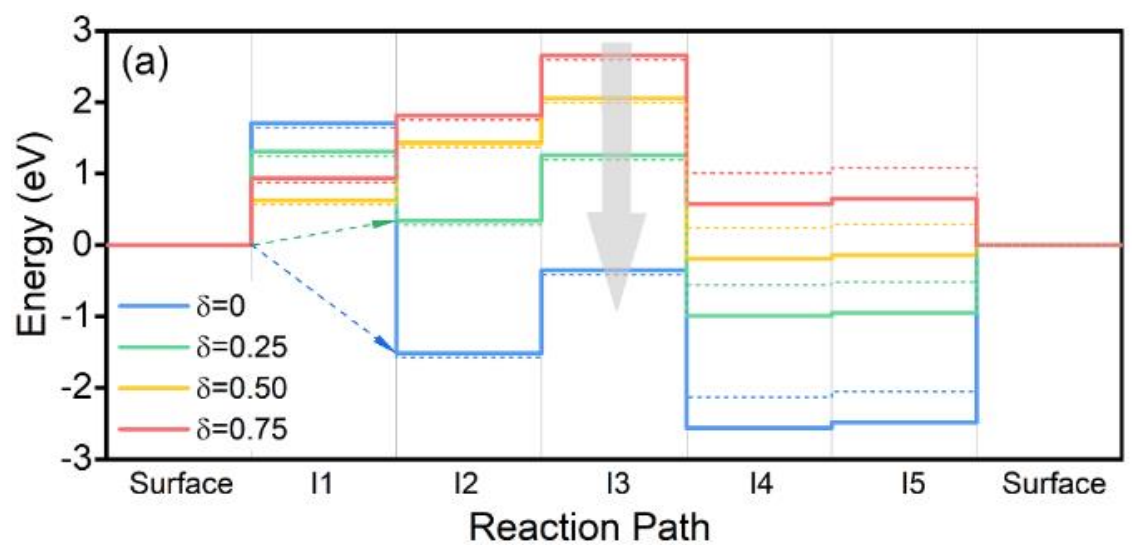

(b) Surface

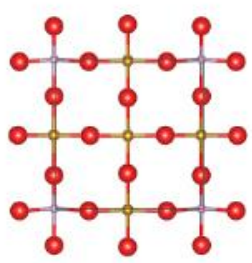

(e) I3 ( $\mathrm{H}_{2} \mathrm{O}$ atM\&Surf_Vo)

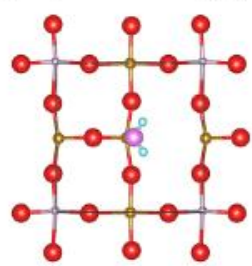

(c) 11 (HatM\&HatO)

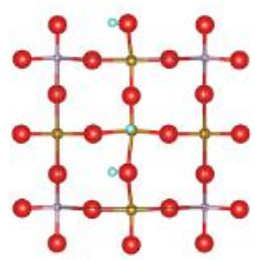

(f) 14 (Surf_Vo)

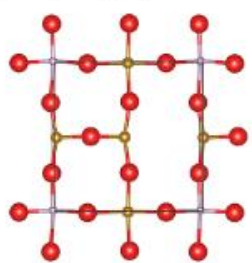

(d) 12 (HatO\&HatO)

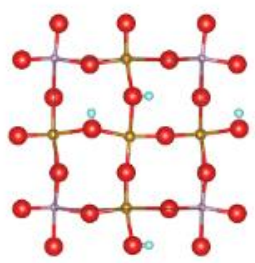

(g)15 (Subsurf_Vo)

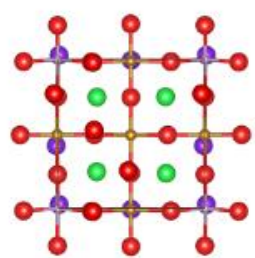

Figure 67. (a) Hydrogen dissociation reaction energy landscape calculated for the $\mathrm{SF} 1.5 \mathrm{M}(001) \mathrm{BO}_{2}$ surface for the dry condition (solid lines) of $\mathrm{T}=1000 \mathrm{~K}, \mathrm{P}_{\mathrm{H} 2}=0.05 \mathrm{bar}$, and $\mathrm{P}_{\mathrm{H} 2 \mathrm{O}}=0.0001$ bar and the wet condition (dashed lines) of $\mathrm{T}=1000 \mathrm{~K}, \mathrm{P}_{\mathrm{H} 2}=0.10 \mathrm{bar}$, and $\mathrm{P}_{\mathrm{H} 2 \mathrm{O}}=0.03$ bar. The color of the lines respresent different slab nonstoichiometry simulated in the slab models: $\delta=0-$ blue, $\delta$ $=0.25-$ green, $\delta=0.5-$ yellow, and $\delta=0.75-$ red. The dotted arrows are to highlight the competing steps of I 2 and $\mathrm{I} 3$ for the $\mathrm{H}_{2}$ dissocative adsorption, in which I 2 is higher in energy than I 3 and can be by-passed to the I3 step. The top view of the surface states presented in Figure 67(a) are provided in (b) Surface, (c) I1 (HatM\&HatO), (d) I2 (HatM\&HatO), (e) I3 (H2OatM\&Surf_Vo), (f) I4 (Surf_Vo), and (g) I5 (Subsurf_Vo), where the second surface layer is only included in the plot (g). The color of the spheres in Figure 67(b-g) are: brown - Fe, light purple - Mo, red - surface layer O, dark purple- the second surface layer $\mathrm{O}$, green - Sr, dark pink - $\mathrm{O}$ of the adsorbed water, and light blue $-\mathrm{H}$. The shaded grey arrow indicates decrease of the $\mathrm{I} 3$ energy with decreasing $\delta$. 


\subsubsection{The Effect of $\mathrm{H}_{2} \mathrm{O}(\mathrm{g})$ on the $\mathrm{HOR}$ with the same $\delta$ change}

The conclusion from the last section is consistent with the rising trend of $\mathrm{k}_{\mathrm{ex}}$ with $\mathrm{P}_{\mathrm{O} 2}$ increase $\left(\mathrm{P}_{\mathrm{H} 2}\right.$ decrease $)$ in LSFM with a constant $\mathrm{P}_{\mathrm{H} 2 \mathrm{O}}\left(3 \% \mathrm{H}_{2} \mathrm{O}\right)$ (Figure 53c). However, the HOR kinetics in different $\mathrm{P}_{\mathrm{H} 2 \mathrm{O}}$ conditions are still unclear. Therefore, ECR tests with the same $\mathrm{P}_{\mathrm{O} 2}$ change in different $\mathrm{P}_{\mathrm{H} 2 \mathrm{O}}$ conditions are designed. Due to the highest sensitivity to the environment change and the best resistance reversibility of LSFM (Figure 68) among the investigated perovskite materials, two ECR tests are carried out on LSFM.

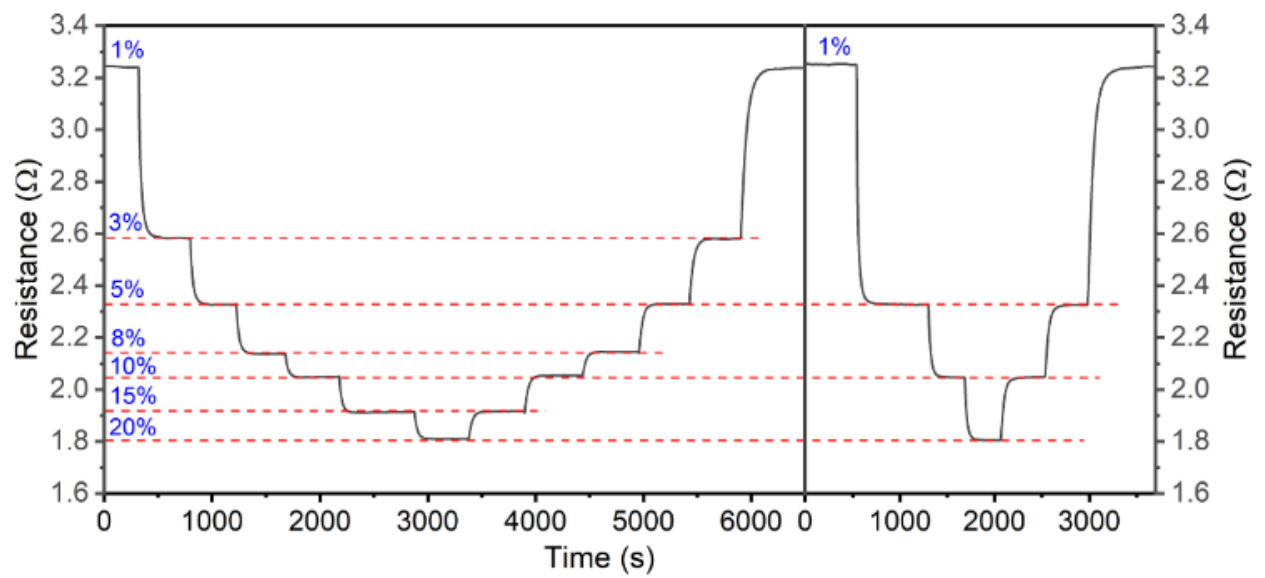

Figure 68. In ECR test, LSFM resistance change with $\mathrm{P}_{\mathrm{H} 2}$ in the humidified atmosphere $\left(3 \% \mathrm{H}_{2} \mathrm{O}\right)$ at $800{ }^{\circ} \mathrm{C}$.
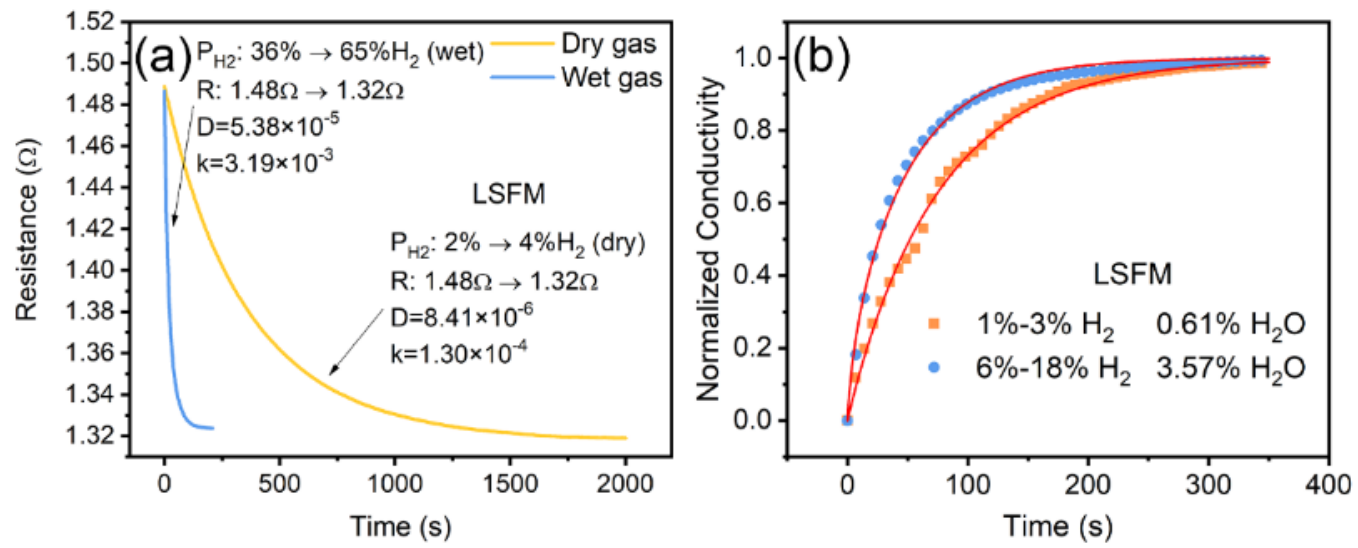

Figure 69. ECR tests on the fresh LSFM bar sample at $800{ }^{\circ} \mathrm{C}$ with (a) the same resistance change, (b) the same theoretical $\mathrm{P}_{\mathrm{O} 2}$ change.

In the first experiment, the equilibrium processes with the same resistance change in dry and humidified gas are compared. Since it is difficult to directly measure the $\mathrm{P}_{\mathrm{O} 2}$ in a dry gas, we use resistance as the $\mathrm{P}_{\mathrm{O} 2}$ 
indicator. As shown in Figure 69a, gas with and without steam are provided to make the sample resistance changed from $1.48 \Omega$ to $1.32 \Omega$. Similar to Figure $62 \mathrm{a}$, the equilibrium process is faster in the humidified gas. For the second experiment, gas mixtures with different $\mathrm{P}_{\mathrm{H} 2 \mathrm{O}}\left(0.61 \% \mathrm{H}_{2} \mathrm{O}\right.$ with ice water, $3.57 \% \mathrm{H}_{2} \mathrm{O}$ with $26.9^{\circ} \mathrm{C}$ water) are applied to theoretically produce the same $\mathrm{P}_{\mathrm{O} 2}$ change. Though the equilibrium rates are closer in this experiment, it can still clearly observe that the equilibrium process is faster in the gas with higher $\mathrm{P}_{\mathrm{H} 2 \mathrm{O}}$.

Meanwhile, the equilibrium time with or without steam are different. For all the tests in the humidified gas $\left(0.61 \% \mathrm{H}_{2} \mathrm{O}\right.$ or $3.57 \% \mathrm{H}_{2} \mathrm{O}$ ), though $\mathrm{P}_{\mathrm{H} 2}$ is quite different (from $1 \%$ to $65 \%$ ), the equilibrium time is always about $300 \mathrm{~s}$. For the test in the dry gas, however, the equilibrium time is about $2000 \mathrm{~s}$ which is 6 to 7 times longer than the tests in the humidified gas. Therefore, it seems that $\delta$ change is not the whole story. Steam may also introduce other changes on the surface.

\subsubsection{The Effect of $\mathrm{H}_{2} \mathrm{O}$ (g) on the Surface HOR Reaction}

As proposed by $\mathrm{Uchida}^{222}$, water dissociation occurs via Eq. (44), which lowers oxygen vacancy concentration on the perovskite surfaces upon formation of $\mathrm{OH}_{O}^{-}$, i.e., the hydroxyl $\left(\mathrm{OH}^{-}\right)$group at the oxygen site. In other words, adsorbed $\mathrm{H}_{2} \mathrm{O}$ can dissociate into a proton $\left(\mathrm{H}^{+}\right)$and a hydroxyl group $\left(\mathrm{OH}^{-}\right)$ (Eq. (44-1)) on the perovskite surfaces at expense of reduced amount of oxygen vacancies, where the positively charged proton $\left(\mathrm{H}^{+}\right)$will attach on lattice oxygen $\left(\mathrm{O}_{O}^{\times}\right)$to form a $\mathrm{OH}_{O}(\mathrm{Eq} .(44-2))$, and the negatively charged hydroxyl group $\left(\mathrm{OH}^{-}\right)$is energetically favorable to fill into the positively charged oxygen vacancy $\left(V_{O}^{*}\right)$ to form another $\mathrm{OH}_{O}$ (Eq. (44-3)). Therefore, when $\mathrm{H}_{2} \mathrm{O}$ dissociation reaction reaches the equilibrium, the hydrated perovskite surface presents fewer oxygen vacancies (i.e., smaller $\delta$ ), more $\mathrm{OH}_{O}$ groups, and higher oxygen chemical potential than the dry surface soaked in the same $\mathrm{P}_{\mathrm{H} 2}$ atmosphere.

$$
\begin{gathered}
\mathrm{H}_{2} \mathrm{O}(\mathrm{g})+V_{O}^{\ddot{*}}+\mathrm{O}_{O}^{\times} \leftrightarrow 2 \mathrm{OH}_{O}^{\cdot} \\
\mathrm{H}_{2} \mathrm{O}(\mathrm{g}) \leftrightarrow \mathrm{H}^{+}+\mathrm{OH}^{-}
\end{gathered}
$$




$$
\begin{aligned}
\mathrm{H}^{+}+\mathrm{O}_{O}^{\times} & \leftrightarrow \mathrm{OH}_{O}^{-} \\
\mathrm{OH}^{-}+V_{O}^{\ddot{ }} & \leftrightarrow \mathrm{OH}_{O}^{\cdot}
\end{aligned}
$$

For a perovskite material with higher oxygen vacancy concentration on the surface, the water dissociation may also occur via Eq. (45), where $\mathrm{M}_{M}^{\times}$denotes the metal site, $\mathrm{HM}_{M}^{\prime}$ presents the hydrogen-bonded metal site. Note that the hydrogen in $\mathrm{HM}_{M}^{\prime}$ is negatively charged hydride species, as indicated by $\left(\mathrm{H}^{-}\right)$in the equation. Same as Eq. (44-1), adsorbed $\mathrm{H}_{2} \mathrm{O}$ dissociates to a proton $\left(\mathrm{H}^{+}\right)$plus a hydroxyl group $\left(\mathrm{OH}^{-}\right)$in this reaction and the hydroxyl group $\left(\mathrm{OH}^{-}\right)$fills into a vacancy (Eq. (44-3). In order to further oxidize the strongly reduced surface and decrease the electron chemical potential, the dissociated proton $\left(\mathrm{H}^{+}\right)$may combine with two electrons from SF1.5M to form a negatively charged hydride species $\left(\mathrm{H}^{-}\right)$and attach on a metal site (Eq. (45-1)). When there is a positively charged oxygen vacancy nearby, hydride $\left(\mathrm{H}^{-}\right)$species is energetically more favorable to fill into the oxygen vacancies $\left(\mathrm{H}_{O}^{*}\right)$ to become a more stable surface state with lower surface free energy (Eq. (45-2)).

$$
\begin{aligned}
& \mathrm{H}_{2} \mathrm{O}(\mathrm{g})+V_{o}^{\ddot{*}}+\mathrm{M}_{M}^{\times}+2 e^{-} \leftrightarrow \mathrm{OH}_{o}^{\cdot}+\mathrm{HM}_{M}^{\prime} \\
& \left(\mathrm{H}^{+}\right) \quad\left(\mathrm{H}^{-}\right) \\
& \mathrm{H}_{2} \mathrm{O}(\mathrm{g}) \leftrightarrow \mathrm{H}^{+}+\mathrm{OH}^{-} \\
& \mathrm{OH}^{-}+V_{o}^{\ddot{*}} \leftrightarrow \mathrm{OH}_{O}^{\cdot} \\
& \mathrm{H}^{+}+\mathrm{M}_{M}^{\times}+2 e^{-} \leftrightarrow \mathrm{HM}_{M}^{\prime} \\
& \left(\mathrm{H}^{-}\right) \\
& \mathrm{HM}_{M}^{\prime}+V_{o}^{\ddot{\prime}} \leftrightarrow \mathrm{H}_{O}^{\cdot}+\mathrm{M}_{M}^{\times} \\
& \left(\mathrm{H}^{-}\right) \quad\left(\mathrm{H}^{-}\right)
\end{aligned}
$$

Based on Eq. (44) and Eq. (45), a greater amount of oxygen vacancies will be filled with hydroxyl groups $\left(\mathrm{H}_{O}^{\circ}\right)$ and hydride species $\left(\mathrm{H}^{-}\right)$at the equilibrium state. In view of that, the nonstoichiometry value $(\delta)$ of $\mathrm{SF} 1.5 \mathrm{M}$ at the surface is reduced together with an increased oxygen chemical potential. Besides, when $\mathrm{H}_{2} \mathrm{O}$ dissociate as Eq. (8), free electrons will be partially consumed and lead to a lower electron chemical potential. 
As $\mathrm{H}_{2} \mathrm{O}$ is on the product side of the $\mathrm{HOR}$, theoretically increasing the $\mathrm{H}_{2} \mathrm{O}$ product concentration $\left(\mathrm{P}_{\mathrm{H} 2 \mathrm{O}}\right)$ in Eq. (40) will restrain the forward reaction and, in that case, slow down the HOR kinetics on the anode side. Nonetheless, compared with the dry surface, the hydrated surface provides a different surface condition with increased oxygen chemical potential, reduced oxygen vacancy concentration, and decreased electron chemical potential. All these aspects are possible to speed up the Eq. (40) towards the forward direction and could potentially accelerate the surface HOR processes. In the following, three scenarios of HOR are discussed for the SF1.5M dry and hydrated surfaces:

(a) Different from the hydrated surface, the hydroxyl groups $\left(\mathrm{OH}_{O}^{\circ}\right)$ and hydride species $\left(\mathrm{HM}_{M}^{\prime}\right.$ or $\mathrm{H}_{O}^{*}$ ) on a dry surface mainly formed via the reaction between hydrogen and material surface (lattice oxygen, metal site, and oxygen vacancy). When a $\mathrm{H}_{2}$ molecule dissociates on two surface oxygen sites (HatO\&HatO), the Eq. (40) can be written as Eq. (46). Driven by the electrochemical energy, the produced $\mathrm{OH}_{O}$ from Eq. (46) is then consumed in Eq. (47) to produce $\mathrm{H}_{2} \mathrm{O}$.

$$
\begin{aligned}
& \mathrm{H}_{2}(\mathrm{~g})+2 \mathrm{O}_{O}^{\times} \leftrightarrow 2 \mathrm{OH}_{O}^{\cdot}+2 e^{-} \\
& 2 \mathrm{OH}_{O}^{\cdot} \leftrightarrow \mathrm{H}_{2} \mathrm{O}(\mathrm{g})+V_{O}^{*}+\mathrm{O}_{O}^{\times}
\end{aligned}
$$

(b) If $\mathrm{H}_{2}$ dissociate on one oxygen site and one metal site (HatO\&HatM), the Eq. (40) can be written as Eq. (48). When there is no oxygen vacancy beside $\mathrm{HM}_{M}^{\prime}$, the hydride species $\left(\mathrm{H}^{-}\right)$ will stay on metal site and react with a hydroxyl group, as shown in Eq. (49).

$$
\begin{gathered}
\mathrm{H}_{2}(\mathrm{~g})+\mathrm{O}_{O}^{\times}+\mathrm{M}_{M}^{\times} \leftrightarrow \mathrm{OH}_{O}^{\cdot}+\mathrm{HM}_{M}^{\prime} \\
\left(\mathrm{H}^{+}\right) \quad\left(\mathrm{H}^{-}\right) \\
\mathrm{OH}_{O}^{\cdot}+\mathrm{HM}_{M}^{\prime} \leftrightarrow \mathrm{H}_{2} \mathrm{O}(\mathrm{g})+V_{O}^{*}+\mathrm{M}_{M}^{\times}+2 e^{-} \\
\left(\mathrm{H}^{+}\right)\left(\mathrm{H}^{-}\right)
\end{gathered}
$$

(c) The third scenario is as mentioned in Eq. (45-2), when $\mathrm{HM}_{M}^{\prime}$ close to an oxygen vacancy, hydride species $\left(\mathrm{H}^{-}\right)$prefer to fall into the vacancy, and the reaction between the hydroxyl group and hydride species $\left(\mathrm{H}^{-}\right)$can occur as Eq. (50). 


$$
\begin{aligned}
& \mathrm{H}_{2}(\mathrm{~g})+\mathrm{O}_{O}^{\times}+\mathrm{M}_{M}^{\times} \leftrightarrow \mathrm{OH}_{O}^{\circ}+\mathrm{HM}_{M}^{\prime} \\
& \left(\mathrm{H}^{+}\right) \quad\left(\mathrm{H}^{-}\right) \\
& \mathrm{HM}_{M}^{\prime}+V_{O}^{\ddot{ }} \leftrightarrow \mathrm{H}_{O}^{\bullet}+\mathrm{M}_{M}^{\times} \\
& \left(\mathrm{H}^{-}\right) \quad\left(\mathrm{H}^{-}\right) \\
& \mathrm{OH}_{O}^{\cdot}+\mathrm{H}_{O}^{\cdot} \leftrightarrow \mathrm{H}_{2} \mathrm{O}(\mathrm{g})+2 V_{o}^{\ddot{*}}+2 e^{-} \\
& \left(\mathrm{H}^{+}\right)\left(\mathrm{H}^{-}\right)
\end{aligned}
$$

For perovskite SF1.5M with inherent oxygen vacancies, hydration reaction and proton conduction have been confirmed under a humidified environment in the previous theoretical studies ${ }^{223-224}$. Unfortunately, the effect of such surface hydration reaction to the HOR activities was limitedly investigated for SF1.5M or other ceramic anodes, where more hydroxyl groups $\left(\mathrm{OH}_{O}^{-}\right)$can be formed with fewer oxygen vacancies existed on the SF1.5M surface in the humidified $\mathrm{H}_{2}$.

In the first principles thermodynamic modeling, two factors were examined for the effects of humidity to the HOR reaction energy landscapes. First, from the $\mathrm{H}_{2} / \mathrm{H}_{2} \mathrm{O}$ gas phase thermodynamic equilibrium, the oxygen chemical potential is determined when both the $\mathrm{H}_{2}$ and $\mathrm{H}_{2} \mathrm{O}$ activities are selected. In the case of fixed $\mathrm{H}_{2}$ gas activity (i.e., at a given $\mathrm{T}$ and $\mathrm{P}_{\mathrm{H} 2}$ ), the $\mathrm{O}$ chemical potential is increased upon increasing humidity (i.e., increasing $\mathrm{P}_{\mathrm{H} 2 \mathrm{O}}$ ). Consequently, the near surface oxygen nonstoichiometry (oxygen vacancy content) will be reduced under humidified $\mathrm{H}_{2}$ as compared to the dry $\mathrm{H}_{2}$ condition. To examine the influence of the slab nonstoichiometry to the HOR, the energy landscapes of the HOR reactions are then investigated for the $\mathrm{SF} 1.5 \mathrm{M}(001) \mathrm{BO}_{2}$ terminated surface with various subsurface lattice oxygen vacancy content in the (001) slab models. Second, considering the hydration reaction of Eq. (44) and Eq. (45), two (001) Bterminated surface models are further examined for the reaction energy landscapes of the HOR: one is the clean surface with oxygen vacancies for the dry surface scenario, and the other is the hydrated surface with surface $\mathrm{OH}_{O}$ and $\mathrm{HM}_{M}^{\prime}$ species. These two surface configurations can be considered to represent the reactant side and the product side of $\mathrm{H}_{2} \mathrm{O}$ dissociation reactions (Eq. (44) and Eq. (45)), respectively. As oxygen vacancies in SF1.5M are more favorable to form along Fe-O-Fe than Mo-O-Fe bonds ${ }^{224}$, in this work surface oxygen vacancies are placed along Fe-O-Fe bonds. The energy landscapes of the HOR on the dry 
surface and hydrated surfaces at various subsurface oxygen nonstoichiometry are then compared to examine the influence of the surface hydroxyl groups on the HOR activities.

\subsubsection{Effect of Surface Hydroxyl Groups on HOR Reaction Energy}

In dry $\mathrm{H}_{2}$ condition, hydrogen gas molecules are dissociated on the perovskite surfaces at higher oxygen vacancy concentration. The dissociated hydrogen then reacts with lattice oxygen to produce $\mathrm{H}_{2} \mathrm{O}$ and surface oxygen vacancies. In wet $\mathrm{H}_{2}$ condition, $\mathrm{H}_{2} \mathrm{O}$ dissociation reactions (i.e., Eq. (44) and Eq. (45)) can occur to hydrate the electrode surfaces, which produces hydroxyl $\left(\mathrm{OH}_{O}^{\circ}\right)$ groups, lower the surface oxygen vacancy concentration, and decrease the electron chemical potential. Therefore, to further understand the influences of the surface hydration, the HOR reaction energy landscapes following the same pathways of Figure 67 are calculated for representative surface models of dry surfaces vs. hydrated surfaces.

As previously shown in Figure 67 and also the work of Ref. 134, the first three steps define the highest energy state in the HOR energy landscape. We then focus on comparing the energy of first three intermediates states for the dry vs. hydrated surface models. In addition, since the stable hydrated surfaces upon filling surface oxygen vacancies with $\mathrm{H}_{2} \mathrm{O}$ can result in two states as $2 \mathrm{HatO}$ and HatM\&HatO, both the hydrated surface models of $2 \mathrm{HatO}$ (contain two protons $\mathrm{H}^{+} \mathrm{s}(\mathrm{atO})$ ) and HatM\&HatO (contain both the hydride $\mathrm{H}^{-}\left(\right.$atM) and the proton $\mathrm{H}^{+}$(atO) species) are included for comparison with the dry surface.

The stable hydrated surface upon filling surface oxygen vacancies with $\mathrm{H}_{2} \mathrm{O}$ can result in the existence of hydroxyl group $\mathrm{OH}_{O}$. The results are shown in Figure 70, and the schematics of the corresponding HOR cycles on the dry vs. wet surface models are illustrated in Figure 71.

It can be seen in Figure 70a that the energy of the I3 - Surf_ $\mathrm{V}_{\mathrm{O}} \& \mathrm{H}_{2} \mathrm{OatM}$ state is consistently lower by $0.4 \sim 0.9 \mathrm{eV}$ for the $2 \mathrm{HatO}$ hydrated surface as compared to the dry surface at all the three $\delta(\delta=0.25,0.5$, and 0.75 ), as indicated by the three grey arrows. In the case of the $2 \mathrm{HatO}$ hydrated surface, the stabilization effect in the Surf_ $\mathrm{V}_{\mathrm{O}} \& \mathrm{H}_{2} \mathrm{OatM}$ state can be realized by looking into the surface configurations - Figure 70c and Figure 70f, as compared to Figure 70e and Figure 70h for the dry surface. The formation of surface 
hydroxyl groups in the hydrated $2 \mathrm{HatO}$ surfaces results in elongation of the $\mathrm{Fe}-\mathrm{O}$ bond as well as distortion of the surface Fe-O polyhedral, when a proton is bonded with a surface lattice oxygen. The spacing between the bound $\mathrm{H}^{+}$with its second nearest neighbor oxygen is found at distance of 2.7 and $3.1 \AA$ (Figure $70 \mathrm{c}$ ). For the plateau intermediate state - Surf_ $\mathrm{V}_{\mathrm{O}} \& \mathrm{H}_{2} \mathrm{OatM}$, formation of $\mathrm{H}_{2} \mathrm{O}$ above the surface Fe site further enhances the in-plane surface Fe-O elongation in the hydrated surface layers, which pushes the bound $\mathrm{H}^{+}$ closer to its second nearest neighbor O (about $2.1 \AA$, see Figure 70f) and causes additional interaction of the bound $\mathrm{H}^{+}$with its second nearest neighbor surface oxygen. In contrast, the surface in-plane hydrogenoxygen network is absent in the case of the dry surface model (Figure 70e) for the initial surface and Figure $70 \mathrm{~h}$ for the $\mathrm{I} 3$ state). Therefore, the stabilization effect of the surface $\mathrm{OH}_{O}$ group for the HOR plateau state Surf_ $\mathrm{V}_{\mathrm{O}} \& \mathrm{H}_{2} \mathrm{OatM}$ state of the hydrated $2 \mathrm{HatO}$ surfaces, is attributed to the enhanced interaction between the bound $\mathrm{H}^{+}$of the hydroxyl $\left(\mathrm{OH}_{O}^{\circ}\right)$ groups with their second nearest surface lattice oxygens. 

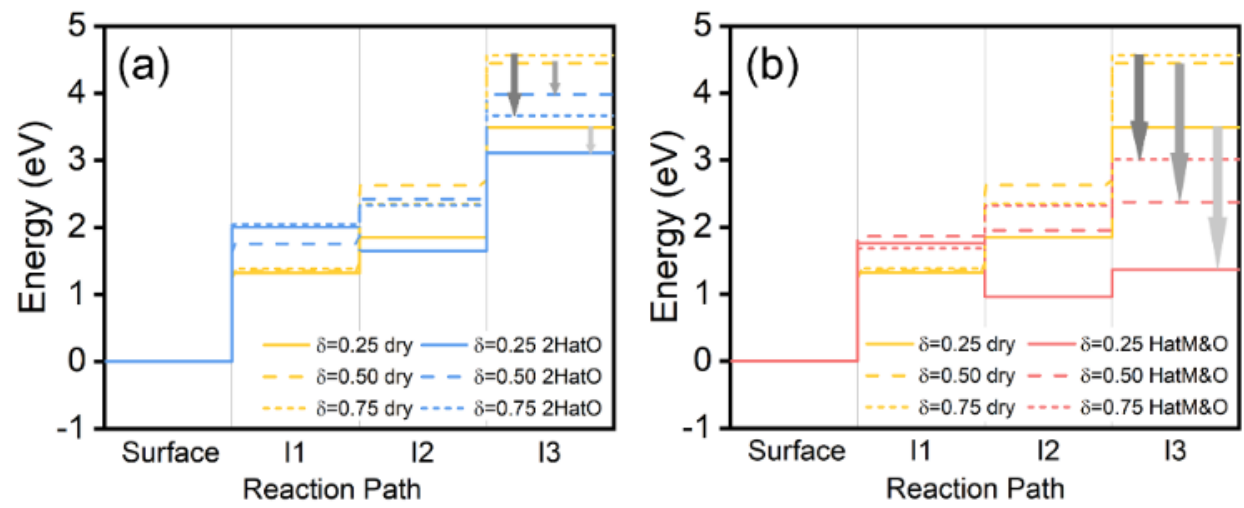

(c) Hydrated $2 \mathrm{HatO}$-- Surface (d) Hydrated HatM\&O -- Surface

(e) Dry surface -- Surface

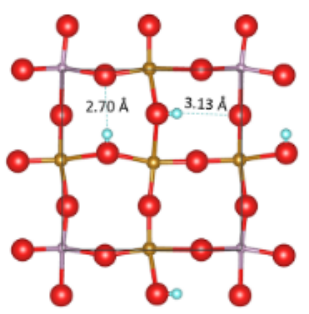

(f) Hydrated $2 \mathrm{HatO}--13$

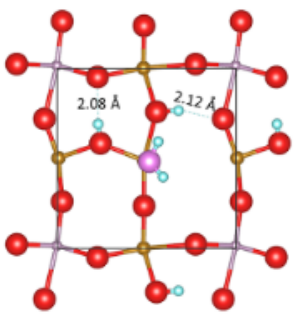

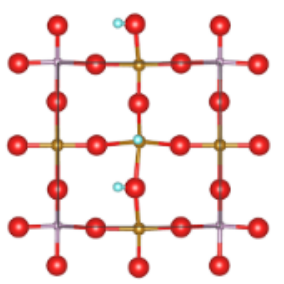

(g) Hydrated HatM\&O - 13

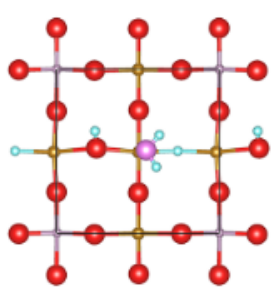

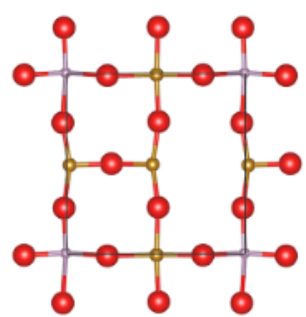

(h) Dry surface -- 13

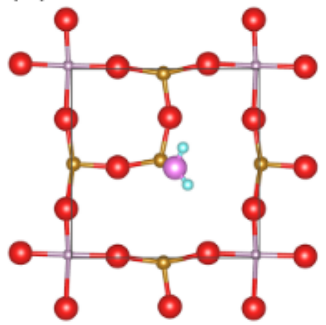

Figure 70. (a) The HOR energy landscapes of the Surface and I1-I3 states for the hydrated surface (blue color) and the dry surface (yellow color) under the condition of $\mathrm{T}=1000 \mathrm{~K}, \mathrm{P}_{\mathrm{H} 2}=0.97$ bar, and $\mathrm{P}_{\mathrm{H} 2 \mathrm{O}}=0.03$ bar. Three different slab $\delta(0.0,0.25$, and 0.5$)$ are included in plot. The top view of the configurations of the hydrated surface model and the dry surface model are presented in (b) and (c), respectively. The top view of the configurations of the plateau intermediate state $-\mathrm{I} 3$ (formation of $\mathrm{H}_{2} \mathrm{O}$ and surface $\mathrm{O}$ vacancy) on the hydrated and dry surfaces are presented in Figure 70 (d) and (e), respectively. The distance between the bound $\mathrm{H}^{+} \mathrm{s}$ of the surface hydroxyl groups and their second nearest neighbor surface $\mathrm{O}$ are labeled in Figure 70 (b) and (d). The color of the spheres for the elements is the same as in Figure 67. 

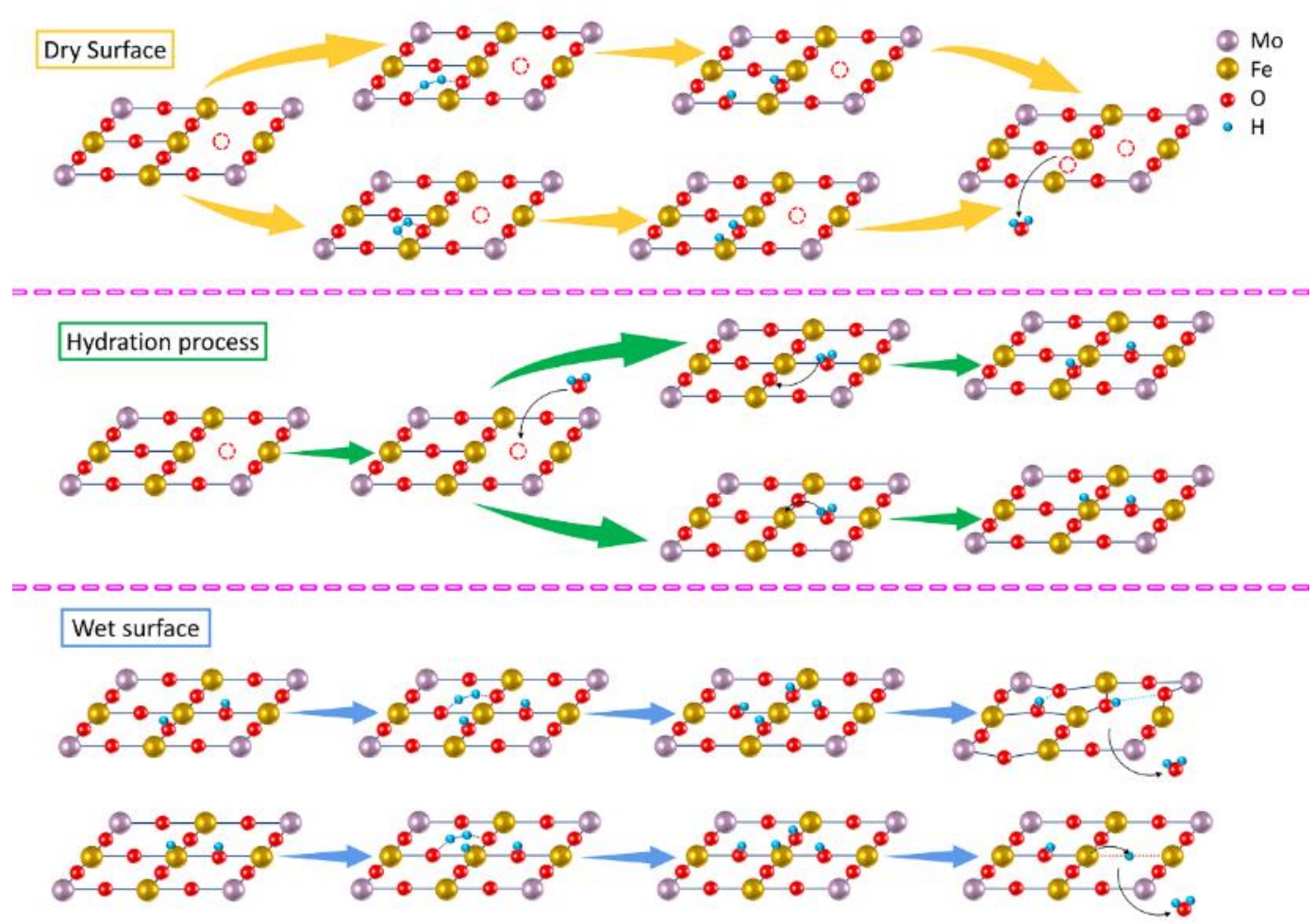

Figure 71. Pathways of hydrogen oxidation reaction on dry surface (yellow line) and wet surface (blue line). The hydration process from dry to wet surface is provided as green line.

In the other case of the HatM\&HatO hydrated surface (Figure 70d and Figure 70g), the surface adsorbed hydride species $\left(\mathrm{H}^{-}\right.$adsorbed on the metal site) is found to be falling into surface oxygen vacancy in the plateau intermediate state $-\mathrm{I} 3$ (Figure $70 \mathrm{~g}$ ), due to interaction between the adsorbed $\mathrm{H}^{-}$and surface oxygen vacancy. The surface $\mathrm{H}^{-}$species can interact with the two neighboring Fe when falling into surface oxygen vacancy and form two Fe-H bonds with bond length about $1.9 \AA$, which results in even greater stabilization of the I3 state (Figure 70g) relative to the dry surface state, as shown in Figure 70b (lowered by $1.6 \sim 2.1 \mathrm{eV}$ as indicated by the arrows). Overall, both the hydrated surface model results point to a faster HOR reaction rate on the hydrated surfaces than on the dry surface. Examining the plateau I 3 intermediate state of the $\mathrm{HOR}$, the beneficial effect in the hydrated $2 \mathrm{HatO}$ surface comes from the in-plane surface hydroxyl interaction with surface lattice oxygen, whereas the beneficial effect in the hydrated HatM\&HatO surface is due to interaction of surface adsorbed hydride species with the surface oxygen vacancies to form substitutional $\mathrm{H}_{O}^{-}$. 


\subsection{Summary}

In this chapter, the catalytic effect of $\mathrm{H}_{2} \mathrm{O}$ on $\mathrm{HOR}$ process based on perovskite material $\mathrm{SF} 1.5 \mathrm{M}$ is demonstrated by ECR at low $\mathrm{P}_{\mathrm{H} 2}$ environment and EIS at high $\mathrm{P}_{\mathrm{H} 2}$ environment. Both results suggest a promotion effect of $\mathrm{H}_{2} \mathrm{O}$ on surface $\mathrm{HOR}$ process of the electrode. Based on the DFT modeling results, which show the $\mathrm{H}_{2} \mathrm{O}$ plus surface oxygen vacancy formation step is the highest energy intermediate state on the $\mathrm{Fe}-\mathrm{O}-\mathrm{Fe}$ site of the $(001) \mathrm{BO}_{2}$ surfaces, it is then revealed that the energy of this plateau state can be reduced on the SF1.5M surfaces with (1) lower $\delta$ near the surfaces, and (2) formation of hydroxyl $\left(\mathrm{OH}_{O}^{\circ}\right)$ and hydride $\left(\mathrm{H}^{-}\right)$relative to the surfaces containing $\mathrm{O}$ vacancies. The promotion effect of humidity is further explained by the lower surface electron chemical potential with increase of $\mathrm{O}$ chemical potential, as well as enhanced interaction between the surface bound $\mathrm{H}^{+}$(surface hydroxyl) with the surface lattice oxygen in the $2 \mathrm{HatO}$ hydrated surfaces and interaction between surface adsorbed hydride $\mathrm{H}^{-}$with surface $\mathrm{O}$ vacancies in the HatM\&HatO hydrated surfaces. Similar phenomenon is also observed in other perovskite materials, indicating the humidity promotion effect and the identified enhancing factors can be general for HOR on perovskite ceramics used in the SOFC anodes. 


\section{Chapter 7 Conclusion}

In this work, a novel Ni-free anode material is developed as $\mathrm{La}_{0.5} \mathrm{Sr}_{1.5} \mathrm{Fe}_{1.5} \mathrm{Mo}_{0.5} \mathrm{O}_{6-\delta}$. Based on this redox reversible ceramic material, in-situ metal exsolution and the enhancement to electrochemical performance with the exsolved nanoparticles (NPs) are investigated. In the last part, the positive influence of $\mathrm{H}_{2} \mathrm{O}$ on the hydrogen oxidation reaction is deeply discussed based on the perovskite material SF1.5M.

In chapter 4, four compositions (SFM, SF1.5M, SFCM, and LSFM) is synthesized via the sol-gel method followed by the dilatometry measurement and the chemical stability test. The CTE values of different compositions suggested the critical influence of metal-oxygen (M-O) bond strength to the expansion behavior. Guided from a careful comparison, the order of M-O bond strength on B-site is summarized as $\mathrm{Mo}-\mathrm{O}>\mathrm{Fe}-\mathrm{O}>\mathrm{Co}-\mathrm{O}$ and the order on A-site is given as $\mathrm{La}-\mathrm{O}>\mathrm{Sr}-\mathrm{O}$. As the stronger M-O bond, La-O bond dedicates to the smaller thermal expansion, milder chemical expansion, and the higher redox reversibility from both expansion behavior and electrical conductivity. In addition, the electrical conductivity test reveals that $\mathrm{La}$ is very friendly to an electrical conductivity performance. Besides of excellent phase stability and redox reversibility, the electrochemical performance of LSFM is also outstanding. The half-tear-drop-shaped impedance spectra of LSFM symmetrical cell shows that LSFM is a good MIEC material with great surface catalytic activity and sufficient ionic conductivity. The active region thickness of LSFM porous electrode is estimated as $4 \mu \mathrm{m}$ and the maximum power density of LSCF/LSGM/LSFM single cell reaches $1156 \mathrm{~mW} \mathrm{~cm}^{-2}$ in humidified $\mathrm{H}_{2}$ at $800{ }^{\circ} \mathrm{C}$. This attractive performance benefits from high electrical conductivity, enough ionic conductivity, and decent surface catalytic activity.

In chapter 5, the in-situ exsolution of Fe NPs in $\mathrm{H}_{2}$, the reversibility of exsolution and the electrochemical performance related to exsolution are investigated based on LSFM. With the influence of $\mathrm{La}^{3+}$ on A-site, Fe NPs are observed with an average size of $120 \mathrm{~nm}$ after reduction. Meanwhile, the excellent reversibility of the exsolved NPs are observed. After re-oxidation, the clear but waved grain boundary and grain surface 
recorded the phase evolution during the redox cycling. The long-term stability (100 hours) in $\mathrm{H}_{2}$ is also verified in this work. In view of our ECR and EIS analysis, the promotion effect of Fe NPs mainly presents as a faster surface kinetics and a higher ionic conductivity. At low $\mathrm{P}_{\mathrm{H} 2}$ atmosphere, ECR results display an obvious $k_{\mathrm{ex}}$ increase after Fe exsolution which implies an accelerated process on surface HOR. At high $\mathrm{P}_{\mathrm{H} 2}$ atmosphere, the increased $\sigma_{i, e f f}$ from the EIS analysis confirmed the increment of the ionic conductivity which contribute to the lower polarization resistance. Overall, the electrochemical performance is improved by Fe exsolution.

In Chapter 6, the catalytic effect of $\mathrm{H}_{2} \mathrm{O}$ on $\mathrm{HOR}$ process based on perovskite material $\mathrm{SF} 1.5 \mathrm{M}$ is demonstrated by ECR at low $\mathrm{P}_{\mathrm{H} 2}$ environment and EIS at high $\mathrm{P}_{\mathrm{H} 2}$ environment. Both results suggest a promotion effect of $\mathrm{H}_{2} \mathrm{O}$ on surface $\mathrm{HOR}$ process of the electrode. Based on the DFT modeling results, which show the $\mathrm{H}_{2} \mathrm{O}$ plus surface oxygen vacancy formation step is the highest energy intermediate state on the $\mathrm{Fe}-\mathrm{O}-\mathrm{Fe}$ site of the $(001) \mathrm{BO}_{2}$ surfaces, it is then revealed that the energy of this plateau state can be reduced on the SF1.5M surfaces with (1) lower $\delta$ near the surfaces, and (2) formation of hydroxyl $\left(\mathrm{OH}_{O}^{\circ}\right)$ and hydride $\left(\mathrm{H}^{-}\right)$relative to the surfaces containing $\mathrm{O}$ vacancies. The promotion effect of humidity is further explained by the lower surface electron chemical potential with increase of $\mathrm{O}$ chemical potential, as well as enhanced interaction between the surface bound $\mathrm{H}^{+}$(surface hydroxyl) with the surface lattice oxygen in the $2 \mathrm{HatO}$ hydrated surfaces and interaction between surface adsorbed hydride $\mathrm{H}^{-}$with surface $\mathrm{O}$ vacancies in the HatM\&HatO hydrated surfaces. Similar phenomenon is also observed in other perovskite materials, indicating the humidity promotion effect and the identified enhancing factors can be general for HOR on perovskite ceramics used in the SOFC anodes. 


\section{References}

1. Adams, T. A.; Nease, J.; Tucker, D.; Barton, P. I., Energy Conversion with Solid Oxide Fuel Cell Systems: A Review of Concepts and Outlooks for the Short- and Long-Term. Ind. Eng. Chem. Res. 2013, 52 (9), 3089-3111.

2. Kordesch, K.; Simader, G., Fuel cells and their applications. VCh Weinheim: 1996; Vol. 117.

3. Kozhukharov, V.; Brashkova, N.; Ivanova, M.; Carda, J.; Machkova, M., Ceramic materials for SOFCs: Current status. Boletín de la Sociedad Española de Cerámica y Vidrio 2002, 41 (5), 471-480.

4. Lutgard C. De Jonghe; Craig P. Jacobson; Visco, S. J., Supported Electrolyte Thin Film Synthesis of Solid Oxide Fuel Cells. Annual Review of Materials Research 2003, 33 (1), 169-182.

5. $\quad$ Badwal, S. P. S., Stability of solid oxide fuel cell components. Solid State Ionics 2001, 143 (1), 3946.

6. Shao, Z.; Zhou, W.; Zhu, Z., Advanced synthesis of materials for intermediate-temperature solid oxide fuel cells. Progress in Materials Science 2012, 57 (4), 804-874.

7. Jørgensen, M. J.; Mogensen, M., Impedance of Solid Oxide Fuel Cell LSM/YSZ Composite Cathodes. J. Electrochem. Soc. 2001, 148 (5), A433-A442.

8. Imanishi, N.; Ohno, R.; Murata, K.; Hirano, A.; Takeda, Y.; Yamamoto, O.; Yamahara, K., LSMYSZ Cathode with Infiltrated Cobalt Oxide and Cerium Oxide Nanoparticles. Fuel Cells 2009, 9 (3), 215221.

9. Liu, M.; Ding, D.; Blinn, K.; Li, X.; Nie, L.; Liu, M., Enhanced performance of LSCF cathode through surface modification. Int. J. Hydrogen Energy 2012, 37 (10), 8613-8620.

10. Shri Prakash, B.; Senthil Kumar, S.; Aruna, S. T., Properties and development of Ni/YSZ as an anode material in solid oxide fuel cell: A review. Renew. Sustainable Energy Rev. 2014, 36, 149-179.

11. Klemens $\varnothing$, T.; Mogensen, M., Ni-YSZ Solid Oxide Fuel Cell Anode Behavior Upon Redox Cycling Based on Electrical Characterization. J. Am. Ceram. Soc. 2007, 90 (11), 3582-3588.

12. He, H.; Hill, J. M., Carbon deposition on Ni/YSZ composites exposed to humidified methane. Appl. Catal., A 2007, 317 (2), 284-292.

13. Cheng, Z.; Liu, M., Characterization of sulfur poisoning of Ni-YSZ anodes for solid oxide fuel cells using in situ Raman microspectroscopy. Solid State Ionics 2007, 178 (13), 925-935.

14. Kan, W. H.; Thangadurai, V., Challenges and prospects of anodes for solid oxide fuel cells (SOFCs). Ionics 2015, 21 (2), 301-318.

15. Electrode materials. https://www.doitpoms.ac.uk/tlplib/fuel-cells/sofc_electrode_materials.php.

16. Laosiripojana, N.; Wiyaratn, W.; Kiatkittipong, W.; Arpornwichanop, A.; Soottitantawat, A.; Assabumrungrat, S., Reviews on solid oxide fuel cell technology. Engineering Journal 2009, 13 (1), 65-84. 
17. Jiang, S. P.; Chan, S. H., A review of anode materials development in solid oxide fuel cells. $J$. Mater. Sci. 2004, 39 (14), 4405-4439.

18. Minh, N. Q., Ceramic Fuel Cells. J. Am. Ceram. Soc. 1993, 76 (3), 563-588.

19. Shaikh, S. P. S.; Muchtar, A.; Somalu, M. R., A review on the selection of anode materials for solid-oxide fuel cells. Renew. Sustainable Energy Rev. 2015, 51, 1-8.

20. Singhal, S. C.; Kendall, K., High-temperature solid oxide fuel cells: fundamentals, design and applications. Elsevier: 2003.

21. Möbius, H.-H., On the history of solid electrolyte fuel cells. Journal of Solid State Electrochemistry 1997, 1 (1), 2-16.

22. Jiang, S. P.; Badwal, S. P. S., Hydrogen Oxidation at the Nickel and Platinum Electrodes on Yttria - Tetragonal Zirconia Electrolyte. J. Electrochem. Soc. 1997, 144 (11), 3777-3784.

23. Uchida, H.; Yoshida, M.; Watanabe, M., Effects of Ionic Conductivities of Zirconia Electrolytes on Polarization Properties of Platinum Anodes in Solid Oxide Fuel Cells. The Journal of Physical Chemistry 1995, 99 (10), 3282-3287.

24. Suzuki, M.; Sasaki, H.; Otoshi, S.; Kajimura, A.; Ippommatsu, M., High power density solid oxide electrolyte fuel cells using $\mathrm{Ru} / \mathrm{Y}_{2} \mathrm{O}_{3}$ stabilized zirconia cermet anodes. Solid State Ionics 1993, 62 (1), 125130.

25. Setoguchi, T.; Okamoto, K.; Eguchi, K.; Arai, H., Effects of Anode Material and Fuel on Anodic Reaction of Solid Oxide Fuel Cells. J. Electrochem. Soc. 1992, 139 (10), 2875-2880.

26. Bieberle, A.; Meier, L. P.; Gauckler, L. J., The Electrochemistry of Ni Pattern Anodes Used as Solid Oxide Fuel Cell Model Electrodes. J. Electrochem. Soc. 2001, 148 (6), A646-A656.

27. Bieberle, A.; Gauckler, L. J., Reaction mechanism of Ni pattern anodes for solid oxide fuel cells. Solid State Ionics 2000, 135 (1), 337-345.

28. Sukeshini, A. M.; Habibzadeh, B.; Becker, B. P.; Stoltz, C. A.; Eichhorn, B. W.; Jackson, G. S., Electrochemical Oxidation of $\mathrm{H}_{2}, \mathrm{CO}$, and $\mathrm{CO} / \mathrm{H}_{2}$ Mixtures on Patterned Ni Anodes on YSZ Electrolytes. J. Electrochem. Soc. 2006, 153 (4), A705-A715.

29. Utz, A.; Störmer, H.; Leonide, A.; Weber, A.; Ivers-Tiffée, E., Degradation and Relaxation Effects of Ni Patterned Anodes in $\mathrm{H}_{2}-\mathrm{H}_{2} \mathrm{O}$ Atmosphere. J. Electrochem. Soc. 2010, 157 (6), B920-B930.

30. Mizusaki, J.; Tagawa, H.; Saito, T.; Kamitani, K.; Yamamura, T.; Hirano, K.; Ehara, S.; Takagi, T.; Hikita, T.; Ippommatsu, M.; Nakagawa, S.; Hashimoto, K., Preparation of Nickel Pattern Electrodes on YSZ and Their Electrochemical Properties in $\mathrm{H}_{2}-\mathrm{H}_{2} \mathrm{O}$ Atmospheres. J. Electrochem. Soc. 1994, 141 (8), 2129-2134.

31. Kawada, T.; Sakai, N.; Yokokawa, H.; Dokiya, M.; Mori, M.; Iwata, T., Structure and polarization characteristics of solid oxide fuel cell anodes. Solid State Ionics 1990, 40-41, 402-406. 
32. Kawada, T.; Sakai, N.; Yokokawa, H.; Dokiya, M.; Mori, M.; Iwata, T., Characteristics of Slurry Coated Nickel Zirconia Cermet Anodes for Solid Oxide Fuel Cells. J. Electrochem. Soc. 1990, 137 (10), 3042-3047.

33. Yamamura, T.; Tagawa, H.; Saito, T.; Mizusaki, J.; Kamitani, K.; Hirano, K.; Ehara, S.; Takagi, T.; Hishinuma, Y.; Sasaki, H.; Sogi, T.; Nakamura, Y.; Hashimoto, K., Reaction Kinetics at the Nickel Pattern Electrode on YSZ and Its Dependence on Temperature. ECS Proceedings Volumes 1995, 1995-1, 741-749.

34. Norby, T.; Velle, O. J.; Leth-Olsen, H.; Tunold, R., Reaction Resistance in Relation to Three Phase Boundary Length of Ni/YSZ Electrodes. ECS Proceedings Volumes 1993, 1993-4, 473-478.

35. Mizusaki, J.; Tagawa, H.; Saito, T.; Yamamura, T.; Kamitani, K.; Hirano, K.; Ehara, S.; Takagi, T.; Hikita, T.; Ippommatsu, M.; Nakagawa, S.; Hashimoto, K., Kinetic studies of the reaction at the nickel pattern electrode on YSZ in $\mathrm{H}_{2}-\mathrm{H}_{2} \mathrm{O}$ atmospheres. Solid State Ionics 1994, 70-71, 52-58.

36. Liu, W.; Flytzanistephanopoulos, M., Total Oxidation of Carbon Monoxide and Methane over Transition Metal Fluorite Oxide Composite Catalysts: I. Catalyst Composition and Activity. Journal of Catalysis 1995, 153 (2), 304-316.

37. de Souza, S.; Visco, S. J.; De Jonghe, L. C., Thin-film solid oxide fuel cell with high performance at low-temperature. Solid State Ionics 1997, 98 (1), 57-61.

38. Yu, J. H.; Park, G. W.; Lee, S.; Woo, S. K., Microstructural effects on the electrical and mechanical properties of Ni-YSZ cermet for SOFC anode. J. Power Sources 2007, 163 (2), 926-932.

39. Pihlatie, M. H.; Kaiser, A.; Mogensen, M.; Chen, M., Electrical conductivity of Ni-YSZ composites: Degradation due to Ni particle growth. Solid State Ionics 2011, 189 (1), 82-90.

40. Jiang, S. P., Resistance Measurement in Solid Oxide Fuel Cells. J. Electrochem. Soc. 2001, 148 (8), A887-A897.

41. Mori, M.; Yamamoto, T.; Itoh, H.; Inaba, H.; Tagawa, H., Thermal Expansion of Nickel - Zirconia Anodes in Solid Oxide Fuel Cells during Fabrication and Operation. J. Electrochem. Soc. 1998, 145 (4), 1374-1381.

42. Toebes, M. L.; Bitter, J. H.; van Dillen, A. J.; de Jong, K. P., Impact of the structure and reactivity of nickel particles on the catalytic growth of carbon nanofibers. Catal. Today 2002, 76 (1), 33-42.

43. McIntosh, S.; Gorte, R. J., Direct Hydrocarbon Solid Oxide Fuel Cells. Chem. Rev. 2004, 104 (10), 4845-4866.

44. Sumi, H.; Lee, Y.-H.; Muroyama, H.; Matsui, T.; Kamijo, M.; Mimuro, S.; Yamanaka, M.; Nakajima, Y.; Eguchi, K., Effect of carbon deposition by carbon monoxide disproportionation on electrochemical characteristics at low temperature operation for solid oxide fuel cells. J. Power Sources 2011, 196 (10), 4451-4457. 
45. Singh, D.; Hernández-Pacheco, E.; Hutton, P. N.; Patel, N.; Mann, M. D., Carbon deposition in an SOFC fueled by tar-laden biomass gas: a thermodynamic analysis. J. Power Sources 2005, 142 (1), 194199.

46. Chen, T.; Wang, W. G.; Miao, H.; Li, T.; Xu, C., Evaluation of carbon deposition behavior on the nickel/yttrium-stabilized zirconia anode-supported fuel cell fueled with simulated syngas. J. Power Sources 2011, 196 (5), 2461-2468.

47. Takeguchi, T.; Kani, Y.; Yano, T.; Kikuchi, R.; Eguchi, K.; Tsujimoto, K.; Uchida, Y.; Ueno, A.; Omoshiki, K.; Aizawa, M., Study on steam reforming of $\mathrm{CH}_{4}$ and $\mathrm{C}_{2}$ hydrocarbons and carbon deposition on Ni-YSZ cermets. J. Power Sources 2002, 112 (2), 588-595.

48. Kishimoto, H.; Horita, T.; Yamaji, K.; Xiong, Y.; Sakai, N.; Brito, M. E.; Yokokawa, H., Feasibility of n-Dodecane Fuel for Solid Oxide Fuel Cell with Ni-ScSZ Anode. J. Electrochem. Soc. 2005, 152 (3), A532-A538.

49. Li, Y.; Fu, Q.; Flytzani-Stephanopoulos, M., Low-temperature water-gas shift reaction over $\mathrm{Cu}-$ and Ni-loaded cerium oxide catalysts. Appl. Catal. B-Environ. 2000, 27 (3), 179-191.

50. Mahato, N.; Banerjee, A.; Gupta, A.; Omar, S.; Balani, K., Progress in material selection for solid oxide fuel cell technology: A review. Progress in Materials Science 2015, 72, 141-337.

51. Chun, C. M.; Mumford, J. D.; Ramanarayanan, T. A., Carbon - Induced Corrosion of Nickel Anode. J. Electrochem. Soc. 2000, 147 (10), 3680-3686.

52. Chun, C. M.; Ramanarayanan, T. A., Mechanism and Control of Carbon Deposition on High Temperature Alloys. J. Electrochem. Soc. 2007, 154 (9), C465-C471.

53. Zha, S.; Cheng, Z.; Liu, M., Sulfur Poisoning and Regeneration of Ni-Based Anodes in Solid Oxide Fuel Cells. J. Electrochem. Soc. 2007, 154 (2), B201-B206.

54. Oliphant, J. L.; Fowler, R. W.; Pannell, R. B.; Bartholomew, C. H., Chemisorption of hydrogen sulfide on nickel and ruthenium catalysts: I. Desorption isotherms. Journal of Catalysis 1978, 51 (2), 229242.

55. Bartholomew, C. H.; Agrawal, P. K.; Katzer, J. R., Sulfur Poisoning of Metals. In Advances in Catalysis, Eley, D. D.; Pines, H.; Weisz, P. B., Eds. Academic Press: 1982; Vol. 31, pp 135-242.

56. Sarantaridis, D.; Atkinson, A., Redox Cycling of Ni-Based Solid Oxide Fuel Cell Anodes: A Review. Fuel Cells 2007, 7 (3), 246-258.

57. Brodnikovskyi, Y.; Vasyliv, B.; Podhurska, V.; Andrzejczuk, M.; McDonald, N.; Kyrpa, O.; Ostash, O.; Vasylyev, O.; Steinberger-Wilckens, R.; Lewandowska, M., Influence of reduction conditions of NiO on its mechanical and electrical properties. Journal of Electrochemical Science and Engineering 2016, 6 (1), 113-121. 
58. Gorte, R. J.; Park, S.; Vohs, J. M.; Wang, C., Anodes for Direct Oxidation of Dry Hydrocarbons in a Solid-Oxide Fuel Cell. Adv. Mater. 2000, 12 (19), 1465-1469.

59. Kim, H.; Vohs, J. M.; Gorte, R. J., Direct oxidation of sulfur-containing fuels in a solid oxide fuel cell. Chem. Commun. 2001, (22), 2334-2335.

60. Gorte, R. J.; Vohs, J. M.; McIntosh, S., Recent developments on anodes for direct fuel utilization in SOFC. Solid State Ionics 2004, 175 (1), 1-6.

61. Murray, E. P.; Tsai, T.; Barnett, S. A., A direct-methane fuel cell with a ceria-based anode. Nature 1999, 400, 649.

62. Yokokawa, H.; Horita, T.; Sakai, N.; Yamaji, K.; Brito, M. E.; Xiong, Y. P.; Kishimoto, H., Protons in ceria and their roles in SOFC electrode reactions from thermodynamic and SIMS analyses. Solid State Ionics 2004, 174 (1), 205-221.

63. Omar, S.; Wachsman, E. D.; Nino, J. C., A co-doping approach towards enhanced ionic conductivity in fluorite-based electrolytes. Solid State Ionics 2006, 177 (35), 3199-3203.

64. Omar, S.; Wachsman, E. D.; Nino, J. C., Higher ionic conductive ceria-based electrolytes for solid oxide fuel cells. Appl. Phys. Lett. 2007, 91 (14), 144106.

65. Tao; Irvine, J. T. S., Catalytic Properties of the Perovskite Oxide $\mathrm{La}_{0.75} \mathrm{Sr}_{0.25} \mathrm{Cr}_{0.5} \mathrm{Fe}_{0.5} \mathrm{O}_{3-\delta}$ in Relation to Its Potential as a Solid Oxide Fuel Cell Anode Material. Chem. Mater. 2004, 16 (21), 41164121.

66. Tao, S.; Irvine, J. T. S., Synthesis and Characterization of $\left(\mathrm{La}_{0.75} \mathrm{Sr}_{0.25}\right) \mathrm{Cr}_{0.5} \mathrm{Mn}_{0.5} \mathrm{O}_{3-\delta}$, a RedoxStable, Efficient Perovskite Anode for SOFCs. J. Electrochem. Soc. 2004, 151 (2), A252-A259.

67. Sengodan, S.; Choi, S.; Jun, A.; Shin, T. H.; Ju, Y.-W.; Jeong, H. Y.; Shin, J.; Irvine, J. T. S.; Kim, G., Layered oxygen-deficient double perovskite as an efficient and stable anode for direct hydrocarbon solid oxide fuel cells. Nature Materials 2014, 14, 205.

68. Subramanian, M. A.; Aravamudan, G.; Subba Rao, G. V., Oxide pyrochlores - A review. Progress in Solid State Chemistry 1983, 15 (2), 55-143.

69. Blundred, G. D.; Bridges, C. A.; Rosseinsky, M. J., New Oxidation States and Defect Chemistry in the Pyrochlore Structure. Angew. Chem. Int. Ed. 2004, 43 (27), 3562-3565.

70. Deng, Z. Q.; Niu, H. J.; Kuang, X. J.; Allix, M.; Claridge, J. B.; Rosseinsky, M. J., Highly Conducting Redox Stable Pyrochlore Oxides. Chem. Mater. 2008, 20 (22), 6911-6916.

71. Vincent, A.; Luo, J.-L.; Chuang, K. T.; Sanger, A. R., Effect of Ba doping on performance of LST as anode in solid oxide fuel cells. J. Power Sources 2010, 195 (3), 769-774.

72. Zhou, X.; Yan, N.; Chuang, K. T.; Luo, J., Progress in La-doped $\mathrm{SrTiO}_{3}$ (LST)-based anode materials for solid oxide fuel cells. RSC Adv. 2014, 4 (1), 118-131. 
73. Huang, Y.-H.; Dass, R. I.; Denyszyn, J. C.; Goodenough, J. B., Synthesis and Characterization of $\mathrm{Sr}_{2} \mathrm{MgMoO}_{6-\delta}$ : An Anode Material for the Solid Oxide Fuel Cell. J. Electrochem. Soc. 2006, 153 (7), A1266-A1272.

74. Escudero, M. J.; Gómez de Parada, I.; Fuerte, A.; Daza, L., Study of $\operatorname{Sr}_{2} \mathrm{Mg}\left(\mathrm{Mo}_{0.8} \mathrm{Nb}_{0.2}\right) \mathrm{O}_{6-\delta}$ as anode material for solid oxide fuel cells using hydrocarbons as fuel. J. Power Sources 2013, 243, 654-660. 75. Liu, Q.; Bugaris, D. E.; Xiao, G.; Chmara, M.; Ma, S.; zur Loye, H.-C.; Amiridis, M. D.; Chen, F., $\mathrm{Sr}_{2} \mathrm{Fe}_{1.5} \mathrm{Mo}_{0.5} \mathrm{O}_{6-\delta}$ as a regenerative anode for solid oxide fuel cells. J. Power Sources 2011, 196 (22), $9148-$ 9153.

76. Zhou, Q.; Cheng, Y.; Li, W.; Yang, X.; Liu, J.; An, D.; Tong, X.; Zhong, B.; Wang, W., Investigation of cobalt-free perovskite $\mathrm{Sr}_{2} \mathrm{FeTi}_{0.75} \mathrm{Mo}_{0.25} \mathrm{O}_{6-\delta}$ as new cathode for solid oxide fuel cells. Mater. Res. Bull. 2016, 74, 129-133.

77. Vasala, S.; Karppinen, M., $\mathrm{A}_{2} \mathrm{~B}^{\prime} \mathrm{B}^{\prime \prime} \mathrm{O}_{6}$ perovskites: A review. Progress in Solid State Chemistry 2015, 43 (1), 1-36.

78. Goldschmidt, V. M., Die Gesetze der Krystallochemie. Naturwissenschaften 1926, 14 (21), 477 485.

79. King, G.; Woodward, P. M., Cation ordering in perovskites. J. Mater. Chem. 2010, 20 (28), 57855796.

80. Jun, A.; Kim, J.; Shin, J.; Kim, G., Perovskite as a Cathode Material: A Review of its Role in SolidOxide Fuel Cell Technology. ChemElectroChem 2016, 3 (4), 511-530.

81. Davies, P. K., Cation ordering in complex oxides. Current Opinion in Solid State and Materials Science 1999, 4 (5), 467-471.

82. Knapp, M. C.; Woodward, P. M., A-site cation ordering in $\mathrm{AA}^{\prime} \mathrm{BB}^{\prime} \mathrm{O}_{6}$ perovskites. Journal of Solid State Chemistry 2006, 179 (4), 1076-1085.

83. King, G.; Thimmaiah, S.; Dwivedi, A.; Woodward, P. M., Synthesis and Characterization of New $\mathrm{AA}^{\prime} \mathrm{BWO}_{6}$ Perovskites Exhibiting Simultaneous Ordering of A-Site and B-Site Cations. Chem. Mater. 2007, 19 (26), 6451-6458.

84. Tadashi, S.; Tetsuo, Y.; Yasuyoshi, T., Cation Ordering in $(\mathrm{NaLa})(\mathrm{MgW}) \mathrm{O}_{6}$ with the Perovskite Structure. Bulletin of the Chemical Society of Japan 1984, 57 (7), 1859-1862.

85. López, M. L.; Veiga, M. L.; Pico, C., Cation ordering in distorted perovskites (MLa)(MgTe) $\mathrm{O}_{6}, \mathrm{M}$ = Na, K. J. Mater. Chem. 1994, 4 (4), 547-550.

86. Arillo, M. A.; Gómez, J.; López, M. L.; Pico, C.; Veiga, M. L., Structural and electrical characterization of new materials with perovskite structure. Solid State Ionics 1997, 95 (3), 241-248. 
87. Arillo, M. A.; Gómez, J.; López, M. L.; Pico, C.; Luisa Veiga, M., Structural characterization and properties of the perovskite $(\mathrm{NaLa})(\mathrm{MW}) \mathrm{O}_{6}(\mathrm{M}=\mathrm{Co}, \mathrm{Ni})$ : two new members in the group-subgroup relations for the perovskite-type structures. J. Mater. Chem. 1997, 7 (5), 801-806.

88. King, G.; Wayman, L. M.; Woodward, P. M., Magnetic and structural properties of $\mathrm{NaLnMnWO}_{6}$ and $\mathrm{NaLnMgWO}_{6}$ perovskites. Journal of Solid State Chemistry 2009, 182 (6), 1319-1325.

89. Kim, G.; Wang, S.; Jacobson, A. J.; Reimus, L.; Brodersen, P.; Mims, C. A., Rapid oxygen ion diffusion and surface exchange kinetics in $\mathrm{PrBaCo}_{2} \mathrm{O}_{5+x}$ with a perovskite related structure and ordered A cations. J. Mater. Chem. 2007, 17 (24), 2500-2505.

90. Hui, S.; Petric, A., Electrical Properties of Yttrium-Doped Strontium Titanate under Reducing Conditions. J. Electrochem. Soc. 2002, 149 (1), J1-J10.

91. Hui, S.; Petric, A., Evaluation of yttrium-doped $\mathrm{SrTiO}_{3}$ as an anode for solid oxide fuel cells. Journal of the European Ceramic Society 2002, 22 (9), 1673-1681.

92. Blennow, P.; Hansen, K. K.; Wallenberg, L. R.; Mogensen, M., Electrochemical characterization and redox behavior of Nb-doped $\mathrm{SrTiO}_{3}$. Solid State Ionics 2009, 180 (1), 63-70.

93. Zhou, X. D.; Scarfino, B.; Anderson, H. U., Electrical conductivity and stability of Gd-doped ceria/Y-doped zirconia ceramics and thin films. Solid State Ionics 2004, 175 (1), 19-22.

94. Singh, M.; Shpargel, T. P.; Asthana, R., Brazing of yttria-stabilized zirconia (YSZ) to stainless steel using $\mathrm{Cu}, \mathrm{Ag}$, and Ti-based brazes. J. Mater. Sci. 2008, 43 (1), 23-32.

95. Pathak, S.; Steinmetz, D.; Kuebler, J.; Andrew Payzant, E.; Orlovskaya, N., Mechanical behavior of $\mathrm{La}_{0.8} \mathrm{Sr}_{0.2} \mathrm{Ga}_{0.8} \mathrm{Mg}_{0.2} \mathrm{O}_{3}$ perovskites. Ceram. Int. 2009, 35 (3), 1235-1241.

96. Tucker, M. C., Progress in metal-supported solid oxide fuel cells: A review. J. Power Sources 2010, 195 (15), 4570-4582.

97. Choi, J.-J.; Choi, J.-H.; Ryu, J.; Hahn, B.-D.; Kim, J.-W.; Ahn, C.-W.; Yoon, W.-H.; Park, D.-S., Low temperature preparation and characterization of $(\mathrm{La}, \mathrm{Sr})(\mathrm{Ga}, \mathrm{Mg}) \mathrm{O}_{3-\delta}$ electrolyte-based solid oxide fuel cells on Ni-support by aerosol deposition. Thin Solid Films 2013, 546, 418-422.

98. Marina, O. A.; Canfield, N. L.; Stevenson, J. W., Thermal, electrical, and electrocatalytical properties of lanthanum-doped strontium titanate. Solid State Ionics 2002, 149 (1), 21-28.

99. Yoo, K. B.; Choi, G. M., LST-GDC composite anode on $\mathrm{LaGaO}_{3}$-based solid oxide fuel cell. Solid State Ionics 2011, 192 (1), 515-518.

100. Huang, Y.-H.; Dass, R. I.; Xing, Z.-L.; Goodenough, J. B., Double Perovskites as Anode Materials for Solid-Oxide Fuel Cells. Science 2006, 312 (5771), 254-257.

101. Ji, Y.; Huang, Y.-H.; Ying, J.-R.; Goodenough, J. B., Electrochemical performance of La-doped $\mathrm{Sr}_{2} \mathrm{MgMoO}_{6-\delta}$ in natural gas. Electrochem. Commun. 2007, 9 (8), 1881-1885. 
102. Huang, Y. H.; Karppinen, M.; Yamauchi, H.; Goodenough, J. B., Systematic studies on effects of cationic ordering on structural and magnetic properties in $\mathrm{Sr}_{2} \mathrm{FeMoO}_{6}$. Physical Review B 2006, 73 (10), 104408.

103. Zhang, L.; Zhou, Q.; He, Q.; He, T., Double-perovskites $\mathrm{A}_{2} \mathrm{FeMoO}_{6-\delta}(\mathrm{A}=\mathrm{Ca}, \mathrm{Sr}, \mathrm{Ba})$ as anodes for solid oxide fuel cells. J. Power Sources 2010, 195 (19), 6356-6366.

104. Zheng, K.; Świerczek, K., Physicochemical properties of rock salt-type ordered $\mathrm{Sr}_{2} \mathrm{MMoO}_{6}$ $(\mathrm{M}=\mathrm{Mg}, \mathrm{Mn}, \mathrm{Fe}, \mathrm{Co}, \mathrm{Ni})$ double perovskites. Journal of the European Ceramic Society 2014, 34 (16), 4273-4284.

105. Wang, Z.; Tian, Y.; Li, Y., Direct $\mathrm{CH}_{4}$ fuel cell using $\mathrm{Sr}_{2} \mathrm{FeMoO}_{6}$ as an anode material. J. Power Sources 2011, 196 (15), 6104-6109.

106. Xiao, G.; Liu, Q.; Dong, X.; Huang, K.; Chen, F., $\mathrm{Sr}_{2} \mathrm{Fe}_{4 / 3} \mathrm{Mo}_{2 / 3} \mathrm{O}_{6}$ as anodes for solid oxide fuel cells. J. Power Sources 2010, 195 (24), 8071-8074.

107. Miao, G.; Yuan, C.; Chen, T.; Zhou, Y.; Zhan, W.; Wang, S., $\mathrm{Sr}_{2} \mathrm{Fe}_{1+\mathrm{x}} \mathrm{Mo}_{1-\mathrm{x}} \mathrm{O}_{6-\delta}$ as anode material of cathode-supported solid oxide fuel cells. Int. J. Hydrogen Energy 2016, 41 (2), 1104-1111.

108. Rager, J.; Zipperle, M.; Sharma, A.; MacManus - Driscoll, J., Oxygen Stoichiometry in $\mathrm{Sr}_{2} \mathrm{FeMoO}_{6}$, the Determination of Fe and Mo Valence States, and the Chemical Phase Diagram of SrO $\mathrm{Fe}_{3} \mathrm{O}_{4}-\mathrm{MoO}_{3}$. J. Am. Ceram. Soc. 2004, 87 (7), 1330-1335.

109. Liu, Q.; Dong, X.; Xiao, G.; Zhao, F.; Chen, F., A novel electrode material for symmetrical SOFCs. Adv. Mater. 2010, 22 (48), 5478-5482.

110. Yates, J. T.; Campbell, C. T., Surface chemistry: Key to control and advance myriad technologies. Proc. Natl. Acad. Sci. 2011, 108 (3), 911-916.

111. Gorte, R. J.; Vohs, J. M., Nanostructured anodes for solid oxide fuel cells. Current Opinion in Colloid \& Interface Science 2009, 14 (4), 236-244.

112. Farmer, J. A.; Campbell, C. T., Ceria Maintains Smaller Metal Catalyst Particles by Strong MetalSupport Bonding. Science 2010, 329 (5994), 933-936.

113. Kim, J.-S.; Wieder, N. L.; Abraham, A. J.; Cargnello, M.; Fornasiero, P.; Gorte, R. J.; Vohs, J. M., Highly Active and Thermally Stable Core-Shell Catalysts for Solid Oxide Fuel Cells. J. Electrochem. Soc. 2011, 158 (6), B596-B600.

114. Neagu, D.; Tsekouras, G.; Miller, D. N.; Ménard, H.; Irvine, J. T. S., In situ growth of nanoparticles through control of non-stoichiometry. Nat. Chem. 2013, 5, 916.

115. Neagu, D.; Oh, T.-S.; Miller, D. N.; Ménard, H.; Bukhari, S. M.; Gamble, S. R.; Gorte, R. J.; Vohs, J. M.; Irvine, J. T., Nano-socketed nickel particles with enhanced coking resistance grown in situ by redox exsolution. Nat. Commun. 2015, 6, 8120 . 
116. Liu, S.; Liu, Q.; Luo, J.-L., Highly Stable and Efficient Catalyst with In Situ Exsolved Fe-Ni Alloy Nanospheres Socketed on an Oxygen Deficient Perovskite for Direct $\mathrm{CO}_{2}$ Electrolysis. ACS Catal. 2016, 6 (9), 6219-6228.

117. Tsekouras, G.; Neagu, D.; Irvine, J. T. S., Step-change in high temperature steam electrolysis performance of perovskite oxide cathodes with exsolution of B-site dopants. Energy Environ. Sci. 2013, 6 (1), 256-266.

118. Qin, Q.; Wu, G.; Chen, S.; Doherty, W.; Xie, K.; Wu, Y., Perovskite titanate cathode decorated by in-situ grown iron nanocatalyst with enhanced electrocatalytic activity for high-temperature steam electrolysis. Electrochim. Acta 2014, 127, 215-227.

119. Xie, K.; Zhang, J.; Xu, S.; Ding, B.; Wu, G.; Xie, T.; Wu, Y., Composite Cathode Based on RedoxReversible $\mathrm{NbTi}_{0.5} \mathrm{Ni}_{0.5} \mathrm{O}_{4}$ Decorated with In Situ Grown Ni Particles for Direct Carbon Dioxide Electrolysis. Fuel Cells 2014, 14 (6), 1036-1045.

120. Yang, L.; Xie, K.; Xu, S.; Wu, T.; Zhou, Q.; Xie, T.; Wu, Y., Redox-reversible niobium-doped strontium titanate decorated with in situ grown nickel nanocatalyst for high-temperature direct steam electrolysis. Dalton Trans. 2014, 43 (37), 14147-14157.

121. Gao, Y.; Chen, D.; Saccoccio, M.; Lu, Z.; Ciucci, F., From material design to mechanism study: nanoscale $\mathrm{Ni}$ exsolution on a highly active A-site deficient anode material for solid oxide fuel cells. Nano Energy 2016, 27, 499-508.

122. Christian, I., The Theory of Transformations in Metals and Alloys, 816. Pergamon Press, Oxford: 1965; Vol. 179.

123. Liu, F.; Sommer, F.; Bos, C.; Mittemeijer, E. J., Analysis of solid state phase transformation kinetics: models and recipes. Int. Mater. Rev. 2007, 52 (4), 193-212.

124. Oh, T.-S.; Rahani, E. K.; Neagu, D.; Irvine, J. T. S.; Shenoy, V. B.; Gorte, R. J.; Vohs, J. M., Evidence and Model for Strain-Driven Release of Metal Nanocatalysts from Perovskites during Exsolution. J. Phys. Chem. Lett. 2015, 6 (24), 5106-5110.

125. Jiang, S. P.; Badwal, S. P. S., An electrode kinetics study of $\mathrm{H}_{2}$ oxidation on $\mathrm{Ni} / \mathrm{Y}_{2} \mathrm{O}_{3}-\mathrm{ZrO}_{2}$ cermet electrode of the solid oxide fuel cell. Solid State Ionics 1999, 123 (1), 209-224.

126. Mogensen, M.; Skaarup, S., Kinetic and geometric aspects of solid oxide fuel cell electrodes. Solid State Ionics 1996, 86-88, 1151-1160.

127. Holtappels, P.; Vinke, I. C.; de Haart, L. G. J.; Stimming, U., Reaction of Hydrogen/Water Mixtures on Nickel - Zirconia Cermet Electrodes: II. AC Polarization Characteristics. J. Electrochem. Soc. 1999, 146 (8), 2976-2982.

128. Brown, M.; Primdahl, S.; Mogensen, M., Structure/Performance Relations for Ni/Yttria Stabilized Zirconia Anodes for Solid Oxide Fuel Cells. J. Electrochem. Soc. 2000, 147 (2), 475-485. 
129. Horita, T.; Kishimoto, H.; Yamaji, K.; Xiong, Y.; Sakai, N.; Brito, M. E.; Yokokawa, H., Materials and reaction mechanisms at anode/electrolyte interfaces for SOFCs. Solid State Ionics 2006, 177 (19), 19411948.

130. Bessler, W. G.; Vogler, M.; Störmer, H.; Gerthsen, D.; Utz, A.; Weber, A.; Ivers-Tiffée, E., Model anodes and anode models for understanding the mechanism of hydrogen oxidation in solid oxide fuel cells. Phys. Chem. Chem. Phys. 2010, 12 (42), 13888-13903.

131. Vogler, M.; Bieberle-Hütter, A.; Gauckler, L.; Warnatz, J.; Bessler, W. G., Modelling Study of Surface Reactions, Diffusion, and Spillover at a Ni/YSZ Patterned Anode. J. Electrochem. Soc. 2009, 156 (5), B663-B672.

132. Takamura, H., MIEC Materials. In Encyclopedia of Applied Electrochemistry, Kreysa, G.; Ota, K.i.; Savinell, R. F., Eds. Springer New York: New York, NY, 2014; pp 1297-1300.

133. Zhu, T.; Fowler, D. E.; Poeppelmeier, K. R.; Han, M.; Barnett, S. A., Hydrogen Oxidation Mechanisms on Perovskite Solid Oxide Fuel Cell Anodes. J. Electrochem. Soc. 2016, 163 (8), F952-F961. 134. Suthirakun, S.; Ammal, S. C.; Muñoz-García, A. B.; Xiao, G.; Chen, F.; zur Loye, H.-C.; Carter, E. A.; Heyden, A., Theoretical Investigation of $\mathrm{H}_{2}$ Oxidation on the $\mathrm{Sr}_{2} \mathrm{Fe}_{1.5} \mathrm{Mo}_{0.5} \mathrm{O}_{6}$ (001) Perovskite Surface under Anodic Solid Oxide Fuel Cell Conditions. J. Am. Chem. Soc. 2014, 136 (23), 8374-8386.

135. Huang, Y.-H.; Liang, G.; Croft, M.; Lehtimäki, M.; Karppinen, M.; Goodenough, J. B., DoublePerovskite Anode Materials $\mathrm{Sr}_{2} \mathrm{MMoO}_{6}(\mathrm{M}=\mathrm{Co}, \mathrm{Ni})$ for Solid Oxide Fuel Cells. Chem. Mater. 2009, 21 (11), 2319-2326.

136. Wei, T.; Ji, Y.; Meng, X.; Zhang, Y., $\mathrm{Sr}_{2} \mathrm{NiMoO}_{6-\delta}$ as anode material for $\mathrm{LaGaO}_{3}$-based solid oxide fuel cell. Electrochem. Commun. 2008, 10 (9), 1369-1372.

137. Qi, H.; Thomas, T.; Li, W.; Li, W.; Xia, F.; Zhang, N.; Sabolsky, E. M.; Zondlo, J. W.; Hart, R.; Liu, X., Reduced Thermal Expansion and Enhanced Redox Reversibility of $\mathrm{La}_{0.5} \mathrm{Sr}_{1.5} \mathrm{Fe}_{1.5} \mathrm{Mo}_{0.5} \mathrm{O}_{6-\delta}$ Anode Material for Solid Oxide Fuel Cells. ACS Appl. Energy Mater. 2019, 2 (6), 4244-4254.

138. Liu, Q.; Yang, C.; Dong, X.; Chen, F., Perovskite $\mathrm{Sr}_{2} \mathrm{Fe}_{1.5} \mathrm{Mo}_{0.5} \mathrm{O}_{6-\delta}$ as electrode materials for symmetrical solid oxide electrolysis cells. Int. J. Hydrogen Energy 2010, 35 (19), 10039-10044.

139. Young, R. A., The rietveld method. International union of crystallography: 1993; Vol. 5.

140. Koehler, W. C.; Wollan, E. O., Neutron-diffraction study of the magnetic properties of perovskitelike compounds $\mathrm{LaBO}_{3}$. J. Phys. Chem. Solids 1957, 2 (2), 100-106.

141. Xia, F.; Chen, D.; Scarlett, N. V. Y.; Madsen, I. C.; Lau, D.; Leoni, M.; Ilavsky, J.; Brand, H. E. A.; Caruso, R. A., Understanding Solvothermal Crystallization of Mesoporous Anatase Beads by In Situ Synchrotron PXRD and SAXS. Chem. Mater. 2014, 26 (15), 4563-4571.

142. Soubeyroux, J. L.; Courbin, P.; Fournes, L.; Fruchart, D.; Le Flem, G., La phase SrLaFeO Structures cristalline et magnétique. Journal of Solid State Chemistry 1980, 31 (3), 313-320. 
143. McCusker, L. B.; Von Dreele, R. B.; Cox, D. E.; Louer, D.; Scardi, P., Rietveld refinement guidelines. Journal of Applied Crystallography 1999, 32 (1), 36-50.

144. Hill, R. J.; Flack, H. D., The use of the Durbin-Watson d statistic in Rietveld analysis. Journal of Applied Crystallography 1987, 20 (5), 356-361.

145. Wang, Y.; Wang, Y.; Xia, C., Surface Process of Doped Ceria Reduction by Electrical Conductivity Relaxation. J. Electrochem. Soc. 2012, 159 (9), F570-F576.

146. den Otter, M. W.; Bouwmeester, H. J. M.; Boukamp, B. A.; Verweij, H., Reactor Flush Time Correction in Relaxation Experiments. J. Electrochem. Soc. 2001, 148 (2), J1-J6.

147. Li, Y.; Gerdes, K.; Horita, T.; Liu, X., Surface Exchange and Bulk Diffusivity of LSCF as SOFC Cathode: Electrical Conductivity Relaxation and Isotope Exchange Characterizations. J. Electrochem. Soc. 2013, 160 (4), F343-F350.

148. Wan, T. H.; Saccoccio, M.; Chen, C.; Ciucci, F., Influence of the Discretization Methods on the Distribution of Relaxation Times Deconvolution: Implementing Radial Basis Functions with DRTtools. Electrochim. Acta 2015, 184, 483-499.

149. Kresse, G.; Hafner, J., Ab initio molecular dynamics for liquid metals. Physical Review B 1993, 47, 558.

150. Kresse, G.; Furthmuller, J., Efficient iterative schemes for ab initio total-energy calculations using a plane-wave basis set. Physical Review B 1996, 54 (16), 11169-11186.

151. Perdew, J. P.; Burke, K.; Ernzerhof, M., Generalized gradient approximation made simple. Phys Rev Lett 1996, 77 (18), 3865-3868.

152. Blochl, P. E., Projector Augmented-Wave Method. Physical Review B 1994, 50 (24), 17953-17979.

153. Kresse, G.; Joubert, D., From ultrasoft pseudopotentials to the projector augmented-wave method. Physical Review B 1999, 59 (3), 1758-1775.

154. Lee, Y.-L.; Kleis, J.; Rossmeisl, J.; Morgan, D., Ab initio energetics of $\mathrm{LaBO}_{3}$ (001) (B = Mn, Fe, Co, and Ni) for solid oxide fuel cell cathodes. Physical Review B (Condensed Matter and Materials Physics) 2009, 80 (22), 224101.

155. Muñoz-García, A. B.; Bugaris, D. E.; Pavone, M.; Hodges, J. P.; Huq, A.; Chen, F.; zur Loye, H.C.; Carter, E. A., Unveiling Structure-Property Relationships in $\mathrm{Sr}_{2} \mathrm{Fe}_{1.5} \mathrm{Mo}_{0.5} \mathrm{O}_{6-\delta}$, an Electrode Material for Symmetric Solid Oxide Fuel Cells. J. Am. Chem. Soc. 2012, 134 (15), 6826-6833.

156. Lee, Y.-L.; Morgan, D., Ab initio defect energetics of perovskite (001) surfaces for solid oxide fuel cells: A comparative study of $\mathrm{LaMnO}_{3}$ versus $\mathrm{SrTiO}_{3}$ and $\mathrm{LaAlO}_{3}$. Physical Review B 2015, 91 (19), 195430. 157. Lee, Y.-L.; Gadre, M. J.; Shao-Horn, Y.; Morgan, D., Ab initio GGA+U study of oxygen evolution and oxygen reduction electrocatalysis on the (001) surfaces of lanthanum transition metal perovskites $\mathrm{LaBO}_{3}(\mathrm{~B}=\mathrm{Cr}, \mathrm{Mn}, \mathrm{Fe}, \mathrm{Co}$ and Ni). Phys. Chem. Chem. Phys. 2015, 17 (33), 21643-21663. 
158. Xiao, G.; Liu, Q.; Zhao, F.; Zhang, L.; Xia, C.; Chen, F., $\mathrm{Sr}_{2} \mathrm{Fe}_{1.5} \mathrm{Mo}_{0.5} \mathrm{O}_{6}$ as Cathodes for Intermediate-Temperature Solid Oxide Fuel Cells with $\mathrm{La}_{0.8} \mathrm{Sr}_{0.2} \mathrm{Ga}_{0.87} \mathrm{Mg}_{0.13} \mathrm{O}_{3}$ Electrolyte. J. Electrochem. Soc. 2011, 158 (5), B455-B460.

159. Forbess, M. J.; Seraji, S.; Wu, Y.; Nguyen, C. P.; Cao, G. Z., Dielectric properties of layered perovskite $\mathrm{Sr}_{1-\mathrm{x}} \mathrm{A}_{\mathrm{x}} \mathrm{Bi}_{2} \mathrm{Nb}_{2} \mathrm{O}_{9}$ ferroelectrics $(\mathrm{A}=\mathrm{La}, \mathrm{Ca}$ and $\mathrm{x}=0,0.1)$. Appl. Phys. Lett. 2000, 76 (20), 29342936.

160. Chou, Y.-S.; Kerstetter, K.; Pederson, L. R.; Williford, R. E., Mechanical and thermal properties of combustion-synthesized perovskites, $\mathrm{La}_{1-\mathrm{x}} \mathrm{Sr}_{\mathrm{x}} \mathrm{Cr}_{0.2} \mathrm{Fe}_{0.8} \mathrm{O}_{3}$. J. Mater. Res. 2001, 16 (12), 3545-3553.

161. He, B.; Zhao, L.; Song, S.; Liu, T.; Chen, F.; Xia, C., $\mathrm{Sr}_{2} \mathrm{Fe}_{1.5} \mathrm{Mo}_{0.5} \mathrm{O}_{6-\delta}-\mathrm{Sm}_{0.2} \mathrm{Ce}_{0.8} \mathrm{O}_{1.9}$ Composite Anodes for Intermediate-Temperature Solid Oxide Fuel Cells. J. Electrochem. Soc. 2012, 159 (5), B619B626.

162. Yang, C.; Yang, Z.; Jin, C.; Xiao, G.; Chen, F.; Han, M., Sulfur-Tolerant Redox-Reversible Anode Material for Direct Hydrocarbon Solid Oxide Fuel Cells. Adv. Mater. 2012, 24 (11), 1439-1443.

163. Du, Z.; Zhao, H.; Yi, S.; Xia, Q.; Gong, Y.; Zhang, Y.; Cheng, X.; Li, Y.; Gu, L.; Świerczek, K., High-Performance Anode Material $\mathrm{Sr}_{2} \mathrm{FeMo}_{0.65} \mathrm{Ni}_{0.35} \mathrm{O}_{6-\delta}$ with In Situ Exsolved Nanoparticle Catalyst. ACS Nano 2016, 10 (9), 8660-8669.

164. Kang, H.; Beauchamp, J. L., Gas-phase studies of alkene oxidation by transition-metal oxides. Ionbeam studies of $\mathrm{CrO}^{+}$. J. Am. Chem. Soc. 1986, 108 (19), 5663-5668.

165. Carter, E. A.; Goddard, W. A., Early- versus late-transition-metal-oxo bonds: the electronic structure of oxovanadium(1+) and oxoruthenium(1+). The Journal of Physical Chemistry 1988, 92 (8), 2109-2115.

166. Marrocchelli, D.; Perry, N. H.; Bishop, S. R., Understanding chemical expansion in perovskitestructured oxides. Phys Chem Chem Phys 2015, 17 (15), 10028-10039.

167. Perry, N. H.; Bishop, S. R.; Tuller, H. L., Tailoring chemical expansion by controlling charge localization: in situ X-ray diffraction and dilatometric study of $(\mathrm{La}, \mathrm{Sr})(\mathrm{Ga}, \mathrm{Ni}) \mathrm{O}_{3-\delta}$ perovskite. J. Mater. Chem. A 2014, 2 (44), 18906-18916.

168. Hrovat, M.; Katsarakis, N.; Reichmann, K.; Bernik, S.; Kuščer, D.; Holc, J., Characterisation of $\mathrm{LaNi}_{1-\mathrm{x}} \mathrm{Co}_{\mathrm{x}} \mathrm{O}_{3}$ as a possible SOFC cathode material. Solid State Ionics 1996, 83 (1), 99-105.

169. Lv, H.; Zhao, B.-Y.; Wu, Y.-J.; Sun, G.; Chen, G.; Hu, K.-A., Effect of B-site doping on $\mathrm{Sm}_{0.5} \mathrm{Sr}_{0.5} \mathrm{M}_{\mathrm{x}} \mathrm{Co}_{1-\mathrm{x}} \mathrm{O}_{3-\delta}$ properties for IT-SOFC cathode material (M=Fe, Mn). Mater. Res. Bull. 2007, 42 (12), 1999-2012.

170. Bucher, E.; Egger, A.; Caraman, G. B.; Sitte, W., Stability of the SOFC Cathode Material $(\mathrm{Ba}, \mathrm{Sr})(\mathrm{Co}, \mathrm{Fe}) \mathrm{O}_{3-\delta}$ in $\mathrm{CO}_{2}$-Containing Atmospheres. J. Electrochem. Soc. 2008, 155 (11), B1218B1224. 
171. Amin, R.; Karan, K., Characterization of $\mathrm{La}_{0.5} \mathrm{Ba}_{0.5} \mathrm{CoO}_{3-\delta}$ as a SOFC Cathode Material. $J$. Electrochem. Soc. 2010, 157 (2), B285-B291.

172. Watanabe, M.; Uchida, H.; Shibata, M.; Mochizuki, N.; Amikura, K., High Performance Catalyzed - Reaction Layer for Medium Temperature Operating Solid Oxide Fuel Cells. J. Electrochem. Soc. 1994, 141 (2), 342-346.

173. Xiong, Y.; Yamaji, K.; Kishimoto, H.; Brito, M. E.; Horita, T.; Yokokawa, H., Deposition of platinum particles at $\mathrm{LSM} / \mathrm{ScSZ} /$ air three-phase boundaries using a platinum current collector. Electrochem. Solid-State Lett. 2009, 12 (3), B31-B33.

174. Rath, M. K.; Lee, K.-T., Characterization of novel $\mathrm{Ba}_{2} \mathrm{LnMoO}_{6}(\mathrm{Ln}=\mathrm{Pr}$ and $\mathrm{Nd})$ double perovskite as the anode material for hydrocarbon-fueled solid oxide fuel cells. J. Alloys Compd. 2018, 737, 152-159. 175. Jiang, L.; Liang, G.; Han, J.; Huang, Y., Effects of Sr-site deficiency on structure and electrochemical performance in $\mathrm{Sr}_{2} \mathrm{MgMoO}_{6}$ for solid-oxide fuel cell. J. Power Sources 2014, 270, 441448.

176. Tao, S.; Irvine, J. T. S., A redox-stable efficient anode for solid-oxide fuel cells. Nat. Mater. 2003, 2, 320-323.

177. Zha, S.; Cheng, Z.; Liu, M., A Sulfur-Tolerant Anode Material for SOFCs. Electrochem. SolidState Lett. 2005, 8 (8), A406-A408.

178. Osinkin, D. A.; Lobachevskaya, N. I.; Suntsov, A. Y., The electrochemical behavior of the promising $\mathrm{Sr}_{2} \mathrm{Fe}_{1.5} \mathrm{Mo}_{0.5} \mathrm{O}_{6-\delta}+\mathrm{Ce}_{0.8} \mathrm{Sm}_{0.2} \mathrm{O}_{1.9-\delta}$ anode for the intermediate temperature solid oxide fuel cells. J. Alloys Compd. 2017, 708, 451-455.

179. Adler, S. B., Factors Governing Oxygen Reduction in Solid Oxide Fuel Cell Cathodes. Chem. Rev. 2004, 104 (10), 4791-4844.

180. Kawada, T.; Suzuki, J.; Sase, M.; Kaimai, A.; Yashiro, K.; Nigara, Y.; Mizusaki, J.; Kawamura, K.; Yugami, H., Determination of oxygen vacancy concentration in a thin film of $\mathrm{La}_{0.6} \mathrm{Sr}_{0.4} \mathrm{CoO}_{3-\delta}$ by an electrochemical method. J. Electrochem. Soc. 2002, 149 (7), E252-E259.

181. Xie, Z.; Zhao, H.; Du, Z.; Chen, T.; Chen, N., Electrical, Chemical, and Electrochemical Properties of Double Perovskite Oxides $\mathrm{Sr}_{2} \mathrm{Mg}_{1-\mathrm{x}} \mathrm{Ni}_{\mathrm{x}} \mathrm{MoO}_{6-\delta}$ as Anode Materials for Solid Oxide Fuel Cells. J. Phys. Chem. C 2014, 118 (33), 18853-18860.

182. Guan, M.; Sun, W.; Ren, R.; Fan, Q.; Qiao, J.; Wang, Z.; Rooney, D.; Feng, J.; Sun, K., Improved electrochemical performance of $\mathrm{Sr}_{2} \mathrm{Fe}_{1.5} \mathrm{Mo}_{0.4} \mathrm{Nb}_{0.1} \mathrm{O}_{6-\delta}-\mathrm{Sm}_{0.2} \mathrm{Ce}_{0.8} \mathrm{O}_{2-\delta}$ composite cathodes by a one-pot method for intermediate temperature solid oxide fuel cells. Int. J. Hydrogen Energy 2016, 41 (4), 30523061.

183. Adler, S. B.; Lane, J. A.; Steele, B. C. H., Electrode Kinetics of Porous Mixed - Conducting Oxygen Electrodes. J. Electrochem. Soc. 1996, 143 (11), 3554-3564. 
184. Adler, S. B., Mechanism and kinetics of oxygen reduction on porous $\mathrm{La}_{1-\mathrm{x}} \mathrm{Sr}_{\mathrm{x}} \mathrm{CoO}_{3-\delta}$ electrodes. Solid State Ionics 1998, 111 (1), 125-134.

185. Yashiro, K.; Onuma, S.; Kaimai, A.; Nigara, Y.; Kawada, T.; Mizusaki, J.; Kawamura, K.; Horita, T.; Yokokawa, H., Mass transport properties of $\mathrm{Ce}_{0.9} \mathrm{Gd}_{0.1} \mathrm{O}_{2-\delta}$ at the surface and in the bulk. Solid State Ionics 2002, 152-153, 469-476.

186. Geary, T. Lanthanum Ferrite-Based Mixed-Conducting Electrodes for Solid Oxide Fuel Cells and Electrolyzers. 2014.

187. Chiodelli, G.; Malavasi, L., Electrochemical open circuit voltage (OCV) characterization of SOFC materials. Ionics 2013, 19 (8), 1135-1144.

188. Ramírez-Cabrera, E.; Atkinson, A.; Chadwick, D., Catalytic steam reforming of methane over Ce0.9Gd0.1O2-x. Appl. Catal. B-Environ. 2004, 47 (2), 127-131.

189. Xiao, G.; Chen, F., Ni modified ceramic anodes for direct-methane solid oxide fuel cells. Electrochem. Commun. 2011, 13 (1), 57-59.

190. Li, H.; Tian, Y.; Wang, Z.; Qie, F.; Li, Y., An all perovskite direct methanol solid oxide fuel cell with high resistance to carbon formation at the anode. RSC Adv. 2012, 2 (9), 3857-3863.

191. Osinkin, D. A.; Beresnev, S. M.; Bogdanovich, N. M., Influence of $\operatorname{Pr}_{6} \mathrm{O}_{11}$ on oxygen electroreduction kinetics and electrochemical performance of $\mathrm{Sr}_{2} \mathrm{Fe}_{1.5} \mathrm{Mo}_{0.5} \mathrm{O}_{6-\delta}$ based cathode. J. Power Sources 2018, 392, 41-47.

192. Feng, J.; Yang, G.; Dai, N.; Wang, Z.; Sun, W.; Rooney, D.; Qiao, J.; Sun, K., Investigation into the effect of Fe-site substitution on the performance of $\mathrm{Sr}_{2} \mathrm{Fe}_{1.5} \mathrm{Mo}_{0.5} \mathrm{O}_{6-\delta}$ anodes for SOFCs. J. Mater. Chem. A 2014, 2 (41), 17628-17634.

193. Osinkin, D. A.; Beresnev, S. M.; Lobachevskaya, N. I., Symmetrical solid oxide fuel cell with strontium ferrite-molybdenum electrodes. Russ. J. Electrochem. 2017, 53 (6), 665-669.

194. Li, Y.; Li, P.; Hu, B.; Xia, C., A nanostructured ceramic fuel electrode for efficient $\mathrm{CO}_{2} / \mathrm{H}_{2} \mathrm{O}$ electrolysis without safe gas. J. Mater. Chem. A 2016, 4 (23), 9236-9243.

195. Ding, H.; Zhou, D.; Liu, S.; Wu, W.; Yang, Y.; Yang, Y.; Tao, Z., Electricity generation in dry methane by a durable ceramic fuel cell with high-performing and coking-resistant layered perovskite anode. Appl. Energy 2019, 233-234, 37-43.

196. Sengodan, S.; Choi, S.; Jun, A.; Shin, T. H.; Ju, Y. W.; Jeong, H. Y.; Shin, J.; Irvine, J. T.; Kim, G., Layered oxygen-deficient double perovskite as an efficient and stable anode for direct hydrocarbon solid oxide fuel cells. Nat. Mater. 2015, 14 (2), 205-209.

197. Malzbender, J.; Steinbrech, R. W.; Singheiser, L., A review of advanced techniques for characterising SOFC behaviour. Fuel Cells 2009, 9 (6), 785-793. 
198. Patakangas, J.; Ma, Y.; Jing, Y.; Lund, P., Review and analysis of characterization methods and ionic conductivities for low-temperature solid oxide fuel cells (LT-SOFC). J. Power Sources 2014, 263, 315-331.

199. Busawon, A. N.; Sarantaridis, D.; Atkinson, A., Ni Infiltration as a Possible Solution to the Redox Problem of SOFC Anodes. Electrochem. Solid-State Lett. 2008, 11 (10), B186-B189.

200. Tucker, M. C.; Lau, G. Y.; Jacobson, C. P.; Visco, S. J.; De Jonghe, L. C., Cu-YSZ cermet solid oxide fuel cell anode prepared by high-temperature sintering. J. Power Sources 2010, 195 (10), 3119-3123. 201. Hornés, A.; Escudero, M. J.; Daza, L.; Martínez-Arias, A., Electrochemical performance of a solid oxide fuel cell with an anode based on $\mathrm{Cu}-\mathrm{Ni} / \mathrm{CeO}_{2}$ for methane direct oxidation. J. Power Sources 2014, 249, 520-526.

202. Sun, Y.-F.; Li, J.-H.; Wang, M.-N.; Hua, B.; Li, J.; Luo, J.-L., A-site deficient chromite perovskite with in situ exsolution of nano-Fe: a promising bi-functional catalyst bridging the growth of CNTs and SOFCs. J. Mater. Chem. A 2015, 3 (28), 14625-14630.

203. Li, Y.; Hu, B.; Xia, C.; Xu, W. Q.; Lemmon, J. P.; Chen, F., A novel fuel electrode enabling direct $\mathrm{CO}_{2}$ electrolysis with excellent and stable cell performance. J. Mater. Chem. A 2017, 5 (39), 20833-20842. 204. Gao, Y.; Wang, J.; Lyu, Y.-Q.; Lam, K.; Ciucci, F., In situ growth of $\mathrm{Pt}_{3} \mathrm{Ni}$ nanoparticles on an Asite deficient perovskite with enhanced activity for the oxygen reduction reaction. J. Mater. Chem. A 2017, 5 (14), 6399-6404.

205. Xu, S.; Dong, D.; Wang, Y.; Doherty, W.; Xie, K.; Wu, Y., Perovskite chromates cathode with resolved and anchored nickel nano-particles for direct high-temperature steam electrolysis. J. Power Sources 2014, 246, 346-355.

206. Li, Y.; Wang, Y.; Doherty, W.; Xie, K.; Wu, Y., Perovskite Chromates Cathode with Exsolved Iron Nanoparticles for Direct High-Temperature Steam Electrolysis. ACS Appl. Mater. Interfaces 2013, 5 (17), 8553-8562.

207. Gao, Y.; Lu, Z.; You, T. L.; Wang, J.; Xie, L.; He, J.; Ciucci, F., Energetics of Nanoparticle Exsolution from Perovskite Oxides. J. Phys. Chem. Lett. 2018, 9 (13), 3772-3778.

208. Arrivé, C.; Delahaye, T.; Joubert, O.; Gauthier, G., Exsolution of nickel nanoparticles at the surface of a conducting titanate as potential hydrogen electrode material for solid oxide electrochemical cells. $J$. Power Sources 2013, 223, 341-348.

209. Wang, Y.; Liu, T.; Li, M.; Xia, C.; Zhou, B.; Chen, F., Exsolved Fe-Ni nano-particles from $\mathrm{Sr}_{2} \mathrm{Fe}_{1.3} \mathrm{Ni}_{0.2} \mathrm{Mo}_{0.5} \mathrm{O}_{6}$ perovskite oxide as a cathode for solid oxide steam electrolysis cells. J. Mater. Chem. A 2016, 4 (37), 14163-14169. 
210. Liu, S.; Chuang, K. T.; Luo, J.-L., Double-Layered Perovskite Anode with in Situ Exsolution of a Co-Fe Alloy To Cogenerate Ethylene and Electricity in a Proton-Conducting Ethane Fuel Cell. ACS Catal. 2016, 6 (2), 760-768.

211. Liu, S.; Liu, Q.; Luo, J.-L., $\mathrm{CO}_{2}$-to-CO conversion on layered perovskite with in situ exsolved CoFe alloy nanoparticles: an active and stable cathode for solid oxide electrolysis cells. J. Mater. Chem. A 2016, 4 (44), 17521-17528.

212. Li, Y.; Gerdes, K.; Diamond, H.; Liu, X., An improved method to increase the predictive accuracy of the ECR technique. Solid State Ionics 2011, 204-205, 104-110.

213. Guan, B.; Li, W.; Zhang, H.; Liu, X., Oxygen Reduction Reaction Kinetics in Sr-Doped $\mathrm{La}_{2} \mathrm{NiO}_{4+\delta}$ Ruddlesden-Popper Phase as Cathode for Solid Oxide Fuel Cells. J. Electrochem. Soc. 2015, 162 (7), F707F712.

214. Schichlein, H.; Feuerstein, M.; Müller, A.; Weber, A.; Krügel, A.; Ivers-Tiffée, E., System Identification: A New Modelling Approach for SOFC Single Cells. ECS Proceedings Volumes 1999, 199919, 1069-1077.

215. Boukamp, B. A.; Rolle, A., Use of a distribution function of relaxation times (DFRT) in impedance analysis of SOFC electrodes. Solid State Ionics 2018, 314, 103-111.

216. Barfod, R.; Mogensen, M.; Klemensø, T.; Hagen, A.; Liu, Y.-L.; Vang Hendriksen, P., Detailed Characterization of Anode-Supported SOFCs by Impedance Spectroscopy. J. Electrochem. Soc. 2007, 154 (4), B371-B378.

217. Yao, W.; Croiset, E., Ni/YSZ pattern anodes fabrication and their microstructure and electrochemical behavior changes in $\mathrm{H}_{2}-\mathrm{H}_{2} \mathrm{O}$ environments. J. Power Sources 2013, 226, 162-172.

218. Ding, H.; Tao, Z.; Liu, S.; Zhang, J., A High-Performing Sulfur-Tolerant and Redox-Stable Layered Perovskite Anode for Direct Hydrocarbon Solid Oxide Fuel Cells. Sci. Rep. 2015, 5, 18129-18137. 219. Ammal, S. C.; Heyden, A., Reaction kinetics of the electrochemical oxidation of CO and syngas fuels on a $\mathrm{Sr}_{2} \mathrm{Fe}_{1.5} \mathrm{Mo}_{0.5} \mathrm{O}_{6-\delta}$ perovskite anode. J. Mater. Chem. A 2015, 3 (43), 21618-21629.

220. Lankhorst, M. H. R.; Bouwmeester, H. J. M.; Verweij, H., Thermodynamics and Transport of Ionic and Electronic Defects in Crystalline Oxides. J. Am. Ceram. Soc. 1997, 80 (9), 2175-2198.

221. Lee, Y.-L.; Kleis, J.; Rossmeisl, J.; Shao-Horn, Y.; Morgan, D., Prediction of solid oxide fuel cell cathode activity with first-principles descriptors. Energy Environ. Sci. 2011, 4 (10), 3966-3970.

222. Uchida, H.; Maeda, N.; Iwahara, H., Relation between proton and hole conduction in $\mathrm{SrCeO}_{3}$-based solid electrolytes under water-containing atmospheres at high temperatures. Solid State Ionics 1983, 11 (2), 117-124. 
223. Muñoz-García, A. B.; Pavone, M., First-Principles Design of New Electrodes for ProtonConducting Solid-Oxide Electrochemical Cells: A-Site Doped $\mathrm{Sr}_{2} \mathrm{Fe}_{1.5} \mathrm{Mo}_{0.5} \mathrm{O}_{6-\delta}$ Perovskite. Chem. Mater. 2016, 28 (2), 490-500.

224. Muñoz-García, A. B.; Pavone, M., From oxide to proton conduction: A quantum-chemical perspective on the versatility of $\mathrm{Sr}_{2} \mathrm{Fe}_{1.5} \mathrm{Mo}_{0.5} \mathrm{O}_{6-\delta}$-based materials. International Journal of Quantum Chemistry 2016, 116 (21), 1501-1506. 